\title{
IMPACT OF SLOPES ON THE LATERAL REISTANCE OF STEEL PILES
}

\author{
by \\ James Cumming \\ Bachelor of Science (Engineering), Queen's University, Kingston, Ontario, Canada, 2011 \\ Bachelor of Arts, Queen's University, Kingston, Ontario, Canada, 2011
}

\author{
A MRP \\ presented to Ryerson University \\ In partial fulfillment of the \\ requirements for the degree of \\ Master of Engineering \\ in the Program of \\ Civil Engineering
}

Toronto, Ontario, Canada, 2017

(C) (James Cumming) 2017 


\section{Author's Declaration for Electronic Submission of a MRP}

I hereby declare that I am the sole author of this MRP. This is a true copy of the MRP, including any required final revisions.

I authorize Ryerson University to lend this MRP to other institutions or individuals for the purpose of scholarly research.

I further authorize Ryerson University to reproduce this MRP by photocopying or by other means, in total or in part, at the request of other institutions or individuals for the purpose of scholarly research.

I understand that my MRP may be made electronically available to the public. 


\title{
Impact of Slopes on the Lateral Resistance of Steel Piles
}

\author{
James Cumming \\ Master of Engineering, 2017 \\ Civil Engineering \\ Ryerson University
}

\begin{abstract}
A soldier pile and lagging wall is one of the most common types of retaining wall. Solider pile walls develop lateral resistance through the stiffness of the piles and the passive resistance of the soil acting upon the embedded portion of the piles. Ground anchors can also be used when additional lateral resistance is required. Using Broms' methods, a parametric study was completed to investigate the performance of laterally loaded short and long steel piles installed in a variety of cohesive and cohesionless soils. The results were compared to those generated using RocScience finite element software. RocScience software was then used to evaluate the lateral resistance of piles installed at various distances from the crest of a 2:1 slope. Finally, two soldier pile walls, to be installed within a sloping railway embankment, were designed.
\end{abstract}




\section{Acknowledgements}

I would like to thank my project supervisor, Dr. Jinyuan Liu, for his time, guidance, and inspiration throughout my graduate studies. Thank you to Dr. Medhat Shehata and Rachel Peluso for their additional reviews of this project.

I would also like to express my gratitude for the encouragement of my parents, David and Elaine Cumming, and my fiancée, Julie Hoang. I would not have been able to complete my Master of Engineering program without their support. 


\section{Table of Contents}

Author's Declaration for Electronic Submission of a MRP .............................................. ii

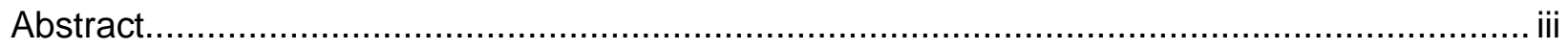

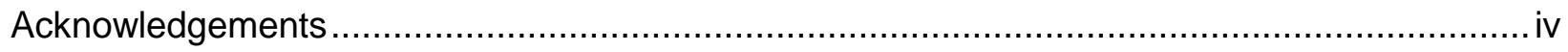

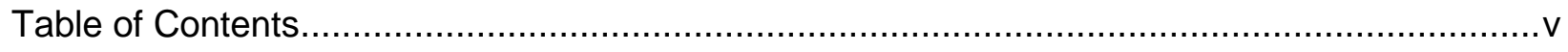

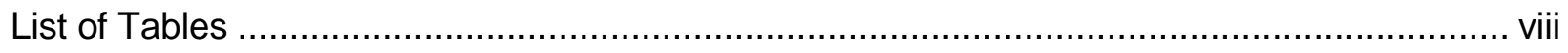

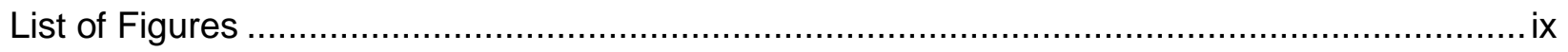

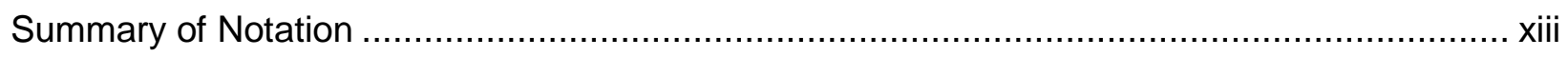

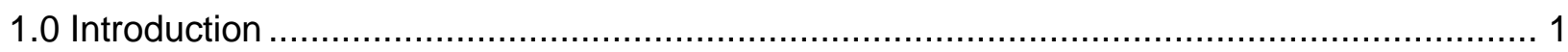

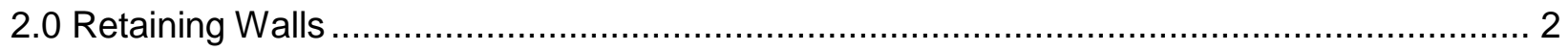

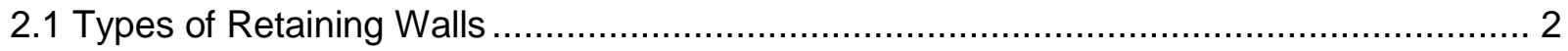

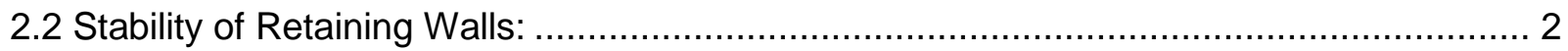

2.2.1 Coulomb's Equations for Shear Failure .................................................. 3

2.2.2 Lateral Earth Pressure Coefficients ......................................................... 3

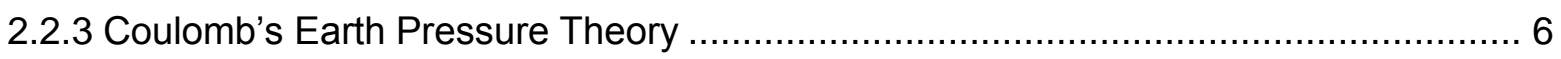

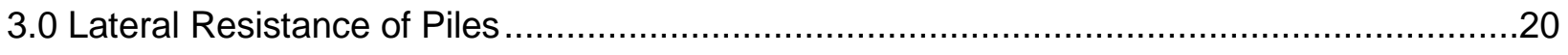

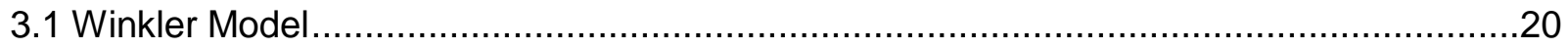

3.2 Lateral Pile Resistance based on Subgrade Reaction ...........................................21

3.2.1 Coefficient of Horizontal Subgrade Reaction ..............................................22

3.3 Broms' Method for Calculating Lateral Resistance and Deflection of a Pile ...................26

3.3.1 Lateral Resistance and Deflection of Piles in Cohesive Soils ...............................26

3.3.2 Lateral Resistance and Deflection of Piles installed in Cohesionless Soils ...............30

3.3 Parametric Study of Lateral Pile Capacity based on Broms' Method.............................33

3.3.1 Broms' Method for Evaluating Lateral Resistance of Long Piles in Cohesive Soils....34

3.3.2 Broms' Method for Evaluating Lateral Resistance of Short Piles in Cohesive Soils ...38

3.3.3 Broms' Method for Evaluating Lateral Resistance of Long Piles in Cohesionless Soils 
3.3.4 Broms' Method for Evaluating Lateral Resistance of Short Piles in Cohesionless Soils

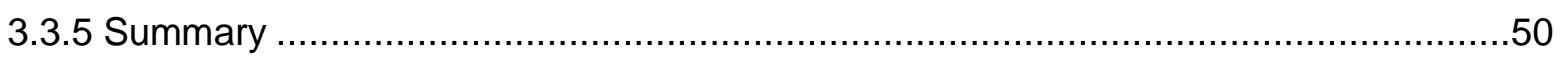

3.3.6 Comparison to RocScience Finite Element Software .....................................53

4.0 Lateral Resistance of Piles installed near a Slope .....................................................61

4.1 Case Study: Laterally Loaded Piles in Sand .........................................................61

4.2 Case Study: Laterally Loaded Piles in Clay ..................................................65

4.3 Finite Element Analysis of Laterally Loaded Piles near Slopes ....................................72

4.3.1 Impact of a 2H:1V Slope on a Long Pile installed in a Cohesive Stiff Cohesive Soil ..73

4.3.2 Impact of a 2H:1V Slope on a Short Pile installed in a Stiff Cohesive Soil ...............73

4.3.3 Impact of a 2V:1H Slope on a Long Pile installed in a Medium Cohesionless Soil.....74

4.3.4 Impact of a 2V:1H Slope on a Short Pile installed in a Medium Cohesionless Soil ....74

4.3.5 Use of Broms' Method for Piles installed near Slopes ....................................75

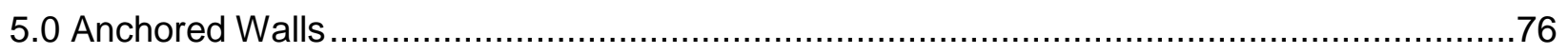

5.1 Loads Resisted by Anchored Walls ............................................................. 77

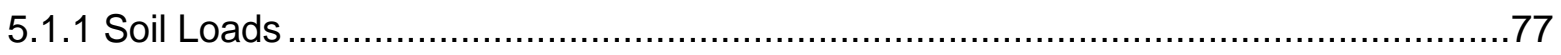

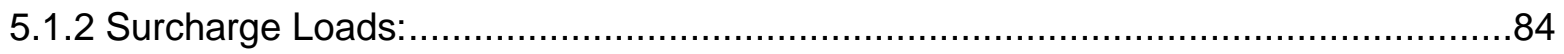

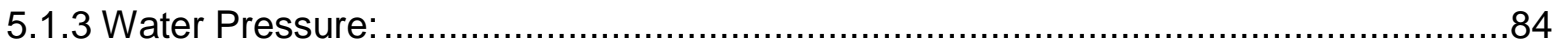

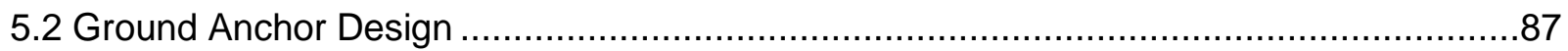

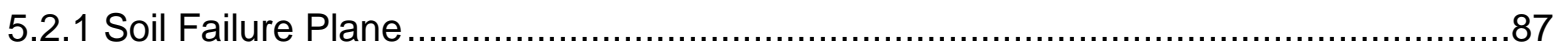

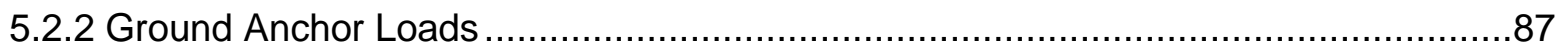

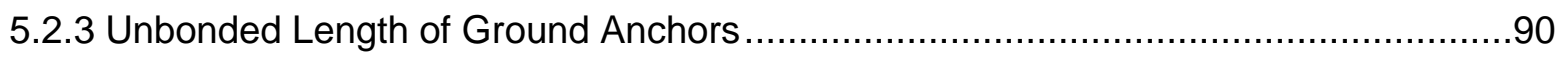

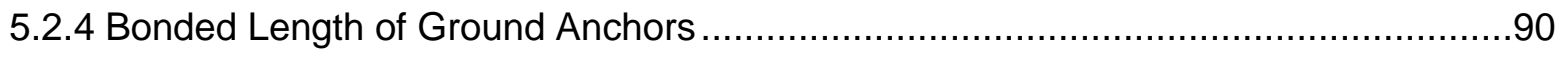

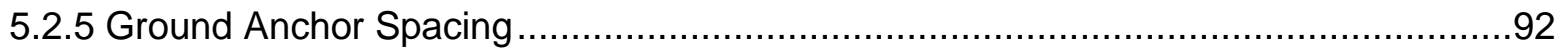

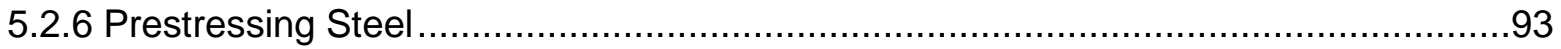

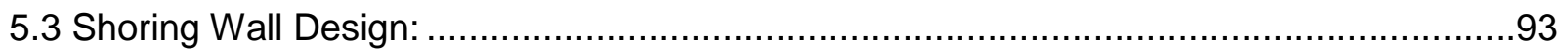

5.3.1 Moment Resistance of Soldier Piles:....................................................... 94 
5.3.2 Lateral Resistance of Embedded Piles.....................................................95

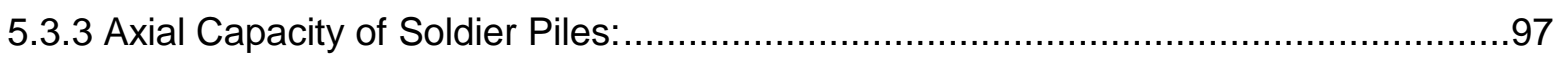

5.3.4 Design of Timber Lagging and Permanent Facing .......................................101

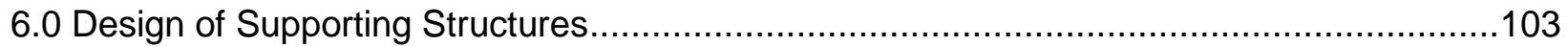

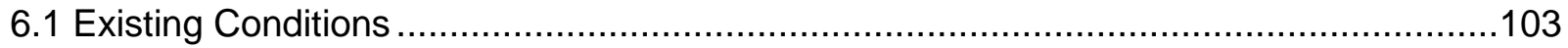

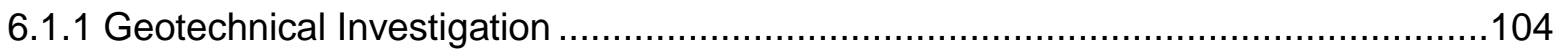

6.2 Supporting Structure for New Access Road ...................................................106

6.2.1 Anticipated Loading on New Retaining Structure: ......................................107

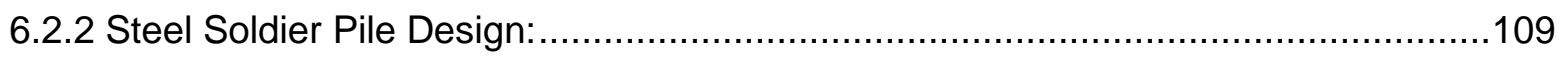

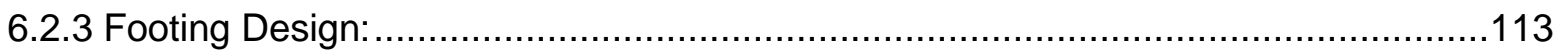

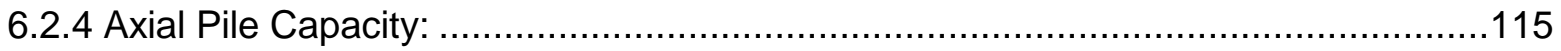

6.2.5 Maximum Moment in Concrete Lagging: ...............................................117

6.2.6 Summary of Retaining Structure for Access Road: .......................................117

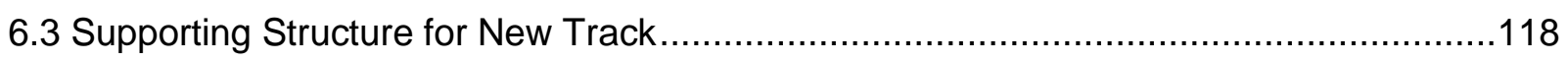

6.3.1 Anticipated Loading on New Retaining Structure: ......................................118

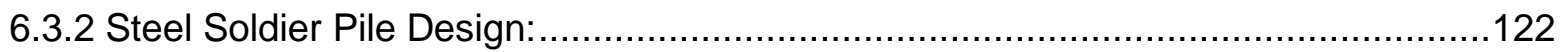

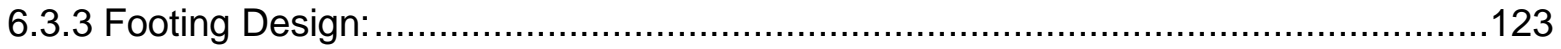

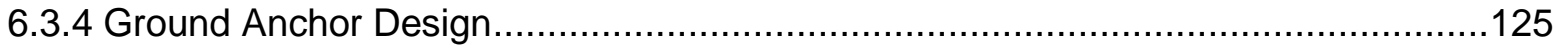

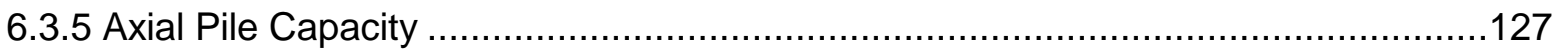

6.3.6 Maximum Moment in Concrete Lagging: ...................................................129

6.3.7 Summary of Retaining Structure for New Track: .......................................130

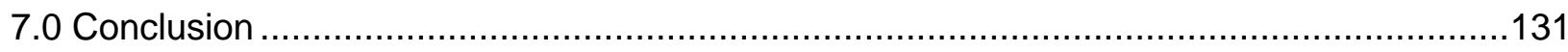

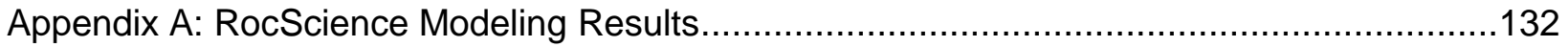

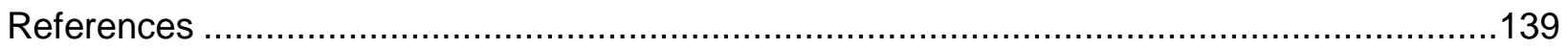




\section{List of Tables}

Table 1: Typical Lateral Earth Pressure Coefficient at Rest for Various Soils ............................. 4

Table 2: Constant of Horizontal Subgrade Reaction for a $1 \mathrm{ft}$ Wide Pile Embedded in Sand .....25

Table 3: Coefficient of Vertical Subgrade Reaction for a Square Area with a $1 \mathrm{ft}$ Width ............26

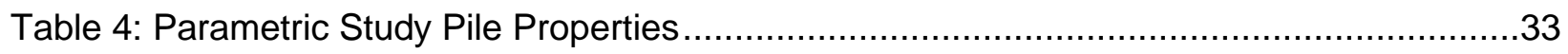

Table 5: Coefficient of Horizontal Subgrade Reaction for a Given Undrained Shear Strength ...37

Table 6: Soil Unit Weight for a Given Internal Angle of Friction ..........................................42

Table 7: Coefficient of Soil Modulus Variation for a Given Internal Angle of Friction...................42

Table 8: Soil Properties used to Estimate Ultimate Lateral Resistance for Piles Installed in Cohesive Soils .54

Table 9: Soil Properties used to Estimate Ultimate Lateral Resistance for Piles Installed in Cohesionless Soils.

Table 10: Comparison of Deflections Estimated using Broms' Method and RocScience Software for 15 metre Long Piles Installed in Cohesive Soils .56

Table 11: Comparison of Deflections Estimated using Broms' Method and RocScience Software for 5 metre Short Piles Installed in Cohesive Soils

Table 12: Comparison of Deflections Estimated using Broms' Method and RocScience Software for $15 \mathrm{~m}$ Long Piles Installed in Cohesionless Soils . .58

Table 13: Comparison of Deflections Estimated using Broms' Method and RocScience Software for 5 metre Short Piles Installed in Cohesionless Soils ........................................................5

Table 14: Estimated Ultimate Transfer Load for a Variety of Soil Types ..................................91

Table 15: Estimated Ultimate Transfer Load for a Variety of Rock Types................................92

Table 16: Properties of 15 mm Diameter Prestressing Strands (ASTM A416, Grade 270) ........93

Table 17: Beta Factors for Drilled Piles in Cohesionless Soils...........................................100

Table 18: Bearing Capacity Factors for End Bearing Resistance of Drilled Piles in Cohesive

Soils 101

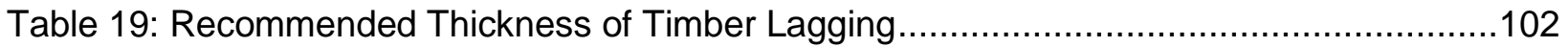

Table 20: Borehole Results for the Proposed Track and New Access Road Locations ...........105

Table 21: AREMA Table 8-20-3: Unit Weights of Soils, and Coefficients of Earth Pressure ....108 Table 22: Properties of Soil Supported by the Proposed Retaining Structure (New Access Road)

Table 23: Final Retaining Structure Design for the Proposed Access Road ..........................117

Table 24: Properties of Soil Supported by the Proposed Retaining Structure (New Track)......118

Table 25: Final Retaining Structure Design for the Proposed Access Road 


\section{List of Figures}

Figure 1: Soil Elements on the Active (Element A) and Passive (Element) Sides of a Retaining Wall. 5

Figure 2: Active and Passive Pressures induced by the Movement of a Retaining Wall. 5

Figure 3: Principal Effective Stresses acting upon Soil Elements on Active and Passive Sides of

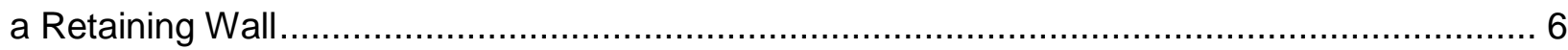

Figure 4: Failed Soil Wedge behind a Retaining Wall ...................................................... 7

Figure 5: Free Body Diagram of a Soil Wedge behind A Retaining Wall................................. 7

Figure 6: Forces Acting on a Soil Wedge with Wall Friction (Active Condition) ........................10

Figure 7: Forces Acting on a Soil Wedge with Wall Friction (Passive Condition) .......................10

Figure 8: Normal and Shear Forces Acting upon a Soil Element.......................................12

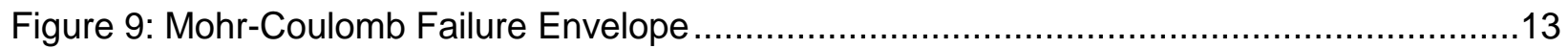

Figure 10: Rankine's Active Earth Pressure at Failure .......................................................14

Figure 11: Rankine's Passive Earth Pressure at Failure........................................................14

Figure 12: Orientation of Failure Planes for both Active and Passive Conditions......................17

Figure 13: Vertical and Horizontal Stresses Acting upon a Soil Element below a Sloping Ground

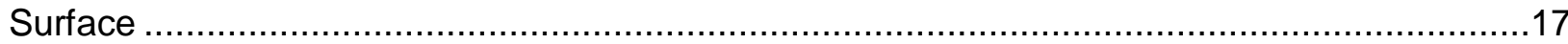

Figure 14: Mohr's Circle of Stress for a Soil Element below a Sloping Ground Surface.............18

Figure 15: Winkler Hypothesis applied to a Laterally Loaded Pile ........................................21

Figure 16: Broms's Distribution of Ultimate Soil Resistance for Piles Installed in Cohesive Soils

Figure 17: Ultimate Lateral Resistance of Short Piles in Cohesive Soils ..............................28

Figure 18: Ultimate Lateral Resistance of Long Piles in Cohesive Soils ................................28

Figure 19: Lateral Deflection at Ground Level under Working Loads for Piles in Cohesive Soils

Figure 20: Ultimate Lateral Resistance of Short Piles in Cohesionless Soils ...........................31

Figure 21: Ultimate Lateral Resistance of Long Piles in Cohesionless Soils...........................31

Figure 22: Lateral Deflection at Ground Level under Working Loads for Piles in Cohesionless

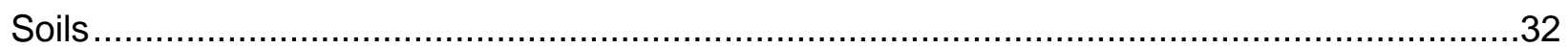

Figure 23: Coefficient of Soil Modulus Variation for Cohesionless Soils ................................32

Figure 24: Broms' Method: Influence of Undrained Shear Strength on the Ultimate Lateral

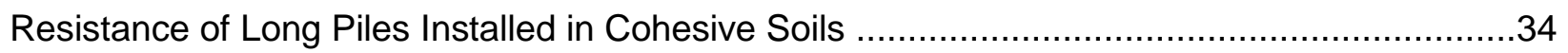

Figure 25: Broms' Method: Influence of Pile Diameter on Ultimate Lateral Resistance of Long

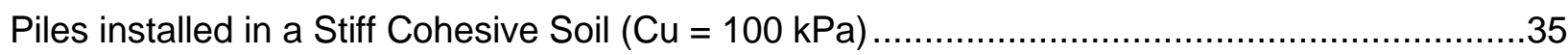


Figure 26: Broms' Method: Influence of Pile Length on Ultimate Lateral Resistance of Long Piles installed in a Stiff Cohesive Soil $(\mathrm{Cu}=100 \mathrm{kPa})$ 36

Figure 27: Broms' Method: Influence of Undrained Shear Strength on Deflection of Long Piles Installed in Cohesive Soils under Working Loads....

Figure 28: Broms' Method: Influence of Undrained Shear Strength on the Ultimate Resistance of Short Piles Installed in Cohesive Soils .38

Figure 29: Broms' Method: Influence of Pile Diameter on the Ultimate Resistance of Short Piles Installed in a Stiff Cohesive Soil $(\mathrm{Cu}=100 \mathrm{kPa})$ 39

Figure 30: Broms' Method: Influence of Pile Length on the Ultimate Resistance of Short Piles Installed in a Stiff Cohesive Soil (100 kPa).... 40

Figure 31: Broms' Method: Influence of Undrained Shear Strength on Deflection of Short Piles Installed in Cohesive Soils under Working Loads.

Figure 32: Broms' Method: Influence of Internal Angle of Friction on the Ultimate Resistance of Long Piles Installed in Cohesionless Soils

Figure 33: Broms' Method: Influence of Pile Diameter on the Deflection of Long Piles Installed in a Medium Cohesionless Soil (Internal Angle of Friction of 32 Degrees, Density $=18.5 \mathrm{kN} / \mathrm{m}^{3}$ ) .44 Figure 34: Broms' Method: Influence of Pile Length on the Ultimate Resistance of Long Piles Installed in a Medium Cohesionless Soil (Internal Angle of Friction of 32 Degrees, Density of $\left.18.5 \mathrm{kN} / \mathrm{m}^{3}\right)$......

Figure 35: Broms' Method: Influence of Internal Angle of Friction on the Deflection of Long Piles Installed in Cohesionless Soils under Working Loads .46 Figure 36: Broms' Method: Influence of Internal Angle of Friction on the Ultimate Resistance of Short Piles Installed in Cohesionless Soils.

Figure 37: Broms' Method: Influence of Pile Diameter on the Ultimate Resistance of Short Piles Installed in a Medium Cohesionless Soil (Internal Angle of Friction of 32 Degrees, Density of $18.5 \mathrm{kN} / \mathrm{m}^{3}$ )

Figure 38: Broms' Method: Influence of Pile Length on the Ultimate Resistance of Short Piles Installed in a Medium Cohesionless Soil (Internal Angle of Friction of 32 Degrees, Density of $18.5 \mathrm{kN} / \mathrm{m}^{3}$ )

Figure 39: Broms' Method: Influence of Internal Angle of Friction on the Deflection of Short Piles Installed in Cohesionless Soils under Working Loads .....................................................50

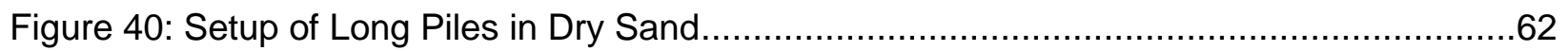

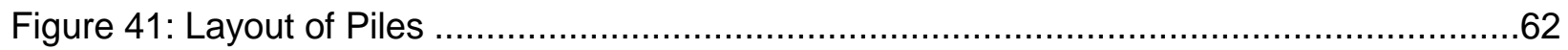

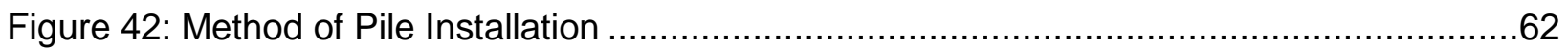




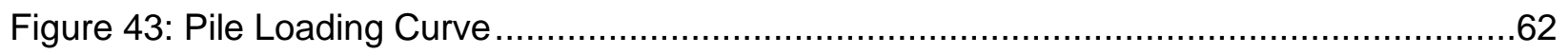

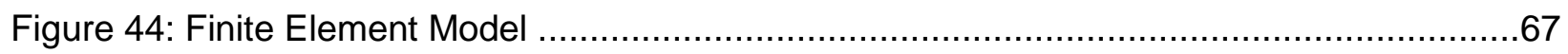

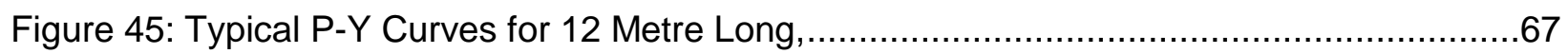

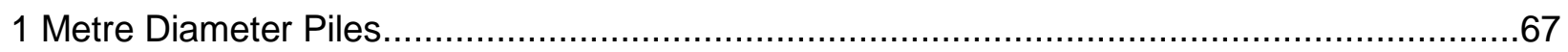

Figure 46: Lateral Bearing Capacity versus Depth for Varying Slope Angles and Adhesion

Factors. .68

Figure 47: Lateral Earth Pressure Diagram for Laterally Loaded Short Piles Installed in Level

Ground. . .71

Figure 48: Lateral Earth Pressure Diagram for Short Piles Laterally Loaded towards a Slope...71 Figure 49: Lateral Earth Pressure Diagram for Short Piles Laterally Loaded Away from a Slope .72

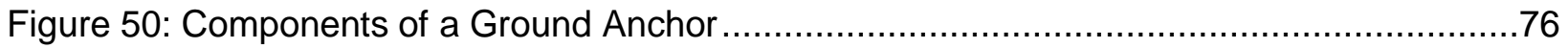

Figure 51: Apparent Earth Pressure Diagram for Excavations in Cohesionless Soils ................79 Figure 52: Apparent Earth Pressure Diagram for Excavations in Cohesionless Soils (One Row of Tie-Backs).....

Figure 53: Apparent Earth Pressure Diagram for Excavations in Cohesionless Soils (Multiple Rows of Tie-Backs) .79

Figure 54: Apparent Earth Pressure Diagram for Temporary Excavations in Stiff to Hard Clays (One Row of Tie-Backs).

Figure 55: Apparent Earth Pressure Diagram for Temporary Excavations in Stiff to Hard Clays (Multiple Rows of Tie-Backs). .81

Figure 56: Apparent Earth Pressure Diagram for Excavations in Soft-Medium Clays..... .82

Figure 57: Henkel Failure for a Soft Clay Layer Extending Below the Base of a Shoring Wall...83 Figure 58: Comparison of Henkel's Stability Numbers to those Developed by Terzaghi and Peck .83

Figure 59: Failure of a Soil Wedge behind a Shoring Wall with One Row of Tie-Backs .84

Figure 60: Free-Body Diagram of a Soil Wedge behind a Shoring Wall with One Row of Tie-

Backs. .84

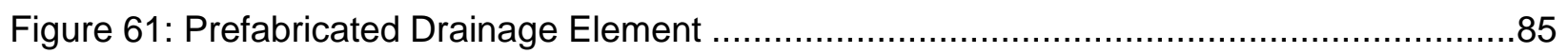

Figure 62: Granular Material with Drain behind Retaining Wall ........................................ 85

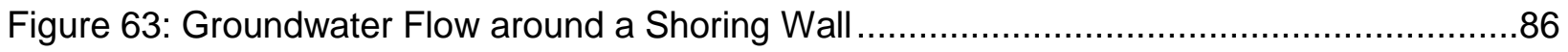

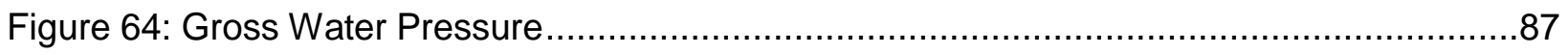

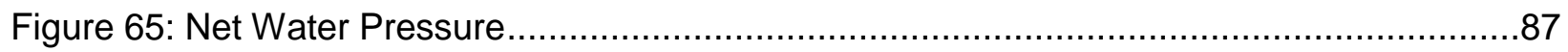

Figure 66: Tributary Area Method for a Single Row of Tie-Backs ..................................... 89 
Figure 67: Tributary Area Method for Multiple Rows of Tie-Backs ...................................... 89

Figure 68: Hinge Method for a Single Row of Tie-Backs .................................................. 89

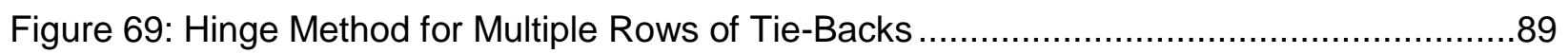

Figure 70: Calculation of Maximum Bending Moment within Soldier Piles for a Single Row of

Tie-Backs .95

Figure 71: Calculation of Maximum Bending Moment within Soldier Piles for Multiple Rows of

Tie-Backs. . .95

Figure 72: Broms' Method for Calculating Passive Resistance in Cohesionless, or Drained Cohesive Soils..... .96

Figure 73: Broms' Method for Calculating Passive Resistance in Undrained Cohesive Soils ....96 Figure 74: Relationship between the Beta Coefficient and Drained Friction Angle as Proposed by Fellenius in 1991 .... .98

Figure 75: Relationship between Toe Bearing Coefficient and Drained Friction Angle as

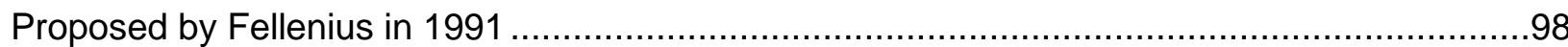

Figure 76: Soil-Pile Adhesion at Failure as Proposed by Thompson in 1980..........................99

Figure 77: Site Locations in Whitby, Ontario ................................................................. 103

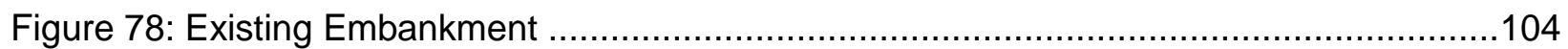

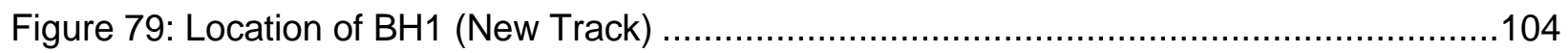

Figure 80: Location of BH2 and BH3: (New Road) ................................................104

Figure 81: Soil Conditions at the Proposed Road.......................................................105

Figure 82: Soil Conditions at the Proposed Track .......................................................105

Figure 83: Transport Canada Standards Respecting Railway Clearances: All Structures over or Beside Railway Tracks .................................................................................... 106

Figure 84: Conceptual Sketch: New Retaining Structure for a New Access Road alongside the

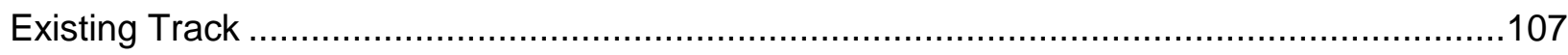

Figure 85: Shear Force Diagram for Upper 7 metres of the Steel Pile................................111

Figure 86: Bending Moment Diagram for Upper 7 metres of the Steel Pile...........................112

Figure 87: New Retaining Structure to allow for a New Track alongside the Existing Track (New

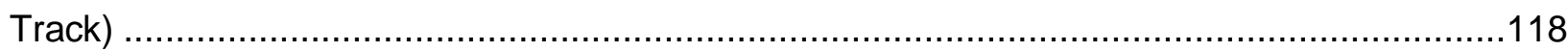

Figure 88: Apparent Earth Pressure Diagram (Cohesionless Soil, One Row of Tie-Backs) .....119

Figure 89: Pressure Distribution for Strip Load........................................................120

Figure 90: Lateral Loads acting upon the entire Support Structure due to Railway Loading ....121

Figure 91: Lateral Loads acting upon the Exposed Portion of the Support Structure due to Railway Loading.... 


\section{Summary of Notation}

Below is a list of notation used within this report:

$A=$ ratio between modulus of elasticity of a cohesionless sand and overburden pressure

$A_{s}=$ pile perimeter

$A_{t}=$ cross-sectional area of a pile

$\alpha=$ inside angle of the back slope of a retaining wall, measured from the horizontal

$\alpha=$ adhesion factor

$\alpha_{\theta}=$ adhesion factor as a function of slope angle

$\beta=$ angle of sloping ground, measured from the horizontal

$\beta=$ empirical coefficient for $p-y$ curve equation

$\beta=$ beta coefficient for pile skin friction

$B, D, d=$ pile width or diameter

$d=$ depth of shoring wall embedment

$d=$ depth of failure surface below shoring wall excavation

$c=$ soil cohesion

$c_{a}=$ soil-pile adhesion at failure

$c_{u}=$ undrained shear strength

$\delta=$ the angle of the force applied by a retaining wall to a soil, measured from the horizontal

$E_{s}=$ modulus of elasticity of a cohesionless soil, given a confining pressure

$E I=$ pile flexural rigidity

$E_{s}=$ soil modulus

$F H=$ horizontal load

$F_{b}=$ maximum allowable bending stress within a soldier pile 
$f_{s}=$ unit skin friction resistance of driven piles under drained conditions

$f_{s}=$ unit shaft resistance for driven piles in cohesive soils (undrained conditions)

$f_{y}=$ steel yield strength

$H_{o}=$ height of retaining wall

$H=$ height of shoring wall excavation

$H_{u}=$ ultimate lateral bearing capacity

$I_{d}=$ density index

$i=$ depth to water on excavation side of a shoring wall

$j=$ depth to water on supported side of a shoring wall

$\gamma^{\prime}=$ effective unit weight of soil

$\gamma_{w}=$ unit weight of water

$\theta=$ angle of slip plane for Coulomb's soil wedge, measured from the horizontal

$\theta_{\text {crit }}=$ critical angle of slip plane for Coulomb's soil wedge, measured from the horizontal

$K=$ ordinate at the origin of the $\mathrm{p}-\mathrm{y}$ curve

$K_{i}=$ initial stiffness (slope of a p-y curve)

$K_{i o}=$ initial stiffness of a pile installed in level ground

$K_{i \theta}=$ initial stiffness of a pile installed near a slope

$K_{O}=$ lateral earth pressure coefficient at rest

$K_{a}=$ active earth pressure coefficient

$K_{p}=$ passive earth pressure coefficient

$k_{h}=$ horizontal coefficient of subgrade reaction

$k_{h 1}=$ coefficient of horizontal subgrade reaction for a vertical beam ( $1 \mathrm{ft}$ width) embedded in clay 
$k_{s}=$ coefficient of vertical subgrade reaction

$k_{s 1}=$ coefficient of vertical subgrade reaction for a square area ( $1 \mathrm{ft}$ width $)$

$L=$ length of slip plane for Coulomb's soil wedge

$L=$ total pile length

$l=$ vertical spacing between adjacent ground anchors

$\lambda=$ non-dimensional factor

$M_{f}=$ maximum bending moment in permanent facing

$M_{\max }=$ maximum positive bending moment within a soldier pile

$m=$ coefficient of proportionality

$m_{h}=$ ratio between the coefficient of horizontal subgrade reaction and depth

$N=$ normal force acting upon Coulomb's soil wedge

$N=$ uncorrected SPT N value within two times the diameter of the base of a drilled pile

$N_{c}=$ bearing capacity factor for driven piles in cohesive soils (undrained conditions)

$N_{p}=$ bearing capacity factor for driven piles under drained conditions

$N_{p c}=$ bearing capacity factor at critical depth

$N_{p o}=$ minimum bearing capacity factor

$N_{p u}=$ maximum bearing capacity factor

$N_{S}=$ stability number

$N_{t}=$ toe bearing coefficient

$n=$ slope of the straight curve for load times pile width vs. displacement

$n_{h}=$ constant of horizontal subgrade reaction (for $\frac{z}{\beta}=1$ )

$\eta=$ coefficient of proportionality 
$\eta_{h}=$ coefficient of soil modulus variation

$P_{a}=$ acting earth pressure

$P_{\text {req }}=$ Required shoring wall resisting force

$p=$ contact pressure between a pile and soil due to the displacement of the pile

$p=$ maximum ordinate of apparent pressure envelope

$p_{o}=$ average effective vertical stress along a pile shaft

$p_{t}=$ vertical effective stress at pile tip

$p_{u}=$ ultimate load per unit length of a pile

$Q_{a l t}=$ ultimate axial capacity of a pile

$q_{t}=$ unit end bearing resistance of a pile

$q_{u}=$ unconfined compressive strength of clay

$R=$ subgrade reaction force

$S_{\text {req }}=$ required section modulus of a soldier pile

$S_{u}=$ undrained shear strength of a soil

$S_{u b}=$ undrained shear strength of the soil providing bearing resistance for shoring wall

$s=$ ground anchor spacing

$\sigma=$ stress acting upon a soil element

$\sigma_{z}^{\prime}=$ normal effective stress acting in the vertical direction

$\sigma_{x}^{\prime}=$ normal effective stress acting in the horizontal direction

$\sigma_{1}^{\prime}=$ major principle effective stress

$\sigma_{1}^{\prime}=$ minor principle effective stress

$\left(\sigma_{n}^{\prime}\right)_{f}=$ normal effective stress acting upon a shear plane at failure

$T=$ shear force acting upon Coulomb's soil wedge 
$T=$ ground anchor load

$T_{h}=$ horizontal component of ground anchor load

$T_{h i}=$ horizontal component of ground anchor load per metre width of shoring wall

$T_{v}=$ vertical component of ground anchor load

$t=$ distance from pile axis to crest of slope

$\tau=$ shear stress acting upon a soil element

$\tau_{f}=$ soil shear stress at failure

$\phi^{\prime}=$ internal angle of friction of the soil

$U_{f}=$ porewater pressure at the base of a shoring wall

$W=$ weight of Coulomb's soil wedge

$y=$ lateral pile displacement

$y_{c}=$ lateral pile displacement under working loads ( $50 \%$ of ultimate load)

$Z$ = pile section modulus

$z_{c}=$ critical pile depth

$z_{o}=$ depth of rotation point for short pile

$z_{m}=$ depth of maximum bending moment in pile 


\subsection{Introduction}

Retaining walls are constructed for the purpose of supporting a soil mass that would otherwise be unstable. Soldier pile and lagging walls are one of the most common types of retaining walls used in practice. Soldier pile walls are able to provide lateral resistance using the stiffness of the pile and the passive resistance of the soil acting upon the embedded length of the pile. Ground anchors may be also be used for additional lateral capacity when the existing soils cannot provide sufficient passive resistance.

The purpose of this report is to investigate the performance of laterally loaded, free head piles in a variety of soil conditions, with the ultimate goal of designing two soldier pile retaining structures. The first structure will be designed with the purpose of widening an existing railway embankment to allow for the construction of a new access road. The second soldier pile wall will be designed permit the construction of an additional track next to the existing tracks.

Prior to carrying out the design, existing literature related to retaining walls and lateral pile capacity will be reviewed. For a clearer understanding of pile performance under a wide range of conditions, a parametric study will be completed using Broms' methods and RocScience finite element software. Finally, the results of the literature review and parametric study will be applied to the design of soldier pile and lagging walls. 


\subsection{Retaining Walls}

\subsection{Types of Retaining Walls}

Retaining walls are structures that are constructed for the purpose of supporting vertical earth banks (Murthy, 2002, p. 419). Retaining walls must resist all lateral forces imposed by the soil (Budhu, 2011, p. 611), including lateral earth pressures, water pressures, and thrust forces (Broms, 1964a, p. 28). First, retaining walls must be designed to remain stable under any anticipated loading conditions at Ultimate Limit States (ULS). Secondly, Serviceability Limit States (SLS) must be considered (Budhu, 2011, p.610) to ensure that any deformation or settlement does impact the intended function of the structure (Budhu, 2011, p.424). Often, it is the performance at SLS that will govern the design of the wall (Budhu, 2011, p. 610). In general, retaining walls can be grouped into one of three categories:

Mass Gravity and Semi-Gravity Retaining Walls: Large, heavy walls that resist the lateral forces using only the mass of the wall (Budhu, 2011, p. 611). Semi-Gravity walls are smaller reinforced walls that make use of a cantilevered base slab to resist movement (Murthy, 2002, $p$. 419).

Flexible Retaining Wall or Sheet Pile Wall: Slender (and sometimes very long) walls that resist lateral forces using a combination of passive soil resistance, anchors, and props (Budhu, 2011, p. 611).

Mechanically Stabilized Earth Wall: A soil wall that resists lateral loads by relying on reinforced steel, fabric, or fibre elements within the soil (Budhu, 2011, p. 611).

\subsection{Stability of Retaining Walls:}

When designing a retaining wall, an engineer must verify the retaining wall is stable under ULS conditions and meets performance requirements under SLS conditions. The first step in the design process is to calculate the lateral earth pressure of the soil acting upon the wall. Traditionally, there are two primary theories that engineers apply when calculating lateral pressures. The first was developed by Coulomb in 1776. A second method was published by Rankine in 1857 (Murthy, 2002, p. 420). Both methods are based on the equilibrium of the soil behind the wall. However, Coulomb's theory looks at the equilibrium of the entire soil mass 
(Das, 2005, p. 366), whereas Rankine's theory focuses on the equilibrium of a single soil element behind the wall (Das, 2005, p. 339).

\subsubsection{Coulomb's Equations for Shear Failure}

A soil mass will maintain a state of equilibrium provided all active forces trying to move the soil (such as a surcharge load, or gravity), are balanced by resistive forces (such as internal forces within the soil, or external support from a retaining structure) (Rankine, 1857, p. 19).

In the late 1700's, Coulomb hypothesized that frictional forces acting between soil particles allow for a certain magnitude of internal resistance when a soil mass is subjected to a force (Budhu, 2011, p. 1). However, there is a limit to how much force the friction between two particles can resist. Every contact point between two soil particles has the potential to become a micro slip plane if the forces acting upon two soil particles exceed the frictional resistance. When exposed to external forces, slip planes will begin to align in the direction of least resistance. At a certain shear stress, the soil will fail as the particles "slip" (moving relative to one another) (Budhu, 2011, p. 270). The shear strength of a soil is can be described as its ability to resist this sliding (Murthy, 2002, p. 253).

Within a soil, the shear stress at failure may be expressed by the equation:

$\tau_{f}=\left(\sigma_{n}^{\prime}\right)_{f} \tan \phi^{\prime}$

(Budhu, 2011, p. 270)

For a granular soil, shearing forces are resisted solely by the friction between the particles. However, in cohesive soils, shear resistance is also developed through the cohesion of the particles:

$\tau_{f}=c+\left(\sigma_{n}^{\prime}\right)_{f} \tan \phi^{\prime}$

(Murthy, 2002, p. 254)

\subsubsection{Lateral Earth Pressure Coefficients}

In order to design a retaining wall, the lateral forces acting upon the retaining wall must be known. This horizontal effective stress can be related to the vertical effective stress within a soil mass using lateral earth pressure coefficients (Budhu, 2011, p. 161). 
A retaining wall is considered to be under at-rest conditions when no movement has occurred (Budhu, 2011, p. 612), the soil around the wall has not deformed, and the wall itself, has not deformed (Budhu, 2011, p. 161). Under this condition, the lateral earth pressure coefficient (known as the lateral earth pressure coefficient at rest), may be defined as "The ratio of the horizontal principal effective stress to the vertical principal effective stress" (Budhu, 2011, p. 161). For a homogenous soil, the ratio between vertical effective stress and horizontal effective stress will remain constant with depth (Murthy, 2002, p. 422). Lateral Earth Pressure Coefficients can generally be approximated by the equation:

$\mathrm{K}_{0}=1-\sin \varnothing ;$

(Murthy, 2002, p. 421)

For a particular depth and effective weight of a soil, the vertical and horizontal effective stresses within a soil element on either side of the retaining wall can then be related by the equations:

Vertical Effective Stress: $\quad \sigma_{z}^{\prime}=\sigma^{\prime}{ }_{1}=\gamma^{\prime} z$

Horizontal Effective Stress: $\quad \sigma_{x}^{\prime}=\sigma_{3}^{\prime}=K_{0} \gamma^{\prime} z$

(Budhu, 2011, p. 612)

Typical values for the Lateral Earth Pressure Coefficient at Rest are shown in Table 1.

\begin{tabular}{|c|c|}
\hline Type of Soil & Lateral Earth Pressure Coefficient at Rest \\
\hline Saturated Loose Sand & 0.46 \\
\hline Saturated Dense Sand & 0.36 \\
\hline Dry Loose Sand & 0.64 \\
\hline Dry Dense Sand & 0.49 \\
\hline Compacted Clay & $0.42-0.60$ \\
\hline Organic Silt Clay & 0.57 \\
\hline
\end{tabular}

Table 1: Typical Lateral Earth Pressure Coefficient at Rest for Various Soils

(Murthy, 2002, p. 424) 
Figure 1, below, shows a condition in which the pressure acting upon a retaining wall is significant enough that it causes the wall to rotate. As the wall begins to rotate, the lateral effective stress on each side of the wall will change. On the active side, the lateral effective stress decreases as the wall moves away from the soil (Budhu, 2011, p. 613). This is considered "active" because the force of the soil is the cause of the movement. After a certain rotation, the lateral force acting upon the wall will reach a constant value. This value is the minimum possible and known as the active pressure (Murthy, 2002, p. 420).

On the passive side of the retaining wall (the side in which the wall is rotating into the soil), the lateral effective stress increases as the wall pushes into the soil (Budhu, 2011, p. 613). This is considered "passive" because the soil resists the movement of the retaining wall. After a particular displacement, the soil pressure on the passive side of the wall will reach a constant value. This value is the maximum possible resistance provided by the soil and is known as the passive pressure. A much larger displacement is required to activate the passive pressure than active pressure. The relationship between displacement and the magnitude of active and passive earth pressures is shown in Figure 2.

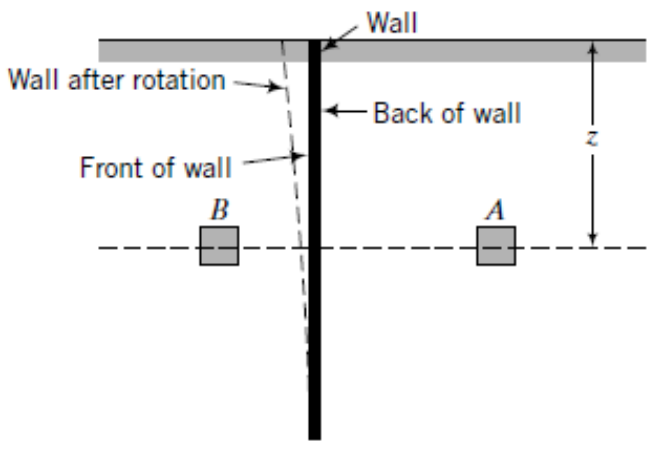

Figure 1: Soil Elements on the Active (Element A) and Passive (Element) Sides of a Retaining Wall

(Budhu, 2011, p.612)

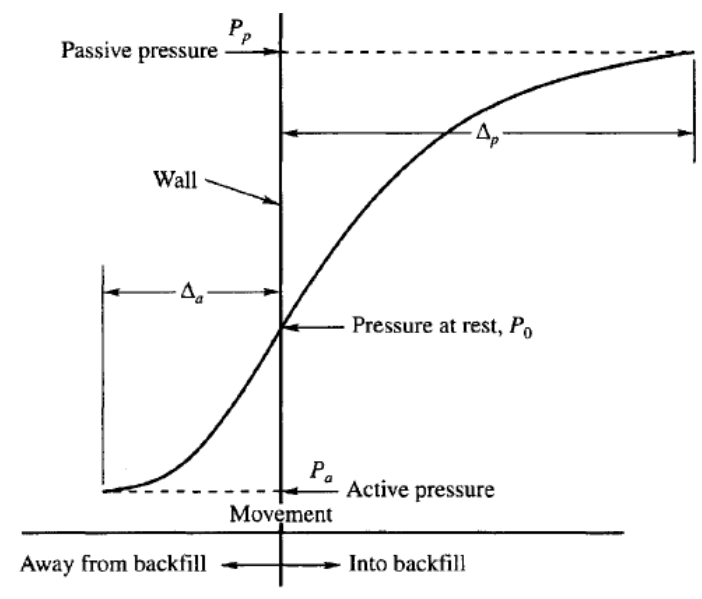

Figure 2: Active and Passive Pressures induced by the Movement of a Retaining Wall

(Murthy, 2002, p.423) 
Once a retaining wall has started to rotate, the lateral earth pressure coefficient at rest no longer applies. The new ratio between the vertical effective stress and horizontal effective stress will depend on whether the soil element is on the active or passive side of the retaining wall:

Active Earth Pressure Coefficient: "Ratio between the lateral and vertical principal effective stresses at the limiting stress state when an earth-retaining structure moves away (by a small amount) from the backfill (retained soil)" (Budhu, 2011, p. 611);

Passive Earth Pressure Coefficient: "Ratio between the lateral and vertical principal effective stresses at the limiting stress state when an earth-retaining structure is forced against a soil mass" (Budhu, 2011, p. 611).
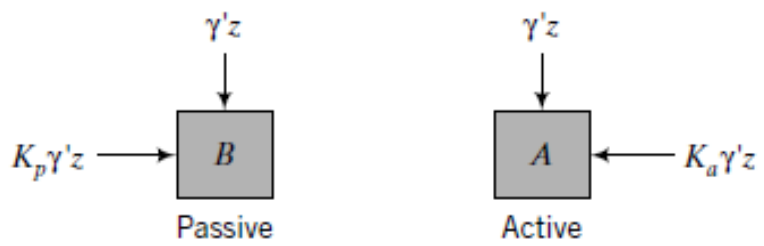

Figure 3: Principal Effective Stresses acting upon Soil Elements on Active and Passive Sides of a Retaining Wall

(Budhu, 2011, p. 612)

\subsubsection{Coulomb's Earth Pressure Theory}

In 1776, Coulomb developed a theory to determine the lateral earth pressure that a retaining wall must resist. This theory considered the equilibrium of a soil wedge behind the retaining wall. At failure, it was assumed the soil wedge would slip along a plane inclined at an angle $(\theta)$ to the horizontal (Figure 4) (Budhu, 2011, p. 620). Assuming the retaining wall does not fail, the soil wedge must remain in equilibrium. Coulomb represented the soil wedge using the free body diagram shown in Figure 5 . 


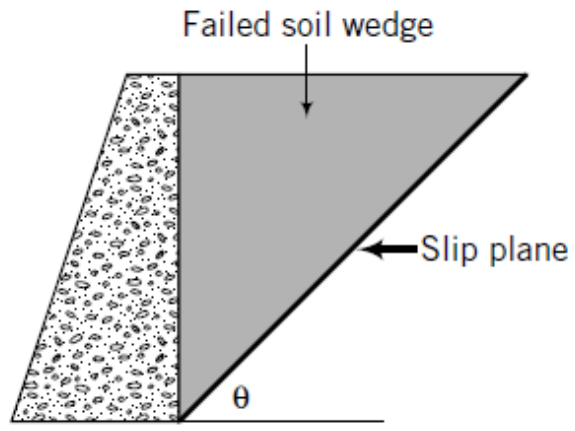

Figure 4: Failed Soil Wedge behind a Retaining Wall

(Budhu, 2011, p. 620)

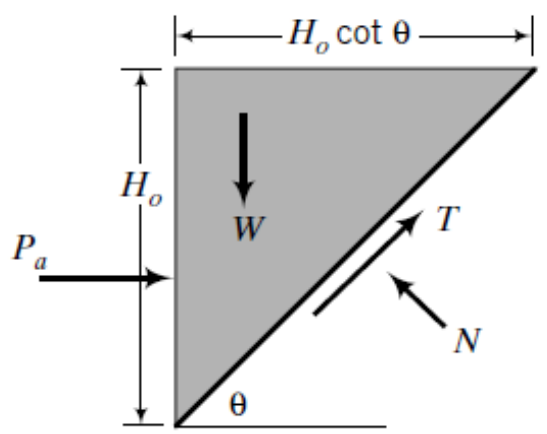

Figure 5: Free Body Diagram of a Soil Wedge behind A Retaining Wall

(Budhu, 2011, p. 620)

Within his analysis, Coulomb made the following assumptions:

- Soil is isotropic and homogeneous;

- Soil failure is along a planer surface;

- Slope of the soil is planer;

- Slope of the retaining wall is planer;

- The failure wedge is rigid.

(Kitch, 2015b)

Since the soil wedge is in equilibrium, the sum of all forces about the horizontal axis must be equal to zero. Similarly, the sum of all forces about the vertical axis must also equal zero. By substituting these equations into Coulomb's equation for shear failure, the pressure acting upon the retaining wall (and therefore the resistance that must be applied by the retaining wall to keep the soil wedge in equilibrium) can be calculated. For a cohesionless soil, the acting pressure may be calculated using the equation:

$P_{a}=\frac{1}{2} \gamma H_{0}{ }^{2} \cot \theta \tan \left(\theta-\phi^{\prime}\right)$

$P_{a}=\frac{1}{2} \gamma H_{0}^{2} K_{a}$

(Kitch, 2015b) 
Once the acting force is known, the next step is to determine the location of the critical slip plane. The critical slip plane will occur where the acting pressure is a maximum. The maximum acting pressure is found by setting the partial derivative of the acting pressure with respect to the angle of the slip plane to zero and solving based on angle of internal friction for the soil. By optimizing the equation for acting earth pressure as described above, the result is an equation for the critical angle:

$\theta_{\text {crit }}=\left(45^{\circ}+\frac{\phi^{\prime}}{2}\right)$

(Kitch, 2015b)

Assuming the critical angle, pressure applied by the retaining wall to maintain equilibrium of the soil:

$P_{a}=\frac{1}{2} \gamma H_{0}{ }^{2} \frac{1-\sin \phi^{\prime}}{1+\sin \phi^{\prime}}$

(Kitch, 2015b)

On the other hand, for a cohesive soil, the shear force acting upon the failure wedge may be described by the equation:

$T=N \tan \phi^{\prime} c L$

(Kitch, 2015b)

Behind the retaining wall, cohesive forces within the soil help maintain equilibrium of the soil wedge. As a result, the required resistive force applied by the retaining wall is reduced and can be calculated using the equation:

$P_{a}=\frac{1}{2} \gamma H_{0}{ }^{2} \cot \theta \tan \left(\theta-\phi^{\prime}\right)-c H_{0}\left(\sin \theta \cos \theta\left(1+\tan \theta \tan \phi^{\prime}\right)\right)$

$P_{a}=\frac{1}{2} \gamma H_{0}^{2} K_{a}-c H_{0} \sqrt{K_{a}}$

(Kitch, 2015b) 
Once again, the acting pressure is a maximum when the partial derivative with respect to the angle of the slip plane is equal to zero. However, as soil cohesion is a constant, the equation for the critical angle for both cohesive and non-cohesive soils is the same:

$\theta_{\text {crit }}=\left(45^{\circ}+\frac{\phi^{\prime}}{2}\right)$

(Kitch, 2015b)

The above equations assumed that the retaining wall is straight and frictionless. In addition, it was assumed that the ground surface behind the wall is horizontal. It is possible to take into account wall friction, a sloping retaining wall back slope, or sloping ground behind the retaining wall by changing the angle of the forces (Kitch, 2005a).

Until this point in the analysis, it did not matter whether the soil was on the active or passive side of the wall. However, once wall friction is introduced, the angle of the acting pressure will depend on which side of the wall the soil element is on. For the active case, the force applied to the soil by the retaining wall acts on an upward angle to the horizontal because of the downward force of the soil on the retaining wall. In the passive case, the force applied to the soil by the retaining wall acts on a downward angle to the horizontal because of the upward force of the soil on the retaining wall. This angle may be assumed to equal the internal friction angle of the soil. By summing all forces about the horizontal and vertical axis (as illustrated by Figure 6 for the active condition and Figure 7 for the passive condition), the following equations result:

$$
\begin{aligned}
& K_{a}= \frac{\sin ^{2}\left(\alpha+\phi^{\prime}\right)}{\sin ^{2} \alpha \sin (\alpha-\delta)\left[1+\sqrt{\frac{\sin \left(\phi^{\prime}+\delta\right) \sin \left(\phi^{\prime}-\beta\right)}{\sin (\alpha-\delta) \sin (\alpha+\beta)}}\right]^{2}} \\
& K_{p}=\frac{\sin ^{2}\left(\alpha-\phi^{\prime}\right)}{\sin ^{2} \alpha \sin (\alpha+\delta)\left[1+\sqrt{\frac{\sin \left(\phi^{\prime}+\delta\right) \sin \left(\phi^{\prime}+\beta\right)}{\sin (\alpha+\delta) \sin (\alpha+\beta)}}\right]^{2}}
\end{aligned}
$$

(Kitch, 2015b)

For a horizontal ground surface, supported by a retaining wall with a frictionless, vertical back face, the above equations may be simplified: 


$$
\begin{aligned}
& K_{a}=\tan ^{2}\left(45-\frac{\phi^{\prime}}{2}\right) \\
& K_{p}=\tan ^{2}\left(45+\frac{\phi^{\prime}}{2}\right)
\end{aligned}
$$

(Das, 2005, p. 339)

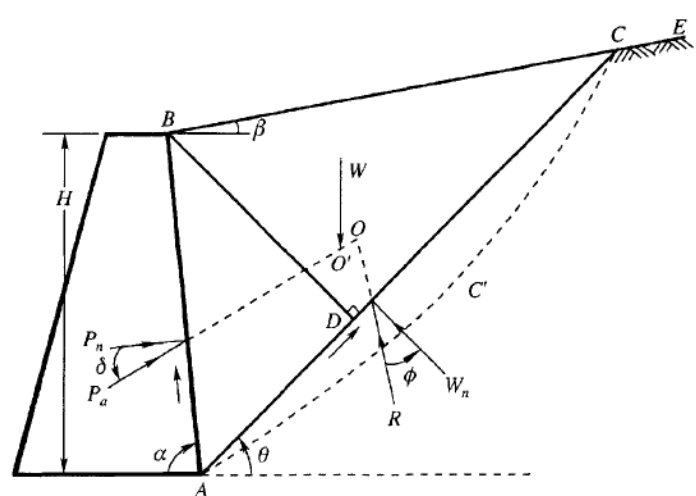

Figure 6: Forces Acting on a Soil Wedge with Wall Friction (Active Condition)

(Murthy, 2002, p. 452)

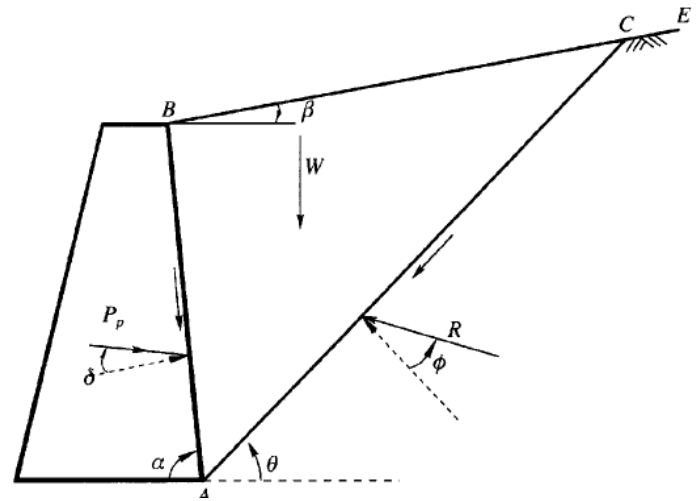

Figure 7: Forces Acting on a Soil Wedge with Wall Friction (Passive Condition)

(Murthy , 2002, p.455)

\subsubsection{Rankine's Earth Pressure Theory}

In his 1856 paper, Rankine approached the problem from another perspective. Unsatisfied with the "limited application" of Coulomb's theory, Rankine proposed to "investigate the mathematical theory of the frictional stability of a granular mass, without the aid of any artifice or assumption" (Rankine, 1857, p. 9). In the first part of the paper, Rankine worked through a number of mathematical equations to demonstrate principles that must apply to every element of a solid material in equilibrium. The second part of the paper applied these general principles of equilibrium to the stability to the specific case of a granular mass (Rankine, 1857, p. 17). In developing his theory, Rankine assumed that the soil mass was in plastic equilibrium: a state in which every point is about to fail (Das, 2005, p. 335).

Rankine's theory is based on the concept that the stability of a granular soil is the result of the frictional resistance of each of the soil elements: a function of the normal pressure multiplied by the coefficient of friction (tangent of the angle of repose) (Rankine, 1857, p. 9). Within any three dimensional solid, there are six stresses acting upon any particular element: three normal 
stresses and three tangential pressures (Rankine 1857, p. 10). A granular soil will only remain stable if the normal pressure between each soil element, no matter which plane, does not exceed the angle of repose (Rankine, 1857, p. 9). Based on the Mosley's principle of least resistance, for a given angle of repose, Rankine determined the limiting ratios between vertical and lateral pressures for which a soil mass is still stable (Rankine, 1857, p. 23).

Rankine summarized Mosley's principles as, "If the forces which balance each other in or upon a given body or structure, be distinguished into two systems, called respectively active and passive, which stand to each other in the relation of cause and effect, then will the passive forces be the least which are capable of balancing the active forces, consistently with the physical condition of the body or structure" (Fidler, 1981, p. 248).

In 1900, Christian Otto Mohr developed a graphical method to relate the normal and shear stresses within a solid material in equilibrium (Murthy, 2002, p. 264). The development of Mohr's Circle allowed for a simpler explanation of the principles developed within Rankin's 1856 paper. As a result, Mohr's circle is used here to explain Rankine's theory.

\subsubsection{Mohr's Circle of Stress}

At every point within a soil, there are three principle planes at right angles to one another. These planes are subjected to normal stresses only, with no shear stresses acting upon the planes. The normal stresses are described as the major principle stress, intermediate principle stress, and minor principle stress. Once the stress on one of the planes is known, the other principle stresses can be calculated. When evaluating the strength of soils, the problem may be simplified to two dimensions as the intermediate principle stress does not have a large affect on failure (Murthy, 2002, p. 260).

Considering a plane through a soil element, at an angle $(\alpha)$ to the chosen $x$-axis, normal and shear stresses acting upon the chosen plane ( as shown in Figure 8) can be calculated by summing all forces in the $x$ and $y$ direction:

$\sigma=\frac{\sigma_{y}+\sigma_{x}}{2}+\frac{\sigma_{y}-\sigma_{x}}{2} \cos 2 \alpha+\tau_{x y} \sin 2 \alpha$

$\tau=\frac{1}{2}\left(\sigma_{y}-\sigma_{x}\right) \sin 2 \alpha-\tau_{x y} \cos 2 \alpha$

(Murthy, 2002, p. 261) 


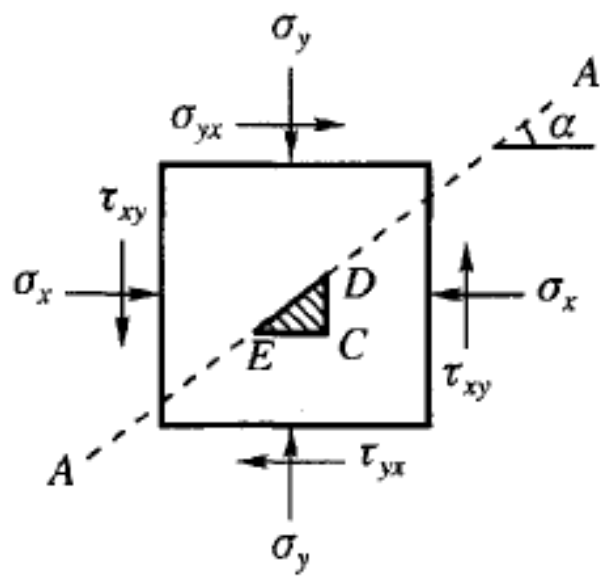

Figure 8: Normal and Shear Forces Acting upon a Soil Element

(Murthy, 2002, p. 261)

By definition, the shear stress acting upon a principle plane is zero. Therefore, the angle of the principle planes can be determined by setting the equation for shear stress, above, to zero:

$\tan 2 \alpha=\frac{2 \tau_{x y}}{\sigma_{y}-\sigma_{x}}$

Solving the above equation produces two principle planes that are at right angles to one another. By differentiating the above equation with respect to the angle of the plane, the result is the same equation. Therefore, the maximum and minimum normal stresses must act upon the principle planes (Murthy, 2002, p. 262).

By squaring and adding the equations found on the previous pages, for normal and shear stresses, the result is the following equation:

$\left[\sigma-\frac{\sigma_{y}+\sigma_{x}}{2}\right]^{2}+\tau^{2}=\left(\frac{\sigma_{y}-\sigma_{x}}{2}\right)^{2}+\tau_{x y}^{2}$

which describes a circle with a radius of:

$\frac{1}{2} \sqrt{\left(\sigma_{y}-\sigma_{x}\right)^{2}-4 \tau^{2} x y}$ 
and a centre at coordinates:

$\left[\frac{1}{2}\left(\sigma_{y}+\sigma_{x}\right), 0\right]$

(Murthy, 2002, p. 264)

By graphic the circle, the normal and shearing stresses on any plane, and the orientation of the principle planes can be easily determined. When combined with Coulomb's equation for shear failure, the result is a clear graphical representation (Figure 9) of the stress states in which a soil mass will fail (Budhu, 2011, p. 275).

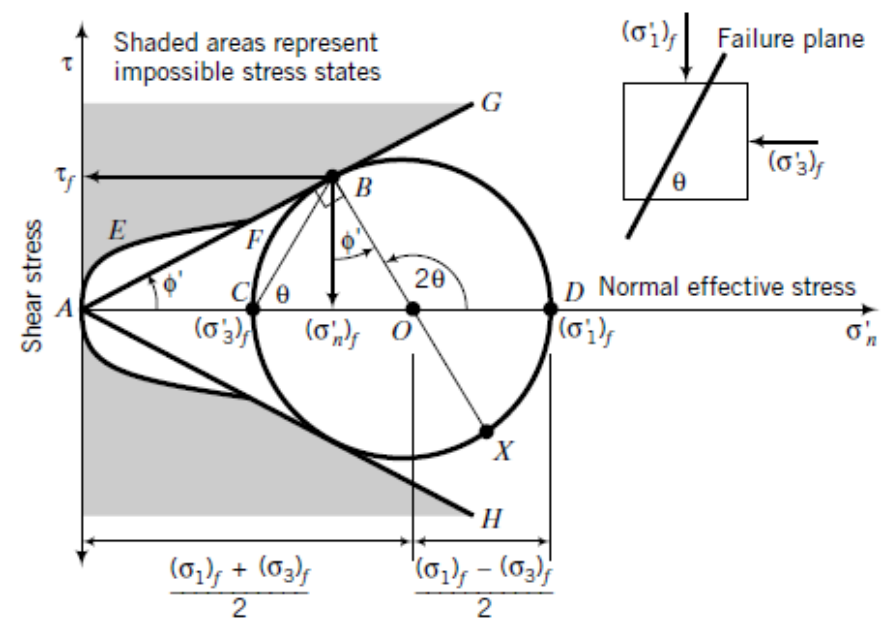

Figure 9: Mohr-Coulomb Failure Envelope

(Budhu, 2011, p. 275)

\subsubsection{Rankine's Earth Pressure Theory using Mohr's Circle of Stress:}

If a soil mass behind a retaining wall is at equilibrium, the soil elements must each be at a stress state below failure. If the forces of the soil cause the retaining wall to begin to rotate away from the soil mass, the soil behind the wall will "stretch". As the wall rotates, the resistive force applied to the soil by the retaining wall will decrease. The minor principle stress of the soil element will also decrease. However, the major principle stress remains constant. Mohr's circle will grow until it touches the Mohr-Coulomb failure envelope as shown in Figure 10. At this point, shear stresses acting along the failure plane will exceed the maximum resistive forces of the soil and shear failure will occur (Kitch, 2014). 
On the other hand, if a retaining wall rotates into a soil, the force applied to the soil by the retaining wall will increase. The soil will compress and the horizontal effective stress within the soil will grow, while the vertical effective stress remains constant. Once again, shear stresses will increase until Mohr's circle reaches the failure envelope (Figure 11). Soil failure under this passive condition requires a larger change in horizontal effective stress (and therefore, more displacement of the retaining wall) than failure under active conditions (Kitch, 2014).

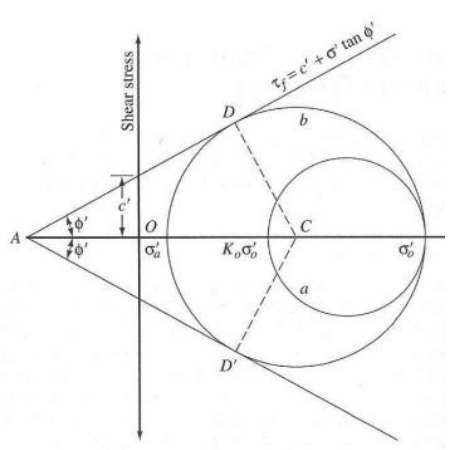

Figure 10: Rankine's Active Earth Pressure at Failure

(Das, 2005, p.336)

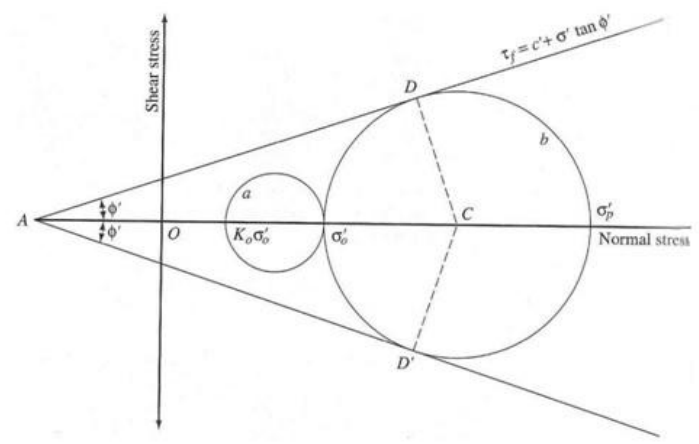

Figure 11: Rankine's Passive Earth Pressure at Failure

(Das, 2005, p. 340)

\subsection{Granular Soils:}

For non-cohesive soils, the Mohr-Coulomb failure envelope passes through the origin as shown in Figure 9. Based on the geometry of Mohr's circle and the failure envelope for the active condition, the following relationship between the internal angle of friction, horizontal stress, and vertical stress applies:

$$
\cos \phi^{\prime}=\frac{\frac{1}{2}\left(\sigma^{\prime}{ }_{z}-\sigma^{\prime}{ }_{x}\right)}{\frac{1}{2}\left({\sigma^{\prime}}_{x}+\sigma^{\prime}{ }_{z}\right) \tan \phi^{\prime}}
$$

(Kitch, 2014)

The above equation can be rearranged to solve for the Active Earth Pressure Coefficient:

$K_{a}=\frac{\sigma_{x}^{\prime}}{\sigma_{z}^{\prime}}=\frac{1-\sin \phi^{\prime}}{1+\sin \phi^{\prime}}$

(Kitch, 2014) 
Based on the geometry of the Mohr-Coulomb failure envelope for a granular soil under passive conditions, the following relationship between the internal angle of friction, horizontal stresses, and vertical stress, applies:

$\cos \phi^{\prime}=\frac{\frac{1}{2}\left({\sigma^{\prime}}_{x}-{\sigma^{\prime}}_{z}\right)}{\frac{1}{2}\left({\sigma^{\prime}}_{x}+\sigma^{\prime}{ }_{z}\right) \tan \phi^{\prime}}$

(Kitch, 2014)

The above equation can be rearranged to solve for the Passive Earth Pressure Coefficient:

$K_{p}=\frac{{\sigma_{x}^{\prime}}_{x}}{{\sigma_{z}^{\prime}}_{z}}=\frac{1+\sin \phi^{\prime}}{1-\sin \phi^{\prime}}$

(Kitch, 2014)

\subsection{Cohesive Soils}

In cohesive soils, the radius of Mohr's circle for the active condition can still be described by the equation:

$\frac{1}{2}\left({\sigma^{\prime}}_{z}-{\sigma^{\prime}}^{\prime}\right)$

(Kitch, 2014)

However, due to the cohesive forces, the failure envelope no longer passes through the origin (as shown in Figure 10). For active conditions, the following relationship between the horizontal stress, internal angle of friction, and vertical stress applies:

$$
\begin{aligned}
& \sigma_{x}^{\prime}=\sigma_{z}^{\prime} \frac{1-\sin \phi^{\prime}}{1+\sin \phi^{\prime}}-2 c^{\prime} \sqrt{\frac{1-\sin \phi^{\prime}}{1+\sin \phi^{\prime}}} \\
& \sigma_{x}^{\prime}=\sigma_{z}^{\prime} K_{a}-2 c^{\prime} \sqrt{K_{a}}
\end{aligned}
$$

(Kitch, 2014) 
Based on the geometry of the Mohr-Coulomb failure envelope for a cohesive soil under passive conditions, the following relationship between the horizontal stress, internal angle of friction, and vertical stress applies:

$\sigma_{x}^{\prime}=\sigma_{z}^{\prime} \frac{1+\sin \phi^{\prime}}{1-\sin \phi^{\prime}}-2 c^{\prime} \sqrt{\frac{1+\sin \phi^{\prime}}{1-\sin \phi^{\prime}}}$

$\sigma_{x}^{\prime}=\sigma_{z}^{\prime} K_{p}+2 c^{\prime} \sqrt{K_{p}}$

(Kitch, 2014)

If the vertical effective stress is known, the equations above may be rearranged to solve for the lateral earth pressures acting upon a retaining wall (Kitch, 2014).

Rankine theory assumes that the soil behind the wall is in a general state of failure. Once the orientation of the shear plane is known, the zone of failed soil can also be determined. Mohr's circle may be used to find the shear plane for both active and passive conditions. Within Mohr's circle, there is a point (known as the pole) in which if a line is drawn from any point on the circle through the pole, the line will be parallel to the plane in which the normal and shear stresses on the point act.

For a soil element in level ground, the vertical stress is equal to the major principal stress of a soil element and the horizontal stress is equal to the minor principle stress (National Programme on Technology Enhanced Learning, n.d., p. 8). Therefore, for both active and passive conditions, the pole point is located on Mohr's circle at the location of the horizontal effective stress (Figure 12). Therefore, based on the geometry of Mohr's circle (Figure 12), the failure planes are at an angle to the horizontal of:

$45^{\circ}+\frac{\phi^{\prime}}{2}$ (Active State)

$45^{\circ}-\frac{\phi^{\prime}}{2}$ (Passive State)

(Kitch, 2015a) 


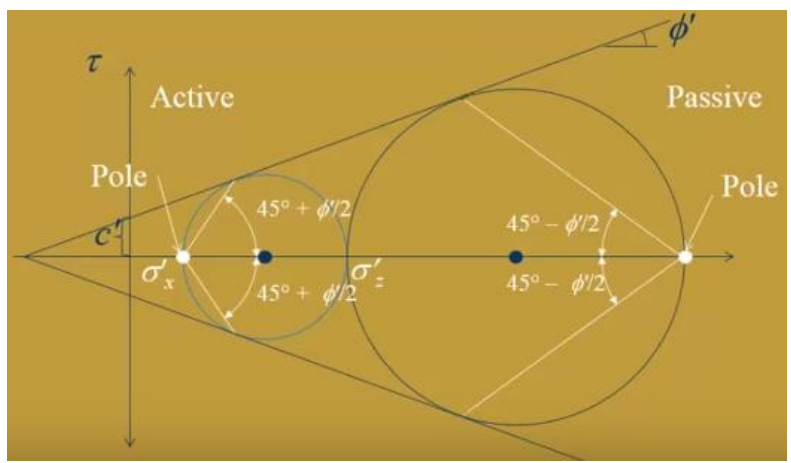

Figure 12: Orientation of Failure Planes for both Active and Passive Conditions

(Kitch, 2015a)

\subsection{Sloped Ground}

In sloping ground, the vertical stress acting upon a soil element is no longer equal to the major principal stress, nor is the horizontal stress equal to the minor principle stress. This problem is solved by representing the soil element as a parallelogram where:

- The two sides of the parallelogram are completely vertical

- The top and bottom of the parallelogram are parallel to the ground surface.

Since the top and bottom are parallel to the ground surface, zero shear stresses act upon the soil element. There is a vertical stress acting upon the top plane and a horizontal stress acting upon the vertical plan at an angle, $\beta$, to the horizontal as shown in Figure 13.

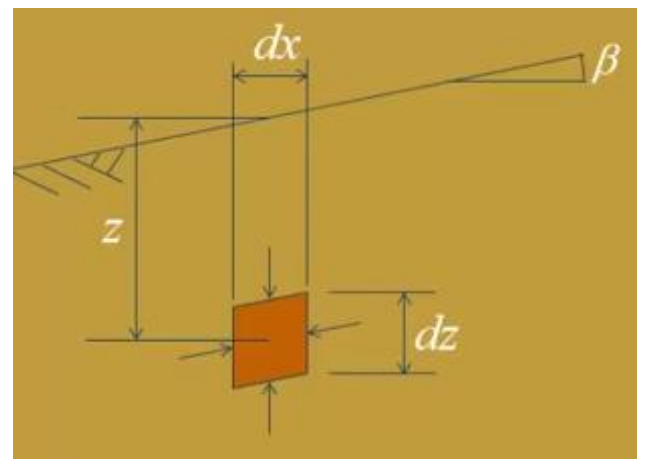

Figure 13: Vertical and Horizontal Stresses Acting upon a Soil Element below a Sloping Ground Surface (Kitch, 2015a) 
By summing the forces about the vertical axis:

${\sigma^{\prime}}_{z}=\gamma^{\prime} z \cos \beta$

(Kitch, 2015a)

If the vertical effective stress is acting upon a plane at an angle $(\beta)$ to the ground surface, the stress will be located at point A on Mohr's Circle as shown in Figure 14. The pole point must be Point E.

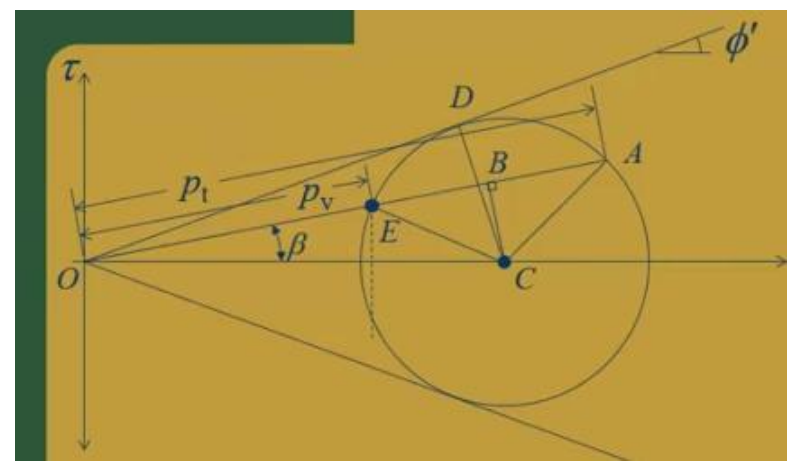

Figure 14: Mohr's Circle of Stress for a Soil Element below a Sloping Ground Surface

(Kitch, 2015a)

Based the geometry of the circle, the magnitude of the vertical effective stress acting upon the soil element can be determined from the equation:

$\sigma_{z}^{\prime}=\cos \beta+\sqrt{\sin ^{2} \phi^{\prime}-\sin ^{2} \beta^{\prime}}$

(Kitch, 2015a)

The magnitude of the horizontal effective stress acting upon the soil element can be calculated using the equation:

$\sigma_{x}^{\prime}=\cos \beta-\sqrt{\sin ^{2} \phi^{\prime}-\sin ^{2} \beta^{\prime}}$

(Kitch, 2015a)

The passive earth pressure coefficient can then be determined by dividing the vertical effective stress by the horizontal effective stress: 
$K_{p}=\cos \beta\left[\frac{\cos \beta+\sqrt{\sin ^{2} \phi^{\prime}-\sin ^{2} \beta^{\prime}}}{\cos \beta-\sqrt{\sin ^{2} \phi^{\prime}-\sin ^{2} \beta^{\prime}}}\right]$

(Kitch, 2015a)

Similarly, for the active condition:

$K_{a}=\cos \beta\left[\frac{\cos \beta-\sqrt{\sin ^{2} \phi^{\prime}-\sin ^{2} \beta^{\prime}}}{\cos \beta+\sqrt{\sin ^{2} \phi^{\prime}-\sin ^{2} \beta^{\prime}}}\right]$

(Kitch, 2015a)

Once again, failure will occur where Mohr's circle of stress touches the Mohr-Coulomb failure envelope. Lines drawn from the failure points through the pole (Point E) will be parallel to the two failure planes (conjugate rupture planes). From the geometry of Mohr's Circle, these planes will be orientated at angles of $i$ (inner failure plane) and $j$ (outer failure plane) to the vertical:

Active state:

$i=\frac{\left(90-\phi^{\prime}\right)}{2}+\frac{(\varepsilon-\beta)}{2}$

$j=\frac{\left(90-\phi^{\prime}\right)}{2}-\frac{(\varepsilon-\beta)}{2}$

Passive state:

$i=\frac{\left(90+\phi^{\prime}\right)}{2}-\frac{(\varepsilon-\beta)}{2}$

$j=\frac{\left(90+\phi^{\prime}\right)}{2}+\frac{(\varepsilon-\beta)}{2}$

where:

$\varepsilon-\sin ^{-1}\left(\frac{\sin \beta}{\sin \phi^{\prime}}\right)$

(Murthy, 2002, p. 834) 


\subsection{Lateral Resistance of Piles}

When designing retaining walls, it is common to transfer lateral loads ground using piles. In order to function appropriately, laterally loaded piles must be designed to limit horizontal movement. Furthermore, piles must not fail, whether by yielding of soil, or by yielding of the pile material (Murthy, 2002, p. 699). The lateral resistance of a pile is a non-linear, three dimensional problem. As a result, it is challenging to estimate ultimate capacity. Numerous methods have been developed to predict the lateral resistance and deflection of piles. However, these solutions are based on a numerous assumptions, approximations, and are semi-empirical in nature. As a result, the various methods tend to produce very different estimates of ultimate capacity (Hazzar, Karray, Bouassida, Nussien, 2013, p. 59).

\subsection{Winkler Model}

In 1867, Emil Winkler proposed that a soil may be represented a number of identical and closely spaced, but independent elastic springs (Sadrekarimi \& Gharmari, 2008m p. 1). This elastic spring model is the basis of subgrade reaction (Terzaghi, 1955, p. 298). Subgrade reaction may be defined as, "Pressure per unit area of the surface of contact between a loaded beam or slab and the subgrade in which it rests an on to which it transfers the loads" (Terzaghi, 1955, p. 298). The ratio between the pressure at any point and resulting settlement of the soil is known as the coefficient of subgrade reaction:

$k_{s}=\frac{p}{y}$

(Terzaghi, 1955, p. 298)

Winkler's theory was based on the concept that if a beam (such as a foundation) is placed upon a soil, the reaction of any point upon the beam is a function of every point of the beam. However, as each spring acts independently, the soil reaction at any point is only related to the deflection of the beam at that point (Murthy, 2002, p. 700). In the 1920's, researchers began to apply theories of subgrade reaction to estimate stresses within piles subjected to horizontal forces applied above ground level (Figure 15) (Terzaghi, 1955, p. 299). 


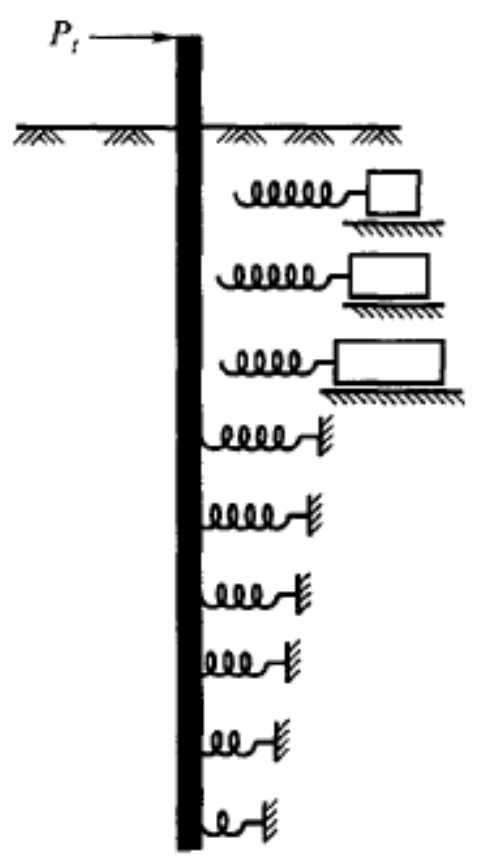

Figure 15: Winkler Hypothesis applied to a Laterally Loaded Pile

(Murthy, 2002, p. 701)
The above situation can be represented by a standard differential equation, provided that compatibly and equilibrium is maintained for pile and soil elements. Along the elastic curve of a pile, deflection is measured normal to the pile axis and the following equations apply:

Slope of the Deflected Pile (S):

$S=\frac{d_{y}}{d_{x}}$

Moment of the Deflected Pile $(\mathrm{X})$ :

$X=E I \frac{\partial^{2} y}{\partial_{x}^{2}}$

Shear of the Deflected Pile (V):

$$
X=E I \frac{\partial^{3} y}{\partial_{x}{ }^{3}}
$$

Magnitude of the Deflected Pile $(p)$ :

$$
p=E I \frac{\partial^{4} y}{\partial_{x}{ }^{4}}
$$

Once the contact pressure between the pile and soil is known, the soil deflection can be determined based on the soil modulus:

$p=E_{s} y$

(Murthy, 2002, p. 702)

\subsection{Lateral Pile Resistance based on Subgrade Reaction}

In 1955, Karl von Terzaghi was the first researcher to investigate the lateral pile resistance (Hazzar et al., 2013, p. 60). Within this paper, Terzaghi investigated the factors which affect the vertical and horizontal subgrade reaction of cohesive and cohesionless soils. Terzaghi also proposed numerical values these factors and presented examples of how theories of subgrade reaction may be applied in practice (Terzaghi, 1955, p. 297). 


\subsubsection{Coefficient of Horizontal Subgrade Reaction}

For a laterally loaded pile, the subgrade reaction acts in a horizontal direction. Therefore, the coefficient of horizontal subgrade reaction is defined as the ratio between the applied pressure and horizontal displacement (Terzaghi, 1955, p. 300). For a cohesionless soil, Terzaghi found that the pressure needed to produce a specified displacement is proportional to the depth and the coefficient of horizontal subgrade reaction may be represented by the equation:

$k_{h}=m_{h} z$

Given the deflection of a laterally loaded pile must equal to deflection of the soil:

$m_{h} z y=E I \frac{\partial^{4} y}{\partial_{x}{ }^{4}}$

(Terzaghi, 1955, p. 300)

From the above equations, it is clear that the coefficient of subgrade reaction is extremely important in estimating the deflection (and internal stresses) of a horizontally loaded pile. To achieve accurate estimates, the selected coefficients must be representative of the deformation properties of the loaded soils (Terzaghi, 1955, p. 297). Prior to Terzaghi's 1955 paper, researchers generally focused on the application of the differential model, assuming that the coefficients were known. Previous papers proposed that the coefficients of subgrade reaction could be determined empirically by loading tests. However, it was not clear that the results of the loading tests were dependant on the size of the area tested. In addition, the specific factors that influenced the coefficients were not discussed (Terzaghi, 1955, p. 300). As a result, researchers often used "unrealistic values", leading to inaccurate results. These inaccuracies were the motivation behind Terzaghi's 1955 study (Terzaghi, 1955, p. 301).

To understand subgrade reactions for laterally loaded piles, Terzaghi considered the case in which a pile is embedded in soil and displaced due to an applied load. Before any loads are applied, the pressure acting between the soil and the surface of the pile is equal to (for buried piles) or greater than the at-rest pressure (for driven piles). As a lateral load is applied and the pile begins to displace, the contact pressure between the pile and the soil begins to increase (Terzaghi, 1955, p. 307). The stresses induced within the soil may be represented by a "pressure bulb", which Terzaghi defined as, "the space within which the... normal stress in the 
subgrade is greater than one-fourth of the normal pressure on the surface of load application" (Terzaghi, 1955, p. 301). A value of one-fourth was chosen as it encompasses most of the deformed soils that contribute to the settlement of a plate loaded on the surface of a subgrade (Terzaghi, 1955, p. 301).

The magnitude of deformation of soils surrounding a deflected pile is dependent on depth. In granular soils, the modulus of elasticity is proportional to the depth of the soil. As a result, the load required to cause a certain displacement of a pile must be proportional to the depth of the soil. As noted above, the coefficient of horizontal subgrade reaction may be represented by the equation:

$k_{h}=m_{h} Z$

(Terzaghi, 1955, p. 307)

On the other hand, deformations of stiff clay are generally independent of depth. As a result, the subgrade reaction will be uniformly distributed and can be represented by the equation:

$k_{h}=\frac{p}{y_{1}}$

(Terzaghi, 1955, p. 308)

It should be noted that over time, settlement will increase leading to a decrease in the coefficient of subgrade reaction. This is due to the fact that consolidation of clay is time dependant. As a result, ultimate vales of $k_{h}$ must be considered (Terzaghi, 1955, p. 307).

In the horizontal direction, the modulus of elasticity of both granular and cohesive soils is constant. As a result, for a given unit pressure, settlement will increase proportionally with pile width.

Therefore, for piles in granular soils:

$k_{h n}=m_{h n} z=\frac{p}{y_{n}}=\frac{p}{y n_{1}}$

(Terzaghi, 1955, p. 309) 
given:

$\frac{p}{y_{1}}=m_{h 1} z=m_{h 1} B_{1} \frac{z}{n B_{1}}$

(Terzaghi, 1955, p. 309)

and substituting:

$k_{h n}=K_{h}, B_{1}=1 \mathrm{ft}, n B_{1}=B$, and $m_{h 1} B_{1}=n_{h}$

$k_{h}=n_{h} \frac{Z}{B}$

(Terzaghi, 1955, p. 309)

Similarly in cohesive soils:

$k_{h n}=\frac{p}{y_{n}}=\frac{p}{n y_{1}}=\frac{p}{y_{1}} \frac{B_{1}}{n B_{1}}$

(Terzaghi, 1955, p. 308)

and substituting:

$k_{h n}=K_{h}, B_{1}=1 f t, n B_{1}=B$, and $\frac{p}{y_{1}}=k_{h 1}$

$K_{h}=\frac{p}{y_{1} B}=\frac{1}{B} K_{h 1}$

(Terzaghi, 1955, p. 308)

Based on the theory of elasticity, at a specified depth below the ground surface, the modulus of elasticity of a granular soil can be calculated from the equation:

$E_{s}=\gamma z A$

(Terzaghi, 1955, p. 316) 
Within his 1943 paper, Terzaghi found that displacements of a soil beyond approximately 3B do not have any impact on local bending moments within a pile. Therefore, Terzaghi proposed that displacement is related to the pressure acting on the soil with a thickness of 3B. Also taking into account that displacement is dependent on the modulus of elasticity of the soil:

$p=\frac{E_{S}}{1.35 B}=y \frac{A \gamma}{1.35} \frac{z}{B}$

(Terzaghi, 1955, p. 316)

and:

$\frac{p}{y}=n_{h} \frac{z}{B}$

(Terzaghi, 1955, p. 316)

gives a factor representing a constant horizontal subgrade reaction for a pile:

$n_{h}=\frac{A \gamma}{1.35}$

(Terzaghi, 1955, p. 316)

Within his paper, Terzaghi proposed the following values for $A$ and $n_{h}$ :

\begin{tabular}{|l|c|c|c|}
\hline Relative Density of Sand & Loose & Medium & Dense \\
\hline Range of Values of $A$ & $100-300$ & $300-1000$ & $1000-2000$ \\
\hline Adopted Values of $A$ & 200 & 600 & 1500 \\
\hline Dry or moist sand, values of $n_{h}$ & 7 & 21 & 56 \\
\hline Submerged sand, values of $n_{h}$ & 4 & 14 & 34 \\
\hline
\end{tabular}

Table 2: Constant of Horizontal Subgrade Reaction for a $1 \mathrm{ft}$ Wide Pile Embedded in Sand

(Terzaghi, 1955, p. 317) 
For stiff cohesive soils, Terzaghi proposed that the coefficient of horizontal subgrade reaction is similar to the coefficient of vertical subgrade reaction for beams on the surface of the soil and could be calculated using the equation:

$k_{h}=\frac{k_{s 1}}{1.5 \beta}$

(Terzaghi, 1955, p. 317)

Suggested values for the coefficient of vertical subgrade reaction (square area with a width of 1 $\mathrm{ft})$ are summarized in Table 3:

\begin{tabular}{|l|c|c|c|}
\hline Consistency of Clay & Stiff & Very Stiff & Hard \\
\hline Values of $q_{\mathrm{u}}$ (tons/ sq. $\mathrm{ft}$ ) & $1-2$ & $2-4$ & $>4$ \\
\hline Range for $k_{s 1}$ & $50-100$ & $100-200$ & $>200$ \\
\hline Proposed values for $\mathrm{k}_{\mathrm{s} 1}$ & 75 & 150 & 300 \\
\hline
\end{tabular}

Table 3: Coefficient of Vertical Subgrade Reaction for a Square Area with a $1 \mathrm{ft}$ Width

(Terzaghi, 1955, p. 315)

\subsection{Broms' Method for Calculating Lateral Resistance and Deflection of a Pile}

In 1964, Bengt Broms developed a new method to estimate the resistance and deflection at ground surface laterally loaded piles (Hazzar et al., 2013, p. 60). Broms presented this method over two papers in 1964: the first to calculate the lateral resistance and deflection of piles installed in cohesive materials and the second to calculate the lateral resistance and deflection of piles installed in cohesionless soils (Murthy, 2002, p. 710).

\subsubsection{Lateral Resistance and Deflection of Piles in Cohesive Soils}

Within the first paper, Broms provided solutions to calculate ultimate lateral resistance and lateral defections experienced by horizontally loaded, free and fixed head piles installed in undrained cohesive soils (Broms, 1964a, p. 27). When investigating deflection, Broms only considered piles within their working load range (approximately half of the ultimate resistance of the pile). His analysis was based on Terzaghi's theory of subgrade reaction (Meyer \& Reese, 
1979 , p. 2), considering the limiting resistive values of the soil (Murthy, 2002, p. 700). Broms also investigated the maximum bending moments within the laterally loaded piles (Broms, 1964a, p. 28).

Assuming a simplified distribution of soil resistance along a pile, Broms used statics to estimate the ultimate lateral capacity for a load applied at the top of a pile, based on the pile width, pile depth, and undrained shear strength of the soil (Georgiadis, Georgiadis \& Anagnostopolus, 2013, p. 1).

Within this paper, Broms divided piles into two types: short, rigid piles and long, flexible piles. A short pile will deflect by rotation or translation of the entire pile (without substantial axial deformation). On the other hand, a long pile will deflect due to a plastic hinge (Jahan \& Abedin, 2012 , p. 2) that forms when moment induced in the pile surpasses the yield strength of the pile (Broms, 1964a, p.30). The plastic hinge allows the top section of the pile to bend and rotate without moving the bottom of the pile. Whether a pile behaves as a long or short pile is dependent on the stiffness of the soil compared to the stiffness of the pile (Jahan \& Abedin, 2012, p. 2), as well as the length of pile embedment (Broms. 1964a, p. 30). A pile is considered short if the dimensionless factor $(\beta L)$ is less than 2.5 and long if the dimensionless factor is greater than 2.5, where:

$\beta=\left(\frac{k_{h} d}{4 E I}\right)^{\frac{1}{4}}$

(Murthy, 2002, p. 711)

For a pile embedded within a cohesive soil, the ultimate resistance varies with depth, from a value of two times the undrained shear strength of the soil to a maximum value of 8 to 12 times the undrained shear strength (at a depth of three metres). For analysis, Broms assumed a constant soil resistance of nine times the undrained shear strength as shown in Figure 16 (Murthy, 2002, p. 711). In addition, Broms assumed that no resistance was developed within 1.5 pile diameters of the ground surface (Meyer \& Reese, 1979, p. 4) and, for a long pile, no resistance would be provided below the depth of maximum moment (Meyer \& Reese, 1979, p. 3). 
Broms presented his results in graphical form, comparing a dimensionless load factor to a dimensionless length factor as shown in Figure 17 and Figure 18.

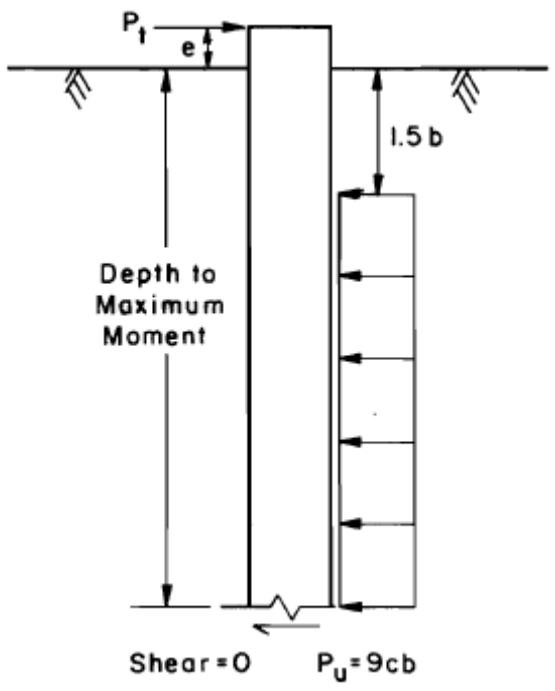

Figure 16: Broms' Distribution of Ultimate Soil Resistance for Piles Installed in Cohesive Soils

(Meyer \& Reese, 1979, p. 4)

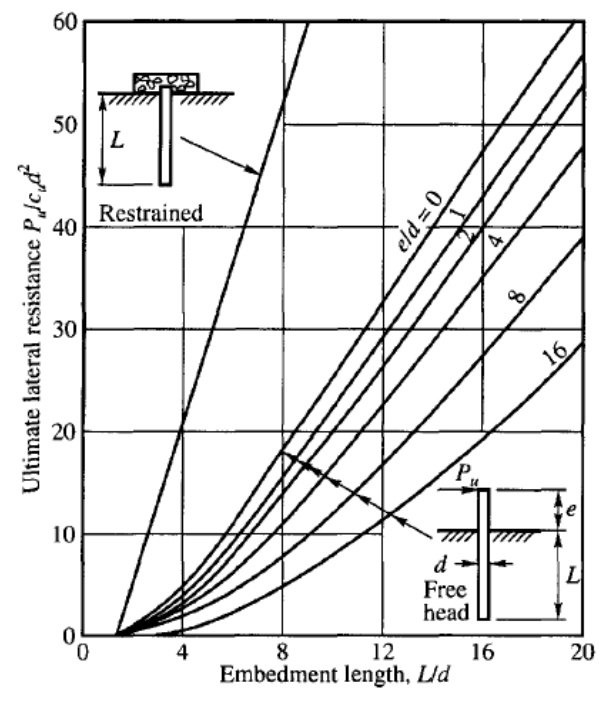

Figure 17: Ultimate Lateral Resistance of Short Piles in Cohesive Soils

(Murthy, 2002, p. 711)

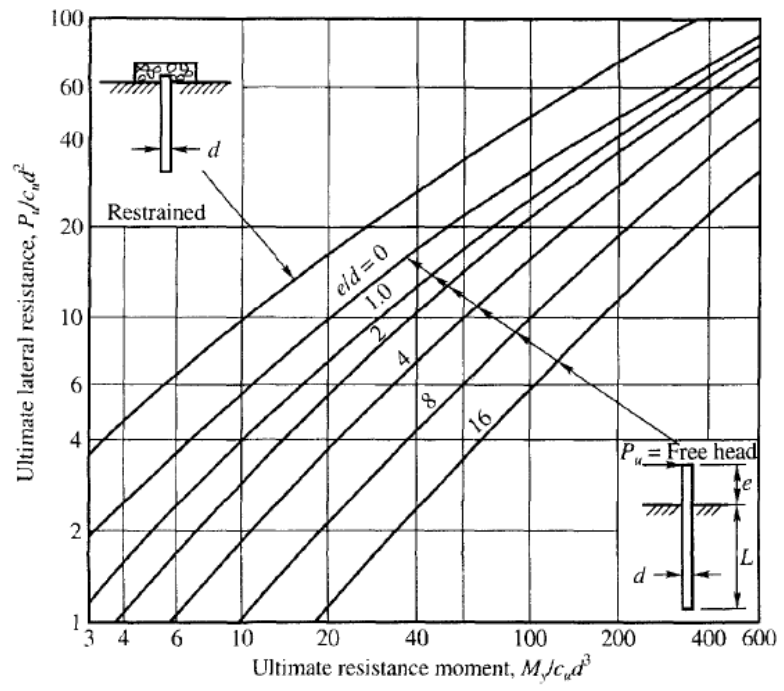

Figure 18: Ultimate Lateral Resistance of Long Piles in Cohesive Soils

(Murthy, 2002, p. 712) 
When evaluating the ultimate lateral resistance of a pile, the ultimate moment resistance of the pile may be calculated using the equations:

H-Pile:

$M_{y}=1.1 f_{y} Z_{\max }$

Cylindrical Section:

$M_{y}=1.3 f_{y} Z$

(Murthy, 2002, p. 713)

In calculating deflections of piles installed in cohesive soils, Broms only considered piles within the working load range of the pile (approximately half the ultimate capacity of the pile) and assumed that soil is linearly elastic with depth. Although incorrect, this assumption would only lead to small errors in the estimated values (Meyer \& Reese, 1979, p. 2). For working loads, piles installed in undrained, cohesive soils will experience a relatively linear relationship between deflection and applied load. Initially, piles deflect as a result of shear deformations of the soil. Over time, further deflection will be observed due to creep and consolidation of the soil (Broms, 1964a, p.31).

When calculating lateral deflection of free head piles, Broms considered any pile with a dimensionless length of less than 1.5 as infinitely stiff (Broms, 1964a, p. 34). As a result, pile length had a significant effect on lateral displacement. Beyond a dimensionless length of 1.5, pile deflection depended on the coefficient of subgrade reaction between the ground surface and the point of maximum pile moment. However, for a dimensionless length greater than 2.0, Broms found that pile and soil properties had a very limited affect on pile deflection. Piles were considered infinitely long once a dimensionless length of 2.5 was reached (Broms, 1964a, p. 35). The results were, once again, presented in graphical form by comparing a dimensionless lateral deflection factor to a dimensionless length factor as shown in Figure 19: 


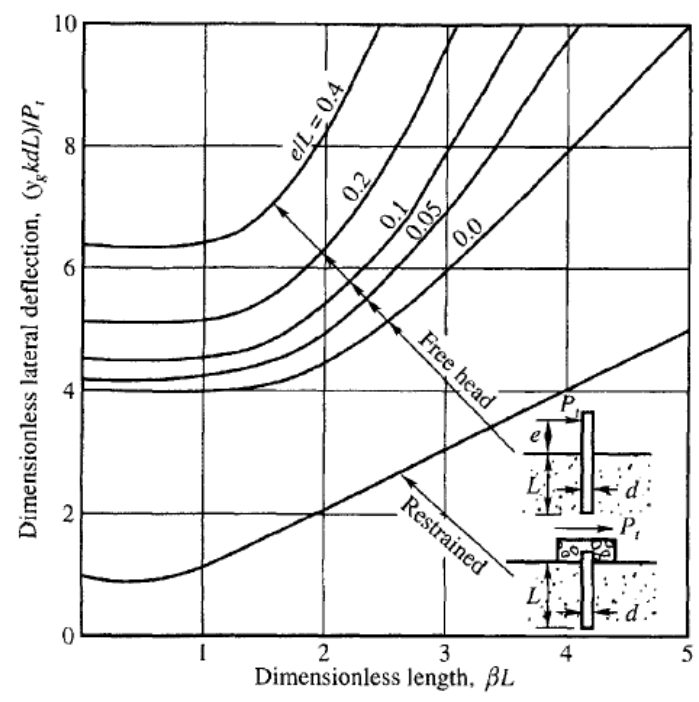

Figure 19: Lateral Deflection at Ground Level under Working Loads for Piles in Cohesive Soils

(Murthy, 2002, p. 710)

\subsubsection{Lateral Resistance and Deflection of Piles installed in Cohesionless Soils}

Within his second 1964 paper, Broms presented a method to calculate lateral resistance and the deflection at ground level for short and long piles installed in cohesionless materials. Once again, Broms applied Terzaghi's theory of subgrade reaction, assuming the horizontal subgrade modulus increased linearly with depth. He also assumed that soils were linearly elastic within the working load range and that a plastic hinge would form in long piles at ultimate load. In his analysis, Broms calculated the horizontal subgrade modulus, using coefficients based on the relative soil density and the diameter of the pile. These coefficients were the same as those used by Terzaghi's 1955 paper (Meyer \& Reese, 1979, p. 3).

In 1956 Reese and Matlock provided non-dimensional curves to solve the Winkler Hypothesis differential equations for laterally loaded piles, given a horizontal subgrade modulus that increases linearly with depth. Based on these curves, Broms used the following equation to calculate ultimate pile resistance:

$P_{u}=3 b \gamma z K_{p}$

(Meyer \& Reese, 1979, p., 5) 
Similar to piles installed in clay, Broms assumed two types of pile failure in cohesionless materials:

- Short piles fail by rotation of the entire pile about the pile toe;

- Long piles fail by the formation of a plastic hinge;

(Broms, 1964b, p. 125)

Once again, for long piles, Broms did not consider the passive soil resistance developed below the plastic hinge due to the small magnitude of pile deflections below this point (as the ultimate passive resistance of the soil would not be fully mobilized) (Broms, 1964b, p. 125).

For estimating deflection, Broms considered piles to be infinitely stiff when the dimensionless length of the pile was less than 2.0. For dimensionless lengths in excess of 4.0, Broms considered the piles to be infinitely long. Therefore, for short piles, an increase in length would result in a decrease in pile deflection for a given load. However, to reduce the lateral deflection of a long pile, it is necessary to increase the stiffness of the pile (Broms, 1964b, p. 128). The charts developed by Broms for the ultimate resistance of short and long piles in cohesionless soils are shown in Figure 20 and Figure 21.

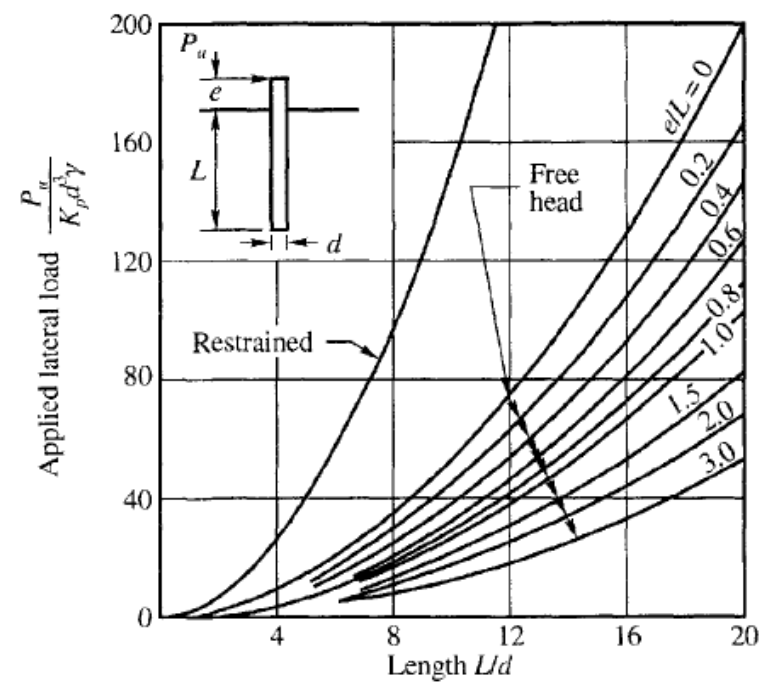

Figure 20: Ultimate Lateral Resistance of Short Piles in Cohesionless Soils

(Murthy, 2002, p. 712)

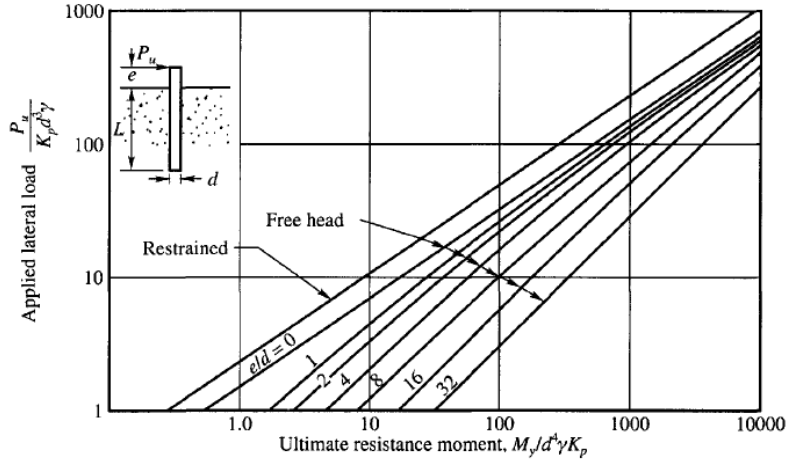

Figure 21: Ultimate Lateral Resistance of Long Piles in Cohesionless Soils

(Murthy, 2002, p. 713) 
Similar to his first paper, Broms only considered the deflection of laterally loaded piles in cohesionless soils for working loads. Using the curves developed by Reese and Matlock, Broms presented the following chart relating a dimensionless lateral deflection factor to a dimensionless length (Figure 22), where $\eta$ may be calculated using the equation:

$\eta=\left(\frac{\eta_{h}}{E I}\right)^{\frac{1}{5}}$

(Murthy, 2002, p. 711)

The relationship between the coefficient of soil modulus variation and density for cohesionless soils is shown in Figure 23.

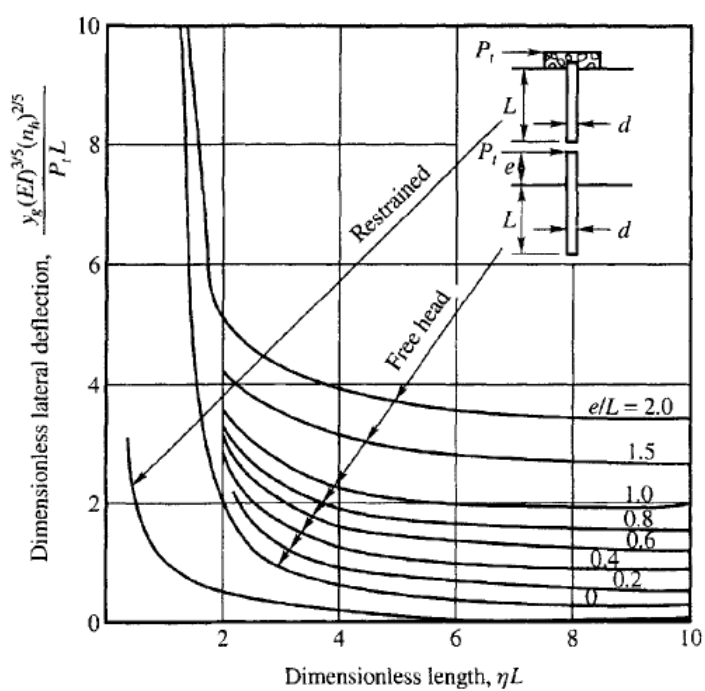

Figure 22: Lateral Deflection at Ground Level under Working Loads for Piles in Cohesionless Soils

(Murthy, 2002, p. 710)

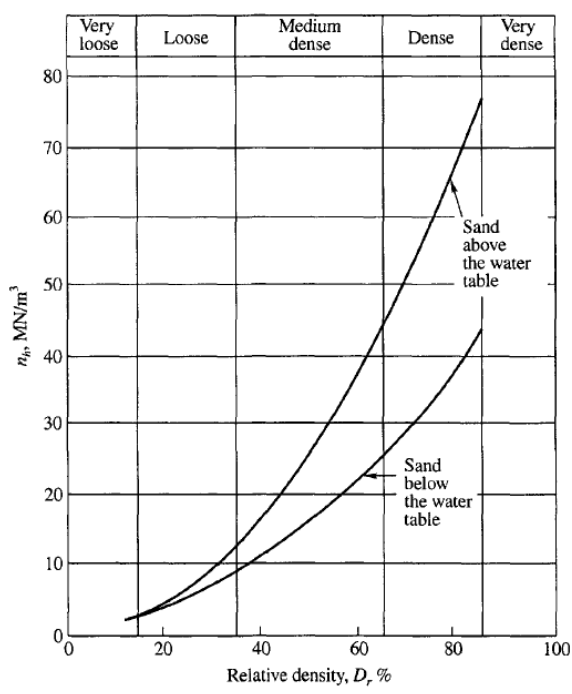

Figure 23: Coefficient of Soil Modulus Variation for Cohesionless Soils

(Murthy, 2002, p. 705) 


\subsection{Parametric Study of Lateral Pile Capacity based on Broms' Method}

Broms' method is still commonly used by engineers to estimate the lateral capacity of a pile at the preliminary design stage. Subgrade reaction methods, such as Broms' Method, provide a simple and relatively accurate ways of estimating the displacement, internal moments, and ultimate resistance of a laterally loaded pile. However, to apply this method, the ' $p$-y curve' must be known in advance (Mezazigh \& Levacher, 1998, p. 433). Based on the Winkler Spring Method (Nguyen, Fatahi \& Khabbaz, 2013, p. 1), a 'p-y curve' relates the displacement (y) of a pile to the reaction force applied by the soil (p). Starting in the late 1960's, researchers began developing ' $p$-y curves' for a laterally loaded, single pile installed in a horizontal ground surface. However, these ' $p$-y curves' cannot be applied if non-ideal field conditions are encountered (Mezazigh \& Levacher, 1998, p. 433).

To better understand how a laterally loaded pile performs under a variety of conditions, a parametric study was completed using the charts presented by Broms in 1964. This study considered fully embedded free-head, circular, steel piles loaded at ground level. In completing this study, the following pile properties were assumed:

\begin{tabular}{|c|c|}
\hline Pile Property & Assumed Value \\
\hline Pile Length (Short Pile) & $5 \mathrm{~m}$ \\
\hline Pile Length (Long Pile) & $15 \mathrm{~m}$ \\
\hline Pile Diameter & $1 \mathrm{~m}$ \\
\hline & \\
\hline Pile Thickness & $0.1 \mathrm{~m}$ \\
\hline Steel Yield Strength & $250 \mathrm{MPa}$ \\
\hline Elastic Modulus & $200 \mathrm{GPa}$ \\
\hline Poisson's Ratio & 0.3 \\
\hline & Calculated Value \\
\hline Cross-Sectional Area & $0.15 \mathrm{~m}{ }^{2}$ \\
\hline Second Moment of Area & $0.01688 \mathrm{~m}^{4}$ \\
\hline Section Modulus & $0.03376 \mathrm{~m}^{3}$ \\
\hline Yield Resistance of Pile Section & $10968 \mathrm{kN}-\mathrm{m}$ \\
\hline
\end{tabular}

Table 4: Parametric Study Pile Properties 
Next, the deflections of laterally loaded piles as calculated by Broms' method for a given load were compared to the deflections estimated using RocScience finite element software. The purpose of this study was to investigate the accuracy of Broms' methods and estimate appropriate factors of safety for use in practice.

\subsubsection{Broms' Method for Evaluating Lateral Resistance of Long Piles in Cohesive Soils}

The first part of the parametric study evaluated the impact of various parameters on the lateral resistance of long piles installed in clay. From Broms' chart for the ultimate lateral resistance of long piles in cohesive soils (Figure 18), ultimate resistance is dependent on the yield resistance of the pile, undrained shear strength of the soil, and the width of the pile.

This investigation first looked at the effect of undrained shear strength on the ultimate lateral resistance of the pile. Assuming a 15 metre long circular steel pile with a diameter of 1 metre and a thickness of 0.1 metres, ultimate pile resistance was calculated for a range of cohesive soils with undrained shear strengths ranging from $20 \mathrm{kPa}$ to $200 \mathrm{kPa}$. The results are presented in Figure 24.

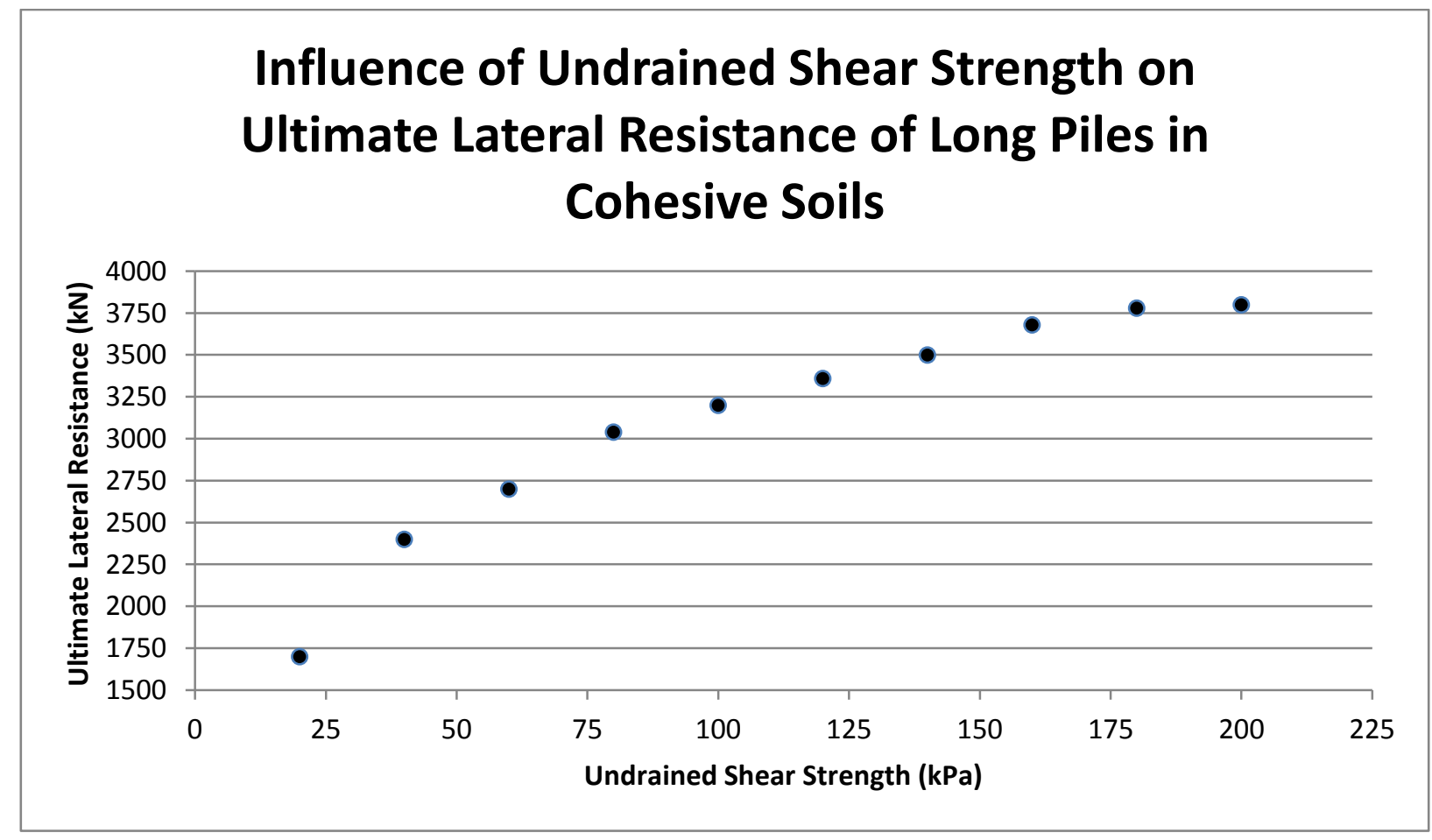

Figure 24: Broms' Method: Influence of Undrained Shear Strength on the Ultimate Lateral Resistance of Long Piles Installed in Cohesive Soils 
It was found that as shear strength increases so does the ultimate lateral resistance. However, the ultimate lateral resistance increases less as shear strength increases. From the results of this study, the relationship between ultimate lateral resistance and soil strength appears logarithmic.

Next, the impact of pile diameter was evaluated. The lateral resistance was calculated for a number of piles with diameters ranging from 0.5 metres to 1.5 metres. The undrained shear strength (100 kPa), pile length (15 metres) and pile thickness $(0.1$ metres) were held constant. The results (Figure 25) appear to show a relationship where the ultimate lateral resistance of the pile increases linearly with pile diameter.

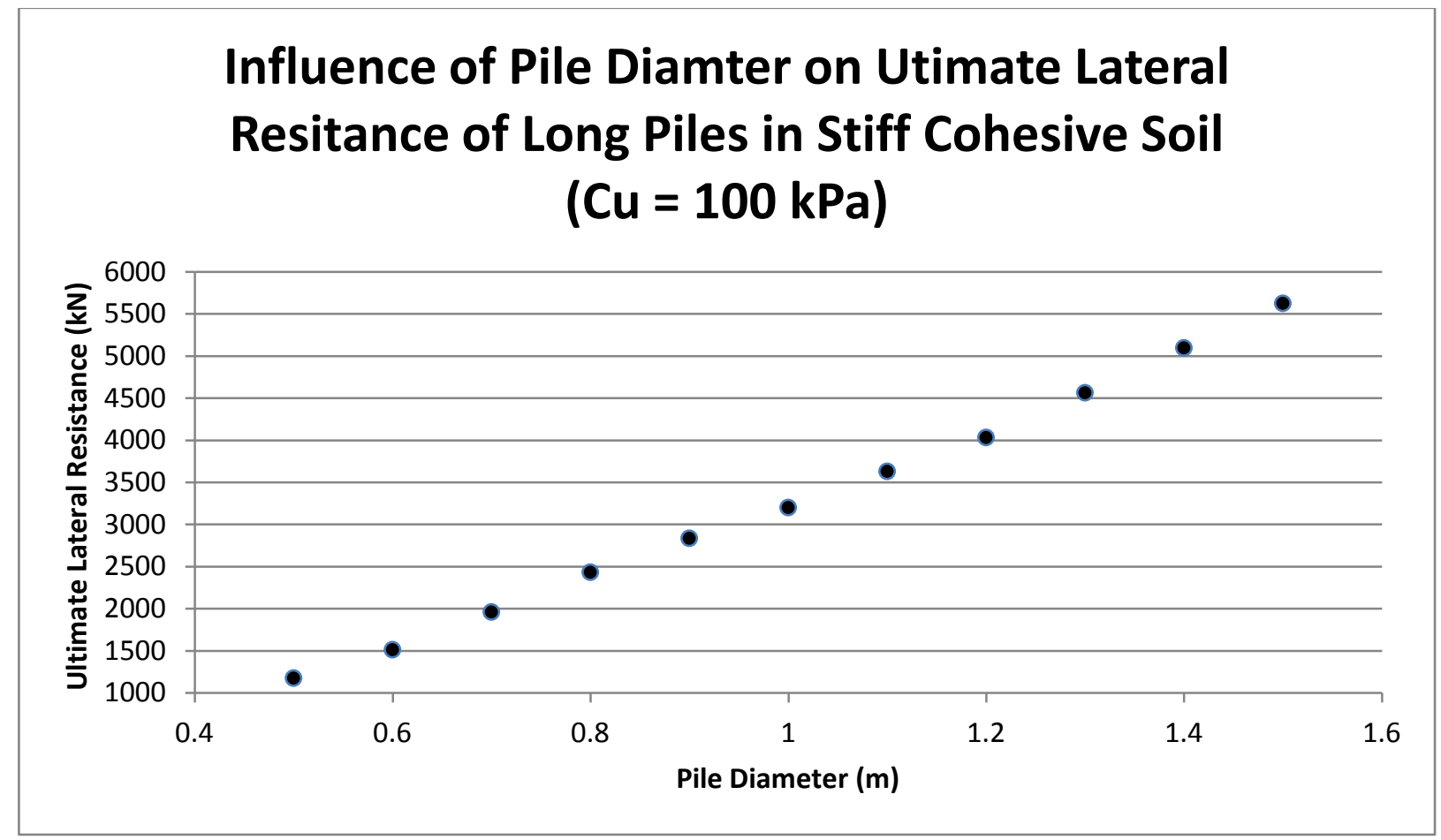

Figure 25: Broms' Method: Influence of Pile Diameter on Ultimate Lateral Resistance of Long Piles installed in a Stiff Cohesive Soil $(\mathrm{Cu}=100 \mathrm{kPa})$

Broms' chart was then used to evaluate the influence of pile length on the ultimate lateral resistance of long piles installed in stiff cohesive soils. For this investigation, a constant soil strength $(100 \mathrm{kPa})$, pile diameter $(0.5$ metres $)$, and pile thickness ( 0.1 metres) were assumed. It was found that the pile length did not have any impact on ultimate lateral resistance (Figure 26). 
This is due to the fact that Broms' treated any long pile as infinitely long and assumed no pile resistance would develop below the point of maximum moment (location of plastic hinge). As a result, additional embedment did not affect the formation of the plastic hinge or provide additional capacity.

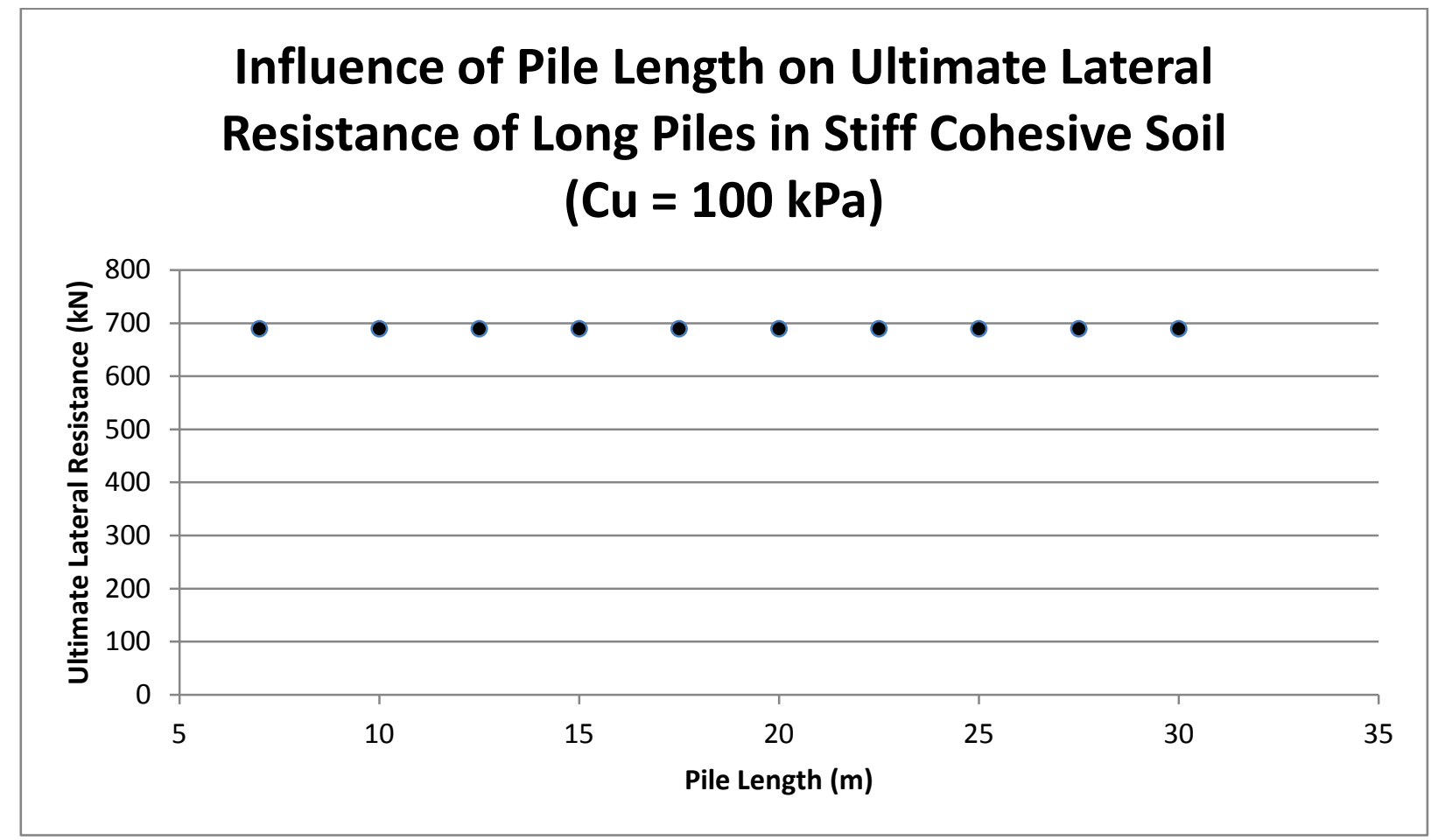

Figure 26: Broms' Method: Influence of Pile Length on Ultimate Lateral Resistance of Long Piles installed in a Stiff Cohesive Soil $(\mathrm{Cu}=100 \mathrm{kPa})$

In practice, the serviceability of a pile generally governs over ultimate resistance. Next, the estimated deflection of a $15 \mathrm{~m}$ long pile was calculated considering undrained shear strengths ranging from $20 \mathrm{kPa}$ to $200 \mathrm{kPa}$. Based on the coefficients of vertical subgrade reaction proposed by Terzaghi, coefficients of horizontal subgrade reaction, for a given undrained shear strength, were assumed as shown in Table 5, below. Pile deflections were then estimated under working loads, with an applied lateral load of half of the calculated ultimate pile resistance. The results are presented in Figure 27. 


\begin{tabular}{|c|c|}
\hline $\begin{array}{c}\text { Undrained Shear Strength } \\
\text { of the Soil } \mathbf{( k P a )}\end{array}$ & $\begin{array}{c}\text { Assumed Coefficient of Horizontal } \\
\text { Subgrade Reaction }\left(\mathbf{M N} / \mathbf{m}^{\mathbf{3}}\right)\end{array}$ \\
\hline 20 & 10 \\
\hline 40 & 20 \\
\hline 60 & 30 \\
\hline 80 & 40 \\
\hline 100 & 50 \\
\hline 120 & 60 \\
\hline 140 & 70 \\
\hline 160 & 80 \\
\hline 180 & 90 \\
\hline 200 & 100 \\
\hline
\end{tabular}

Table 5: Coefficient of Horizontal Subgrade Reaction for a Given Undrained Shear Strength

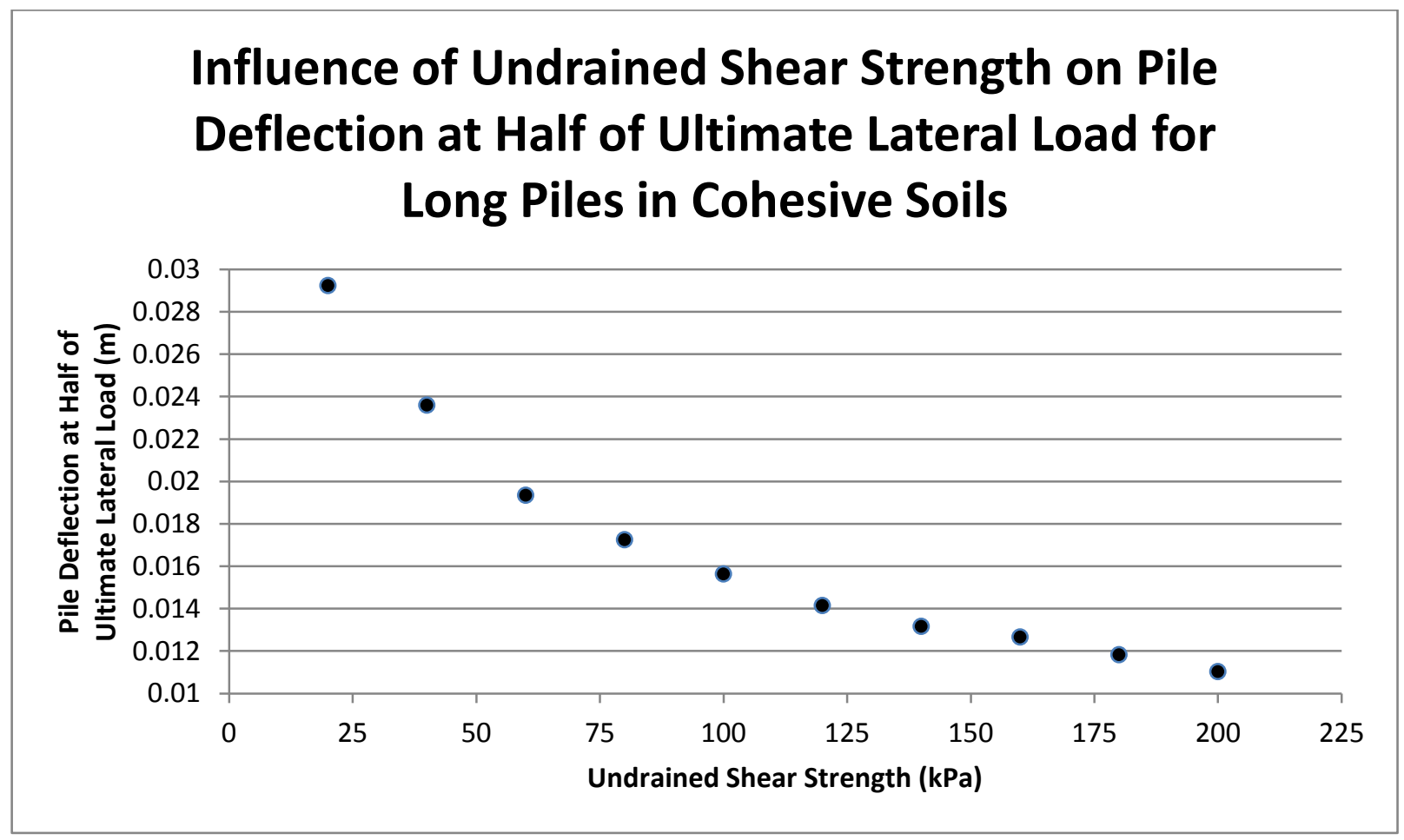

Figure 27: Broms' Method: Influence of Undrained Shear Strength on Deflection of Long Piles Installed in Cohesive Soils under Working Loads 
It was found that as the strength of the soil increases, deflection decreases. However, it should be noted that deflection is not proportional to ultimate resistance. For soft cohesive soils, the magnitude of deflection decreases rapidly for incremental increases in soil strength when compared to hard cohesive soils. As a result, undrained shear strength has a greater impact on deflection for laterally loaded piles installed in soft cohesive soils when compared to piles installed in stiff cohesive soils.

\subsubsection{Broms' Method for Evaluating Lateral Resistance of Short Piles in Cohesive Soils} Next, Broms' methods were used to evaluate the lateral resistance of short piles installed in cohesive soils. For short piles, resistance is developed through the passive resistance of the soil. From Broms' chart for the ultimate lateral resistance of short piles in cohesive soils (Figure 17), lateral resistance is a function of the undrained shear strength of the soil, along with the length and diameter of the pile. The first part of this study looked at the effect of undrained shear strength on ultimate capacity, evaluating the resistance of a 5 metre long, 1 metre diameter, and 0.1 metre thick steel pile installed in cohesive soils with strengths ranging from 20 $\mathrm{kPa}$ to $200 \mathrm{kPa}$. It was found that ultimate resistance increased linearly with the undrained shear strength of the soil (Figure 28).

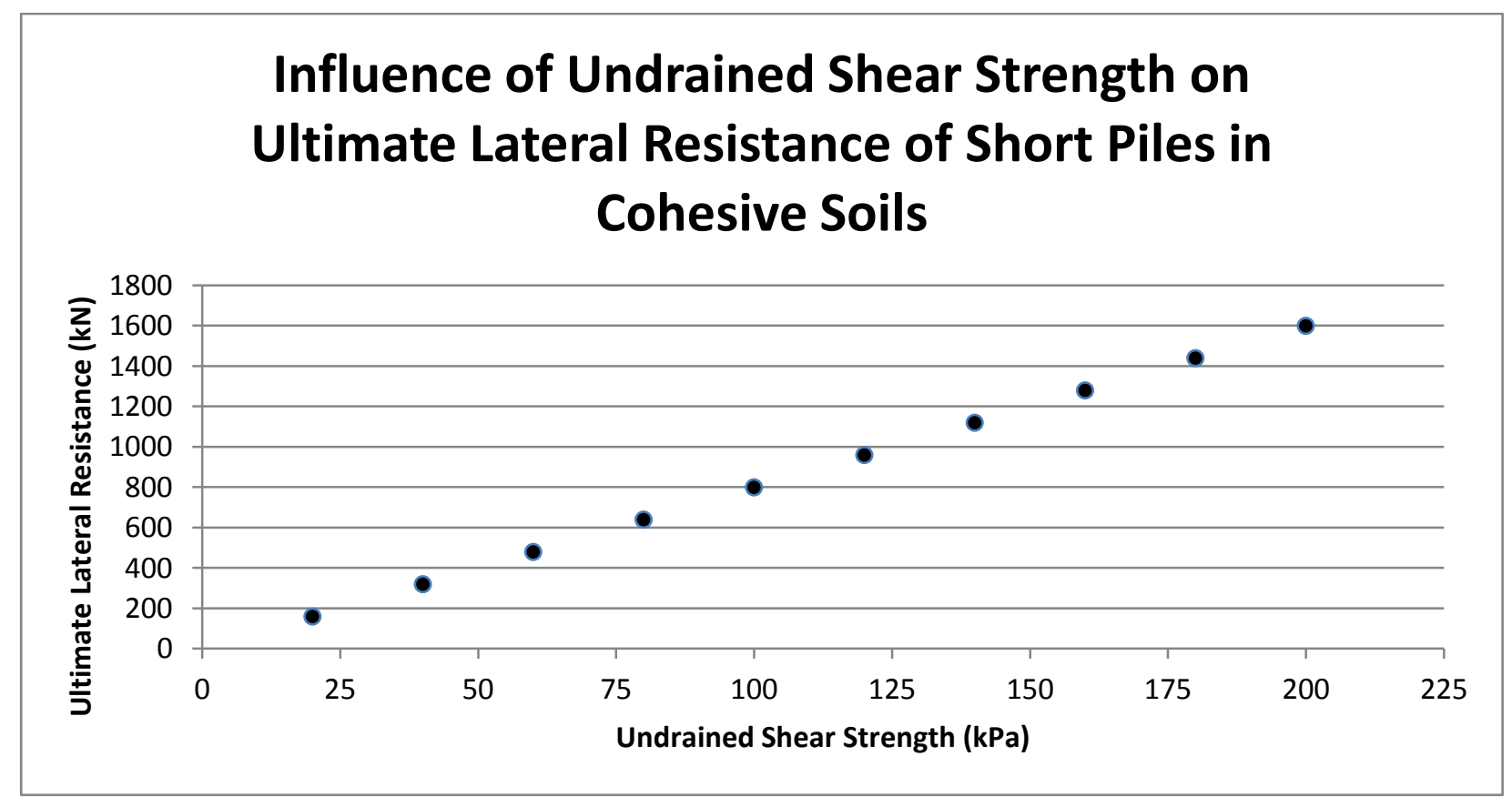

Figure 28: Broms' Method: Influence of Undrained Shear Strength on the Ultimate Resistance of Short Piles Installed in Cohesive Soils 
The next stage of the study looked at the impact of pile diameter on ultimate lateral resistance (Figure 29). For small pile diameters, a small increase in pile diameter resulted in a large increase in ultimate lateral resistance. However, as diameter increased, the lateral resistance of the pile eventually reached a plateau of approximately $800 \mathrm{kN}$. This is due to Broms' assumption that no passive resistance is developed within a distance of 1.5 pile diameters below the ground surface. Given the finite length of the pile, as pile diameter increases, any gains in lateral capacity resulting from the larger pile diameter are eventually off-set by the losses in lateral capacity due to reduced length of passive resistance along the pile.

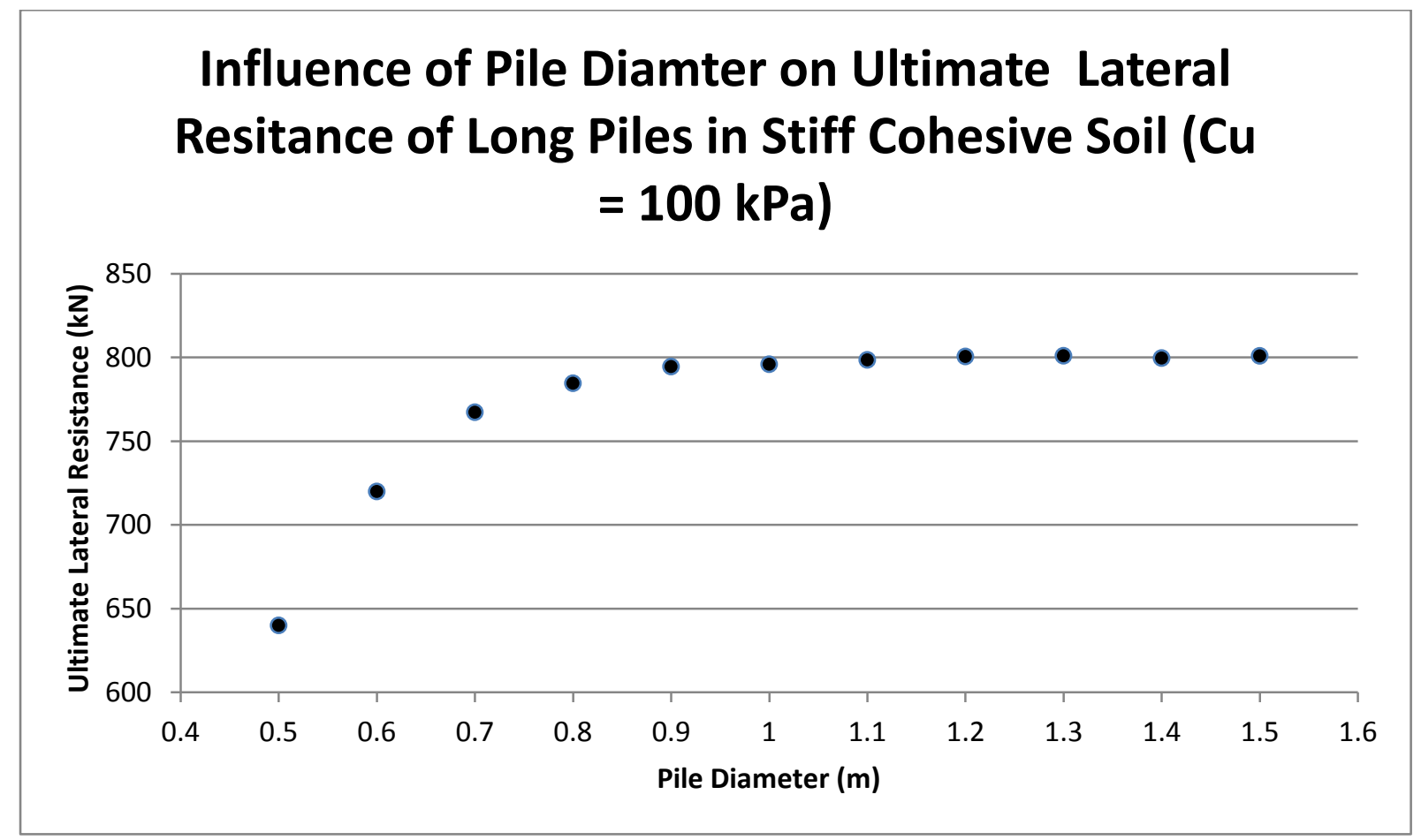

Figure 29: Broms' Method: Influence of Pile Diameter on the Ultimate Resistance of Short Piles Installed in a Stiff Cohesive Soil $(\mathrm{Cu}=100 \mathrm{kPa})$

The impact of pile length on ultimate lateral resistance for a short pile with a diameter of 0.5 metres, installed in cohesionless soil with an undrained shear strength of $100 \mathrm{kPa}$ is shown in Figure 30. During this study, it was found that the ultimate lateral resistance of a pile increases linearly with pile length. This was expected as, when using Broms' method, the passive resistance of the soil is directly proportional to the length of the pile (for a constant pile diameter and soil conditions). 


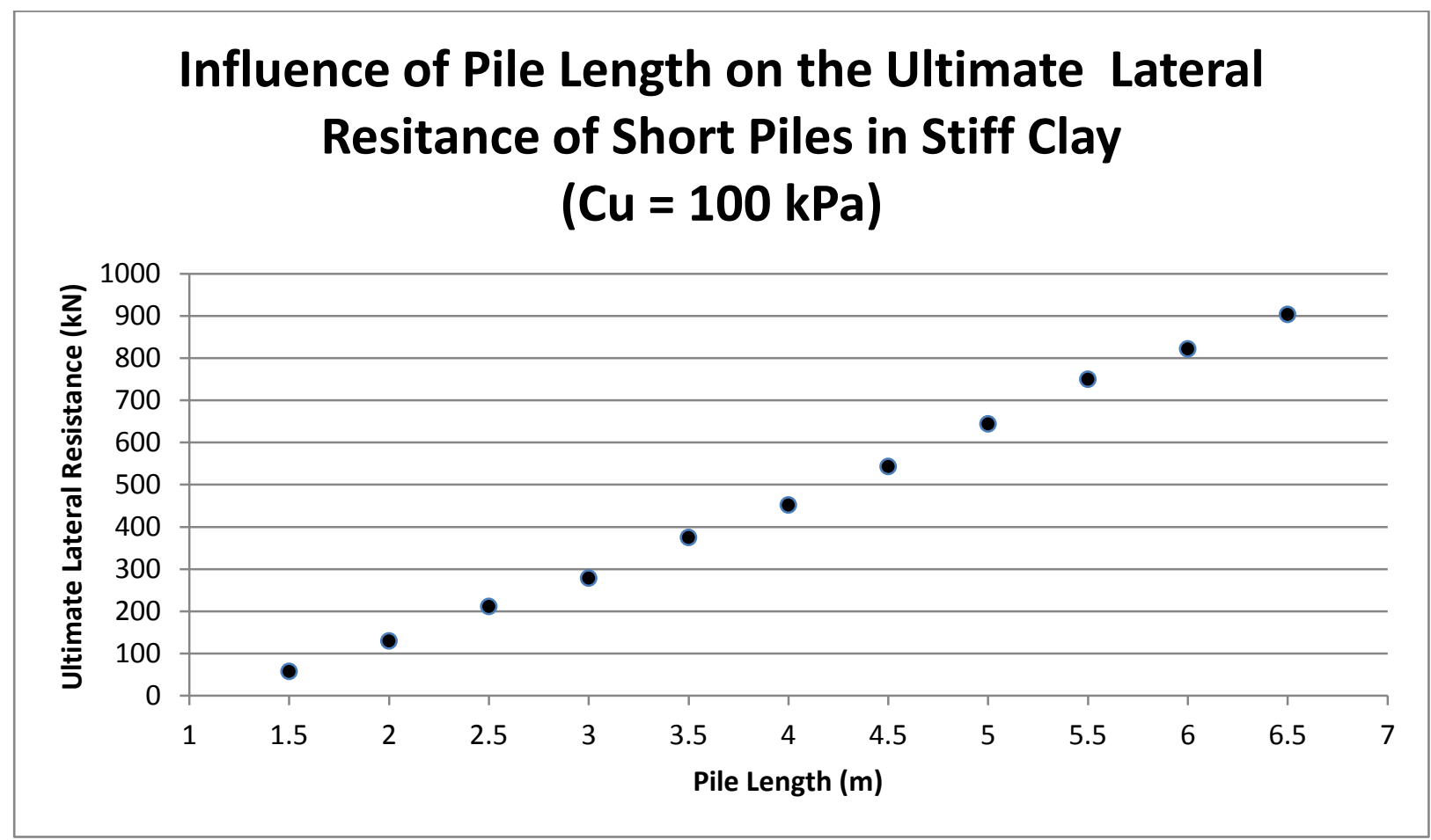

Figure 30: Broms' Method: Influence of Pile Length on the Ultimate Resistance of Short Piles Installed in a Stiff Cohesive Soil (100 kPa)

Once again, pile deflection was estimated under working loads, with an applied lateral load of half of the ultimate pile resistance as calculated using Broms' method. The results are shown in Figure 31. According to Broms' method, the dimensionless lateral deflection for a free head pile, laterally loaded at the ground surface, is constant for a dimensionless length of less than 1.5. This is due to the fact that Broms considered all piles with a dimensionless length of 1.5 as infinitely stiff. In this parametric study, it was assumed that the coefficient of horizontal subgrade reaction increases proportionally to the undrained shear strength (Table 5). Based on the equations provided by Broms, an increase in ultimate moment (due to the increase in undrained shear strength) was off-set by the proportionally larger coefficient of subgrade reaction associated with the stiffer soil. As a result, the total deflection at half of the ultimate lateral load remained constant. As the undrained shear strength of the soil increased, so did the dimensionless length. As the dimensionless length approached 1.5 (and the pile was no longer considered to be infinitely stiff), pile deflection under working loads slowly began to increase. 


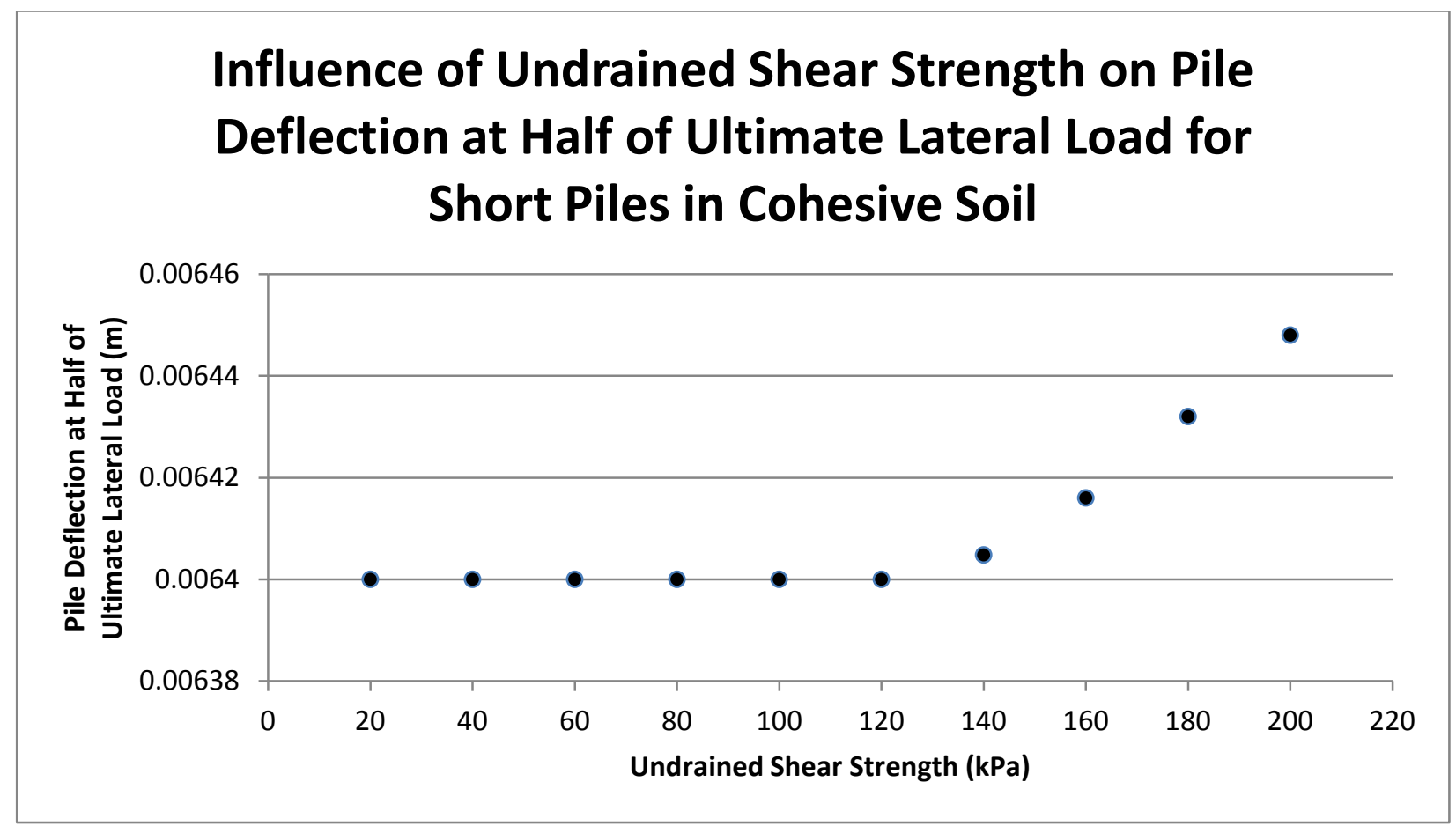

Figure 31: Broms' Method: Influence of Undrained Shear Strength on Deflection of Short Piles Installed in Cohesive Soils under Working Loads

\subsubsection{Broms' Method for Evaluating Lateral Resistance of Long Piles in Cohesionless}

\section{Soils}

Broms' method was also used to investigate the impact of soil type, pile diameter, and length for cohesionless soils. From Figure 21, it is clear that the properties of both the pile and surrounding soil will affect ultimate lateral resistance. From a geotechnical perspective, soil type and pile diameter have the largest impact on ultimate resistance by supporting the pile and preventing the formation of a plastic hinge. First the impact of the internal angle of friction of the pile was investigated. Once again, a $15 \mathrm{~m}$ long steel pile, with an outside diameter of 1 metre and a wall thickness of 0.1 metres, was considered. For a given angle of internal friction, the soil unit weights shown in Table 6 and the coefficients of soil modulus variation shown in Table 7 were assumed. 


\begin{tabular}{|c|c|}
\hline Internal Angle of Friction (Degrees) & Assumed Soil Unit Weight $\left(\mathbf{k N} / \mathbf{m}^{\mathbf{3}}\right)$ \\
\hline 28 & 16.5 \\
\hline 30 & 17.5 \\
\hline 32 & 18.5 \\
\hline 34 & 19.5 \\
\hline 36 & 20.5 \\
\hline 38 & 21.5 \\
\hline 40 & 22.5 \\
\hline
\end{tabular}

Table 6: Soil Unit Weight for a Given Internal Angle of Friction

Using Figure 23, the following coefficients of soil modulus variation were selected for a given angle of internal friction:

\begin{tabular}{|c|c|}
\hline Internal Angle of Friction (Degrees) & Coefficient of Soil Modulus Variation (MN/m $\left.\mathbf{~}^{\mathbf{}}\right)$ \\
\hline 28 & 10 \\
\hline 30 & 15 \\
\hline 32 & 28 \\
\hline 34 & 42 \\
\hline 36 & 48 \\
\hline 38 & 60 \\
\hline 40 & 75 \\
\hline
\end{tabular}

Table 7: Coefficient of Soil Modulus Variation for a Given Internal Angle of Friction 
It was found that as the internal angle of friction and density of a soil increases, so does the pile resistance (Figure 32). However, opposite to the cohesive soils, the ultimate lateral resistance increases at a greater rate, as the internal angle of friction increases.

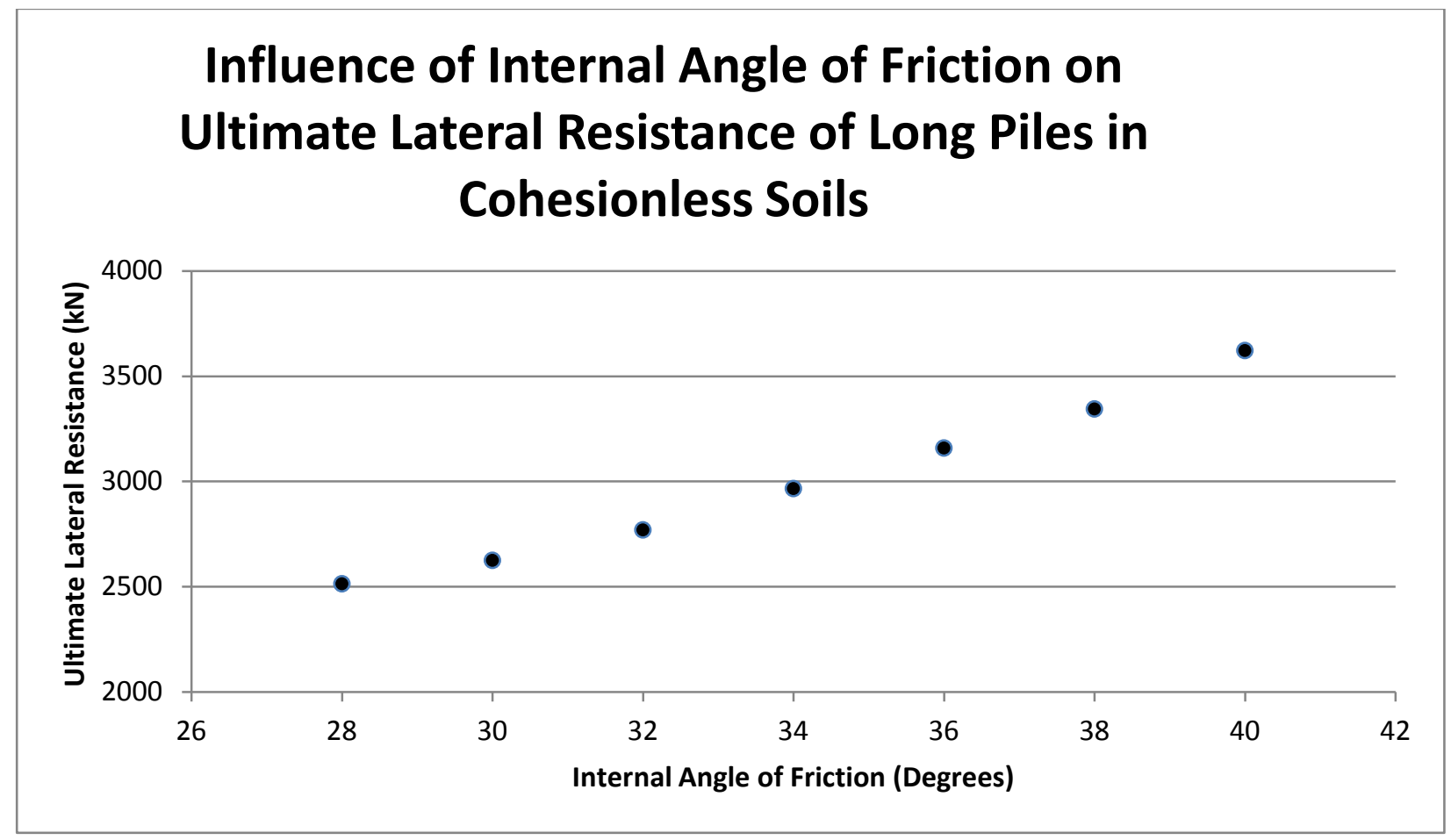

Figure 32: Broms' Method: Influence of Internal Angle of Friction on the Ultimate Resistance of Long Piles Installed in Cohesionless Soils

Next, the effect of pile diameter was investigated. It was assumed that the piles were installed in a medium density sand with an angle of internal friction of 32 degrees and unit weight of 18.5 $\mathrm{kN} / \mathrm{m}^{3}$. The results are shown in Figure 33. It was found that an increase in pile diameter resulted in an improved lateral resistance. For larger diameter piles, an incremental increase in diameter resulted in a greater increase in ultimate lateral resistance when compared to smaller pile diameters. 


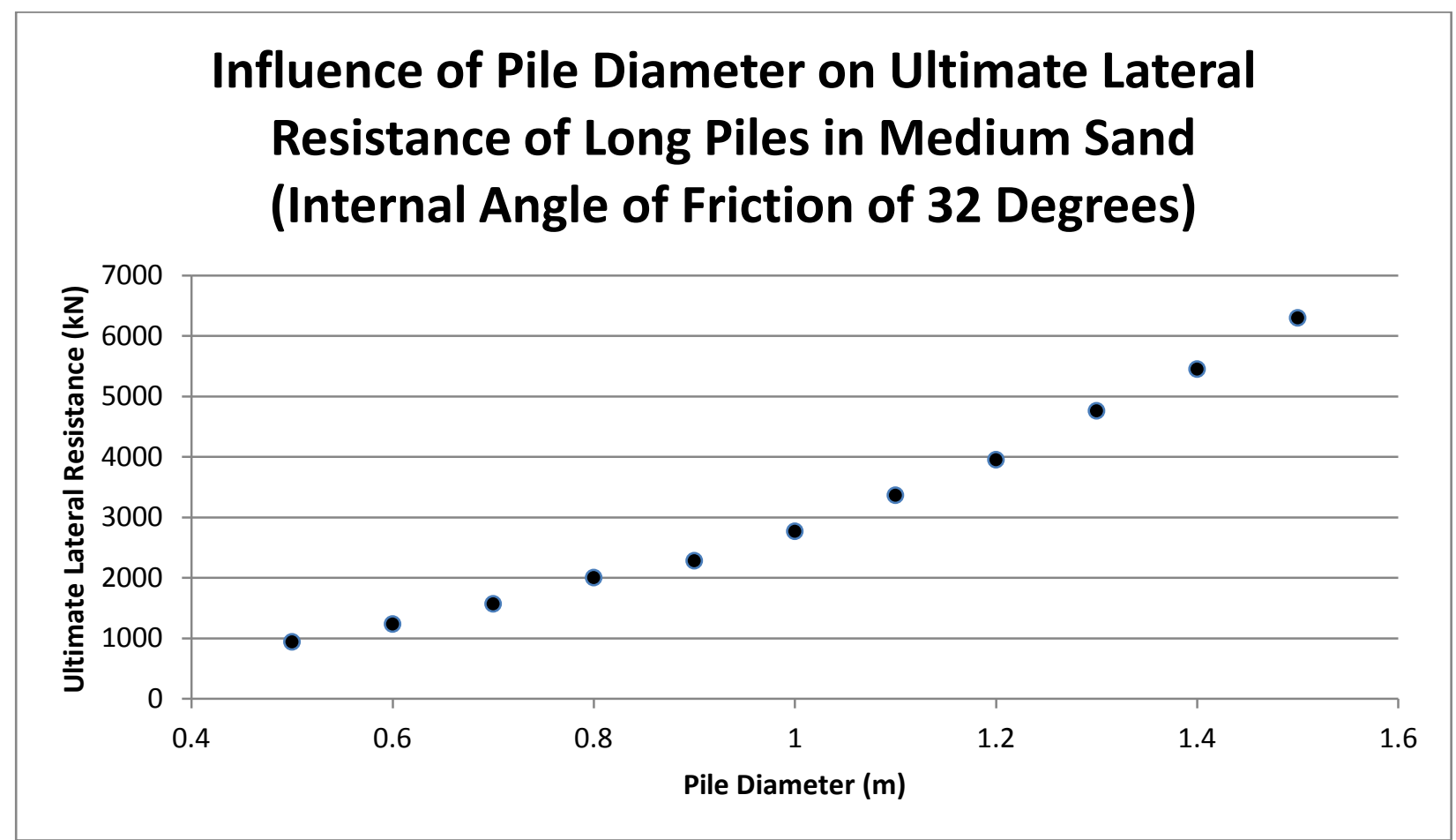

Figure 33: Broms' Method: Influence of Pile Diameter on the Deflection of Long Piles Installed in a Medium Cohesionless Soil (Internal Angle of Friction of 32 Degrees, Density $=18.5 \mathrm{kN} / \mathrm{m}^{3}$ )

The next study looked at the impact of pile length on resistance. Again, a circular steel pile with an outside diameter of 1 metre and a thickness of $0.1 \mathrm{~m}$ was used. It was assumed the pile was installed in a medium sand with an internal angle of friction of 32 degrees and a unit weight of $18.5 \mathrm{kN} / \mathrm{m}^{3}$. Similar to long piles installed in cohesionless soils, Broms did not consider the passive resistance of the soil below the plastic hinge. As a result, increasing the length (and therefore, the embedment) of the long piles did not provide any additional lateral resistance (Figure 34). 


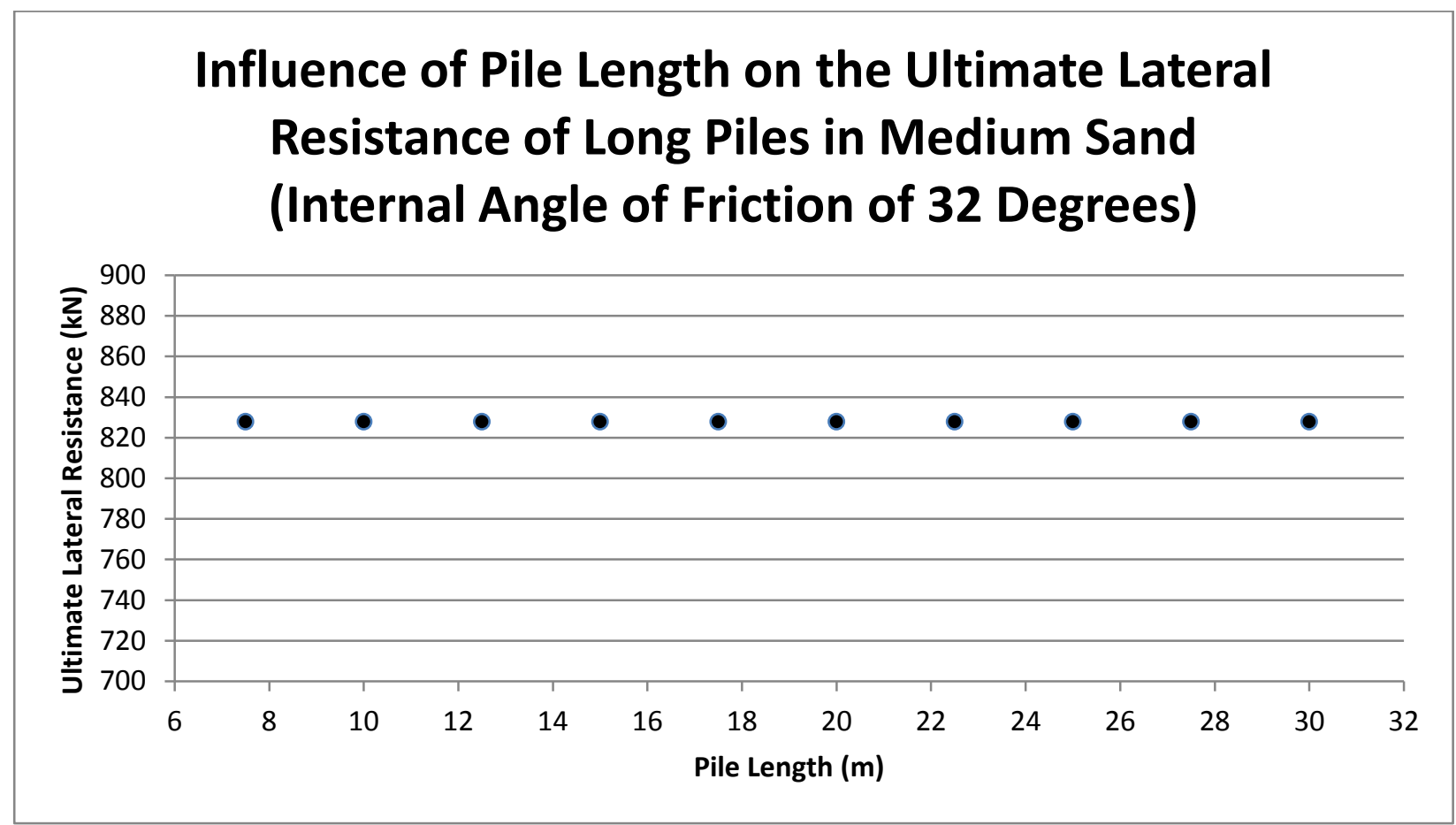

Figure 34: Broms' Method: Influence of Pile Length on the Ultimate Resistance of Long Piles Installed in a Medium Cohesionless Soil (Internal Angle of Friction of 32 Degrees, Density of $18.5 \mathrm{kN} / \mathrm{m}^{3}$ )

The study also considered the impact of soil strength on deflection under working loads. Again, the magnitude of deflection at half of the ultimate lateral capacity was compared for various soil types ranging from a loose sand (with an internal angle of friction of 28 , a unit weight of 16.5 $\mathrm{kN} / \mathrm{m}^{3}$, and a coefficient of soil modulus variation of $10 \mathrm{MN} / \mathrm{m}^{3}$ ) to a dense sand (with an internal angle of friction of 40 and a unit weight of $22.5 \mathrm{kN} / \mathrm{m}^{3}$ ) and a coefficient of soil modulus variation of $75 \mathrm{MN} / \mathrm{m}^{3}$ ). The results are shown in Figure 35. In completing this study, it was found that pile deflections at half of the ultimate lateral load decreased within an increase in soil strength. For loose soils, a unit increase in soil strength resulted in a larger decrease in deflection than for denser sands. 


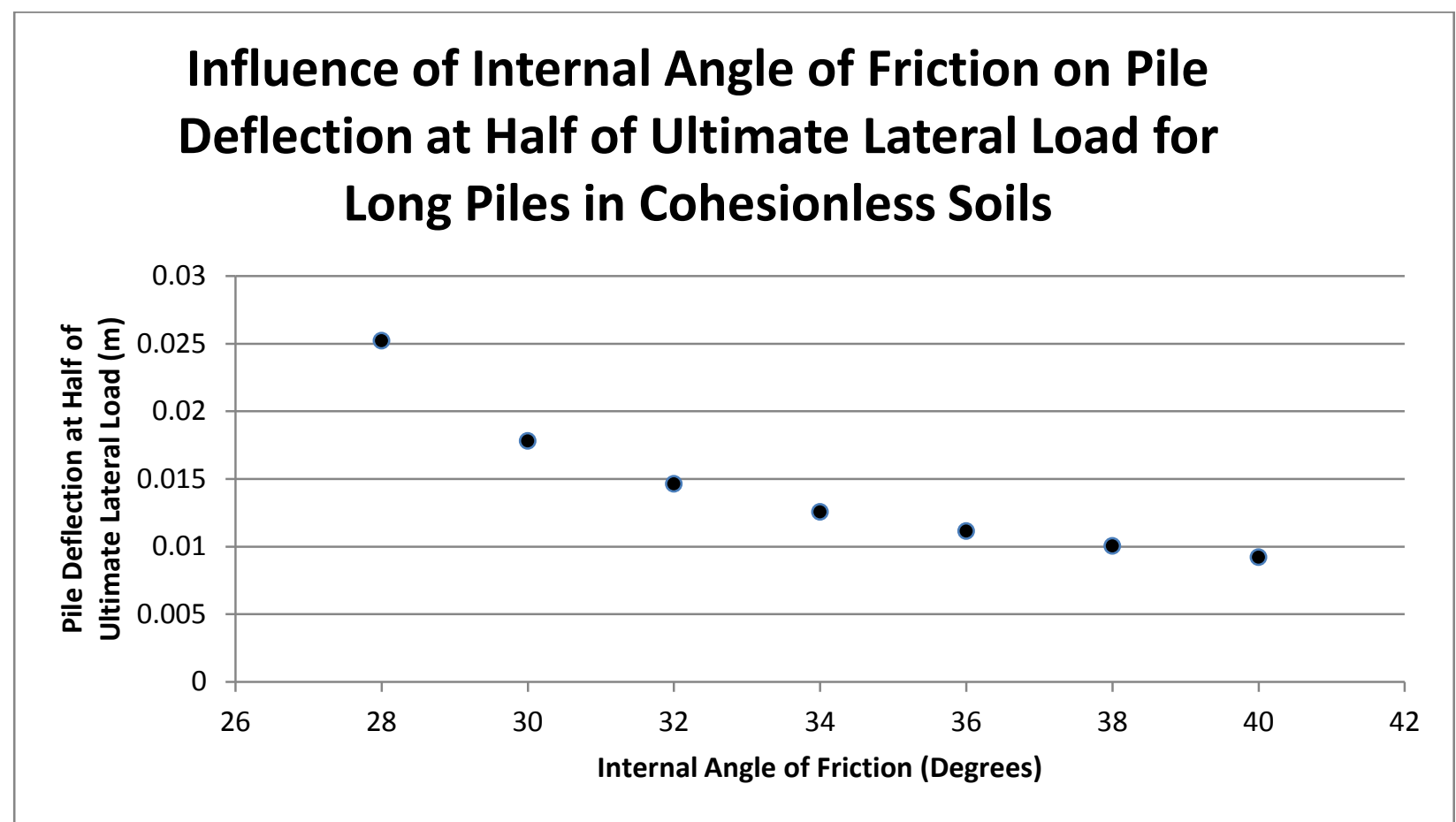

Figure 35: Broms' Method: Influence of Internal Angle of Friction on the Deflection of Long Piles Installed in Cohesionless Soils under Working Loads

\subsubsection{Broms' Method for Evaluating Lateral Resistance of Short Piles in Cohesionless Soils}

Finally, the lateral resistance of short piles installed in cohesionless soils was investigated using Broms' method. For this study, $5 \mathrm{~m}$ long steel piles with a diameter of 1 metre and a thickness of 0.1 metres were evaluated in a range of loose, medium, and dense cohesionless soils. The relationships observed with short piles was similar to long piles installed in cohesionless soils. Once again, it was found that as the internal angle of friction and unit weight of the soil increases, so does the ultimate lateral resistance (Figure 36). The increase in ultimate resistance for an incremental increase in angle of internal friction and density is greater for dense soils compared to looser soils. 


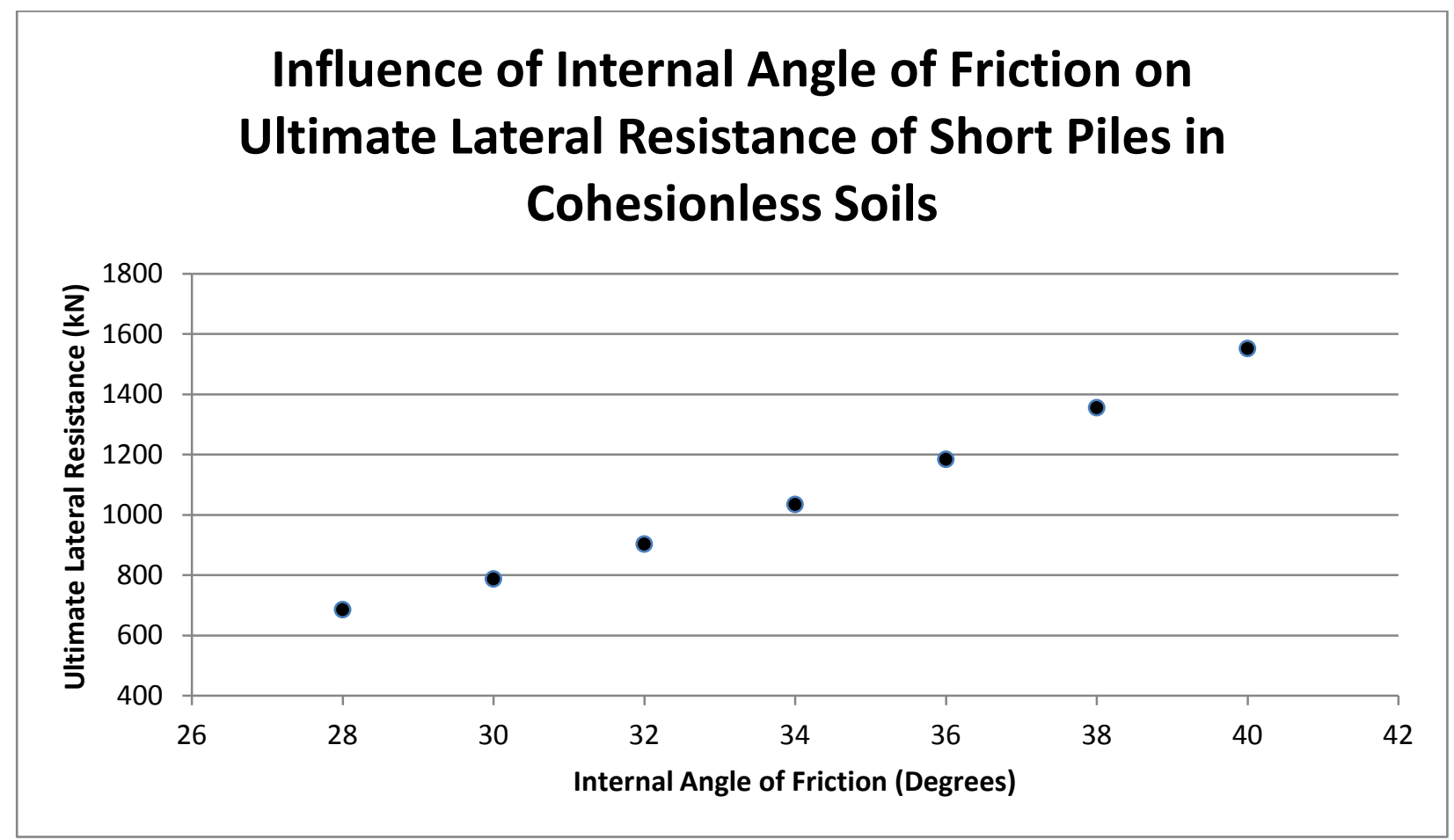

Figure 36: Broms' Method: Influence of Internal Angle of Friction on the Ultimate Resistance of Short Piles Installed in Cohesionless Soils

Next, the ultimate lateral resistance was evaluated for a number of short piles installed in a medium cohesionless soil (internal angle of friction of 32 degrees and soil unit weight of 18.5 $\mathrm{kN} / \mathrm{m}^{3}$ ). During this study, it was found that ultimate lateral resistance increased linearly with pile diameter (Figure 37). 


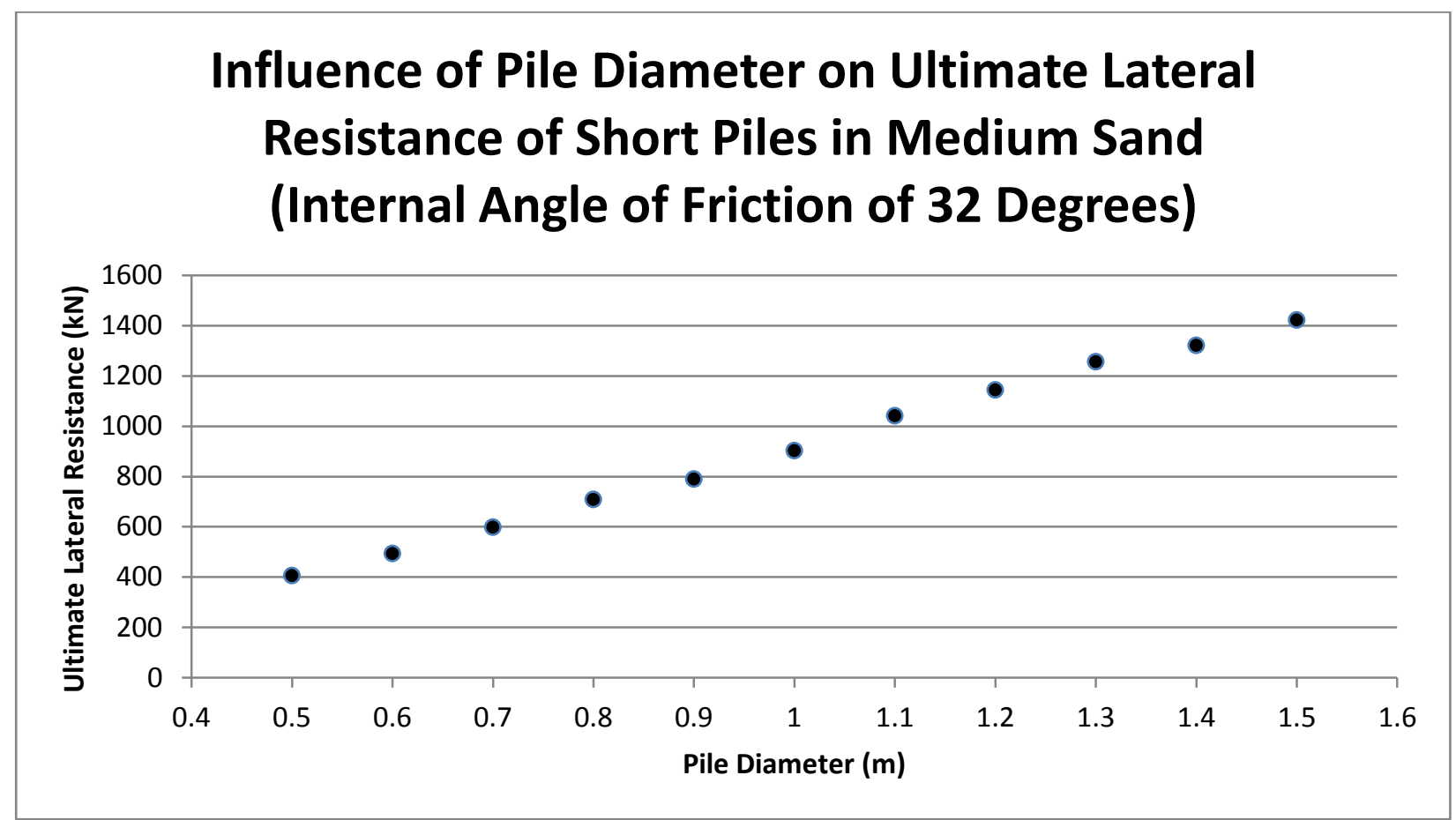

Figure 37: Broms' Method: Influence of Pile Diameter on the Ultimate Resistance of Short Piles Installed in a Medium Cohesionless Soil (Internal Angle of Friction of 32 Degrees, Density of $18.5 \mathrm{kN} / \mathrm{m}^{3}$ )

For the same soil, the effect of length on the ultimate resistance of piles was evaluated. Pile diameter was held constant at 0.5 metres, while the length was varied from 1.5 metres to 7.5 metres. It was found that as pile length increased, so did the ultimate resistance of the pile (Figure 38). For longer piles, an incremental increase in length resulted in a greater increase in ultimate lateral resistance. 


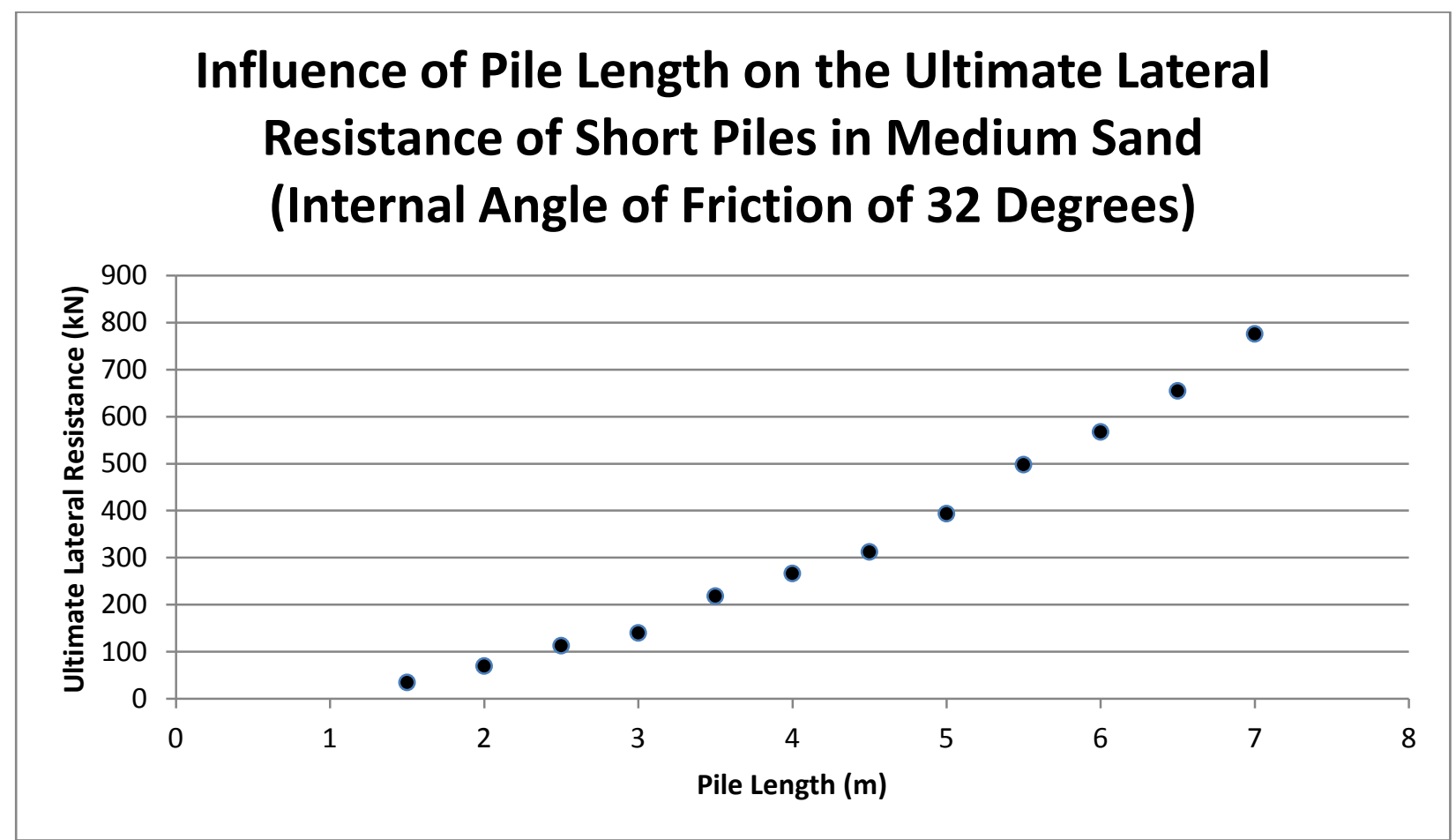

Figure 38: Broms' Method: Influence of Pile Length on the Ultimate Resistance of Short Piles Installed in a Medium Cohesionless Soil (Internal Angle of Friction of 32 Degrees, Density of $18.5 \mathrm{kN} / \mathrm{m}^{3}$ )

When comparing pile deflection under working loads, the results were similar to those observed for long piles installed in cohesionless soils. Once again, it was found that pile deflections under working loads decreased within an increase in soil strength (Figure 39). An incremental increase in the internal angle of friction, unit weight, and coefficient of soil modulus variation had a much larger impact on the magnitude of deflection for weaker soils than stronger soils. 


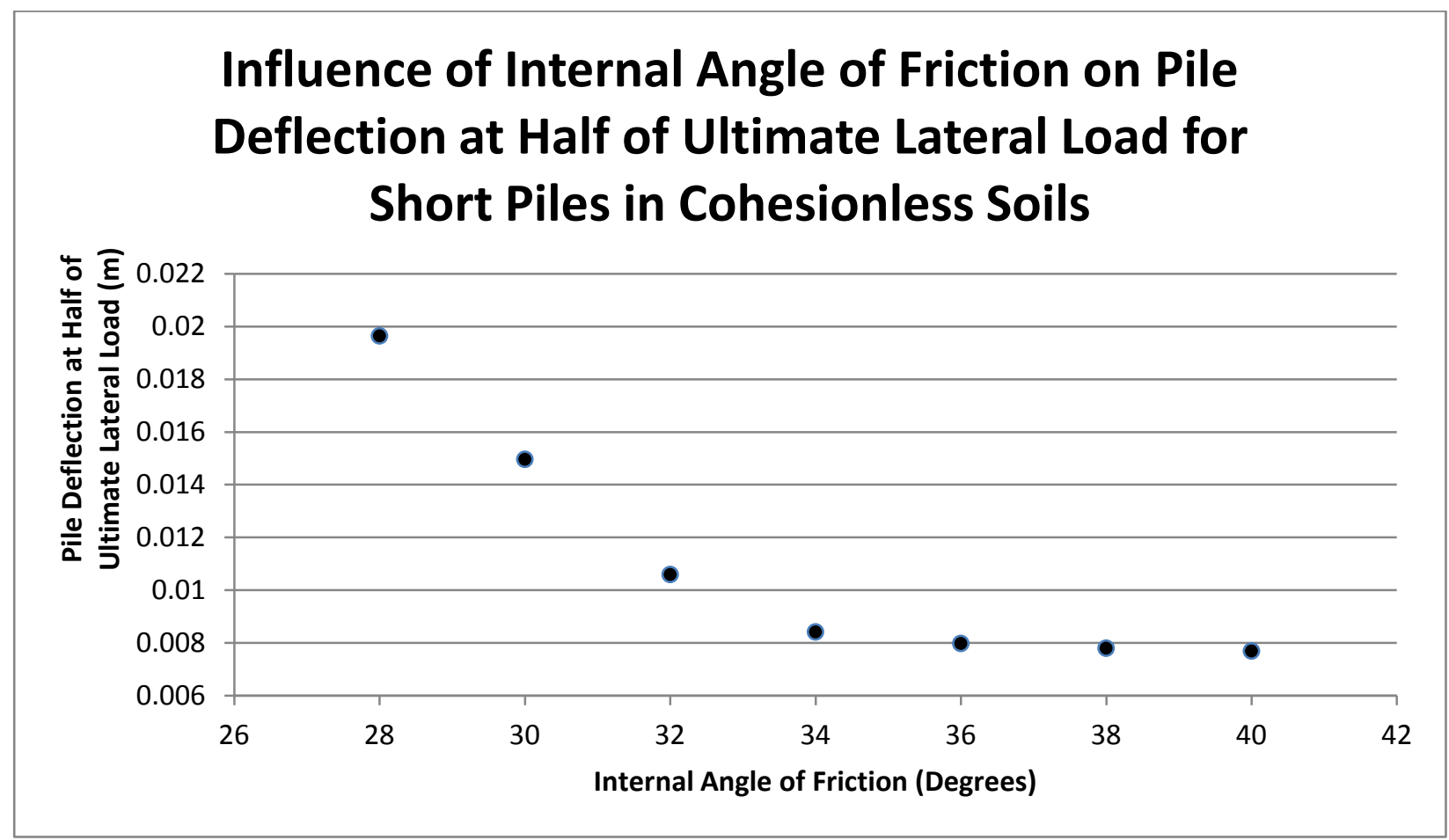

Figure 39: Broms' Method: Influence of Internal Angle of Friction on the Deflection of Short Piles Installed in Cohesionless Soils under Working Loads

\subsubsection{Summary}

The results of the parametric study of Broms' Methods for estimating ultimate capacity of laterally loaded piles are summarized below:

\section{Long Piles in Cohesive Soils:}

For a 15 metre long circular steel pile, with an outside diameter of 1 metre and a wall thickness of 0.1 metres installed in cohesive soils with an undrained shear strength ranging from $20 \mathrm{kPa}$ to $200 \mathrm{kPa}$, it was found that:

- Ultimate lateral resistance increases logarithmically with an increase in undrained shear strength of the soil;

- Pile deflection under working loads decreases with an increase in undrained shear strength:

- The lower the undrained shear strength of the soil, the greater the impact of a unit increase in soil strength on pile deflection. 
For a long pile installed in a stiff cohesionless soil with an undrained shear strength of $100 \mathrm{kPa}$ :

- Ultimate lateral resistance increases linearly with an increase in pile diameter;

- Ultimate lateral resistance is not affected by pile length.

\section{Short Piles in Cohesive Soils:}

For a 5 metre long circular steel pile, with an outside diameter of 1 metre and a wall thickness of 0.1 metres installed in cohesive soils with an undrained shear strength ranging from $20 \mathrm{kPa}$ to $200 \mathrm{kPa}$, it was found that:

- Ultimate lateral resistance increases linearly with an increase in soil strength;

- Deflection at half of ultimate lateral resistance is constant until a dimensionless length of 1.5 is reached. Beyond this point, deflection at half of the ultimate load increases linearly with undrained shear strength.

For a short pile installed in a stiff cohesionless soil with an undrained shear strength of $100 \mathrm{kPa}$ :

- Ultimate lateral resistance increases with an increase in pile diameter, up to a maximum lateral resistance:

- The smaller the pile diameter, the greater the increase in ultimate resistance for a unit increase in pile diameter;

- Ultimate lateral resistance increases approximately linearly with an increase in pile length.

\section{Long Piles in Cohesionless Soils:}

For a 15 metre long circular steel pile, with an outside diameter of 1 metre and a wall thickness of 0.1 metres installed in cohesionless soils with an internal angle of friction ranging from 28 degrees to 40 degrees, it was found that:

- Ultimate lateral resistance increases with an increase in soil strength:

- The greater the density of the soil, the greater the increase in ultimate resistance for a unit increase in internal angle of friction and soil density; 
- Pile deflection under working loads decreases for an increase in soil strength:

- The looser the soil, the greater the decrease in pile deflection (at half of the ultimate lateral load) for a unit increase in soil strength.

For a long pile installed in a medium cohesionless soil with an internal angle of friction of 32 degrees and a unit weight of $18.5 \mathrm{kN} / \mathrm{m}^{3}$ :

- Ultimate lateral resistance increases with an increase in pile diameter:

- The greater the pile diameter, the greater the increase in ultimate resistance for a unit increase in pile diameter;

- Ultimate lateral resistance is not affected by pile length.

\section{Short Piles in Cohesionless Soils:}

For a 5 metre long circular steel pile, with an outside diameter of 1 metre and a wall thickness of 0.1 metres installed in cohesionless soils with an internal angle of friction ranging from 28 degrees to 40 degrees, it was found that:

- Ultimate lateral resistance increases with an increase in soil strength:

- The greater the density of the soil, the greater the increase in ultimate resistance for a unit increase in internal angle of friction and soil density;

- Pile deflection under working loads decreases for an increase in soil strength:

- The looser the soil, the greater the decrease in pile deflection (at half of the ultimate lateral load) for a unit increase in soil strength.

For a short pile installed in a medium cohesionless soil with an internal angle of friction of 32 degrees and a unit weight of $18.5 \mathrm{kN} / \mathrm{m}^{3}$ :

- Ultimate lateral resistance increases linearly with an increase in pile diameter;

- Ultimate lateral resistance increases with an increase in pile length:

- The greater the pile length, the greater the increase in ultimate resistance for a unit increase in pile length. 


\subsubsection{Comparison to RocScience Finite Element Software}

Typically, serviceability limits states govern pile design. In an attempt to better understand the advantages and disadvantages of Broms' Methods, deflections calculated using Broms' methods were compared to those estimated using RocScience finite element software. The study considered long and short piles installed in a range of cohesive and cohesionless soils. This study also provided insight into appropriate factors of safety when applying Broms' methods in practice. Actual pile deflections were estimated using finite element software, after applying a factor of safety to the ultimate lateral pile capacity calculated using Broms' method. A factor of 1.5 was chosen, as recommended by the U.S. Department of Transportation's Geotechnical Circular No. 4: Ground Anchors and Anchored Systems (Sabatini, Pass \& Bachus, 1999, p. 86).

Within the RocScience software, piles were modeled as an elastic beam with a defined crosssectional area and moment of inertia. Once again, a lateral load was applied to the top of a fully embedded, free head pile. The same pile properties, as described by Table 4, were used for analysis for both Broms' method and RocScience finite element software. The soil properties shown in Table 8 (cohesive soils) and Table 9 (cohesionless soils) were also assumed for analysis. 


\begin{tabular}{|c|l|c|}
\hline Soil Type & \multicolumn{1}{|c|}{ Soil Property } & Value \\
\hline \multirow{4}{*}{ Medium Clay } & Undrained Shear Strength & $50 \mathrm{kPa}$ \\
\cline { 2 - 3 } & Modulus of Elasticity & $10 \mathrm{GPa}$ \\
\cline { 2 - 3 } & Poisson's Ratio & 0.1 \\
\cline { 2 - 3 } & Coefficient of Horizontal Subgrade Reaction & $25 \mathrm{MN} / \mathrm{m}^{3}$ \\
\hline \multirow{5}{*}{ Stiff Clay } & Undrained Shear Strength & $150 \mathrm{kPa}$ \\
\cline { 2 - 3 } & Modulus of Elasticity & $30 \mathrm{GPa}$ \\
\cline { 2 - 3 } & Poisson's Ratio & 0.2 \\
\cline { 2 - 3 } & Coefficient of Horizontal Subgrade Reaction & $50 \mathrm{MN} / \mathrm{m}^{3}$ \\
\hline & Undrained Shear Strength & $200 \mathrm{kPa}$ \\
\cline { 2 - 3 } & Modulus of Elasticity & $60 \mathrm{GPa}$ \\
\cline { 2 - 3 } & Poisson's Ratio & 0.3 \\
\cline { 2 - 3 } & Coefficient of Horizontal Subgrade Reaction & $100 \mathrm{MN} / \mathrm{m}^{3}$ \\
\hline
\end{tabular}

Table 8: Soil Properties used to Estimate Ultimate Lateral Resistance for Piles Installed in Cohesive Soils 


\begin{tabular}{|c|l|c|}
\hline Soil Type & \multicolumn{1}{|c|}{ Soil Property } & Value \\
\hline \multirow{5}{*}{ Loose Sand } & Internal Angle of Friction & 28 Degrees \\
\cline { 2 - 3 } & Unit Weight & $16 \mathrm{kN} / \mathrm{m}^{3}$ \\
\cline { 2 - 3 } & Cohesion & $0 \mathrm{kPa}$ \\
\cline { 2 - 3 } & Modulus of Elasticity & $20 \mathrm{GPa}$ \\
\cline { 2 - 3 } & Poisson's Ratio & 0.2 \\
\cline { 2 - 3 } & Rankine's Passive Earth Pressure Coefficient & 2.77 \\
\cline { 2 - 3 } & Coefficient of Soil Modulus Variation & $7 \mathrm{MN} / \mathrm{m}^{3}$ \\
\hline \multirow{5}{*}{ Medium Sand } & Internal Angle of Friction & $30 \mathrm{Degrees}$ \\
\cline { 2 - 3 } & Unit Weight & $19 \mathrm{kN} / \mathrm{m}^{3}$ \\
\cline { 2 - 3 } & Cohesion & $0 \mathrm{kPa}$ \\
\cline { 2 - 3 } & Modulus of Elasticity & $50 \mathrm{GPa}$ \\
\cline { 2 - 3 } & Poisson's Ratio & 0.3 \\
\cline { 2 - 3 } & Rankine's Passive Earth Pressure Coefficient & 3 \\
\cline { 2 - 3 } & Coefficient of Soil Modulus Variation & $25 \mathrm{MN} / \mathrm{m}^{3}$ \\
\hline & Internal Angle of Friction & $36 \mathrm{Degrees}$ \\
\cline { 2 - 3 } & Unit Weight & $22 \mathrm{kN} / \mathrm{m}^{3}$ \\
\cline { 2 - 3 } & Cohesion & $0.4 \mathrm{KPa}$ \\
\cline { 2 - 3 } & Modulus of Elasticity & $80 \mathrm{GPa}$ \\
\cline { 2 - 3 } & Poisson's Ratio & 3.85 \\
\cline { 2 - 3 } & Rankine's Passive Earth Pressure Coefficient & 0.4 \\
\cline { 2 - 3 } & Coefficient of Soil Modulus Variation & \\
\hline
\end{tabular}

Table 9: Soil Properties used to Estimate Ultimate Lateral Resistance for Piles Installed in Cohesionless Soils 


\subsubsection{Long Piles in Cohesive Soils:}

First, Broms' method was compared to finite element analysis for the long piles described by Table 4, installed in various cohesive soils with the properties described by Table 8 . For the given soil conditions, the dimensionless length of the long pile ranged from approximately 3.1 to 4.4. The results are summarized in Table 10, below.

\begin{tabular}{|l|c|c|c|}
\hline & Medium Clay & Stiff Clay & Very Stiff Clay \\
\hline $\begin{array}{l}\text { Ultimate Lateral Load } \\
\text { (Broms' Method) }\end{array}$ & $2500 \mathrm{kN}$ & $3450 \mathrm{kN}$ & $3800 \mathrm{kN}$ \\
\hline $\begin{array}{l}\text { Estimated Deflection at Ultimate Load } \\
\text { (RocScience) }\end{array}$ & $24.0 \mathrm{~mm}$ & $47.3 \mathrm{~mm}$ & $41.6 \mathrm{~mm}$ \\
\hline $\begin{array}{l}\text { Estimated Deflection for a FOS of } 1.5 \\
\text { (RocScience) }\end{array}$ & $22.7 \mathrm{~mm}$ & $31.5 \mathrm{~mm}$ & $26.1 \mathrm{~mm}$ \\
\hline $\begin{array}{l}\text { Estimated Deflection at } 50 \% \text { of Ultimate } \\
\text { Load (Broms' Method) }\end{array}$ & $12.2 \mathrm{~mm}$ & $10.6 \mathrm{~mm}$ & $31.1 \mathrm{~mm}$ \\
\hline $\begin{array}{l}\text { Estimated Deflection at } 50 \% \text { of Ultimate } \\
\text { Load (RocScience) }\end{array}$ & $17.0 \mathrm{~mm}$ & $31.6 \mathrm{~mm}$ & $20.0 \mathrm{~mm}$ \\
\hline
\end{tabular}

Table 10: Comparison of Deflections Estimated using Broms' Method and RocScience Software for 15 metre Long Piles Installed in Cohesive Soils

To summarize, RocScience finite element software produced the following general results for a 15 metre long circular steel pile, with a flexural rigidity of approximately $3400 \mathrm{MN} / \mathrm{m}^{2}$ and a dimensionless length between 3.1 and 4.4 , installed in various cohesive soils:

- At ultimate lateral loads calculated using Broms' method, deflections of approximately 25 $\mathrm{mm}$ to $50 \mathrm{~mm}$ at ultimate loads were estimated;

- Assuming a factor of safety of 1.5 , deflections of approximately $20 \mathrm{~mm}$ to $30 \mathrm{~mm}$ were estimated;

- Deflections at half of the ultimate load were typically larger than those calculated using Broms' method:

- Broms' method was only conservative for very stiff clay. 


\subsubsection{Short Piles in Cohesive Soils:}

Next, a similar finite element analysis was complete for short piles described by Table 4, installed in various cohesive soils with the properties described by Table 8. For the given soil conditions, the dimensionless length of the short pile ranged from 1.0 to 1.5. The results are summarized in Table 11, below.

\begin{tabular}{|l|c|c|c|}
\hline & Medium Clay & Stiff Clay & Very Stiff Clay \\
\hline $\begin{array}{l}\text { Ultimate Lateral Load } \\
\text { (Broms' Method) }\end{array}$ & $400 \mathrm{kN}$ & $1200 \mathrm{kN}$ & $1600 \mathrm{kN}$ \\
\hline $\begin{array}{l}\text { Estimated Deflection at Ultimate Load } \\
\text { (RocScience) }\end{array}$ & $5.8 \mathrm{~mm}$ & $17.5 \mathrm{~mm}$ & $15.8 \mathrm{~mm}$ \\
\hline $\begin{array}{l}\text { Estimated Deflection for a FOS of } 1.5 \\
\text { (RocScience) }\end{array}$ & $3.8 \mathrm{~mm}$ & $11.7 \mathrm{~mm}$ & $10.6 \mathrm{~mm}$ \\
\hline $\begin{array}{l}\text { Estimated Deflection at } 50 \% \text { of Ultimate } \\
\text { Load (Broms' Method) }\end{array}$ & $6.5 \mathrm{~mm}$ & $9.6 \mathrm{~mm}$ & $6.6 \mathrm{~mm}$ \\
\hline $\begin{array}{l}\text { Estimated Deflection at } 50 \% \text { of Ultimate } \\
\text { Load (RocScience) }\end{array}$ & $2.9 \mathrm{~mm}$ & $8.8 \mathrm{~mm}$ & $7.9 \mathrm{~mm}$ \\
\hline
\end{tabular}

Table 11: Comparison of Deflections Estimated using Broms' Method and RocScience Software for 5 metre Short Piles Installed in Cohesive Soils

To summarize, RocScience finite element software produced the following general results for a 5 metre short circular steel pile, with a flexural rigidity of approximately $3400 \mathrm{MN} / \mathrm{m}^{2}$ and a dimensionless length between 1.0 and 1.5 installed in various cohesive soils:

- At ultimate lateral loads calculated using Broms' method, deflections of approximately 5 $\mathrm{mm}$ to $15 \mathrm{~mm}$ were estimated;

- Assuming a factor of safety of 1.5 , deflections of approximately $4 \mathrm{~mm}$ to $12 \mathrm{~mm}$ were estimated;

- Deflections at half of the ultimate load were very close to those estimated using Broms' method, expect for soft to medium soils where Broms' method overestimated the deflection estimated using the finite element software. 


\subsubsection{Long Piles in Cohesionless Soils:}

A finite element analysis was also performed for the same long pile installed in cohesionless soils. The soil properties described by Table 9 were used for the analysis. For the given soil conditions, the dimensionless length of the long piles varied from 2.7 to 5.1. The results of the RocScience finite element analysis are summarized in Table 12.

\begin{tabular}{|l|c|c|c|}
\hline & Loose Sand & Medium Sand & Dense Sand \\
\hline $\begin{array}{l}\text { Ultimate Lateral Load } \\
\text { (Broms' Method) }\end{array}$ & $2216 \mathrm{kN}$ & $2850 \mathrm{kN}$ & $3390 \mathrm{kN}$ \\
\hline $\begin{array}{l}\text { Estimated Deflection at Ultimate Load } \\
\text { (RocScience) }\end{array}$ & $30.7 \mathrm{~mm}$ & $38.8 \mathrm{~mm}$ & $46.0 \mathrm{~mm}$ \\
\hline $\begin{array}{l}\text { Estimated Deflection for a FOS of } 1.5 \\
\text { (RocScience) }\end{array}$ & $20.4 \mathrm{~mm}$ & $25.8 \mathrm{~mm}$ & $30.6 \mathrm{~mm}$ \\
\hline $\begin{array}{l}\text { Estimated Deflection at } 50 \% \text { of Ultimate } \\
\text { Load (Broms' Method) }\end{array}$ & $25.6 \mathrm{~mm}$ & $18.0 \mathrm{~mm}$ & $9.1 \mathrm{~mm}$ \\
\hline $\begin{array}{l}\text { Estimated Deflection at } 50 \% \text { of Ultimate } \\
\text { Load (RocScience) }\end{array}$ & $15.3 \mathrm{~mm}$ & $19.3 \mathrm{~mm}$ & $23 \mathrm{~mm}$ \\
\hline
\end{tabular}

Table 12: Comparison of Deflections Estimated using Broms' Method and RocScience Software for $15 \mathrm{~m}$ Long Piles Installed in Cohesionless Soils

To summarize, RocScience finite element software produced the following general results for a 10 metre long circular steel pile, with a flexural rigidity of approximately $3400 \mathrm{MN} / \mathrm{m}^{2}$ and a dimensionless length between 2.7 and 5.0, installed various cohesionless soils:

- At ultimate lateral loads calculated using Broms' method, deflections of approximately 30 $\mathrm{mm}$ to $46 \mathrm{~mm}$ were estimated;

- Assuming a factor of safety of 1.5 , deflections of approximately $20 \mathrm{~mm}$ to $30 \mathrm{~mm}$ were estimated;

- Deflections at half of the ultimate load varied from half of those calculated using Broms' method (loose sand) to twice those calculated using Broms' method (dense sand). 


\subsubsection{Short Piles in Cohesionless Soils:}

Finally, a finite element analysis was performed for short piles installed in cohesionless soils with properties described by Table 9. The dimensionless length of the short piles ranged from 0.9 to 1.7 for the given soil conditions. The results of the RocScience finite element analysis are summarized below in Table 13.

\begin{tabular}{|l|c|c|c|}
\hline & Loose Sand & Medium Sand & Dense Sand \\
\hline $\begin{array}{l}\text { Ultimate Lateral Load } \\
\text { (Broms' Method) }\end{array}$ & $665 \mathrm{kN}$ & $885 \mathrm{kN}$ & $1270 \mathrm{kN}$ \\
\hline $\begin{array}{l}\text { Estimated Deflection at Ultimate Load } \\
\text { (RocScience) }\end{array}$ & $9.8 \mathrm{~mm}$ & $12.4 \mathrm{~mm}$ & $18.3 \mathrm{~mm}$ \\
\hline $\begin{array}{l}\text { Estimated Deflection for a FOS of } 1.5 \\
\text { (RocScience) }\end{array}$ & $6.5 \mathrm{~mm}$ & $8.6 \mathrm{~mm}$ & $12.2 \mathrm{~mm}$ \\
\hline $\begin{array}{l}\text { Estimated Deflection at } 50 \% \text { of Ultimate } \\
\text { Load (Broms' Method) }\end{array}$ & $58.2 \mathrm{~mm}$ & $13.5 \mathrm{~mm}$ & $8.2 \mathrm{~mm}$ \\
\hline $\begin{array}{l}\text { Estimated Deflection at } 50 \% \text { of Ultimate } \\
\text { Load (RocScience) }\end{array}$ & $4.9 \mathrm{~mm}$ & $6.4 \mathrm{~mm}$ & $9.2 \mathrm{~mm}$ \\
\hline
\end{tabular}

Table 13: Comparison of Deflections Estimated using Broms' Method and RocScience Software for 5 metre Short Piles Installed in Cohesionless Soils

To summarize, RocScience finite element software produced the following general results for a 5 metre short circular steel pile with a flexural rigidity of approximately $3400 \mathrm{MN} / \mathrm{m}^{2}$ and a dimensionless length between 0.9 and 1.7 , installed in various cohesionless soils:

- At ultimate lateral loads calculated using Broms' method, deflections of approximately 9 $\mathrm{mm}$ to $20 \mathrm{~mm}$ were estimated;

- Assuming a factor of safety of 1.5 , deflections of approximately $6 \mathrm{~mm}$ to $12 \mathrm{~mm}$ were estimated;

- Deflections were equal to those calculated using Broms' method (dense sand) to significantly less than those calculated using Broms' method (loose sand). 


\subsubsection{Summary}

From the finite element analysis of a long pile with a flexural rigidity of approximately 3400 $\mathrm{MN} / \mathrm{m}^{2}$ and a dimensionless length between approximately 3 and 5 , installed in various soils as described by Table 8 and Table 9, Broms' methods were generally unconservative. When used in conjunction with a factor of safety of 1.5 , Broms' methods produced an ultimate lateral resistance associated with approximately $15 \mathrm{~mm}$ to $30 \mathrm{~mm}$ of lateral deflection.

From the finite element analysis of a short pile with a flexural rigidity of approximately 3400 $\mathrm{MN} / \mathrm{m}^{2}$ and a dimensionless length between approximately 1 and 2 , installed in various soils as described by Table 8 and Table 9, Broms' methods were approximately equal to, or more conservative than the deflections estimated using finite element software. When used in conjunction with a factor of safety of 1.5 , Broms' methods produced an ultimate lateral resistance associated with approximately $4 \mathrm{~mm}$ to $12 \mathrm{~mm}$ of lateral deflection.

\subsubsection{Advantages and Disadvantages of Broms' Method}

From the parametric study and finite element analysis for the pile and soil properties noted above, Broms' methods provided for a reasonably accurate preliminary estimate of short pile deflections for the estimated ultimate lateral load. For cohesive soils, Broms' method estimated deflections at working loads that were very close to those resulting from finite element analysis. For short piles installed cohesionless soils, Broms' Method typically overestimated deflections at working loads. In both cases, Broms' Method estimated ultimate lateral loads that resulted in less than $20 \mathrm{~mm}$ of deflection.

For the long piles analysed, Broms' Method typically underestimated deflection in both cohesive and cohesionless soils. It was found that the ultimate lateral load calculated using Broms' method resulted in deflections of $25 \mathrm{~mm}$ to $50 \mathrm{~mm}$. Under working loads, the finite element software produced deflections up to three times those estimated by Broms' Method. However, it should be noted that Broms' method overestimated deflection under working loads for long piles installed in loose sand or very stiff clay. For the pile properties and soil conditions analysed within this project, it was found that a factor of safety of 1.5 , when applied to ultimate lateral load, was sufficient to limit deflection to less than $30 \mathrm{~mm}$. 


\subsection{Lateral Resistance of Piles installed near a Slope}

Broms' method for calculating the ultimate lateral resistance and deflection of piles can only be used for piles located in level ground. The analysis of a piles installed near slopes is a complex, three dimensional problem, which requires the use of finite element software to accurately evaluate the behaviour of the pile and surrounding soil, and ultimately, calculate moments induced within the pile and estimate the magnitude of deflections (Nguyen et al., 2013, p. 1).

In recent years, there have been a number of studies evaluating the impact of slopes on the lateral capacity and deflection of piles. As part of this report, two popular studies were reviewed. The first was the research of Salim Mezazigh and Daniel Levacher, who studied the impact of slopes on p-y curves for long piles installed in dry sand using centrifuge modeling. The second is the more recent work of Konstantinos Georgiadis et al., who investigated the impact of slopes on piles installed in cohesive materials. In this section RocScience finite element software will also be used to evaluate the impact of slopes on laterally loaded piles.

\subsection{Case Study: Laterally Loaded Piles in Sand}

Within their 1998 paper, Laterally Loaded Piles in Sand: slope effect on P-Y reaction curves, Mezazigh and Levacher investigated the impact of slopes on long piles installed in dry sand, including the effect of the slopes on the p-y curves for the piles (Mezazigh \& Levacher, 1998, p. 434). The study looked at piles installed at various distances from both $2 \mathrm{H}: 1 \mathrm{~V}$ and $3 \mathrm{H}: 1 \mathrm{~V}$ slopes and considered two different soil densities: $15.5 \mathrm{kN} / \mathrm{m}$ and $16.1 \mathrm{kN} / \mathrm{m}$. The researchers started by filling a $1200 \mathrm{~mm}$ long by $800 \mathrm{~mm}$ wide by $350 \mathrm{~mm}$ deep container with white Fontainebleau sand. Aluminum piles with a length of $380 \mathrm{~mm}$, a diameter of $18 \mathrm{~mm}$, and a wall thickness of $1.5 \mathrm{~mm}$ were embedded $300 \mathrm{~mm}$ into the sand (Mezazigh \& Levacher, 1998, p. 435) as shown in Figure 40 and Figure 41. Piles were driven using a $695 \mathrm{~g}$ hammer, falling a distance of 470 $\mathrm{mm}$ as shown in Figure 42. 


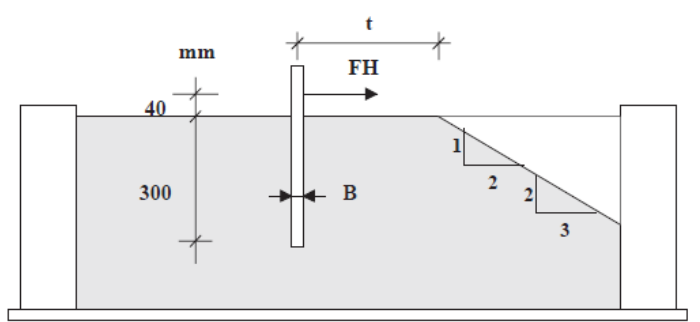

Figure 40: Setup of Long Piles in Dry Sand

(Mezazigh \& Levacher, 1998, p. 435)

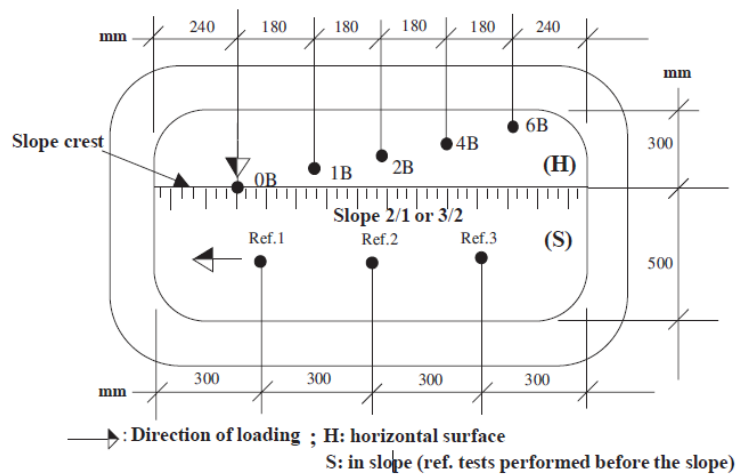

Figure 41: Layout of Piles

(Mezazigh \& Levacher, 1998, p. 435)

The piles were outfitted with three displacement sensors at depths of $0 \mathrm{~mm}, 20 \mathrm{~mm}$, and $65 \mathrm{~mm}$ from the surface of the soil and 20 strain gauges were equally spaced every $15 \mathrm{~mm}$ along the length of the pile. Tests were performed by loading the piles under free head conditions (Figure 43), using a steel cable attached $40 \mathrm{~mm}$ below the top of the pile. A centrifuge acceleration of $40 \mathrm{~g}$ allowed the model to simulate a $12 \mathrm{~m}$ long pile with a diameter of $720 \mathrm{~mm}$. The authors first performed baseline tests of the piles, loaded horizontally with a flat sand surface. After, the authors performed similar centrifuge tests with the piles located at various distances from slopes in the sand (Mezazigh \& Levacher, 1998, p. 435).

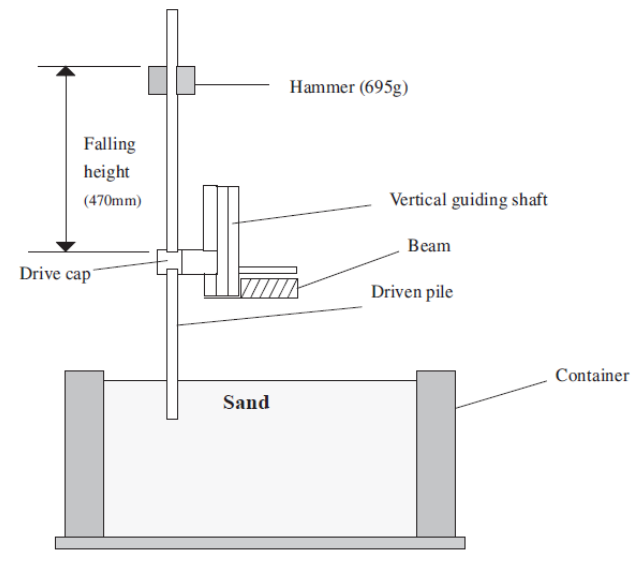

Figure 42: Method of Pile Installation

(Mezazigh \& Levacher, 1998, p. 434)

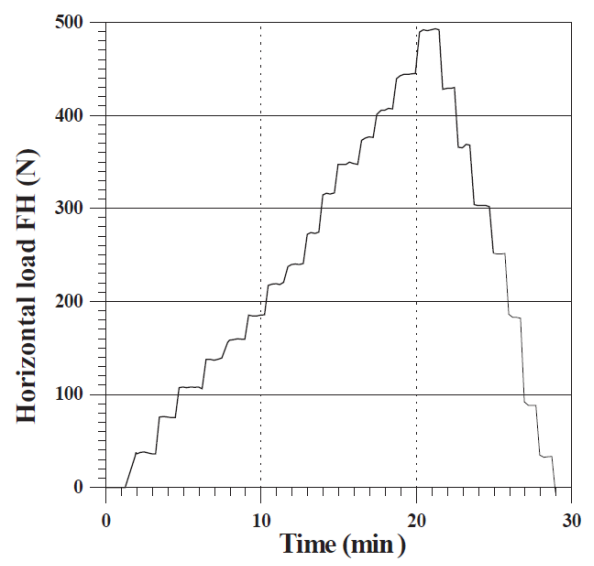

Figure 43: Pile Loading Curve

(Mezazigh \& Levacher, 1998, p. 435) 
During this study, the following general trends were observed:

- The closer the pile is to the slope, the greater the head displacement;

- The closer the pile is to the slope, the greater the maximum moment within the pile;

- The closer the pile is to the slope, the deeper the point of maximum moment.

(Mezazigh \& Levacher, 1998, p. 436)

For a $2 \mathrm{H}: 1 \mathrm{~V}$ slope:

- The slope has an impact on head displacement when the pile is within approximately eight pile diameters of the crest of the slope (Mezazigh \& Levacher, 1998, p. 440);

- At the crest of the slope, head displacement is $60 \%$ larger than head displacement for a pile installed in level ground (Mezazigh \& Levacher, 1998, p. 438);

- The maximum moment in the pile is approximately $25 \%$ larger than the maximum moment for a pile embedded in level ground (Mezazigh \& Levacher, 1998, p. 439).

For a 3H:1V slope:

- The slope has an impact on the head displacement when the pile is within approximately 12 pile diameters of the crest of the slope (Mezazigh \& Levacher, 1998, p. 440);

- At the crest of the slope, head displacement is $240 \%$ larger than head displacement for a pile installed in level ground (Mezazigh \& Levacher, 1998, p. 438);

- The maximum moment in the pile is approximately $75 \%$ larger than the maximum moment for a pile embedded in level ground (Mezazigh \& Levacher, 1998, p. 439).

P-Y Curves:

- The resistance of the soil increases up to a depth of four to five times the pile diameter;

- Beyond this depth, soil resistance is constant;

- Experimental results can be best modeled by $p-y$ curves with a parabolic shape:

$p d=K\left(\frac{y}{d}\right)^{n}$

(Mezazigh \& Levacher, 1998, p. 437) 
- The value of the ordinate at the origin of the $p-y$ curve is proportional with depth:

- The value depends on a coefficient of proportionality which is a function of the proximity of the pile to the slope, the density of the soil, and the angle of the slope:

$$
K=\eta\left(\frac{t}{B}, I_{D}, \beta\right) \frac{z}{B}
$$

(Mezazigh \& Levacher, 1998, p. 438)

Maximum Moment:

- The maximum moment within the pile is proportional to the applied lateral load:

- This value also depends on a coefficient of proportionality which is a function of pile location:

$M_{\text {max }}=m\left(\frac{t}{B}\right) F H$

(Mezazigh \& Levacher, 1998, p. 439)

- The authors found the value of the coefficient of proportionality for the sloped condition to equal that of the base condition (level ground) and increased to approximately 1.6 times the base condition for a pile located at the crest of the slope (Mezazigh \& Levacher, 1998, p. 439).

As a summary to the investigation, the authors proposed reduction coefficients that could be applied to the $p$-y curves for horizontal ground to adjust for the effects of a slope. Mezazigh and Levacher suggested for a pile installed in dry sand at the crest of a 2:1 slope, the load for a given deflection is only $47.2 \%$ of that for a pile installed in level ground. As the pile is moved away from the slope, the coefficient increases linearly, reaching $100 \%$ at a distance of eight pile diameters from the slope. Similarly, for a pile installed in dry sand at the crest of a 3:1 slope, it was proposed that the load for a given deflection is only $33.1 \%$ of that for a pile installed in level ground. As the pile is moved away from the slope, the coefficient increases linearly, reaching $100 \%$ at a distance of 12 pile diameters from the slope (Mezazigh \& Levacher, 1998, p. 440). 
In general, the reduction factor may be calculated using the equation:

$\left\{\begin{array}{l}r=\frac{17-15 \tan \beta}{100} \cdot \frac{t}{\beta}+\frac{1-\tan \beta}{2} \text { if } t \leq t_{\text {lim }} \\ r=1 \\ \text { if } t>t_{\text {lim }}\end{array}\right.$

where:

$t_{\text {lim }}=4 \beta(6 \tan \beta-1)$

(Mezazigh \& Levacher, 1998, p. 440)

\subsection{Case Study: Laterally Loaded Piles in Clay}

In 2010 and 2012, Konstantinos Georgiadis published papers evaluating the behaviour of piles imbedded in cohesive materials near clay slopes. The first paper, Undrained lateral pile response in sloping ground, was published with Michael Georgiadis. In their 2012 paper, Development of $p-y$ curves for undrained response of piles near slopes, Georgiadis and Georgiadis refined the equations published in 2010. Later in 2012, Georgiadis and Georgiadis worked with Christos Anagnostopoulous to publish a third paper, specific to short, rigid piles: Lateral bearing capacity of rigid piles near clay slopes.

Within the 2010 paper, the authors worked to modify common p-y curve equations for the condition in which a pile is installed within a cohesive soil within close proximity of a slope. Based on the work of a number of researchers including Matlock (1970), Reese et al. (1974), and Reese and Welch (1975), the p-y curve for a pile is typically described by the equation:

$p=0.5 p_{u}\left(\frac{y}{y_{c}}\right)^{\beta}$

(Georgiadis \& Georgiadis, 2010, p. 1489)

This $p$-y curve can also be described by the equation, where the initial stiffness of the p-y curve depends on the diameter and flexural stiffness of the pile, and the deformation characteristics of the soil: 
$p=\frac{y}{\left(\frac{1}{K_{i}}\right)+\left(\frac{y}{p_{u}}\right)}$

(Georgiadis \& Georgiadis, 2010, p. 1489)

At ultimate load, soil failure at any point may be the result of lateral soil flow, or a wedge type failure, depending on the depth of the pile (Georgiadis \& Georgiadis, 2010, p. 1489). Using statics, the ultimate lateral resistance per unit length of a pile, at a given depth, may be calculated using the relationship:

$p_{u}=N_{p} c_{u} d$

(Georgiadis \& Georgiadis, 2010, p. 1489)

The bearing capacity factor is a minimum at the ground surface and increases with depth until a maximum value at the bottom of the pile. After a review of existing theories, Georgiadis and Georgiadis found limited information regarding the behaviour of piles installed in clay soils near slopes. As a result, within their 2010 investigation, Georgiadis and Georgiadis performed a finite element analysis, using Plaxis 3D Foundation V2.2. The researches modeled piles installed at the crest of slopes (as shown in Figure 44) under a variety conditions:

- Pile lengths of 12 and 20 metres;

- Pile diameters of 0.5 and 1 metre(s);

- Slope angles of 0, 20, 30, and 40 degrees;

- Undrained shear strengths of 25,50, and $100 \mathrm{kPa}$;

- Young's modulus of 5, 10, and $20 \mathrm{MPa}$ for soil;

- Poisson's ratio of 0.49 for soil;

- Soil unit weights of 16,18 , and $20 \mathrm{kN} / \mathrm{m}^{3}$;

- Adhesion factors of 0.3, 0.5, and 1.0;

- Slope heights of 8 to 15 metres;

- Young's modulus of $2.9 \times 10^{7} \mathrm{kPa}$ for piles;

- Poisson's ratio of 0.1 for the piles;

(Georgiadis \& Georgiadis, 2010, p. 1491) 
Typical p-y curves resulting from the finite element analysis, for piles with a length of 12 metres and a width of 1 metre are shown in Figure 45.

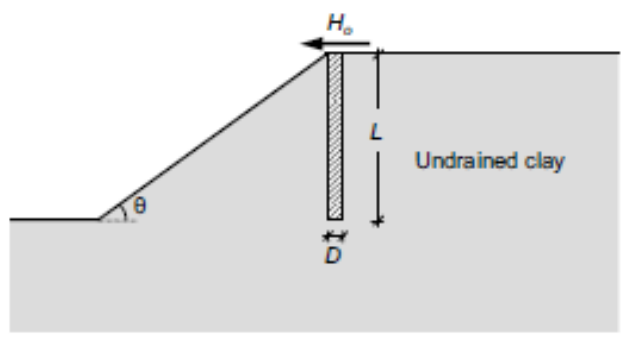

Figure 44: Finite Element Model

(Georgiadis \& Georgiadis, 2010, p. 1490)

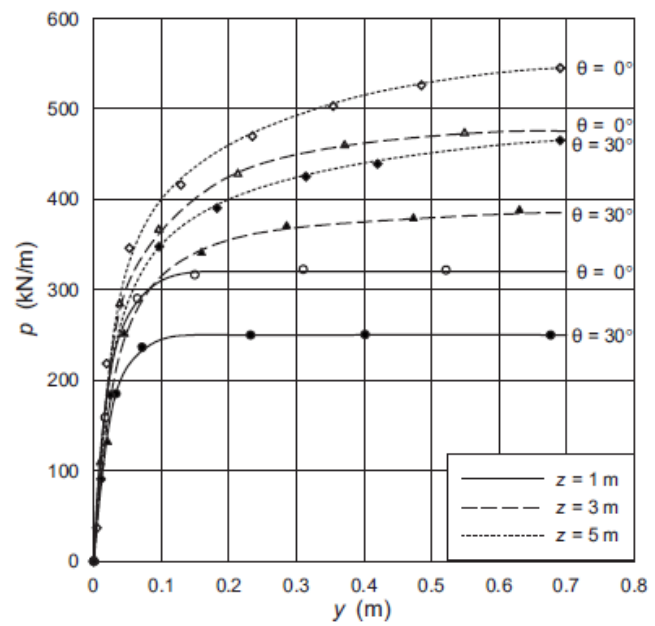

Figure 45: Typical P-Y Curves for 12 Metre Long, 1 Metre Diameter Piles

(Georgiadis \& Georgiadis, 2010, p. 1492)

Based on the results of their analysis, the authors proposed the following equation to calculate the bearing capacity factor (taking into consideration soil-pile adhesion and the angle of the sloping ground):

$N_{p}=N_{p u}-\left(N_{p u}-N_{p o} \cos \theta\right) e^{\left(\frac{-\lambda\left(\frac{Z}{D}\right)}{1+\tan \theta}\right)}$

(Georgiadis \& Georgiadis, 2010, p. 1493)

When calculating the bearing capacity factor, the authors suggested using the using the ultimate lateral bearing capacity factor for deep lateral soil flow as proposed by Randolph and Houlsby in 1984:

$N_{p u}=\pi+2 \Delta+2 \cos \Delta+4\left(\cos \frac{\Delta}{2}+\sin \frac{\Delta}{2}\right)$ 
where:

$\Delta=\sin ^{-1} \alpha$

(Georgiadis \& Georgiadis, 2010, p. 1493)

The bearing capacity factor at ground surface for level ground was calculated using the following equation, taking into account an adhesion factor (ratio of adhesion to undrained shear strength) ranging from zero for a smooth pile and one for a rough pile:

$N_{p o}=2+1.5 \alpha$

The equation proposed by Georgiadis and Georgiadis also required a non-dimensional factor calculated as:

$\lambda=0.55-0.15 \alpha$

This equation correlated extremely well with the finite analysis results for bearing capacity factor versus depth for varying slope angles and adhesion factors (Figure 46):

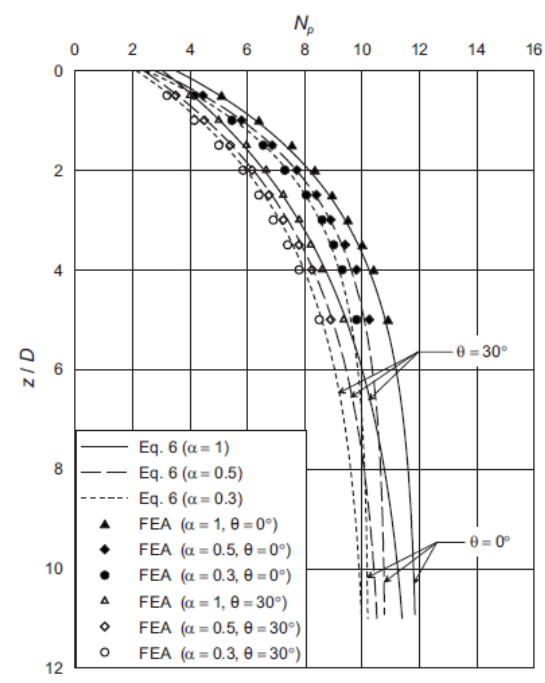

Figure 46: Lateral Bearing Capacity versus Depth for Varying Slope Angles and Adhesion Factors

(Georgiadis \& Georgiadis, 2010, p.1493) 
As part of their research, the authors also considered the effect of a slope on the initial stiffness. Upon review of existing literature, the authors derived an equation to relate the initial stiffness for a pile located near a slope $\left(K_{i \theta}\right)$ to the initial stiffness of a pile in level ground $\left(K_{i 0}\right)$ :

$K_{i \theta}=\left[\cos \theta+\frac{z}{6 D}(1-\cos \theta)\right] K_{i o}$

(Georgiadis \& Georgiadis, 2010, p. 1494)

From their 2010 investigation Georgiadis and Georgiadis made the following general conclusions regarding pile-soil adhesion and ground inclination for piles installed in cohesive materials:

Adhesion: Pile-soil adhesion has a large impact on lateral pile resistance. As adhesion decreases, so does the ultimate resistance of the pile. Lower adhesion also results in larger pile deflections.

Ground Inclination: Sloped ground will result in a lower lateral pile resistance and much larger pile deflections.

(Georgiadis \& Georgiadis, 2010, p. 1498)

In 2012, Georgiadis and Georgiadis used 3D finite element modeling to further refine the equations developed in 2010. The authors found that for driven piles (under drained conditions), the bearing capacity factor for piles near slopes is the same as the bearing capacity factor for level ground, up until a critical depth. When the head of a pile is subjected to a lateral load, the result is a narrow, but shallow area of soil displacement. This failure area only affects the ground surface in a horizontal direction. As a result, the slope has no impact on the lateral resistance of the pile. However, as the load is increased and the area of soil displacement becomes wider and deeper, a critical depth is reached where the displaced soil begins to intersect the slope, thereby impacting the lateral capacity of the pile (Georgiadis \& Georgiadis, 2012, p. 56). Based on the results of the finite element analysis, the critical depth may be calculated using the equation: 
$\frac{Z_{c}}{D}=8.5-10 \log _{10}\left(8-\frac{b}{D}\right)$

(Georgiadis \& Georgiadis, 2012, p. 56)

Above the critical depth, the bearing capacity factor may be calculated using the equation for piles installed in level ground:

$N_{p}=N_{p u}-\left(N_{p u}-N_{p o}\right) e^{-\lambda\left(\frac{Z}{D}\right)}$

where:

$\lambda=0.55-0.15 \alpha$

(Georgiadis \& Georgiadis, 2012, p. 54)

Beyond the critical depth, the bearing capacity factor equation is adjusted for an adhesion factor that is dependent on slope angle:

$N_{p}=N_{p u}-\left(N_{p u}-N_{p c}\right) e^{-\lambda \alpha_{\theta}\left(z-z_{c}\right) / D}$

where:

$\alpha_{\theta}=1-\frac{\sin \theta(1+\sin \theta)}{2}$

(Georgiadis \& Georgiadis, 2012, p. 57)

and:

$N_{p c}$ is a constant equal to the value of $N_{p}$ for $z=z_{c}$

(Georgiadis \& Georgiadis, 2012, p. 58)

Finite element analysis demonstrated that the above equations did a good job of estimating the ultimate lateral soil reaction per unit length of pile (Georgiadis et al., 2013, p. 145). However, due to the variable bearing capacity factors along the length of the pile, a single load reduction factor, for a given displacement, cannot be applied for piles installed in clay near slopes (Georgiadis \& Georgiadis, 2012, p. 60). 
In 2013, Georgiadis et al. continued to investigate the performance of piles installed in clay soils near slopes. In this paper, the authors specifically focused on short, rigid piles. Using the equations developed within the previous publications, the authors proposed new equations to estimate the ultimate lateral bearing capacity and corresponding maximum bending moments for short piles (Georgiadis et al., 2013, p. 146). The authors considered scenarios in which piles were installed in level ground (Figure 47), as well as in close proximity to a slope (Figure 48 and Figure 49.

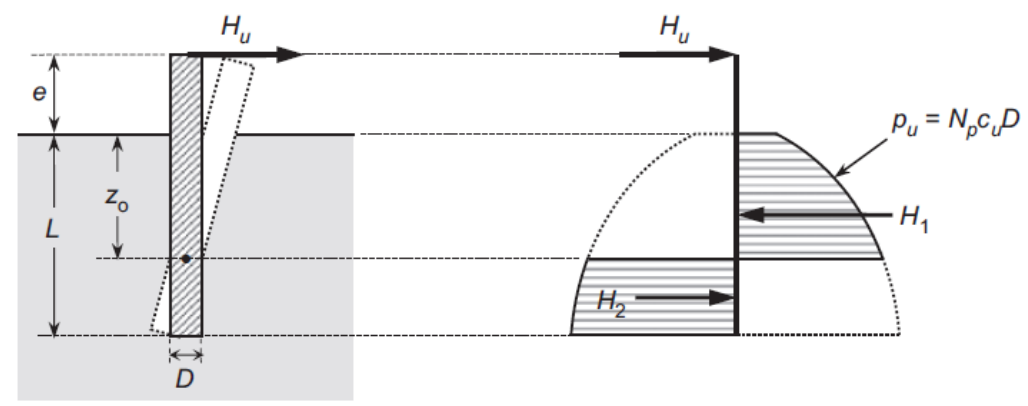

Figure 47: Lateral Earth Pressure Diagram for Laterally Loaded Short Piles Installed in Level Ground (Georgiadis et al., 2013 p. 147)

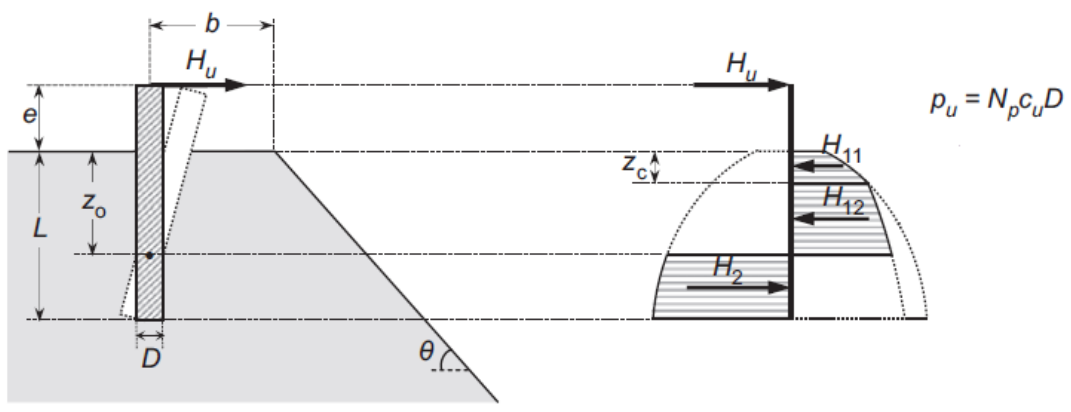

Figure 48: Lateral Earth Pressure Diagram for Short Piles Laterally Loaded towards a Slope

(Georgiadis et al., 2013, p. 148) 


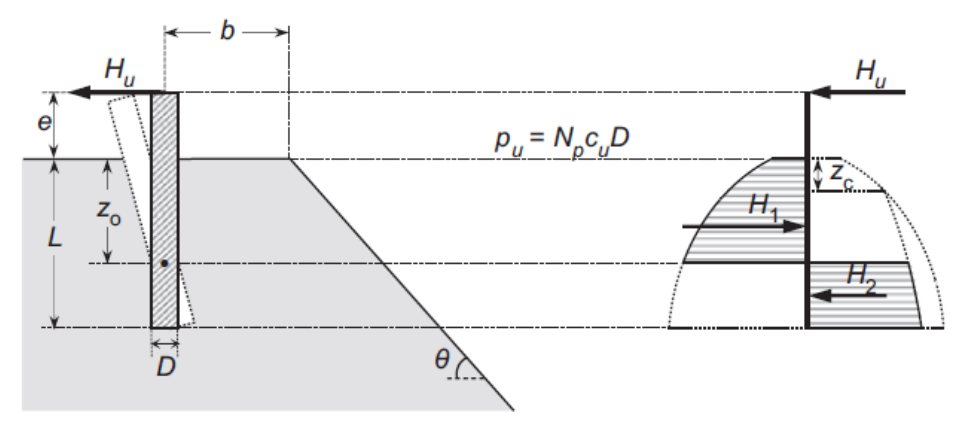

Figure 49: Lateral Earth Pressure Diagram for Short Piles Laterally Loaded Away from a Slope

(Georgiadis et al., 2013, p. 148)

The authors found that for smooth piles in level ground, the newly proposed were less conservative than Broms' methods. However, the results generated using the new equations corresponded well with actual field tests (Georgiadis et al., 2013, p. 153).

\subsection{Finite Element Analysis of Laterally Loaded Piles near Slopes}

To better understand the impact of slopes on the ultimate resistance of laterally loaded piles, RocScience RS2 finite element software was used to analyse a number of piles installed in a variety of soil conditions. As noted earlier, pile design is typically governed by the deflection of the pile. Since the ultimate goal of this investigation is to design two solider pile retaining walls within the slope of a railway embankment additional guidance was sought regarding maximum allowable deflection.

The Union Pacific Temporary Shoring Guideline suggests a deflection limit of $12.7 \mathrm{~mm}$ for shoring walls installed between 5.5 metres and 7.5 metres of the centreline of a railway track (Union Pacific, 2004, p.10). Therefore, for this finite element investigation, fully embedded, free head piles were installed 15 metres away from the crest of a $2 \mathrm{H}: 1 \mathrm{~V}$ slope. The piles were loaded laterally at the top of the pile until $12.7 \mathrm{~mm}$ of deflection was achieved. Piles were then moved closer to the crest of the slope and the impact of the slope on pile head displacement and bending moments within the pile were evaluated. As part of this study, long and short piles were evaluated in both stiff cohesive and medium cohesionless soils. Once again, the pile properties define in Table 4 and the soil properties described by Table 5 through Table 9 were assumed. The following results were observed (see Appendix A for additional model output): 


\subsubsection{Impact of a 2H:1V Slope on a Long Pile installed in a Cohesive Stiff Cohesive Soil}

For a 15 metre long pile, with a 1 metre diameter and a wall thickness of 0.1 metres (with a flexural rigidity of approximately $3400 \mathrm{MN} / \mathrm{m}^{2}$ and a dimensionless length of 3.7) installed in a stiff cohesionless soil (undrained shear strength of $100 \mathrm{kPa}$ ), it was found that an applied lateral force of $925 \mathrm{kN}$ was required to generate $12.7 \mathrm{~mm}$ of deflection. As the pile was moved towards the crest of the slope, the following results were observed:

- For an applied lateral load of $925 \mathrm{kN}$, pile deflection at the slope crest was $123 \%$ of the deflection in level ground;

- For an applied lateral load of $925 \mathrm{kN}$, the maximum moment in the pile at the slope crest was $107 \%$ of the moment in level ground;

- To limit the deflection at the slope crest to $12.7 \mathrm{~mm}$, the applied load was reduced to $81 \%$ of the applied load for $12.7 \mathrm{~mm}$ of deflection in level ground;

- For a deflection of $12.7 \mathrm{~mm}$ at the slope crest, the applied load was reduced to $22 \%$ of the maximum pile capacity in level ground as calculated using Broms' Method;

- For a deflection of $12.7 \mathrm{~mm}$ at the slope crest, the maximum moment within the pile was $22 \%$ of the maximum moment within the pile in level ground.

\subsubsection{Impact of a 2H:1V Slope on a Short Pile installed in a Stiff Cohesive Soil}

Next, the study looked at the performance of a 5 metre short pile installed in a stiff cohesive soil (undrained shear strength of $100 \mathrm{kPa}$ ). Once again, the pile had a diameter of 1 metre, a wall thickness of 0.1 metres, and a flexural rigidity of $3400 \mathrm{MN} / \mathrm{m}^{2}$. The pile had a dimensionless length of 1.23. It was found that an applied lateral force of $850 \mathrm{kN}$ was necessary to produce $12.7 \mathrm{~mm}$ of deflection in level ground. As the pile was moved towards the crest of the slope, the following results were observed:

- For an applied lateral load of $850 \mathrm{kN}$, the pile deflection at the slope crest was $127 \%$ of the deflection in level ground;

- For an applied lateral load of $850 \mathrm{kN}$, the maximum moment in the pile at the slope crest was $130 \%$ of the moment in level ground;

- To limit the deflection at the slope crest to $12.7 \mathrm{~mm}$, the applied load was reduced to $88 \%$ of the applied load for $12.7 \mathrm{~mm}$ of deflection in level ground; 
- For a deflection of $12.7 \mathrm{~mm}$ at the slope crest, the applied load was reduced to $56 \%$ of the maximum pile capacity in level ground as calculated using Broms' Method;

- For a deflection of $12.7 \mathrm{~mm}$ at the slope crest, the maximum moment within the pile was $103 \%$ of the maximum moment within the pile in level ground.

\subsubsection{Impact of a 2V:1H Slope on a Long Pile installed in a Medium Cohesionless Soil}

The 15 metre long pile was then modeled in a medium sand with an internal angle of friction of 30 degrees. Based on the soil conditions, the dimensionless length of the pile was calculated to be 4.77. To achieve a lateral deflection of $12.7 \mathrm{~mm}$, an applied load of $950 \mathrm{kN}$ was required. The following results were observed as the pile was moved towards the slope:

- For an applied lateral load of $950 \mathrm{kN}$, pile deflection at the slope crest was $122 \%$ of the deflection in level ground;

- For an applied lateral load of $950 \mathrm{kN}$, the maximum moment in the pile at the slope crest was $107 \%$ of the moment in level ground;

- To limit the deflection at the slope crest to $12.7 \mathrm{~mm}$, the applied load was reduced to $79 \%$ of the applied load for $12.7 \mathrm{~mm}$ of deflection in level ground;

- For a deflection of $12.7 \mathrm{~mm}$ at the slope crest, the applied load was reduced to $26 \%$ of the maximum pile capacity in level ground as calculated using Broms' Method;

- For a deflection of $12.7 \mathrm{~mm}$ at the slope crest, the maximum moment within the pile was $84 \%$ of the maximum moment within the pile in level ground.

\subsubsection{Impact of a 2V:1H Slope on a Short Pile installed in a Medium Cohesionless Soil}

The 5 metre short pile was also modelled in a medium stand with an internal angle of friction of 30 degrees (dimensionless length of 1.2). In level ground, an applied load of $885 \mathrm{kN}$ produced $12.7 \mathrm{~mm}$ of lateral deflection. As the pile was moved closer to the slope, the following impacts were noted:

- For an applied lateral load of $885 \mathrm{kN}$, pile deflection at the slope crest was $126 \%$ of the deflection in level ground;

- For an applied lateral load of $885 \mathrm{kN}$, the maximum moment in the pile at the slope crest was $130 \%$ of the moment in level ground; 
- To limit the deflection at the slope crest to $12.7 \mathrm{~mm}$, the applied load was reduced to $85 \%$ of the applied load for $12.7 \mathrm{~mm}$ of deflection in level ground;

- For a deflection of $12.7 \mathrm{~mm}$ at the slope crest, the applied load was reduced to $80 \%$ of the maximum pile capacity in level ground as calculated using Broms' Method;

- For a deflection of $12.7 \mathrm{~mm}$ at the slope crest, the maximum moment within the pile was $102 \%$ of the maximum moment within the pile in level ground.

\subsubsection{Use of Broms' Method for Piles installed near Slopes}

For the soils and pile conditions noted above, it was found that Broms' Method for estimating deflections of piles near slopes was much more accurate for short piles than long piles. For the short piles analysed within this investigation, it was found that a factor of safety of 2 , when applied to the ultimate lateral load determined using Broms' method, would produce deflections less than $12.7 \mathrm{~mm}$. However, for the long piles analysed within this investigation, it was found that a factor of safety of 4 , when applied to the lateral load determined using Broms' method, would limit deflections to less than $12.7 \mathrm{~mm}$. 


\subsection{Anchored Walls}

The use of ground anchors in conjunction with retaining wall systems is a common technique employed for both temporary and permanent retaining structures. When compared to traditional gravity retaining walls, flexible retaining walls with ground anchors are able to support large lateral forces with smaller wall cross-sections, while reducing overall construction time. Ground anchors also allow for unobstructed excavation and construction works along the wall (Sabatini et al., 1999, p. 2).

Ground anchors, or "tiebacks", are prestressed steel tendons that allow tensile forces from the retaining, or shoring wall to be transferred to the ground. The components of a ground anchor are shown in Figure 50:

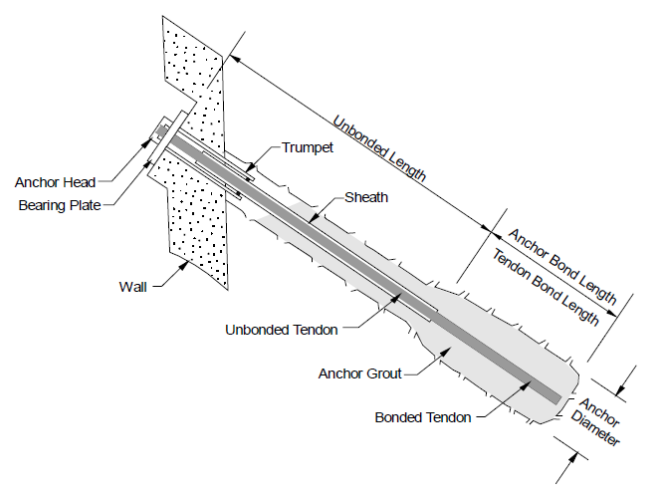

Figure 50: Components of a Ground Anchor

(Sabatini et al., 1999, p. 4)

A ground anchor works by installing a tendon into the soil or rock behind the wall. The end of the tendon is grouted into place behind the failure surface of the soil. The grout enables the transfer of tensile forces from the wall to the soil or rock. A bond-breaker, such as a smooth plastic sleeve, is installed around the tendon in front of the anchor allow the steel to be prestressed without obstruction and prevents the transfer of tensile forces to the ground in front of the anchor (Sabatini et al., 1999, p. 5). The next section of this report reviews anchored wall design procedures as recommended by the Federal Highway Administration's Geotechnical Engineering Circular No. 4: Ground Anchors and Anchor Systems dated June 1999. 


\subsection{Loads Resisted by Anchored Walls}

Similar to traditional retaining walls, anchored walls must be designed to resist the lateral loads applied to the wall by soil, water, and any other external loads. The design must also consider serviceability requirements and ensure that any movement or deflection of the wall and ground are kept within acceptable tolerances (Sabatini et al., 1999, p. 26). An anchored wall must be designed to account for a variety of potential failure mechanisms including:

- Failure of the tendon due to excessive tensile forces;

- Pullout of the tendon due to the failure of the grout bond with the soil or rock;

- Pullout of the tendon due to failure of the tendon bond with the grout;

- Bending failure of the wall due to excessive moments;

- Failure at the toe due to inadequate passive soil resistance;

- Failure at the toe due to inadequate axial capacity;

- Rotation of the wall before anchors are installed;

- Overturning of the entire shoring and tieback system;

- Siding of the entire shoring and tieback system;

- Slope (rotational) failure of the entire shoring and tieback system.

(Sabatini et al., 1999, p. 27)

\subsubsection{Soil Loads}

For any retaining wall design, the first step is to determine the loads that will be acting upon the structure. However, shoring walls are unique due to the top-down nature of construction and the presence of ground anchors (Sabatini et al., 1999, p. 48). These walls are extremely flexible and lateral movements can result in active earth pressures that extend the entire height of the wall (Sabatini et al., 1999, p. 47). In addition, the installation and stressing of tie-backs can result in earth pressures at tie-back locations that are greater than the active earth pressure for the soil. As a result, typical earth pressure distributions, such as those proposed by Rankine and Coulomb, cannot be applied. The U.S. Department of Transportation Federal Highway Administration recommends the use of modified versions of the apparent earth pressure diagrams developed by Terzaghi and Peck in 1967, and Peck in 1969 (Sabatini et al., 1999, p. 48). 
Terzaghi and Peck developed apparent earth pressure diagrams for the purpose of designing struts to support excavations in homogenous soils. The diagrams are semi-empirical in nature and were created for three separate cases:

- Drained granular soils;

- Undrained soft to medium clays;

- Undrained stiff to hard fissured clays.

(Sabatini et al., 1999, p. 48)

In developing the earth pressure diagrams, it was assumed:

- Excavation is more than 6 metres deep;

- Excavation is relatively wide;

- Soil is homogeneous;

- Wall displacements are significant enough that the full soil shear strength may be considered:

- Shearing is under drained conditions for cohesionless soils;

- Shearing is under undrained conditions for cohesive soils;

- Groundwater is below the bottom of the excavation in cohesionless soils;

- Water pressure in negligible in cohesive soils;

(Sabatini et al., 1999, p. 49)

\subsubsection{Excavations in Granular Soils}

The apparent pressure diagram for sand, developed by Terzaghi and Peck, assumed that active pressure is uniform with depth, as shown in Figure 51 and can be calculated using the equation:

$P_{a}=0.65 \gamma H K_{a}$

(Murthy, 2002, p. 936) 


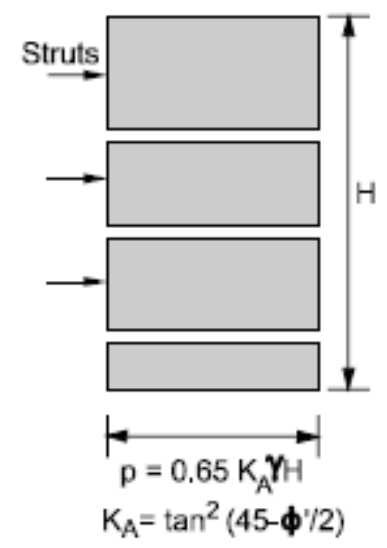

Figure 51: Apparent Earth Pressure Diagram for Excavations in Cohesionless Soils

(Sabatini et al., 1999, p. 50)

The diagram was revised by the Federal Highway Administration to account for the additional earth pressures that are induced behind the shoring wall, due to the presence of tie-backs (Sabatini et al., 1999, p. 48). The FHWA recommends using the following pressure distributions for excavations in cohesionless soils with one level of tiebacks (Figure 52) and with multiple levels of tie-backs (Figure 53):

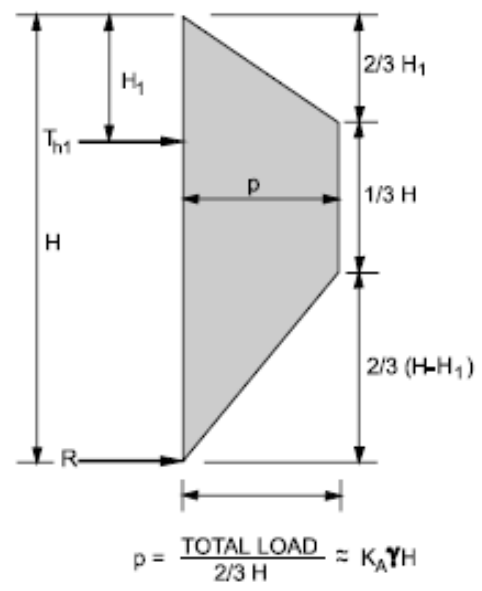

Figure 52: Apparent Earth Pressure Diagram for Excavations in Cohesionless Soils (One Row of Tie-Backs)

(Sabatini et al., 1999, p. 51)

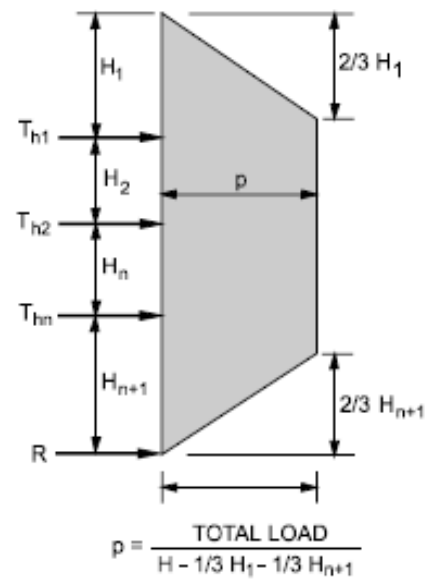

Figure 53: Apparent Earth Pressure Diagram for Excavations in Cohesionless Soils (Multiple Rows of Tie-Backs)

(Sabatini et al., 1999, p. 51) 


\subsubsection{Excavations in Cohesive Soils}

In 1969, Peck developed apparent earth pressure diagrams for both soft to medium clays and stiff to hard clays. Peck classified soils according to their stability number: a dimensionless value dependant on the unit weight and undrained shear strength of the soil, as well as the exposed height of the wall. The stability number can be calculated using the equation:

$N_{s}=\frac{\gamma H}{S_{u}}$

(Murthy, 2002, p. 936)

For stability numbers less than 4 , peck considered the soil to be stiff to hard. A soil was considered to be soft to medium if the stability number was greater than 4 (Murthy, 2002, p. 936).

\subsubsection{Temporary Excavations in Stiff to Hard Clays}

For stiff to hard fissured clays, Peck assumed the apparent earth pressure to increase linearly from zero to the maximum pressure over the upper quarter of the exposed wall, remain consistent for middle half of the exposed wall, and decrease linearly back to zero over the bottom quarter of the exposed wall. The maximum apparent earth pressure is assumed to be somewhere between $20 \%$ and $40 \%$ of the unit weight of the soil, times the height of the exposed wall:

$0.2 \gamma H<P_{a}>0.4 \gamma H$

(Murthy, 2002, p. 936)

Similar to cohesionless soils, the FHWA has also provided revised apparent earth pressure diagrams for cohesive soils, taking into account the force of tie-backs. Apparent earth pressure diagrams for temporary excavations are detailed in Figure 54 and Figure 55: 


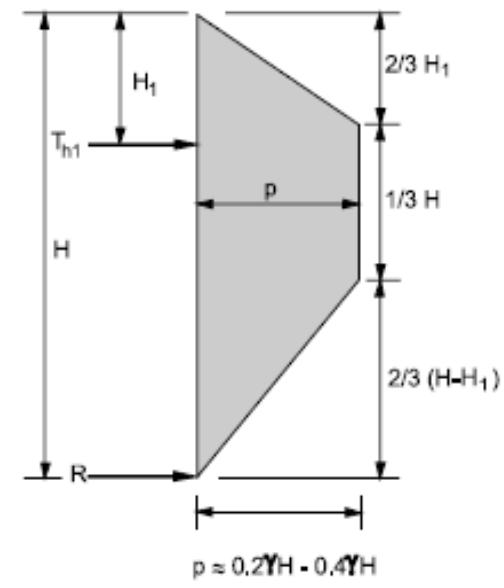

Figure 54: Apparent Earth Pressure Diagram for Temporary Excavations in Stiff to Hard Clays (One Row of Tie-Backs)

(Sabatini et al., 1999, p. 56)

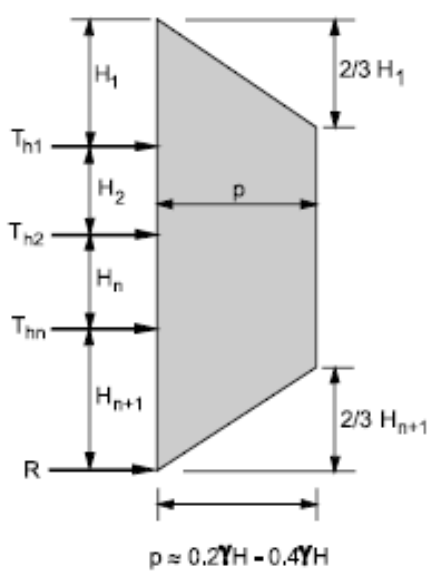

Figure 55: Apparent Earth Pressure Diagram for Temporary Excavations in Stiff to Hard Clays (Multiple Rows of Tie-Backs)

(Sabatini et al., 1999, p. 56)

\subsubsection{Permanent Excavations in Stiff to Hard Clays}

During the excavation of clays, excess negative porewater pressures are induced within the soil. As a result, the soil will exhibit additional shear strength. However, this increase in available shear strength is a temporary condition. Over time, the soils in front of and behind the wall will absorb water and the shear strength of the soil will decrease, leading to an increase in pressures acting on the wall. The total resultant force of the soil acting on the wall is equal to:

$0.65 K_{A} \gamma H^{2}$

(Sabatini et al., 1999, p. 56)

For purposes of calculating the active earth pressure coefficient, the friction angle (drained or fully softened) that produces the maximum pressure ordinate should be used.

\subsubsection{Excavations in Soft to Medium Clays}

For temporary or permanent excavations in soft to medium clays, the apparent earth pressure is assumed to increase linearly from zero to the maximum pressure over the upper quarter of the exposed wall. It then remains constant over the remaining area of the wall as shown in Figure 55. The maximum apparent earth pressure may be estimated according to the equation: 
$P_{a}=\gamma H-4 S_{u}$

(Murthy, 2002, p. 936)

However, if soft clay is present below the bottom of the exposed wall, this equation must be modified to account for the potential for instability:

$P_{a}=K_{a} \gamma H$

where:

$K_{a}=1-m \frac{4 S_{u}}{\gamma H}$

where:

$m=0.4$ if there is an underlying layer of soft clay, otherwise, $m=1$

It should be noted that the above equation only applies when the stability number is less than 6 . Otherwise, the above equation will not be conservative.

(Sabatini et al., 1999, p. 57)

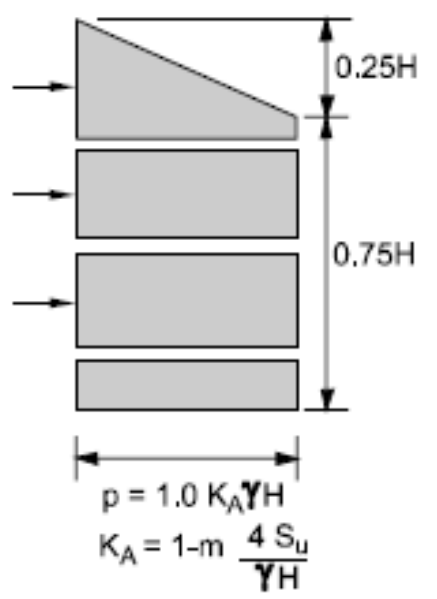

Figure 56: Apparent Earth Pressure Diagram for Excavations in Soft-Medium Clays

(Sabatini et al., 1999, p. 50) 
The coefficient of active earth pressure was modified by Henkel in 1971 to account for the possibility of deep seated failure in soft clays below the wall (Figure 57) (Sabatini et al., 1999, p. 48). A comparison of Henkel's stability numbers to those developed by Terzaghi and Peck is shown in Figure 58. For shoring walls installed in soft to medium clays with a stability number equal to or greater than 5.14 , Henkel's equation should be used:

$K_{a}=1-\frac{4 S_{u}}{\gamma H}+2 \sqrt{2} \frac{d}{H}\left(1-\frac{5.14 S_{u b}}{\gamma H}\right)$

(Sabatini et al., 1999, p. 58)

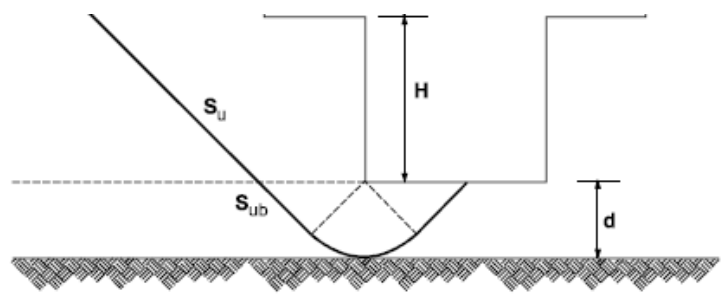

Figure 57: Henkel Failure for a Soft Clay Layer Extending Below the Base of a Shoring Wall

(Sabatini et al., 1999, p. 56)

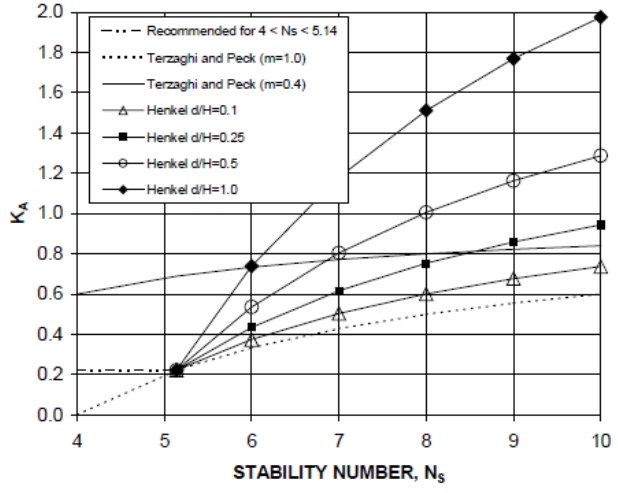

Figure 58: Comparison of Henkel's Stability Numbers to those Developed by Terzaghi and Peck

(Sabatini et al., 1999, p. 59)

For more complex conditions, such as stratified soils, or complicated surcharges, it may be necessary to perform limit equilibrium calculations (Sabatini et al., 1999, p. 49). This method is based on the assumption that a soil wedge will fail along a slip plane as shown in Figure 59. Considering the free body diagram of a soil wedge behind the shoring wall (Figure 60), the total resisting force can be calculated using the equation:

$P_{\text {req }}=\frac{1}{2} \gamma H^{2}\left[\frac{\left(1+\frac{d}{H}\right)^{2}}{\tan (\alpha)}-K_{p}\left(\frac{d}{H}\right)^{2}\left(\sin (\delta)+\frac{\cos (\delta)}{\tan (\alpha-\phi)}\right)\right] \tan (\alpha-\phi)$

(Sabatini et al., 1999, p. 61) 


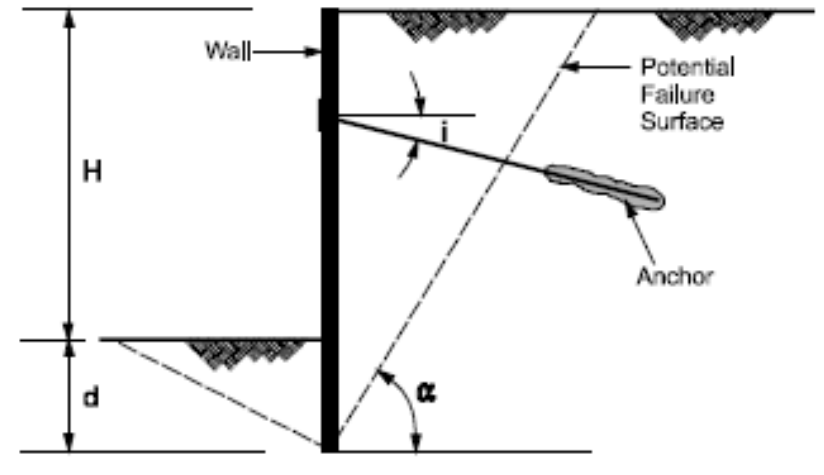

Figure 59: Failure of a Soil Wedge behind a Shoring Wall with One Row of Tie-Backs

(Sabatini et al., 1999, p. 61)

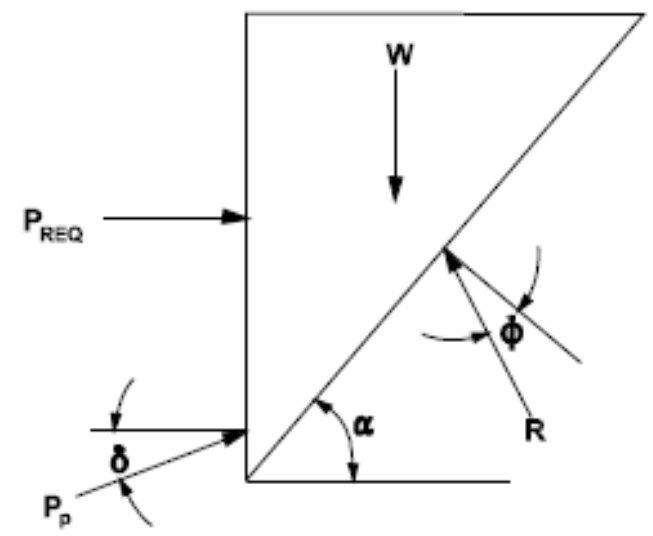

Figure 60: Free-Body Diagram of a Soil Wedge behind a Shoring Wall with One Row of TieBacks

(Sabatini et al., 1999, p. 61)

\subsubsection{Surcharge Loads:}

Surcharge loads applied behind a shoring wall will lead to an increase in lateral earth pressure loads applied to the retaining system. These loads may include dead loads such as structures, or live loads such as traffic, construction equipment, or other materials. It is assumed that the increase in lateral stress will be uniform over the entire height of the wall. As a result, the additional lateral stress may be calculated by multiplying vertical surcharge load by the lateral earth pressure coefficient (Sabatini et al., 1999, p. 64).

\subsubsection{Water Pressure:}

One of the primary assumptions when estimating lateral earth pressures was that the wall would not be subjected to any groundwater forces. Generally, to prevent the buildup of hydrostatic pressure behind the wall, horizontal and vertical drains are incorporated into the design (Sabatini et al., 1999, p. 120).

Depending on the type of shoring or retaining wall, there are a variety of drainage systems that may be used. If the construction sequence permits, prefabricated drainage elements may be installed directly between the wall and the soil as shown in Figure 61 (ABG Geosynthetics, n.d.). For a cast-in-place concrete wall constructed in front of temporary shoring, prefabricated drainage elements can also be installed between the two walls. For shotcrete shoring walls, the drainage elements may be attached directly to the soil behind the wall using nails. Alternately, if 
precast concrete facing is installed in front of the shoring, the space between the facing and the shoring wall can be filled a porous material such as gravel. A typical gravel drain behind a retaining wall is shown in Figure 62. Gravel behind the wall will allow water to drain freely to the bottom of the structure, where it can be removed using collector piles in conjunction with outlet pipes and weep-holes (Sabatini et al., 1999, p.120). For locations that experience large groundwater flows, hydrostatic pressures can be controlled by installing perforated, horizontal drains in the soil behind the wall. The drains should extend beyond the critical failure surface of the soil and should be spaced horizontally and vertically as required to relieve water pressures (Sabatini et al., 1999, p.121).

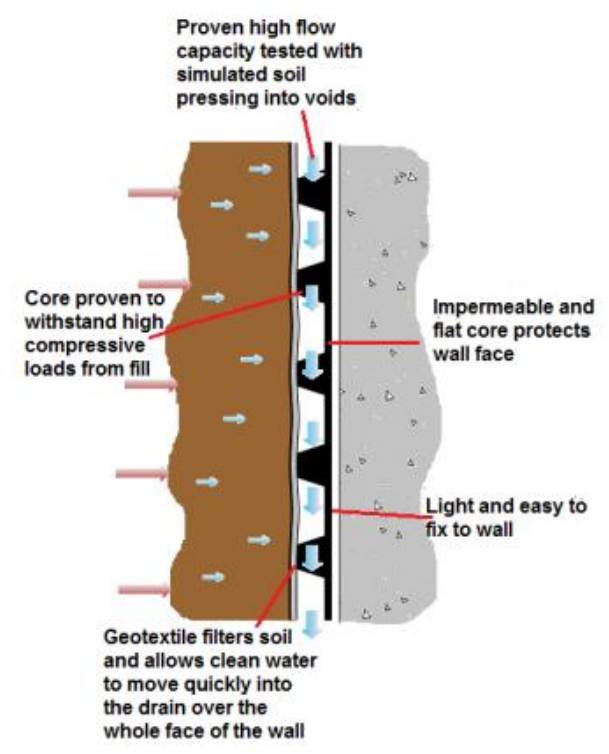

Figure 61: Prefabricated Drainage Element

(ABG Geosynthetics, n.d.)

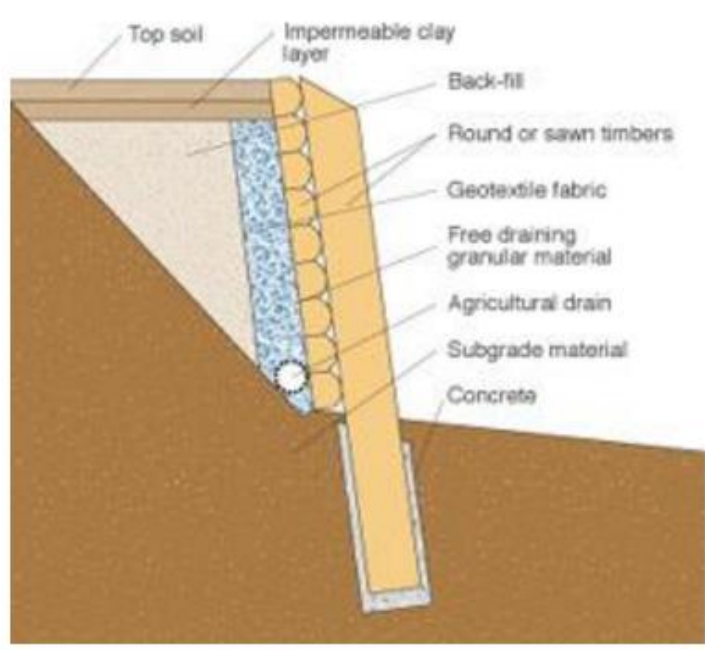

Figure 62: Granular Material with Drain behind Retaining Wall

(Australian Hardwood Network, n.d.)

In some cases (such as temporary shoring systems), a drainage system may not be installed and porewater pressures must be considered. The Federal Highway Administration suggests that porewater pressures may be estimated by assuming that a pressure head will be dissipated in a uniform manner along the shortest potential flow path as illustrated by in Figure 63 (Sabatini 
et al., 1999, p. 62). Gross and net water pressures acting upon a shoring wall are shown in Figures 64 and 65.

The porewater pressure at the base of the shoring wall must be equal on both sides of the wall. This pressure can be calculated by the equation:

$U_{f}=\frac{2(d+H-j)(d-i)}{2 d+H-i-j} \gamma_{w}$

(Sabatini et al., 1999, p. 62)

From Figure 62, it is clear that the maximum net water pressure $\left(U_{c}\right)$ will occur behind the shoring wall, located at the same level as the water on the excavated side of the wall. The maximum net water pressure may be calculated according to the equation:

$U_{c}=(H+i-j) \frac{2(d-i)}{2 d+H-i-j} \gamma_{w}$

(Sabatini et al., 1999, p. 62)

If there is no seepage, the net water pressure may be calculated using the equation:

$$
U_{n}=(H+i-j) \gamma_{w}
$$

(Sabatini et al., 1999, p. 63)

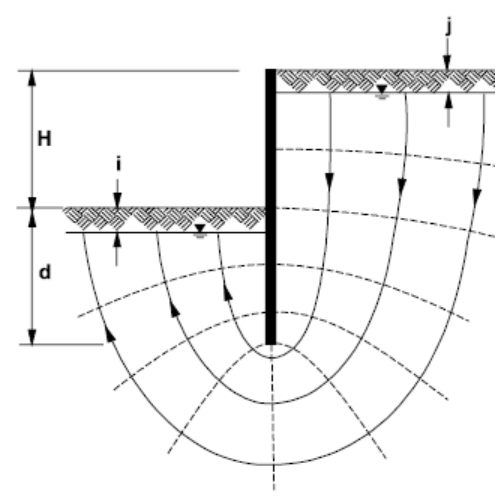

Figure 63: Groundwater Flow around a Shoring Wall

(Sabatini et al., 1999, p. 62) 


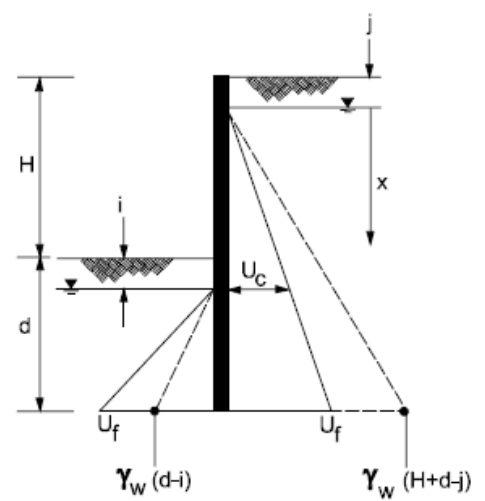

Figure 64: Gross Water Pressure

(Sabatini et al., 1999, p. 63)

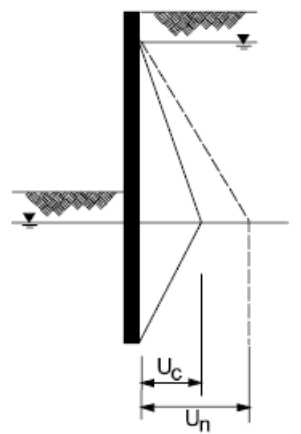

Figure 65: Net Water Pressure

(Sabatini et al., 1999, p. 64)

\subsection{Ground Anchor Design}

\subsubsection{Soil Failure Plane}

The first step in designing tie-backs for a shoring wall is to locate the failure plane for the soil wedge located behind the shoring wall. Tie-backs must be installed behind the failure plane, otherwise as the soil wedge fails, so will the tie-backs. The Federal Highway Administration recommends that the critical failure plane be located in accordance with the free body analysis as shown in Figure 57. In lieu of more detailed calculations, the critical failure surface for cohesionless soils may be assumed to extend from the corner of the excavation at an angle of:

$45+\frac{\phi^{\prime}}{2}$

(Sabatini et al., 1999, p. 65)

\subsubsection{Ground Anchor Loads}

Ground anchor loads may be calculated based on the apparent earth pressure envelopes. The Federal Highway Administration has recommended two design methods that may be used to estimated ground anchor loads: Tributary Area Method or Hinge Method.

Although an indeterminate problem, both methods allow for simplified hand calculations to provide acceptable estimates of ground anchor loads and maximum bending moments within the shoring wall. Both methods assume a strut support and zero bending moments at the top of the subgrade, and the maximum bending moment occurs in the exposed portion of the wall 
(Sabatini et al., 1999, p. 65). The Tributary Area Method is shown in Figure 66 for a single row of tie-backs and in Figure 67 for multiple rows of tie-backs. Similarly, the Hinge Method is shown for both a single row of tie-backs Figure 68 and multiple rows of tie-backs Figure 69.

Assuming the shoring wall is installed in a competent soil material, both methods assume that the reaction force of the subgrade is developed through the passive resistance of the soil below the excavation. It is assumed that the passive resistance of the subgrade resists all apparent pressure loads below a line half way between the lowest tieback and the bottom of the excavation. For shoring walls where the subgrade does provide sufficient passive resistance, the additional load may be picked up by the lowest level of tie-backs (Sabatini et al., 1999, p. 66).

The total ground anchor load is calculated using the equation:

$T=\frac{T_{h}}{\cos \theta}$

(Sabatini et al., 1999, p. 66)

where:

$T_{h}=T_{h i} S$

and:

$T_{v}=T \sin \theta$

(Sabatini et al., 1999, p. 67) 


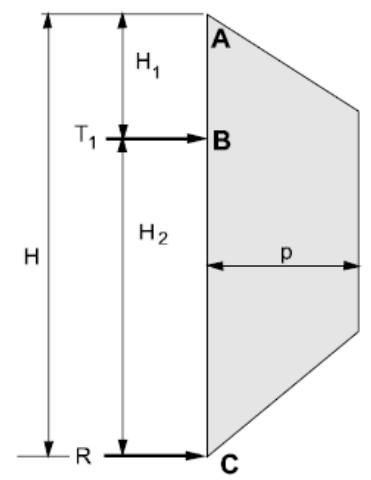

Tributary area method

$T_{1}=$ Load over length $\mathrm{H}_{1}+\mathrm{H}_{2} / 2$

$\mathrm{R}=$ Load over length $\mathrm{H}_{2} / 2$

Figure 66: Tributary Area Method for a Single Row of Tie-Backs

(Sabatini et al., 1999, p. 66)

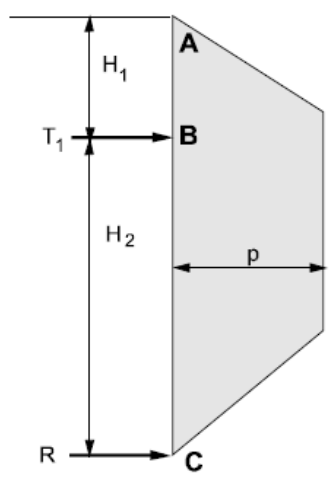

Hinge method

$\mathrm{T}_{1}$ Calculated from $\boldsymbol{\Sigma} \mathrm{M}_{\mathrm{C}}=0$

$R=$ Total earth pressure $-T_{1}$

Figure 68: Hinge Method for a Single Row of TieBacks

(Sabatini et al., 1999, p. 66)

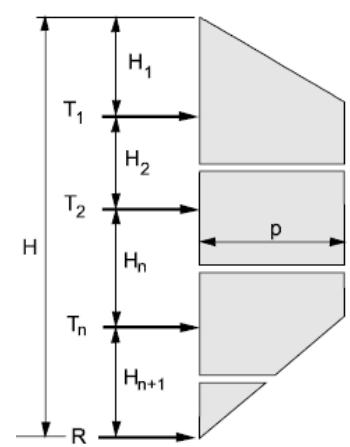

Tributary area method

$T_{1}=$ Load over length $\mathrm{H}_{1}+\mathrm{H}_{2} / 2$

$T_{2}=$ Load over length $\mathrm{H}_{2} / 2+\mathrm{H}_{\mathrm{n}} / 2$

$T_{n}=$ Load over length $H_{n} / 2+H_{n+1} / 2$

$R=$ Load over length $H_{n+1} / 2$

Figure 67: Tributary Area Method for Multiple Rows of Tie-Backs

(Sabatini et al., 1999, p. 67)

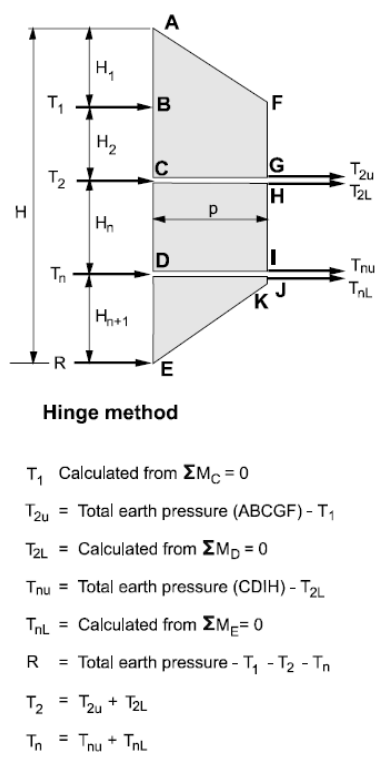

Figure 69: Hinge Method for Multiple Rows of TieBacks

(Sabatini et al., 1999, p. 67) 


\subsubsection{Unbonded Length of Ground Anchors}

The unbonded length of a ground anchor must be designed to prevent load reductions due to seating losses during stressing of the tie-backs and creep in the steel or soils (Sabatini et al., 1999, p. 70). According to the FHWA the unbonded length of the tie-back should extend a minimum of 1.5 metres, or $20 \%$ of the height of the shoring wall, beyond the failure plane (Sabatini et al., 1999, p. 65). At a minimum, the ground anchor unbonded length should be at least 3 metres for bar tendons and 3.5 metres for strand tendons. However, it should be noted that longer unbonded lengths may be required to locate the bonded length within appropriate soils behind the soil failure plane. The bonded length must also be located to accommodate long term movements and ensure the stability of the entire shoring system (Sabatini et al., 1999, p. 68).

\subsubsection{Bonded Length of Ground Anchors}

The capacity of a ground anchor depends on a variety of field specific conditions including:

- Length of anchor bond zone;

- Method of drilling;

- Drill hole diameter;

- Quality of drill hole;

- Cleaning of drill hole;

- Time drill hole is left open;

- Grouting method;

- Grout pressure.

The Federal Highway Administration recommends that for preliminary design purposes, a ground anchor should be installed at an inclination of 15 degrees, with an assumed bonded length of 12 metres in soil or 7.5 metres in rock. If the bonded length extends through both rock and soil, the more conservative length of 12 metres should be chosen. If the above bonded lengths cannot be achieved, ground anchors are typically installed at angles up to 30 degrees, with the anchor ending at a distance of 0.6 metres from the limits of the right-of-way. In practice, ground anchor angles of 10 to 45 degrees are possible (Sabatini et al., 1999, p. 70). After determining the required bonded length, it is imperative that the check that the required unbonded length can still be achieved (Sabatini et al., 1999, p. 71). 


\subsubsection{Ultimate Transfer Loads in Soil}

Estimated ultimate transfer loads for various soils types are summarized in Table 14. To calculate the allowable anchor design load, the ultimate transfer load is multiplied by the bonded length of the ground anchor. A factor of safety of 2 should be used when calculating the maximum allowable load (Sabatini et al., 1999, p. 71). In practice, drill holes ranging from 150 $\mathrm{mm}$ to $300 \mathrm{~mm}$ in diameter (Sabatini et al., 1999, p. 70) and anchor bond lengths of 4.5 metres to 12 metres are typical (Sabatini et al., 1999, p. 71). However, given the number of site specific factors that may affect the capacity of a ground anchor, the capacity of each anchor must be field tested and verified before any anchor is accepted (Sabatini et al., 1999, p. 70).

\begin{tabular}{|l|c|c|}
\hline \multicolumn{1}{|c|}{ Soil type } & $\begin{array}{c}\text { Relative density/Consistency } \\
\text { (SPT range) }\end{array}$ & $\begin{array}{c}\text { Estimated ultimate transfer load } \\
(\mathrm{kN} / \mathrm{m})\end{array}$ \\
\hline \multirow{3}{*}{ Sand and Gravel } & Loose (4-10) & 145 \\
& $\begin{array}{c}\text { Medium dense (11-30) } \\
\text { Dense (31-50) }\end{array}$ & 220 \\
\hline Sand & Loose (4-10) & 290 \\
\hline Sand and Silt & Medium dense (11-30) & 100 \\
& Dense (31-50) & 145 \\
& Loose (4-10) & 70 \\
\hline Silt-clay mixture with low & Medium dense (11-30) & 100 \\
plasticity or fine micaceous sand & Dense (31-50) & 130 \\
or silt mixtures & Stiff (10-20) & 30 \\
& Hard (21-40) & 60 \\
\hline
\end{tabular}

Note: (1) SPT values are corrected for overburden pressure.

Table 14: Estimated Ultimate Transfer Load for a Variety of Soil Types

(Sabatini et al., 1999, p. 71)

\subsubsection{Ultimate Transfer Loads in Rock}

Rock anchors will generally have an anchor bond length between 3 metres and 10 metres. Typical ultimate transfer loads for sound rock are shown in Table 15. Lower ultimate transfer loads should be considered if the rock is known to have discontinuities. Due to the potential for joints, fractures, and fissures with a rock mass, a factor of safety of 3 is recommended when calculating the capacity of a rock anchor. The factor of safety may be reduced to 2 if the rock 
anchors are installed in weak rocks, such as clay shale, with compressive strengths less than 5 MPa (Sabatini et al., 1999, p. 74).

\begin{tabular}{|c|c|}
\hline Rock type & $\begin{array}{c}\text { Estimated ultimate transfer load } \\
(\mathrm{kN} / \mathrm{m})\end{array}$ \\
\hline Granite or Basalt & 730 \\
\hline Dolomitic Limestone & 580 \\
\hline Soft Limestone & 440 \\
\hline Sandstone & 440 \\
\hline Slates and Hard Shales & 360 \\
\hline Soft Shales & 150 \\
\hline
\end{tabular}

Table 15: Estimated Ultimate Transfer Load for a Variety of Rock Types

(Sabatini et al., 1999, p. 74)

\subsubsection{Ground Anchor Spacing}

When designing ground anchors, it is assumed that each anchor carries a load associated with a tributary area according to the spacing of the anchors. Ground anchor spacing is a function of the required shoring wall performance including:

- Maximum lateral movements of the shoring system;

- Existing underground structures;

- Vertical wall elements chosen during design.

The position of the top ground anchor is chosen based on the allowable deformation of the cantilevered portion of the shoring wall above the anchor. This anchor must also be located to minimize the risk of ground heave during proof testing, where the anchor is typically stressed to $133 \%$ of the design load. For gravity grouted anchors, the top anchor must be installed at depth that will provided sufficient overburden to develop the required anchor capacity. For pressure grouted anchors, a minimum depth of $4.5 \mathrm{~m}$ is recommended to prevent ground heave or grout leakage during installation (Sabatini et al., 1999, p. 76). 
The Federal Highway Administration recommends a minimum horizontal ground anchor spacing of 1.2 metres to prevent crossing of anchors due to drilling deviations and to minimize group affects between adjacent ground anchors. The flexural capacity of soldier beams must also be taken into account when choosing ground anchor spacing. A horizontal soldier pile spacing of up to 3 metres is typical (Sabatini et al., 1999, p. 76).

\subsubsection{Prestressing Steel}

The last step when designing ground anchors is to select the prestressing steel. As a factor of safety against tendon failure, the Federal Highway Administration recommends that the design load does not exceed $60 \%$ of the steel's specified minimum tensile strength, the lock-off load does not exceed $70 \%$ of the specified minimum tensile strength, and the test load does not exceed $80 \%$ of the specified minimum tensile strength (Sabatini et al., 1999, p. 77). Properties of $15 \mathrm{~mm}$ diameter, ASTM A416, Grade 270 prestressing strands are shown in Table 16:

\begin{tabular}{|c|c|c|c|c|c|c|c|c|c|c|}
\hline \multirow[t]{3}{*}{$\begin{array}{c}\text { Number of } 15-\mathrm{mm} \\
\text { diameter strands }\end{array}$} & \multicolumn{2}{|c|}{ Cross section area } & \multicolumn{2}{|c|}{$\begin{array}{l}\text { Ultimate } \\
\text { strength }\end{array}$} & \multicolumn{6}{|c|}{ Prestressing force } \\
\hline & \multirow[b]{2}{*}{$\left(\right.$ in. $\left.^{2}\right)$} & \multirow[b]{2}{*}{$\left(\mathrm{mm}^{2}\right)$} & \multirow[b]{2}{*}{ (kips) } & \multirow[b]{2}{*}{$(\mathrm{kN})$} & \multicolumn{2}{|c|}{$0.8 \mathrm{f}_{\mathrm{pu}} \mathrm{A}_{\mathrm{ps}}$} & \multicolumn{2}{|c|}{$0.7 f_{p u} A_{p s}$} & \multicolumn{2}{|c|}{$0.6 f_{p u} A_{p s}$} \\
\hline & & & & & (kips) & $(\mathrm{kN})$ & (kips) & $(\mathrm{kN})$ & (kips) & $(\mathrm{kN})$ \\
\hline 1 & 0.217 & 140 & 58.6 & 260.7 & 46.9 & 209 & 41.0 & 182 & 35.2 & 156 \\
\hline 3 & 0.651 & 420 & 175.8 & 782.1 & 140.6 & 626 & 123.1 & 547 & 105.5 & 469 \\
\hline 4 & 0.868 & 560 & 234.4 & 1043 & 187.5 & 834 & 164.1 & 730 & 140.6 & 626 \\
\hline 5 & 1.085 & 700 & 293.0 & 1304 & 234.4 & 1043 & 205.1 & 912 & 175.8 & 782 \\
\hline 7 & 1.519 & 980 & 410.2 & 1825 & 328.2 & 1460 & 287.1 & 1277 & 246.1 & 1095 \\
\hline 9 & 1.953 & 1260 & 527.4 & 2346 & 421.9 & 1877 & 369.2 & 1642 & 316.4 & 1408 \\
\hline 12 & 2.604 & 1680 & 703.2 & 3128 & 562.6 & 2503 & 492.2 & 2190 & 421.9 & 1877 \\
\hline 15 & 3.255 & 2100 & 879.0 & 3911 & 703.2 & 3128 & 615.3 & 2737 & 527.4 & 2346 \\
\hline 19 & 4.123 & 2660 & 1113.4 & 4953 & 8907 & 3963 & 7794 & 3467 & 6680 & 2972 \\
\hline
\end{tabular}

Table 16: Properties of 15 mm Diameter Prestressing Strands (ASTM A416, Grade 270)

(Sabatini et al., 1999, p. 78)

\subsection{Shoring Wall Design:}

Anchored shoring walls develop lateral resistance through both ground anchors and the passive soil resistance of embedded portion of the wall. Throughout construction, the wall is subjected to a variety of conditions:

1) At the beginning of excavation, before any tie-backs are installed, the shoring system acts as a cantilever and develops lateral resistance through the passive resistance of the soil along the buried portion of the wall; 
2) As excavation continues and tie-backs are installed, the tie-backs begin to provide lateral resistance. The wall only relies on the passive resistance of the soil until the next row of tiebacks is installed;

3) Once all tie backs are installed, the tie-backs provide most of the lateral resistance. The soil in front of the wall only provides resistance for the active earth pressures acting just above the bottom of the excavation and the active pressures acting along the embedded portion of the wall (Sabatini et al., 1999, p. 84).

Typically, an engineer will only need to consider the forces acting within the wall after construction. However, for the following cases, additional analysis may be required at each stage of construction:

- Shoring wall design is based on triangular earth pressure diagrams;

- Contractor is permitted to excavate a significant distance beyond the previous level of ground anchors prior to stressing those anchors;

- The soil below each stage of excavation is unable to provide the required passive resistance for the excavated height;

- The hydrostatic pressure behind the shoring wall is maintained using a cut-off wall;

- There are structures supported by the shoring wall.

(Sabatini et al., 1999, p. 81)

\subsubsection{Moment Resistance of Soldier Piles:}

Soldier piles must be design to resist all loads acting upon the tributary area for each pile (Sabatini et al., 1999, p. 79). Using the tributary method, maximum bending moments within a soldier pile may be calculated by summing all moments acting upon the pile as shown in Figures 70 and 71 . Based on the tributary method, the maximum positive moment within the exposed portion of a soldier pile, between any two rows of tie-backs, may be calculated using the equation:

$M_{\max }=\frac{1}{10} p l^{2}$

(Sabatini et al., 1999, p. 79) 
For the hinge method, the maximum bending moment between two ground anchors can be found by calculating the bending moment within the pile at the location of zero shear (Sabatini et al., 1999, p. 79).

It should be noted that for shoring walls embedded in weak materials, the maximum bending moment may be located within the embedded portion of the wall (Sabatini et al., 1999, p. 79).

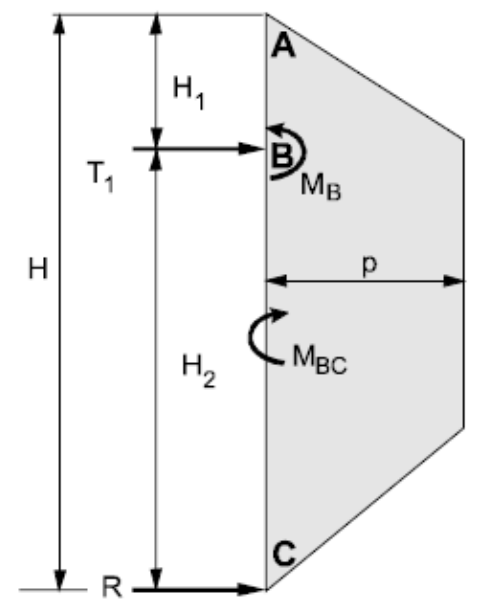

Figure 70: Calculation of Maximum Bending Moment within Soldier Piles for a Single Row of Tie-Backs

(Sabatini et al., 1999, p. 79)

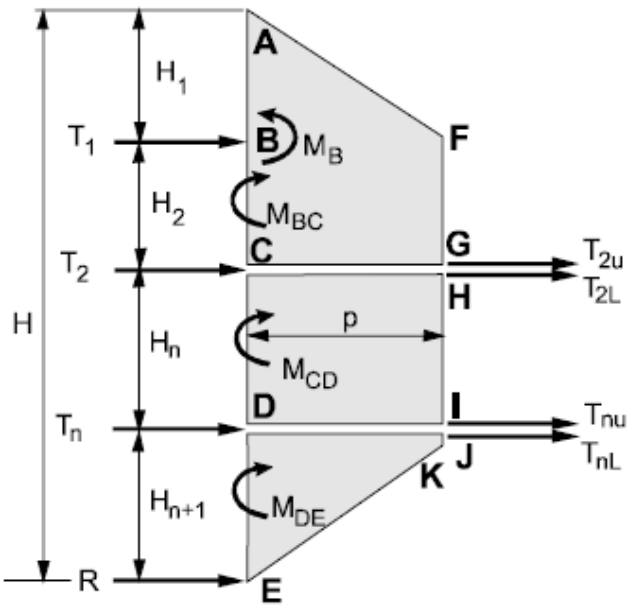

Figure 71: Calculation of Maximum Bending Moment within Soldier Piles for Multiple Rows of Tie-Backs

(Sabatini et al., 1999, p. 79)

It is recommended that the allowable bending stress in any soldier pile does not exceed $55 \%$ of the steel yield stress. The required section modulus of a solider pile can be calculated using the equation:

$S_{\text {req }}=\frac{M_{\max }}{F_{b}}$

(Sabatini et al., 1999, p. 81)

\subsubsection{Lateral Resistance of Embedded Piles}

The embedded end of a soldier piles provides a reaction force that resists pressures applied to the lower portion of the shoring wall. Engineers typically use the equations developed by Broms (1965) to estimate the capacity of laterally loaded piles. For piles embedded in cohesionless 
soils (Figure 72), or cohesive soils under drained conditions, Broms assumed that passive soil resistance increases with depth and is developed over three times the width of the soldier pile. The magnitude of resistance is a function of Rankine's passive earth pressure coefficient (Sabatini et al., 1999, p. 84). According to Broms, the passive soil resistance of piles installed in cohesive soils (Figure 73) is constant over the entire depth of the pile. The magnitude of resistance is equal to nine times the undrained shear strength of the pile (Sabatini et al., 1999, p. 84). However, it is assumed that no passive resistance is provided by the first 1.5 pile widths below the bottom of the excavation (Sabatini et al., 1999, p. 85). A factor of safety of 1.5 should be used when calculating the lateral resistance of an embedded pile (Sabatini et al., 1999, p. 86).

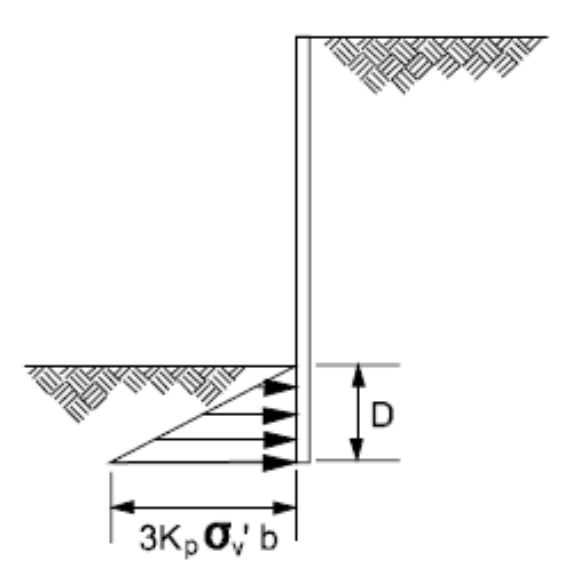

Figure 72: Broms' Method for Calculating Passive Resistance in Cohesionless, or Drained Cohesive Soils

(Sabatini et al., 1999, p. 86)

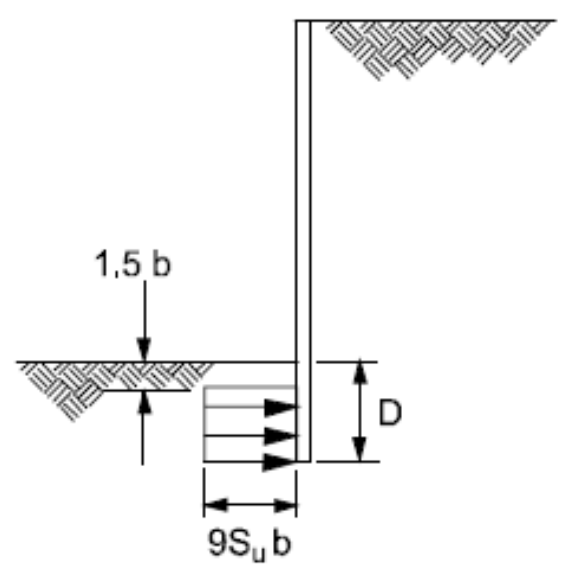

Figure 73: Broms' Method for Calculating Passive Resistance in Undrained Cohesive Soils

(Sabatini et al., 1999, p. 86)

For piles embedded in weak soils, such as loose sands or soft clays (with a stability number greater than four), no passive soil resistance can be assumed. In this case, the bottom of the pile, below the lowest level of ground anchors, should be assumed to behave as a cantilever. In addition, the embedment depth of the piles should not exceed $20 \%$ of the total height of the excavation, unless otherwise necessary to provide resistance to vertical loading (Sabatini et al., 1999, p. 87). 


\subsubsection{Axial Capacity of Soldier Piles:}

In addition to lateral loads, soldier piles must also be designed to resist vertical loads (Sabatini et al., 1999, p. 88). Typical vertical loads acting upon soldier piles include:

- Shoring wall dead loads;

- Vertical component of ground anchors;

- Surcharge loads acting upon the retained soil;

- Downdrag due to settlement of the retained soil.

(Sabatini et al., 1999, p. 89)

For both driven and drilled piles, ultimate pile capacity may be calculated using the equation:

$Q_{u l t}=f_{s} A_{s}+q_{t} A_{t}$

(Sabatini et al., 1999, p. 90)

\subsubsection{Driven Piles in Cohesionless Soils and Analysis under Drained Conditions}

For solider piles driven into cohesionless soils, or for long term, drained analysis of solider piles driven into cohesionless soils, the unit skin resistance is calculated using the equation:

$f_{s}=\beta p_{o}$

(Sabatini et al., 1999, p. 90)

The beta coefficient, above, may be estimated from Figure 74 and the average vertical stress (acting along the pile for uniform soils) can be calculated from the equation:

$p_{o}=0.5 H \gamma+0.5 d \gamma$

The end bearing resistance of the pile is determined using the equation:

$q_{t}=N_{t} p_{t}$

(Sabatini et al., 1999, p. 91)

The toe bearing coefficient is a function of the friction angle of the soil and may be estimated from Figure 75 below: 


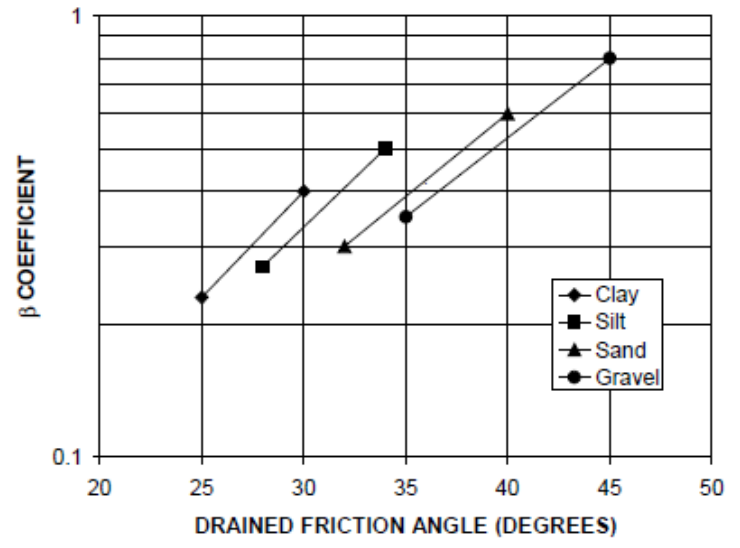

Figure 74: Relationship between the Beta Coefficient and Drained Friction Angle as Proposed by Fellenius in 1991

(Sabatini et al., 1999, p. 91)

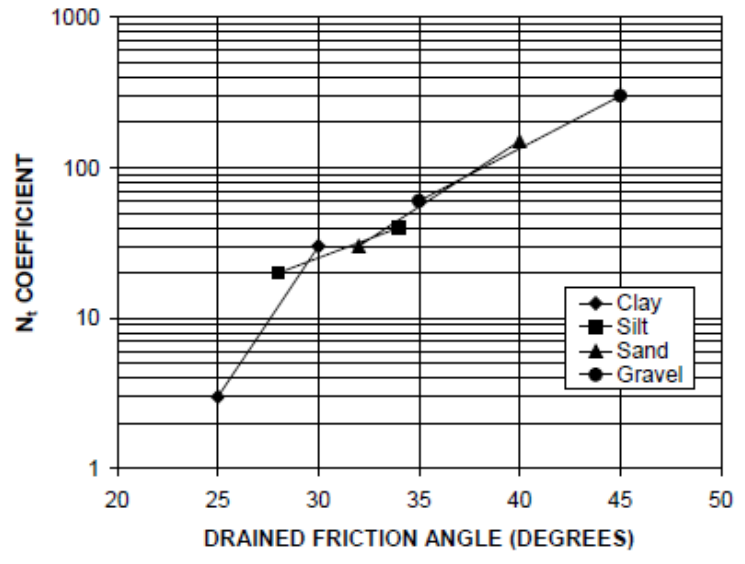

Figure 75: Relationship between Toe Bearing Coefficient and Drained Friction Angle as Proposed by Fellenius in 1991

(Sabatini et al., 1999, p. 92)

When calculating the skin friction and end bearing resistance for piles installed in sand, a factor of safety of 2.0 and 2.5, respectively, is recommended (Sabatini et al., 1999, p. 90).

\subsubsection{Driven Piles in Cohesive Soils and Analysis under Undrained Conditions}

For soldier piles driven into cohesive soils, the unit shaft resistance is equal to the soil-pile adhesion at failure (Figure 76) and is based on the adhesion factor and undrained shear strength of the clay:

$f_{s}=c_{a}=\alpha S_{u}$

(Sabatini et al., 1999, p. 92)

The end bearing resistance for a pile driven in cohesionless soils can be calculated using the equation:

$q_{t}=S_{u} N_{c}$

For anchored walls, a value of 9 should be used for the bearing capacity factor (Sabatini et al., 1999, p. 92). 


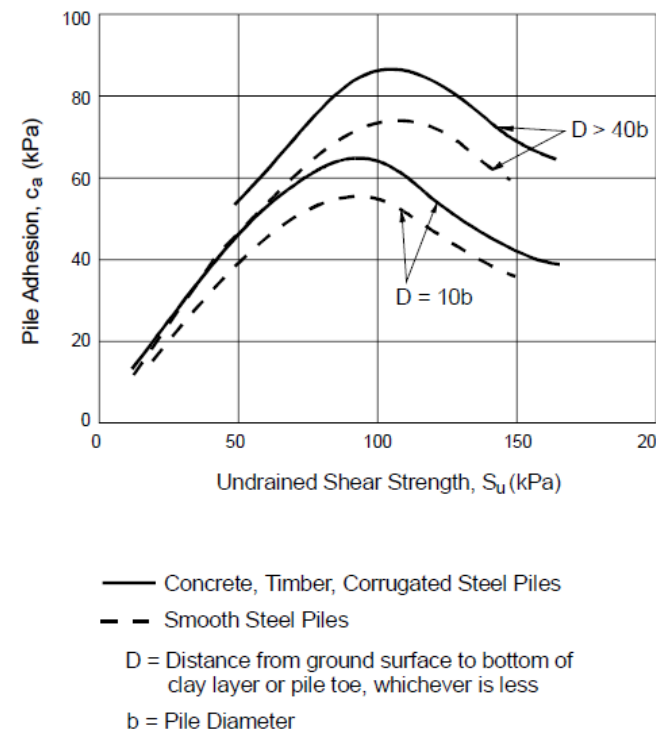

Figure 76: Soil-Pile Adhesion at Failure as Proposed by Thompson in 1980

(Sabatini et al., 1999, p. 93)

For piles installed in clay, a factor of safety of 2.5 should be used when calculated both skin friction and end bearing capacity (Sabatini et al., 1999, p. 90).

\subsubsection{Drilled Piles in Cohesionless Soils and Analysis under Drained Conditions}

Similar to piles driven in cohesionless materials, the skin friction for drilled piles installed in cohesionless soils, or for the long term, drained analysis of piles in cohesive soils, may be calculated using the equation:

$f_{s}=\beta p_{o}$

(Sabatini et al., 1999, p. 94)

However, in this case, the beta factor is dependent on the soil properties (Table 17) and also takes into account the soil stress changes as a result of the drilling, the affects of fluid concrete on the soil, and the friction between the concrete and the soil. If the pile passes through multiple soil layers, the beta factor should be considered at the midpoint of each layer (Sabatini et al., 1999, p. 94). 


\begin{tabular}{|l|l|}
\hline $\begin{array}{l}\text { Sands with SPT N values } \geq 15 \text { blows per } \\
300 \mathrm{~mm}\end{array}$ & $\beta=1.5-0.42 z^{0.34}, 0.25 \leq \beta \leq 1.2$ \\
\hline $\begin{array}{l}\text { Sands with SPT N values }<15 \text { blows per } \\
300 \mathrm{~mm}\end{array}$ & $\beta=N / 15\left(1.5-0.42 z^{0.34}\right)$ \\
\hline Gravelly Soils & $\beta=2.0-0.15 z^{0.75}$ \\
\hline
\end{tabular}

Table 17: Beta Factors for Drilled Piles in Cohesionless Soils

(Sabatini et al., 1999, p. 94)

For drilled piles in cohesionless soils, the end bearing resistance may be calculated using the equation:

$q_{t}=57.5 \mathrm{~N}$

(Sabatini et al., 1999, p. 94)

\subsubsection{Drilled Piles in Cohesive Soils and Analysis under Undrained Conditions}

Similar to piles driven in cohesive materials, the skin friction for drilled piles may be calculated using the equation:

$f_{s}=\alpha S_{u}$

(Sabatini et al., 1999, p. 94)

In this case, the adhesion factor is calculated using the equation:

$\alpha=0.29+0.19 \frac{S_{u}}{p_{o}}$

(Sabatini et al., 1999, p. 94)

For drilled piles, the end bearing resistance is dependent on the depth of the pile base. For pile tips located more than five pile widths below the bottom of the excavation, the following equation may be used:

$q_{t}=S_{u} N_{c}$

(Sabatini et al., 1999, p. 94) 
For pile tips located less than five pile widths below the bottom of the excavation, end bearing resistance may be calculated by the equation:

$q_{t}=\left(0.667+0.667\left(\frac{d}{B}\right) N_{c} S_{u}\right.$

(Sabatini et al., 1999, p. 95)

In both cases, the bearing capacity factor is related to the undrained shear strength of the soil as specified by Table 18, below:

\begin{tabular}{|c|c|}
\hline $\mathrm{S}_{\mathrm{u}}(\mathrm{kPa})$ & $\mathrm{N}_{\mathrm{c}}$ \\
\hline \hline 24 & 6.5 \\
\hline 48 & 8.0 \\
\hline 96 & 8.7 \\
\hline$>96$ & 9.0 \\
\hline
\end{tabular}

Table 18: Bearing Capacity Factors for End Bearing Resistance of Drilled Piles in Cohesive Soils (Sabatini et al., 1999, p. 95)

\subsubsection{Design of Timber Lagging and Permanent Facing}

Timber lagging, wales, and permanent facing between the soldier piles must be designed to resist forces applied to the shoring wall. Based on experience, the Federal Highway Administration recommends timber lagging ranging in thickness from $50 \mathrm{~mm}$ to $150 \mathrm{~mm}$ depending on the soil type and depth of retaining wall (Table 19).

Permanent concrete facing is typically $200 \mathrm{~mm}$ to $300 \mathrm{~mm}$ thick and must be able to accommodate some deviations in the location of solider piles. The maximum bending moment in a 1 metre tall section of permanent facing installed between soldier piles can be calculated using the following equations:

No soil arching (soft cohesive soils, or where rigid facing is placed tightly against soils):

$M_{f}=\frac{p s^{2}}{8}$ 
Soil arching (granular or stiff clay soils, flexible facing, or rigid facing installed with space for soil to $\operatorname{arch}$ ):

$M_{f}=\frac{p s^{2}}{12}$

(Sabatini et al., 1999, p. 83)

\begin{tabular}{|c|c|c|c|c|c|c|c|c|c|}
\hline & \multirow[t]{2}{*}{ Soil Description } & \multirow{2}{*}{$\begin{array}{l}\text { Unified Soil } \\
\text { Classification }\end{array}$} & \multirow{2}{*}{$\begin{array}{l}\text { Depth } \\
\text { (m) }\end{array}$} & \multicolumn{6}{|c|}{ Recommended thickness of lagging (roughcut) for clear spans of: } \\
\hline & & & & $1.5 \mathrm{~m}$ & $1.8 \mathrm{~m}$ & $2.1 \mathrm{~m}$ & $2.4 \mathrm{~m}$ & $2.7 \mathrm{~m}$ & $3.0 \mathrm{~m}$ \\
\hline $\begin{array}{l}\text { COMPETENT } \\
\text { SOILS }\end{array}$ & $\begin{array}{l}\text { Silt or fine sand and silt } \\
\text { above water table } \\
\text { Sands and gravels } \\
\text { (medium dense to dense) } \\
\text { Clays (stiff to very stiff); } \\
\text { non-fissured } \\
\text { Clays, medium } \\
\text { consistency and } \frac{\gamma \mathrm{H}}{\mathrm{S}_{\mathrm{u}}}<5\end{array}$ & $\begin{array}{l}\text { ML, SM-ML } \\
\text { GW, GP, GM, } \\
\text { GS, SW, SP, } \\
\text { SM } \\
\text { CL, CH } \\
\text { CL, CH }\end{array}$ & $\begin{array}{l}0-8 \\
8-18\end{array}$ & $\begin{array}{l}50 \mathrm{~mm} \\
75 \mathrm{~mm}\end{array}$ & $\begin{array}{l}75 \mathrm{~mm} \\
75 \mathrm{~mm}\end{array}$ & $\begin{array}{l}75 \mathrm{~mm} \\
75 \mathrm{~mm}\end{array}$ & $\begin{array}{l}75 \mathrm{~mm} \\
100 \mathrm{~mm}\end{array}$ & $\begin{array}{l}100 \mathrm{~mm} \\
100 \mathrm{~mm}\end{array}$ & $\begin{array}{l}100 \mathrm{~mm} \\
125 \mathrm{~mm}\end{array}$ \\
\hline $\begin{array}{l}\text { DIFFICULT } \\
\text { SOILS }\end{array}$ & $\begin{array}{l}\text { Sand and silty sand (loose) } \\
\text { Clayey sands (medium } \\
\text { dense to dense) below } \\
\text { water table } \\
\text { Clay, heavily } \\
\text { overconsolidated, fissured } \\
\text { Cohesionless silt or fine } \\
\text { sand and silt below water } \\
\text { table }\end{array}$ & $\begin{array}{c}\text { SW, SP, SM } \\
\text { SC } \\
\mathrm{CL}, \mathrm{CH} \\
\mathrm{ML}, \mathrm{SM}-\mathrm{SL}\end{array}$ & $\begin{array}{l}0-8 \\
8-18\end{array}$ & $\begin{array}{l}75 \mathrm{~mm} \\
75 \mathrm{~mm}\end{array}$ & $\begin{array}{l}75 \mathrm{~mm} \\
75 \mathrm{~mm}\end{array}$ & $\begin{array}{l}75 \mathrm{~mm} \\
100 \mathrm{~mm}\end{array}$ & $\begin{array}{l}100 \mathrm{~mm} \\
100 \mathrm{~mm}\end{array}$ & $\begin{array}{l}100 \mathrm{~mm} \\
125 \mathrm{~mm}\end{array}$ & $\begin{array}{l}125 \mathrm{~mm} \\
125 \mathrm{~mm}\end{array}$ \\
\hline $\begin{array}{l}\text { POTENTIALLY } \\
\text { DANGEROUS } \\
\text { SOILS }\end{array}$ & $\begin{array}{l}\text { Soft clays } \frac{\gamma \mathrm{H}}{\mathrm{S}_{\mathrm{u}}}>5 \\
\text { Slightly plastic silts below } \\
\text { water table } \\
\text { Clayey Sands (loose), } \\
\text { below water table }\end{array}$ & $\begin{array}{c}\mathrm{CL}, \mathrm{CH} \\
\mathrm{ML} \\
\mathrm{SC}\end{array}$ & $\begin{array}{l}0-5 \\
5-8 \\
8-11\end{array}$ & $\begin{array}{l}75 \mathrm{~mm} \\
75 \mathrm{~mm} \\
100 \mathrm{~mm}\end{array}$ & $\begin{array}{l}75 \mathrm{~mm} \\
100 \mathrm{~mm} \\
125 \mathrm{~mm}\end{array}$ & $\begin{array}{l}100 \mathrm{~mm} \\
125 \mathrm{~mm} \\
150 \mathrm{~mm}\end{array}$ & $\begin{array}{l}125 \mathrm{~mm} \\
150 \mathrm{~mm}\end{array}$ & …- & ㄱ..… \\
\hline $\begin{array}{l}\text { 1) In the } \\
\text { 2) The v } \\
\text { 3) Local }\end{array}$ & $\begin{array}{l}\text { egory of "potentially danger } \\
\text { es shown are based on constr } \\
\text { perience may take precedence }\end{array}$ & $\begin{array}{l}\text { s soils", use of s } \\
\text { tion grade lumb } \\
\text { ver recommend }\end{array}$ & $\begin{array}{l}\text { dier bear } \\
\text { values } i\end{array}$ & $\begin{array}{l}\text { aggin } \\
\text { is table. }\end{array}$ & & stionable. & & & \\
\hline
\end{tabular}

Table 19: Recommended Thickness of Timber Lagging

(Sabatini et al., 1999, p. 82) 


\subsection{Design of Supporting Structures}

During construction of the railways, embankments were used as a way of mitigating uneven ground topography. By balancing cut and full sections, engineers could build relatively level sections of ground, suitable for the operation of locomotives (Skempton, 1996, p. 36) However, embankments create a unique problem when it comes to installing additional tracks or operational facilities along the railway line. This section of the report investigates two locations in Whitby, Ontario where an embankment must be widened to provide additional room alongside the existing track (Figure 77). At the first site, the railway would like to construct a road that will allow maintenance vehicles to access existing infrastructure. At the second site, the embankment must be widened to construct another track to allow trains to access a new maintenance shop. However, with the property line at the toe of the embankment, the railway is company is unable to widen the overall embankment. As a result, retaining structures are required for the construction of the new access road and track bed.

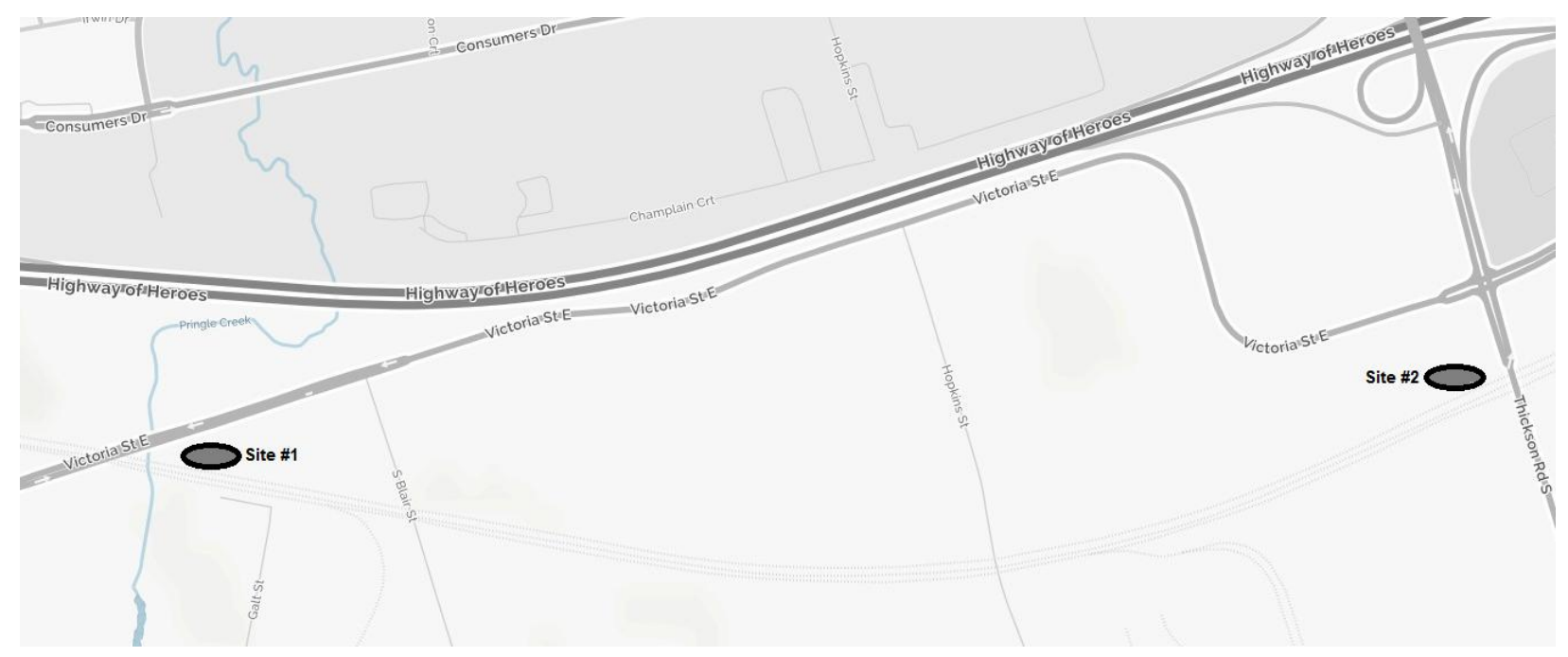

Figure 77: Site Locations in Whitby, Ontario

(MapQuest, 2017)

\subsection{Existing Conditions}

At the above locations, the existing railway embankment is 9.0 metres tall, with a $2 \mathrm{H}: 1 \mathrm{~V}$ slope to the original ground, below. The shoulder of the slope starts 4.0 metres (measured horizontally) from the centerline of the existing track. The toe of the slope is 18.0 metres (measured 
horizontally) from the shoulder. A sketch of the typical embankment cross section is shown in Figure 78.

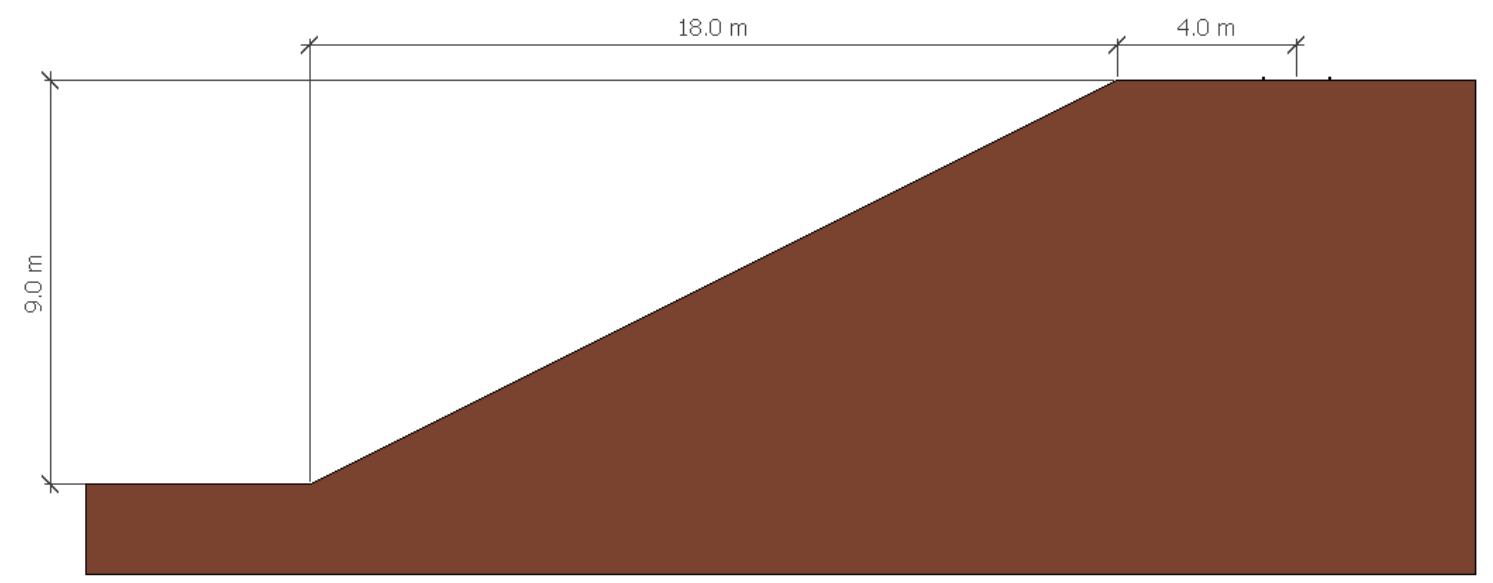

Figure 78: Existing Embankment

\subsubsection{Geotechnical Investigation}

Prior to designing a new retaining structure, a geotechnical investigation was completed to determine the existing ground conditions. As part of this investigation, three boreholes were completed at the locations shown in Figures 79 and 80. At the location of the new track (Site $\# 1$ ), one borehole was completed at the toe of the slope. At the location of the new road (Site \#2), two boreholes were completed: one at the toe of the slope and one in the embankment, eight metres from the toe of the slope.

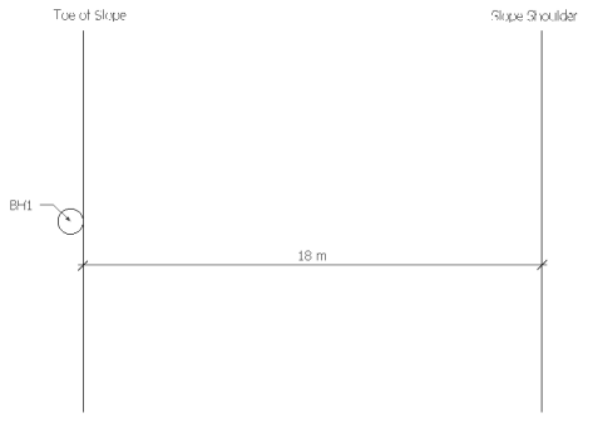

Figure 79: Location of BH1 (New Track)
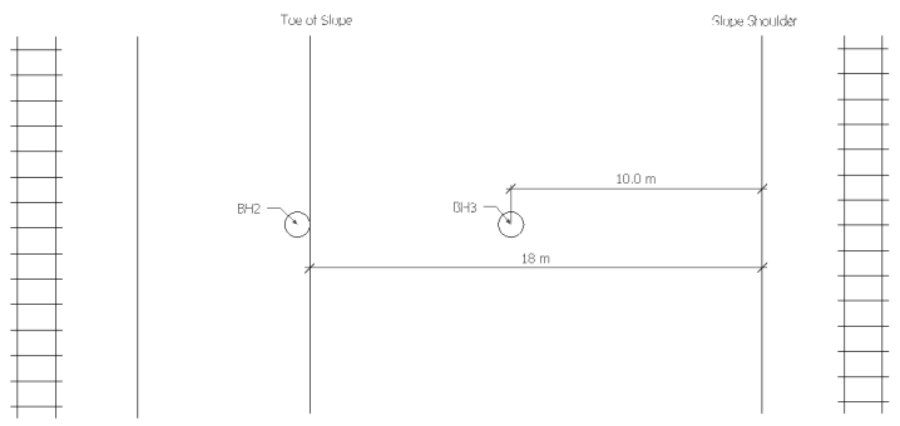

Figure 80: Location of BH2 and BH3: (New Road) 
The borehole logs showed similar ground conditions at both locations, with a layer of sandy fill above sandy silt. Till was found in $\mathrm{BH} 1$ at a depth of $6.7 \mathrm{~m}$. Ground conditions are summarized below, in Table 20, as well as Figures 81 and 82.

\begin{tabular}{||c|c|c|c|c||}
\hline Name & Depth (m) & Description & N Value & Water \% \\
\hline \multirow{3}{*}{ BH1 } & 1.1 & Fill: Sand with Gravel & 8.5 & 9.7 \\
\cline { 2 - 5 } & 4.3 & Clayey Silt (Possible Till) & 9.67 & 24.46 \\
\cline { 2 - 5 } & 4.9 & Loose Sand Seam & 7 & 7.4 \\
\cline { 2 - 5 } & 7.7 & \multirow{2}{*}{ Silty Sand to Sandy Silt (Till) } & $>100$ & 10 \\
\cline { 2 - 5 } & & & 61 & 9.2 \\
\hline BH2 & 1.5 & Fill: Sandy Silt & 6 & 11.5 \\
\hline \multirow{3}{*}{ BH3 } & 1.4 & Fill: Sandy Silt & 18 & 8.3 \\
\cline { 2 - 5 } & 2.2 & Clayey Silt & 13 & 22.1 \\
\cline { 2 - 5 } & 3.1 & Clayey Silt (Till) & 13 & 24 \\
\hline \hline
\end{tabular}

Table 20: Borehole Results for the Proposed Track and New Access Road Locations

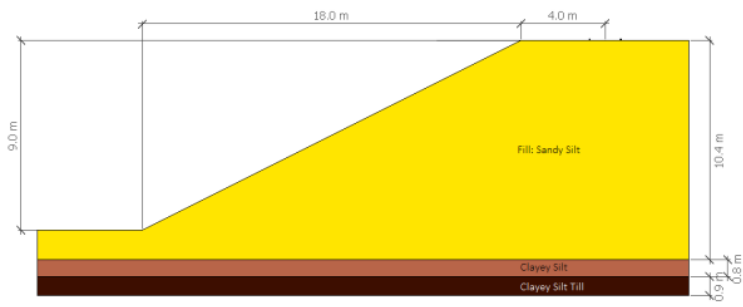

Figure 81: Soil Conditions at the Proposed Road

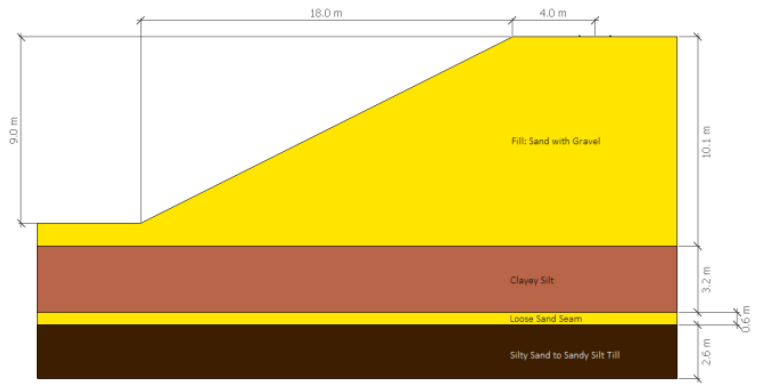

Figure 82: Soil Conditions at the Proposed Track 


\subsection{Supporting Structure for New Access Road}

According to Transport Canada's Standard Respecting Railway Clearances, when constructing an access road between a track and a structure, such as a bridge pier, a clearance of approximately 8.0 metres is required from the centerline of track (Figure 83). This will allow for an access road width of approximately 5.5 metres, without encroaching on the minimum train envelope.

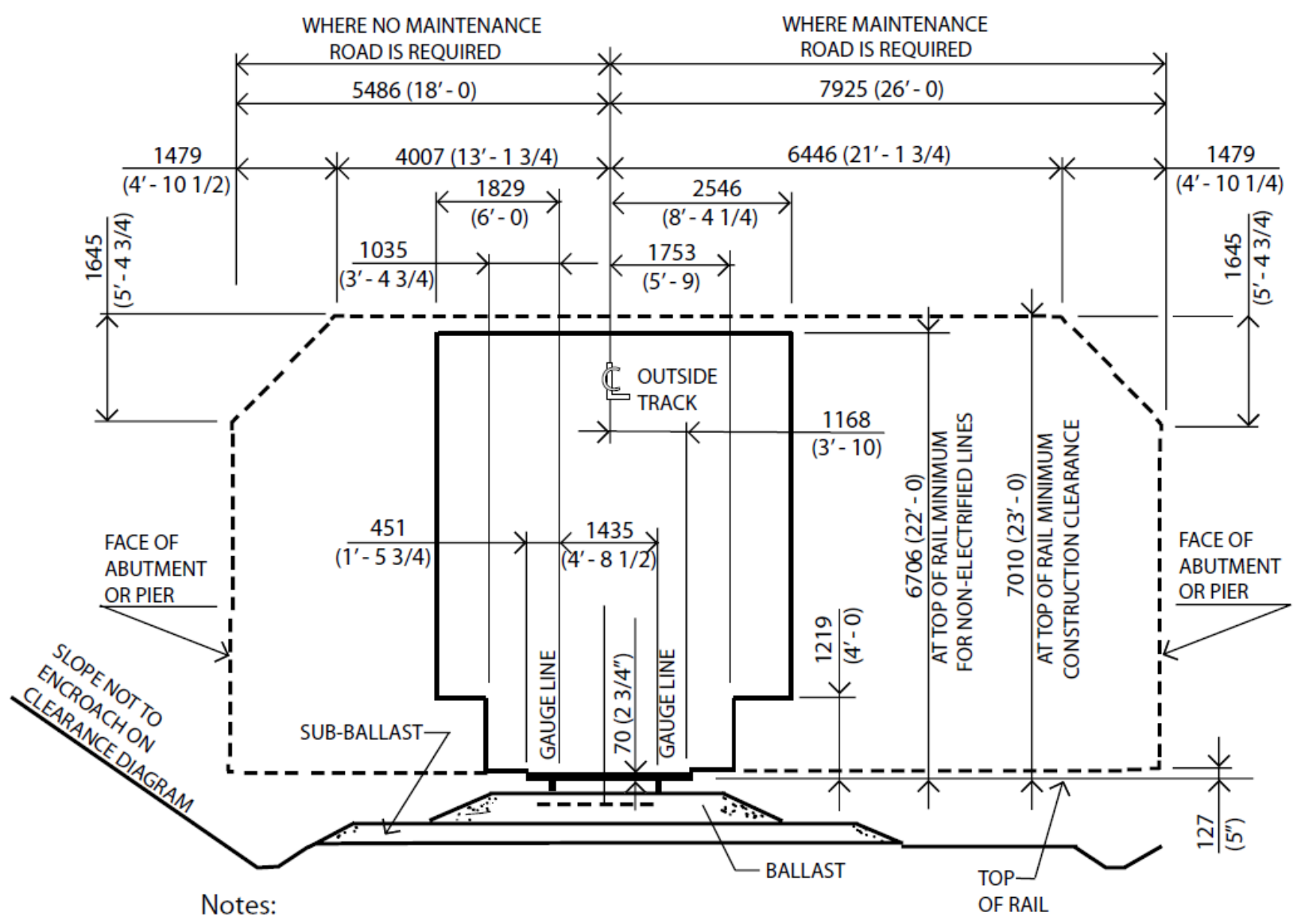

Figure 83: Transport Canada Standards Respecting Railway Clearances: All Structures over or Beside Railway Tracks

(Transport Canada, 1992)

In order to achieve a similar road width at this location, the existing embankment must be built out an additional 4 metres. As a result, a retaining structure will be required. A conceptual sketch of the new retaining structure is shown in Figure 84. 


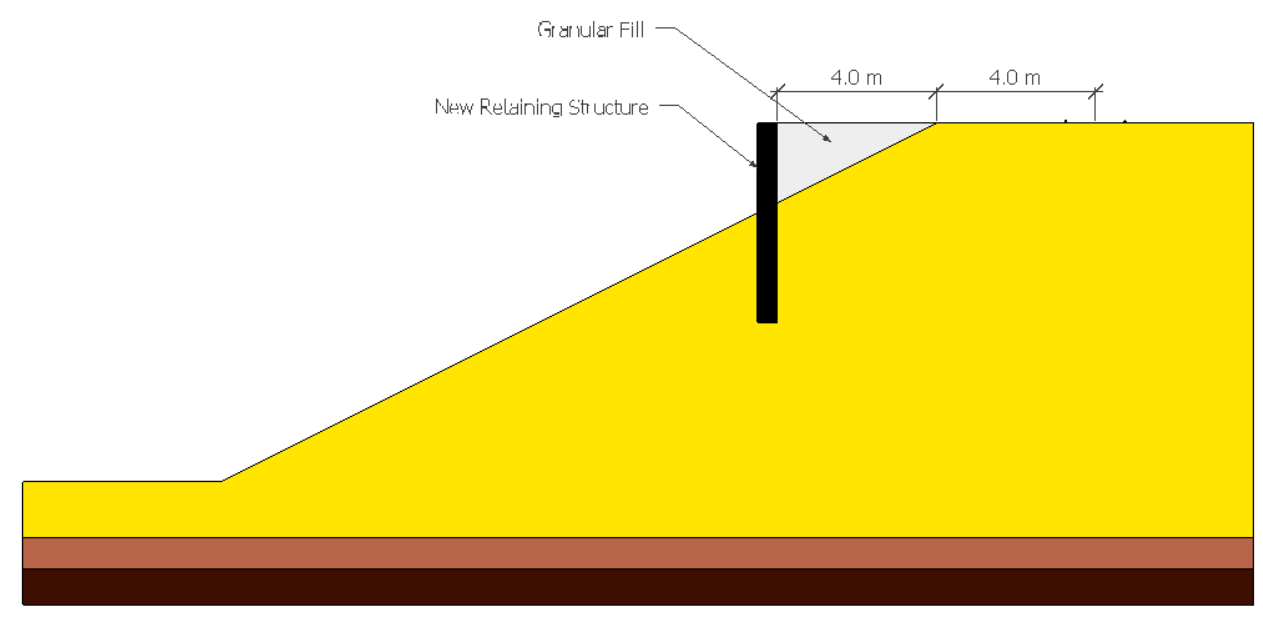

Figure 84: Conceptual Sketch: New Retaining Structure for a New Access Road alongside the Existing Track

\subsubsection{Anticipated Loading on New Retaining Structure:}

In order to widen the top of the embankment by four metres, the retaining wall must extend a height of two metres above the existing top of the slope. The first step in designing a new retaining structure was to estimate the earth pressures acting upon the wall. Within $\mathrm{BH} 2$, the sandy silt fill was found to have an $\mathrm{N}$ value of 6 . It was assumed that in constructing the road, the slope behind the wall would be backfilled with a suitable granular material, such as compacted Granular B. The Federal Highway Administration's Geotechnical Engineering Circular No. 4: Ground Anchors and Anchor Systems suggests that a soil may be classified according to the SPT blowcount value (Sabatini et al., 1999, p. 24). However, specific material properties were not provided. Given the railway nature of the design, Table 8-20-3 of the AREMA Manual for Railway Engineering was consulted for appropriate soil properties. The table is shown in Figure 85, below: 


\begin{tabular}{|c|c|c|c|c|c|c|c|c|c|c|c|}
\hline \multirow{3}{*}{$\begin{array}{l}\text { Type of } \\
\text { Soil }\end{array}$} & \multirow{2}{*}{\multicolumn{2}{|c|}{$\begin{array}{l}\text { Unit Weight of } \\
\text { Moist Soil, } \gamma \\
\text { (Note 1) }\end{array}$}} & \multirow{2}{*}{\multicolumn{2}{|c|}{$\begin{array}{l}\text { Unit Weight of } \\
\text { Submerged Soil, } \gamma^{\prime} \\
\text { (Note 1) }\end{array}$}} & \multicolumn{4}{|c|}{$\begin{array}{l}\text { Coefficient of Active Earth Pressure, } \\
\qquad \mathrm{K}_{\mathrm{a}}\end{array}$} & \multicolumn{3}{|c|}{$\begin{array}{l}\text { Coefficient of Passive } \\
\text { Earth Pressure, } \mathrm{K}_{\mathbf{p}}\end{array}$} \\
\hline & & & & & \multirow[t]{2}{*}{$\begin{array}{c}\text { For } \\
\text { Backfill }\end{array}$} & \multirow[t]{2}{*}{$\begin{array}{l}\text { For Soils } \\
\text { in Place }\end{array}$} & \multicolumn{2}{|c|}{$\begin{array}{l}\text { Friction Angles } \\
\text { (Note 2) }\end{array}$} & \multirow{2}{*}{$\begin{array}{l}\text { For } \\
\text { Soils in } \\
\text { Place }\end{array}$} & \multicolumn{2}{|c|}{$\begin{array}{l}\text { Friction } \\
\text { Angles } \\
\text { (Note 2) }\end{array}$} \\
\hline & Minimum & Maximum & Minimum & Maximum & & & $\phi$ & $\delta$ & & $\phi$ & $\delta$ \\
\hline (1) & (2) & (3) & (4) & (5) & (6) & (7) & (8) & (9) & (10) & (11) & (12) \\
\hline \multicolumn{12}{|l|}{ Clean Sand: } \\
\hline Dense & 110 & 140 & 65 & 78 & & 0.20 & 38 & 20 & 9.0 & 38 & 25 \\
\hline Medium & 110 & 130 & 60 & 68 & & 0.25 & 34 & 17 & 7.0 & 34 & 23 \\
\hline Loose & 90 & 125 & 56 & 63 & 0.35 & 0.30 & 30 & 15 & 5.0 & 30 & 20 \\
\hline \multicolumn{12}{|l|}{ Silty Sand: } \\
\hline Dense & 110 & 150 & 70 & 88 & & 0.25 & & & 7.0 & & \\
\hline Medium & 95 & 130 & 60 & 68 & & 0.30 & & & 5.0 & & \\
\hline Loose & 80 & 125 & 50 & 63 & 0.50 & 0.35 & & & 3.0 & & \\
\hline $\begin{array}{l}\text { Silt and } \\
\text { Clay Note } \\
\text { 3) }\end{array}$ & \multicolumn{2}{|c|}{$\frac{165(1+w)}{1+2.65 w}$} & \multicolumn{2}{|c|}{$\frac{103}{1+2.65 w}$} & 1.00 & $1-\frac{\mathrm{q}_{\mathrm{u}}}{\overline{\mathrm{p}}+\gamma_{\mathrm{z}}}$ & & & $1+\frac{\mathrm{q}_{\mathrm{u}}}{\overline{\mathrm{p}}+\gamma_{\mathrm{z}}}$ & & \\
\hline \multicolumn{12}{|c|}{$\begin{array}{l}\text { Note 1: In pounds per cubic foot. } \\
\text { Note 2: These angles, expressed in degrees, are } \phi \text {, the angle of internal friction, and } 5 \text {, the angle of wall friction, and are used in estimating the coefficients } \\
\text { under which they are listed. }\end{array}$} \\
\hline Note 3: & $\begin{array}{l}\text { he symbol } \gamma \text { re } \\
\text { ompressive str }\end{array}$ & $\begin{array}{l}\text { epresents } \gamma \text { or } \gamma \\
\text { ength; } w \text { is the }\end{array}$ & $\begin{array}{l}\text { ', whichever is } \\
\text { natural water }\end{array}$ & $\begin{array}{l}\text { applicable; } \overline{\mathrm{p}} \\
\text { outent, in perce }\end{array}$ & $\begin{array}{l}\text { is the effectiv } \\
\text { ntage of dry }\end{array}$ & $\begin{array}{l}\text { e unit pressure } \\
\text { weight; and } z \text { is }\end{array}$ & $\begin{array}{l}\text { on the to } \\
\text { the dept. }\end{array}$ & face of $t$. & $\begin{array}{l}\text { he stratum; } q_{u} \text { i } \\
\text { op surface of th }\end{array}$ & $\begin{array}{l}\text { the unce } \\
\text { stratum }\end{array}$ & nfined \\
\hline
\end{tabular}

Table 21: AREMA Table 8-20-3: Unit Weights of Soils, and Coefficients of Earth Pressure

(AREMA, 2016, p. 8-20-4)

Based on the information provided from the borehole logs, the following properties were estimated using Table 21:

\begin{tabular}{|l|c|c|}
\hline & Granular Fill & Sandy Silt \\
\hline Unit Weight $\left(\mathrm{kN} / \mathrm{m}^{3}\right)$ & 19.5 & 16.0 \\
\hline Angle of Internal Friction (Degrees) & 34 & 30 \\
\hline Active Earth Pressure Coefficient & 0.25 & 0.3 \\
\hline Passive Earth Pressure Coefficient & & 5.0 \\
\hline
\end{tabular}

Table 22: Properties of Soil Supported by the Proposed Retaining Structure (New Access Road)

It was assumed that the wall would not require any tiebacks. From the apparent earth pressure diagram for excavations in cohesionless soils, the maximum earth pressure ordinate was calculated: 
$P_{a}=0.65 \gamma H K_{a}$

$P_{a}=0.65(19.5)(2)(0.25)$

$P_{a}=6.34 \mathrm{kN} / \mathrm{m}^{2}$

Based on the properties of the granular fill material, a maximum earth pressure ordinate of 6.34 $\mathrm{kN} / \mathrm{m}^{2}$ was determined. Next, the live loads acting upon the new wall were estimated. Based on the CL-625-ONT truck load, a uniformly distributed lane load of $9 \mathrm{kN} / \mathrm{m}^{2}$ was considered (Canadian Highway Bridge Design Code, 2006, p. 54). Assuming the lateral surcharge can be calculated my multiplying the vertical surcharge by lateral earth pressure coefficient of the soil:

$P_{s}=K_{a} q_{s}$

$P_{s}=0.25(9)$

$P_{S}=2.25 \mathrm{kN} / \mathrm{m}^{2}$

The resulting lateral surcharge, assumed to act upon the entire height of the wall, was calculated to be $2.25 \mathrm{kN} / \mathrm{m}^{2}$. Given a total retained height of two metres, the total soil load acting upon each metre of wall was determined:

$R_{s}=H\left(P_{a}+P_{s}\right)$

$R_{S}=2(6.34+2.25)$

$R_{s}=17.18 \mathrm{kN} / \mathrm{m}^{2}$

Therefore, assuming a tributary area of one metre, the wall must be able to resist a total lateral load of $17.18 \mathrm{kN} / \mathrm{m}$.

\subsubsection{Steel Soldier Pile Design:}

A soldier pile wall was chosen as the retaining structure for this application as it allows the wall to be constructed with minimal disturbance to the existing embankment. The steel soldier piles must be designed to resist the maximum moments resulting from the lateral soil and surcharge loads. Considering the pile as a cantilevered beam, the maximum bending moment will act at 
the point of zero shear on the pile. The active forces acting upon the shoring wall for a given depth below road level $(x)$ was calculated using the equation:

$F_{a}=P_{e}+K_{a} \gamma x D$

Assuming a pile spacing of 3 metres:

$F_{a}=2.25+0.25(19)(3) x$

$F_{a}=2.25+14.25 x$

Similarly, the passive forces acting upon the shoring wall for a given depth below the bottom of excavation $\left(x_{1}\right)$ were calculated using the equation:

$F_{p}=K_{p} \gamma x_{1} D$

For preliminary calculations, assuming a minimum pile foundation width of 0.4 metres:

$F_{p}=5(16)(0.4) x_{1}$

$F_{p}=32 x_{1}$

Shear force equations may be determined by integrating the load equations, above. As the pile may be considered as a cantilevered beam, there must be zero shear force in the pile at the top of the retaining wall. The following active and passive shear force equations result:

$S_{a}=2.25 x+7.125 x^{2}$

$S_{p}=16 x^{2}$

The shear force diagram for the pile is constructed by summing the shear forces resulting from both the active and passive forces acting upon the wall. The resulting Shear Force Diagram is shown in Figure 85, below (top of existing slope is at an elevation of zero metres). 


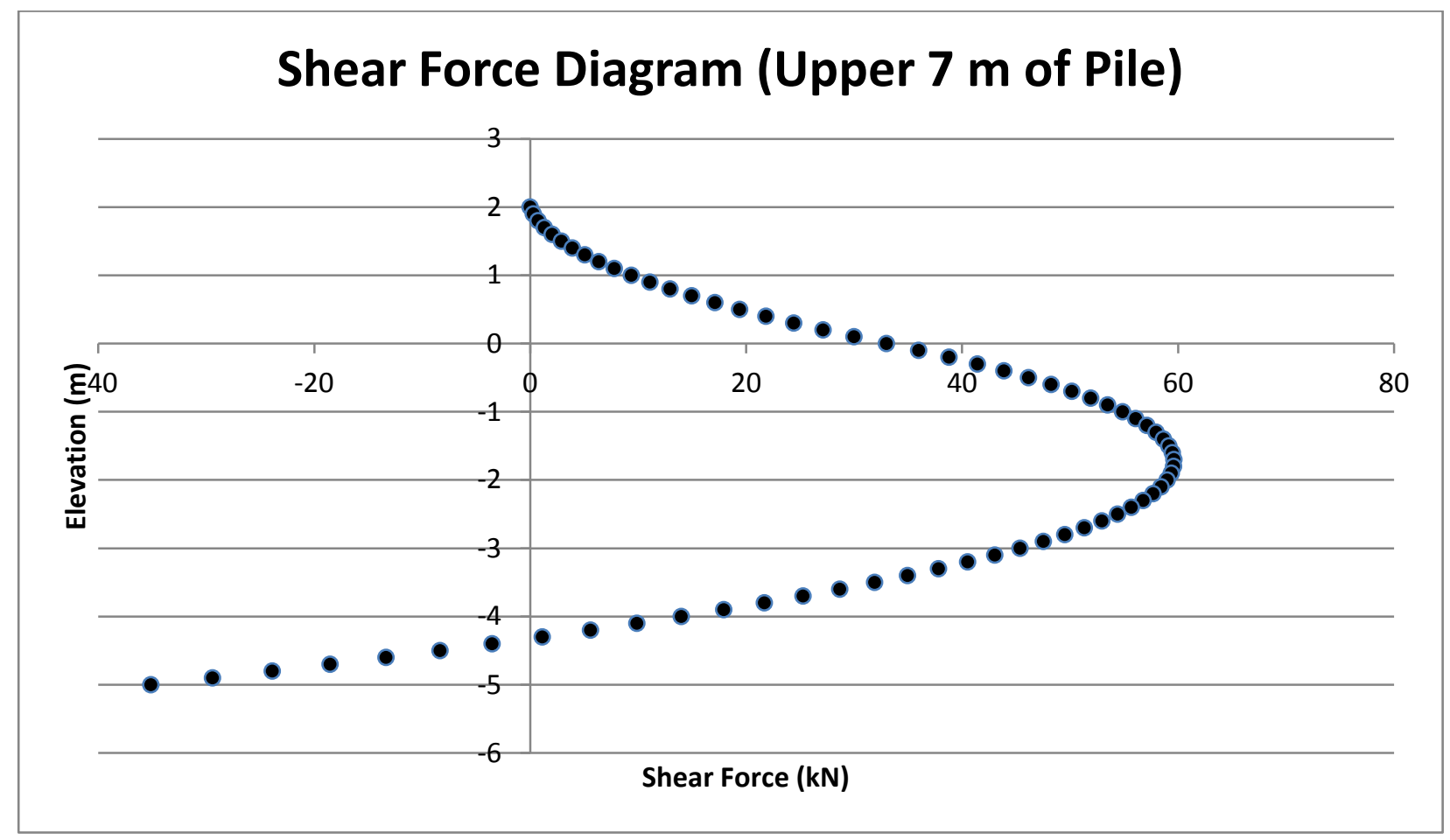

Figure 85: Shear Force Diagram for Upper 7 metres of the Steel Pile

From Figure 85, a maximum shear force of $59.63 \mathrm{kN}$ acts at a depth of 1.7 metres below the bottom of the excavation. At a depth of approximately 4.3 metres below the bottom of the excavation, the shear force is equal to zero.

The bending moment equations were then calculated by integrating the shear force equations above. As a cantilevered beam, bending moments at the top of the retaining wall are equal to zero and the following bending moment equations result:

$M_{a}=1.125 x^{2}+2.375 x^{3}$

$M_{p}=5.33 x^{3}$

By summing the bending moments caused by the active and passive forces acting upon the wall, the result is the Bending Moment Diagram Shown in Figure 86. 


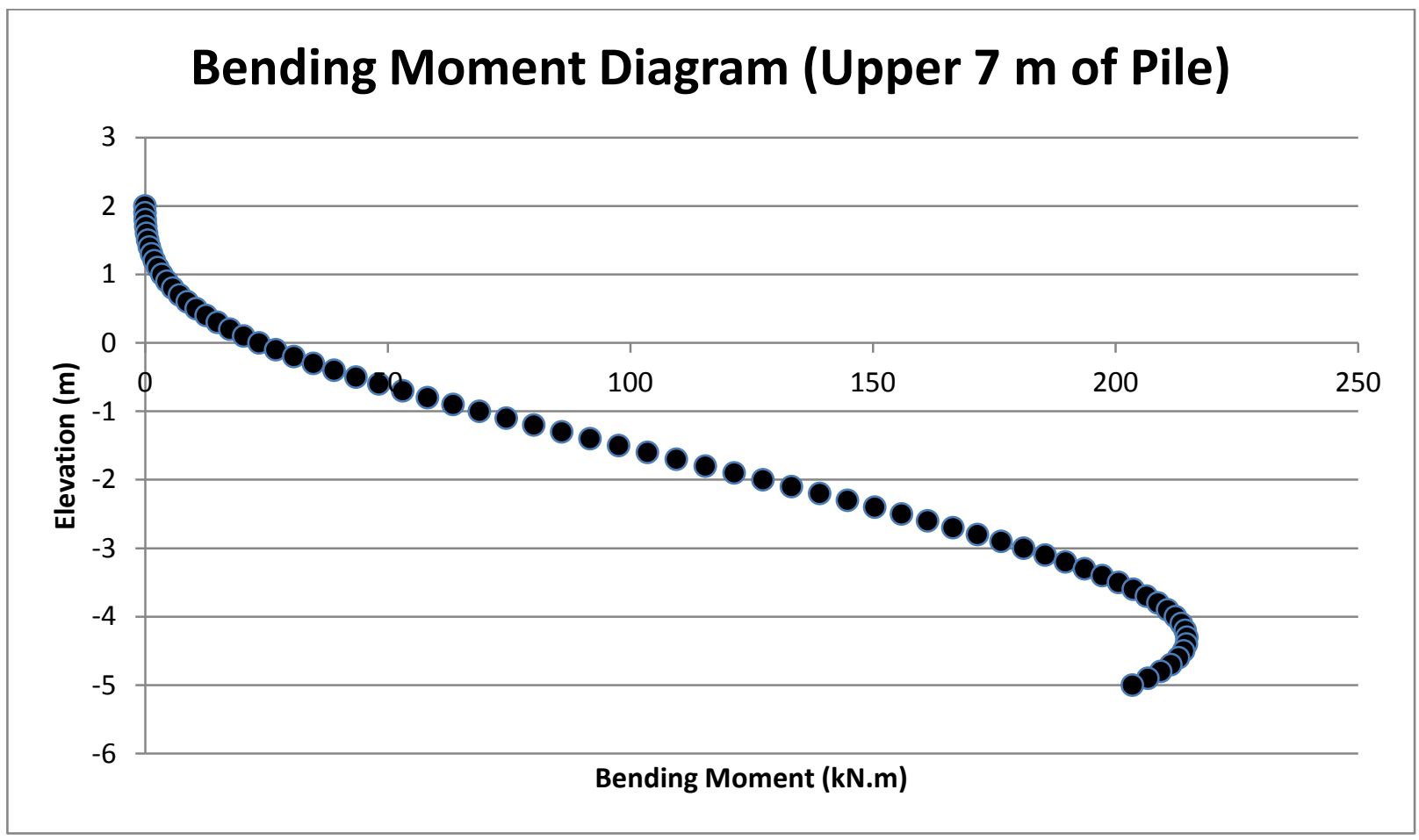

Figure 86: Bending Moment Diagram for Upper 7 metres of the Steel Pile

From the Bending Moment Diagram in Figure 86, assuming a maximum pile spacing of 3 metres, the pile must be able to resist a maximum moment of $215 \mathrm{kN} . \mathrm{m}$. This maximum moment acts at a depth of 4.3 metres below the bottom of the excavation. Based on the research performed by Mezazigh and Levacher, the maximum moment of a pile installed at the crest of a $2 \mathrm{H}: 1 \mathrm{~V}$ slope (in loose sand) is $25 \%$ greater than if the pile were installed in level ground (Mezazigh \& Levacher, 1998, p. 439). As a result, the pile was sized according to a maximum moment of:

$M_{\max }=215(125 \%)$

$M_{\max }=270 \mathrm{kN} \cdot \mathrm{m}$

In order to select a pile capable of resisting the maximum bending moment, the required pile section modulus was calculated. For a soldier pile, the bending stress should not exceed $55 \%$ of the yield stress of the steel (Sabatini et al., 1999, p. 81). Assuming the pile is constructed of Grade 300 steel with a yield stress of $300 \mathrm{MPa}$ : 
$S_{\text {req }}=\frac{M_{\max }}{0.55 F_{y}}$

$S_{\text {req }}=\frac{270}{0.55(300)}$

$S_{\text {req }}=1,636,000 \mathrm{~mm}^{3}$

Therefore a solder pile with a minimum section modulus of $1,636,000 \mathrm{~mm}^{3}$ was required to resist this maximum moment. A W360x101 steel section $\left(S_{x}=1,690,000 \mathrm{~mm}^{3}\right)$ was chosen. This pile will accommodate precast lagging with a thickness of up to approximately $275 \mathrm{~mm}$. Assuming $75 \mathrm{~mm}$ cover on the steel soldier pile, the minimum concrete footing diameter:

$D_{\min }=(2) 0.075+\sqrt{(0.5 b)^{2}+d^{2}}$

$D_{\min }=0.15+\sqrt{(0.5(0.255))^{2}+(0.357)^{2}}$

$D_{\min }=0.529 \mathrm{~m}$

Therefore, a footing with a minimum diameter of 0.55 metres is required to accommodate the W360x101 steel pile.

\subsubsection{Footing Design:}

The diameter of the soldier pile footing must be sized to develop the necessary lateral resistance through the passive resistance of the pile. In addition to the loads applied by the supported soils, the soldier pile must also be able to resist the active pressures acting upon the embedded portion of the pile according to the equation:

$R_{\text {Load }}=R_{S}+0.5 D K_{a} \gamma(2 H+D) b$

$R_{\text {Load }}=17.18+0.5 D(0.3)(16)(2(2)+D) b$

$R_{\text {Load }}=17.18+9.6 D b+2.4 D^{2} b$

Broms' method was used to calculate the lateral resistance of the pile. As recommended by the Federal Highway Administration, a factor of safety of 1.5 was applied to the lateral resistance of the pile estimated using Broms' Method. In their 1998 paper, Mezazigh and Levacher noted 
that for a pile installed in dry sand at the crest of a 2:1 slope, the load for a given deflection is approximately half of that for a pile installed in level ground (Mezazigh \& Levacher, 1998, p. 440). As a result, the estimated resistance of the pile was further reduced by $50 \%$ (for a total FOS of 3) to account for the presence of the slope:

Maximum Lateral Resistance at Bottom of Pile Using Broms' Method:

$R_{p}=3 K_{p} \gamma D b$

$R_{p}=3(5)(16) D b$

Total Passive Resistance per Pile:

$P=0.5 R_{p} D$

Considering a Factor of Safety of 3:

$P_{F O S=3}=\frac{0.5 R_{p} D}{3}$

Through an iterative process, considering a maximum soldier pile spacing of 3 metres, an embedment of 2.5 metres would be sufficient given a footing diameter of 0.55 metres:

$R_{\text {Load }}=17.18+9.6(2.5)(0.55)+2.4(2.5)^{2}(0.55)$

$$
R_{p}=240(2.5)(0.55)
$$

$R_{\text {Load }}=38.63 \mathrm{kN} / \mathrm{m}$

$$
R_{p}=330 \mathrm{kN}
$$

Considering a pile spacing of $3 \mathrm{~m}$ :

$$
P=0.5(330)(2.5)
$$

$R_{\text {Load }}=38.63(3)$

$$
P=412.5 k N
$$

$R_{\text {Load }}=115.89 \mathrm{kN}$

$$
\begin{aligned}
& P_{\text {FOS }=3}=\frac{412.5}{3} \\
& P_{\text {FOS }=3}=137.5 \mathrm{kN}
\end{aligned}
$$

$P_{F O S=3}>R_{\text {Load }}$ 


\subsubsection{Axial Pile Capacity:}

The soldier pile must also be checked to ensure that the vertical dead loads of the shoring system do not exceed the axial bearing capacity of the soldier pile. The first step was to calculate total dead loads:

W360x101 Steel Pile:

$$
\begin{aligned}
& D L_{\text {Steel }}=\text { Length } \times \text { Unit Mass } \\
& D L_{\text {Steel }}=4.5(0.99) \\
& D L_{\text {Steel }}=4.46 \mathrm{kN}
\end{aligned}
$$

Precast Concrete Lagging:

$$
\begin{aligned}
& D L_{\text {Lagging }}=\text { Length } \times \text { Height } \times \text { Thickness } \times \text { Density } \\
& D L_{\text {Lagging }}=3(2)(0.275)(23) \\
& D L_{\text {Lagging }}=37.95 \mathrm{kN}
\end{aligned}
$$

Concrete Footing:

$$
\begin{aligned}
& D L_{\text {Footing }}=\text { Footing Area } \times \text { Depth } \times \text { Density } \\
& D L_{\text {Footing }}=\frac{\pi(0.55)^{2}}{4}(2.5)(23) \\
& D L_{\text {Footing }}=13.66 \mathrm{kN}
\end{aligned}
$$

Total Dead Load $=56.07 \mathrm{kN}$

The next step was to calculate the skin friction acting upon the embedded concrete footing, based on the beta coefficient and average vertical stress acting upon the footing:

$$
\begin{aligned}
& \beta=\frac{N}{15}\left(1.5-0.42 z^{0.34}\right) \\
& \beta=\frac{6}{15}\left(1.5-0.42(2.5)^{0.34}\right)
\end{aligned}
$$


$\beta=0.37$

$p_{o}=0.5 H \gamma+0.5 D \gamma$

$p_{o}=0.5(2)(19)+0.5(2.5)(16)$

$p_{o}=39 \mathrm{kN} / \mathrm{m}^{2}$

$f_{s}=\beta p_{o}$

$f_{s}=0.37(39)$

$f_{s}=14.43 \mathrm{kN} / \mathrm{m}^{2}$

The end bearing resistance of the embedded concrete footing was calculated, with the toe bearing coefficient estimated from Figure 75:

$q_{t}=N_{t} p_{t}$

$q_{t}=6(25)$

$q_{t}=150 \mathrm{kN} / \mathrm{m}^{2}$

Considering a factor of safety of 2 for the skin friction and a factor of safety of 2.5 for end bearing resistance, the axial capacity of the pile was calculated as:

$Q_{u l t}=\frac{f_{s} A_{s}}{2}+\frac{q_{t} A_{t}}{2.5}$

$Q_{u l t}=\frac{14.43(2.5) \pi(0.55)}{2}+\frac{150 \pi(0.55)^{2}}{2.5(4)}$

$Q_{u l t}=45.42 \mathrm{kN}$ 
Since the axial resistance of the pile is less than the dead loads, the diameter of the pile must be increased. Through an iterative process, footing diameter and depth were increased until the ultimate axial resistance exceeded dead load. Using the equations above, it was found that a concrete footing with a diameter of 0.65 metres and depth of 3.5 metres would be sufficient to resist the axial pile loads:

$Q_{u l t}=80 \mathrm{kN}>D L=70 \mathrm{kN}$

\subsubsection{Maximum Moment in Concrete Lagging:}

No soil arching would be expected as the granular fill would be packed tightly against the concrete lagging. As a result, the precast concrete lagging shall be designed to resist a moment:

$M_{f}=\frac{1}{12} R_{s}$ Length ${ }^{2}$

$M_{f}=\frac{1}{12}(17.18)\left(3^{2}\right)$

$M_{f}=13 \mathrm{kN} / \mathrm{m}$

Therefore, the timber lagging must be designed to resist a moment of $13 \mathrm{kN}$ per metre height of retained soil.

\subsubsection{Summary of Retaining Structure for Access Road:}

The final retaining structure design is summarized in Table 23:

\begin{tabular}{|l|l|}
\hline Height of Exposed Wall: & 2 metres \\
\hline Embedment Depth: & 3.5 metres \\
\hline Concrete Footing Diameter: & 0.65 metres \\
\hline Soldier Pile: & W360x101 Grade 300 Steel Section \\
\hline Concrete Lagging Thickness: & Maximum 0.25 metres \\
\hline Concrete Lagging Moment Resistance: & Moment Resistance of 13 kN.m per metre Height \\
\hline
\end{tabular}

Table 23: Final Retaining Structure Design for the Proposed Access Road 


\subsection{Supporting Structure for New Track}

According to Transport Canada's Standard Respecting Railway Clearances, main and siding tracks should have a minimum centre to centre spacing of 4.27 metres (Transport Canada, 1992). Allowing a minimum horizontal clearance of 5.5 metres from the centerline of new track to the retaining wall (Transport Canada, 1992), the existing embankment shall be built out 6.0 metres. A concept sketch of the new retaining structure is shown in Figure 87.

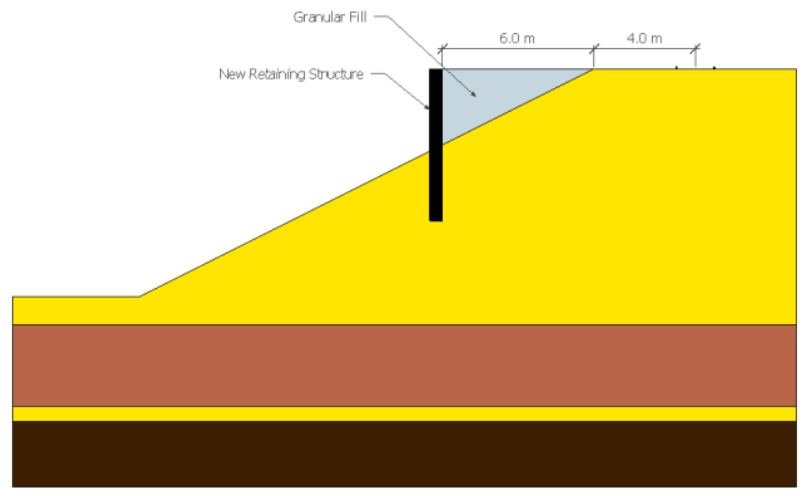

Figure 87: New Retaining Structure to allow for a New Track alongside the Existing Track (New Track)

\subsubsection{Anticipated Loading on New Retaining Structure:}

Once again, the first step was to estimate the lateral loads that would be applied to the new retaining structure. In order to widen the top of the embankment by six metres, the retaining structure must extend a height of three metres above the top of the slope. From $\mathrm{BH} 1$, the sand with gravel fill was found to have an $\mathrm{N}$ value of 8.5. In order to construct the new track, it is assumed the slope behind the wall will be filled with a suitable granular material, such as compacted Granular B. From Table 8-20-3 of the AREMA Manual for Railway Engineering, the following properties were estimated:

\begin{tabular}{|l|c|c|}
\hline & Granular Fill & Sand Fill \\
\hline Unit Weight $\left(\mathrm{kN} / \mathrm{m}^{3}\right)$ & 19.5 & 18 \\
\hline Angle of Internal Friction (Degrees) & 34 & 30 \\
\hline Active Earth Pressure Coefficient & 0.25 & 0.3 \\
\hline Passive Earth Pressure Coefficient & & 5.0 \\
\hline
\end{tabular}

Table 24: Properties of Soil Supported by the Proposed Retaining Structure (New Track) 
The maximum earth pressure ordinate resulting from the granular fill acting upon the top of the wall was calculated. Due to the railway loading acting upon the retaining structure, it was assumed that that ground anchors would be required. As a result, one row of ground anchors was assumed at a depth of 2.5 metres below the top of the wall. The maximum earth pressure ordinate apparent earth pressure diagram (Figure 88) was estimated from Figure 52: Apparent Earth Pressure Diagram for Excavations in Cohesionless Soils (One Row of Tie-Backs). The maximum earth pressure ordinate was calculated using the equation:

$p_{a}=K a \gamma H$

$p_{a}=0.25(19.5)(3)$

$p_{a}=14.62 \mathrm{kN} / \mathrm{m}^{2}$

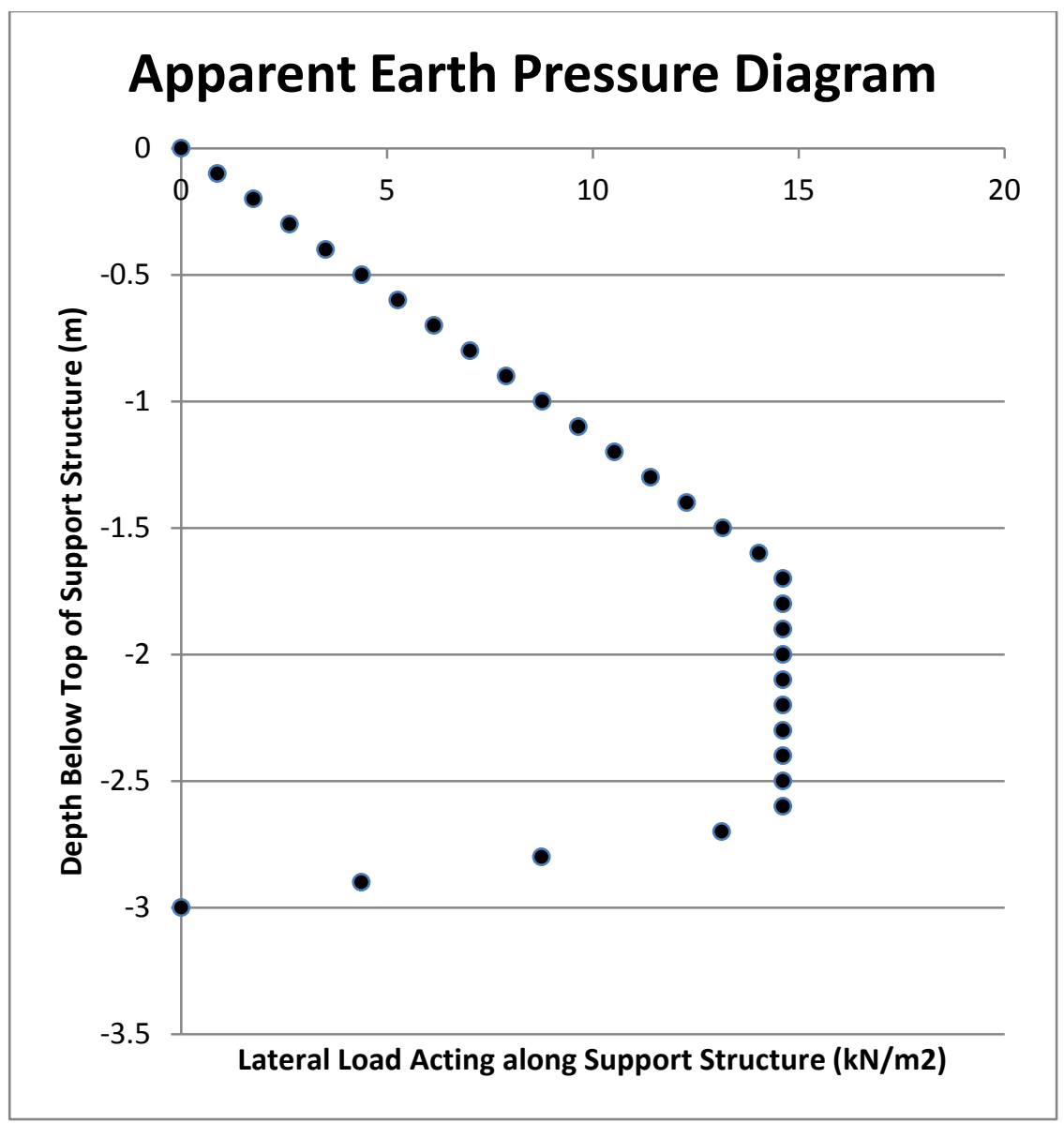

Figure 88: Apparent Earth Pressure Diagram (Cohesionless Soil, One Row of Tie-Backs) 
The surcharge load acting upon the ground surface supported by the wall consisted of both dead loads (track infrastructure and ballast) and live loads (train loads). In accordance with AREMA CL. 2.2.3, a total dead load of $4.67 \mathrm{kN} / \mathrm{m}$ and a live load of $262 \mathrm{kN} / \mathrm{m}$ were assumed (AREMA, 2016, p. 8-2-12). Lateral pressures acting upon the shoring wall (due to railway surcharge loads) were calculated in accordance with CL.20.3.2.2 and Table 8-20-2: Pressure Distribution for Strip Load (Figure 89) (AREMA, 2016). The estimated lateral loads due to railway loading (Figure 90 and Figure 91) were calculated using the following equation:

$p_{s}=\frac{2 q}{\pi}\left(\beta+\sin \beta \sin ^{2} \alpha-\sin \beta \cos ^{2} \alpha\right)$

(AREMA, 2016, p. 8-20-6)
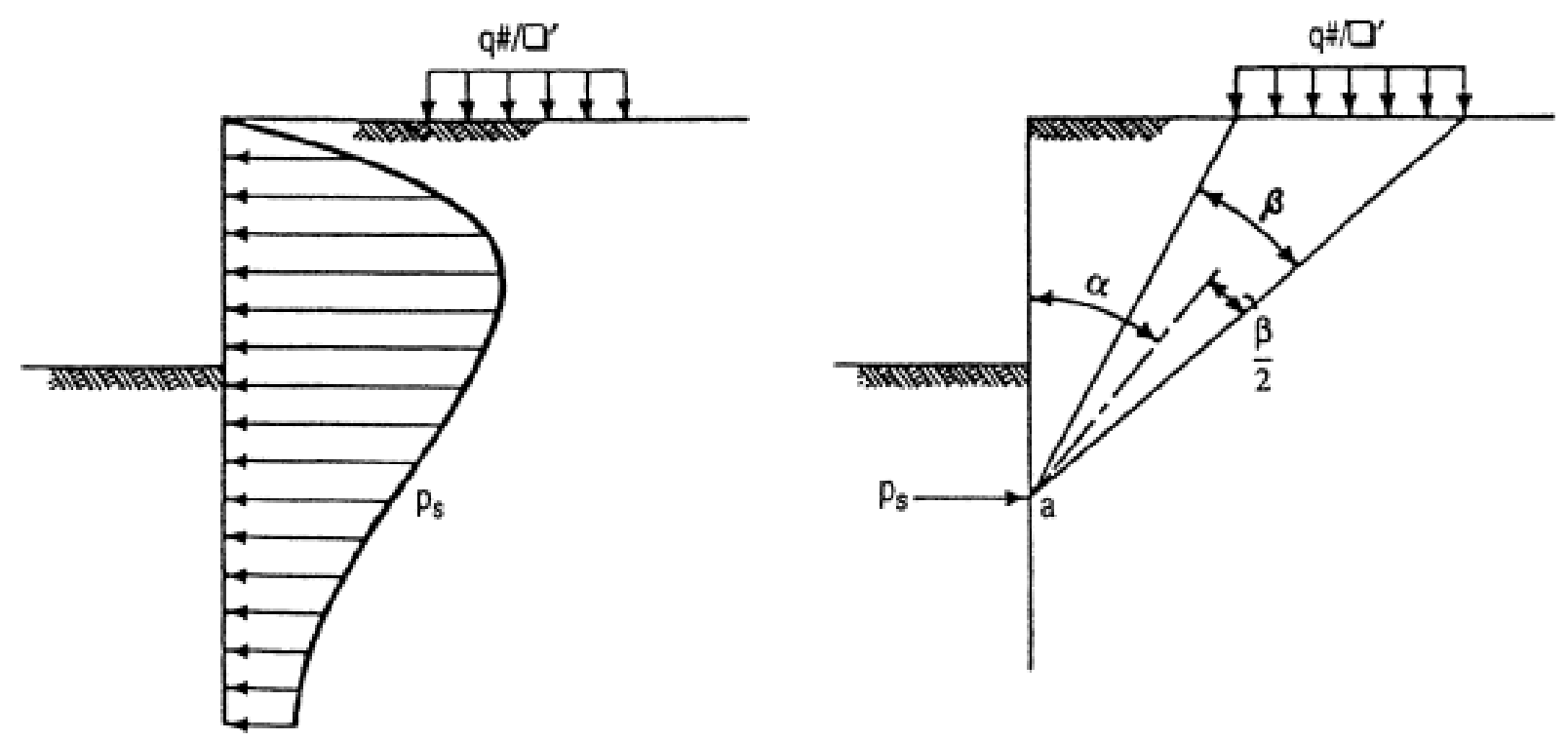

Figure 89: Pressure Distribution for Strip Load

(AREMA, 2016, p. 8-20-6) 


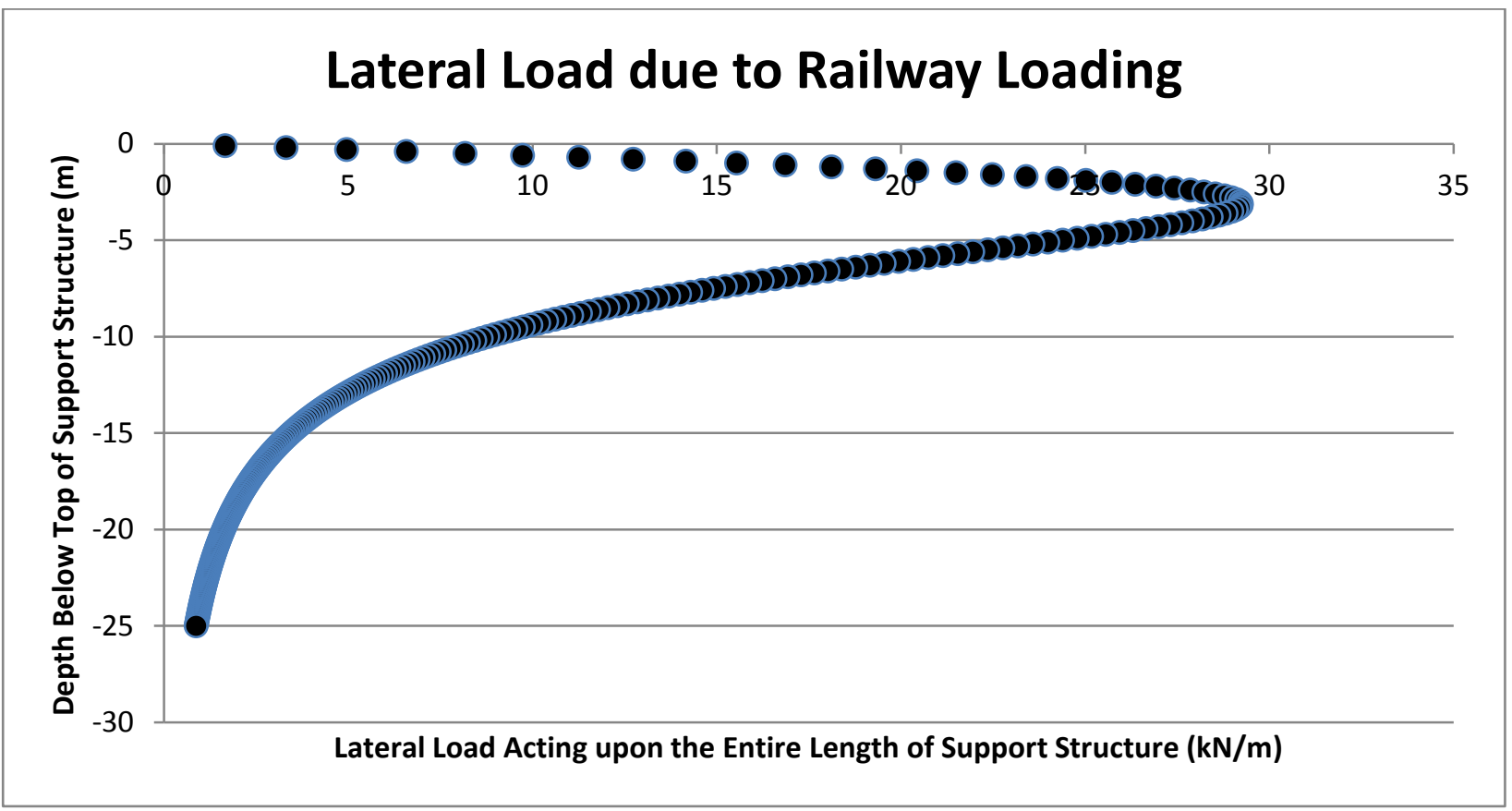

Figure 90: Lateral Loads acting upon the entire Support Structure due to Railway Loading

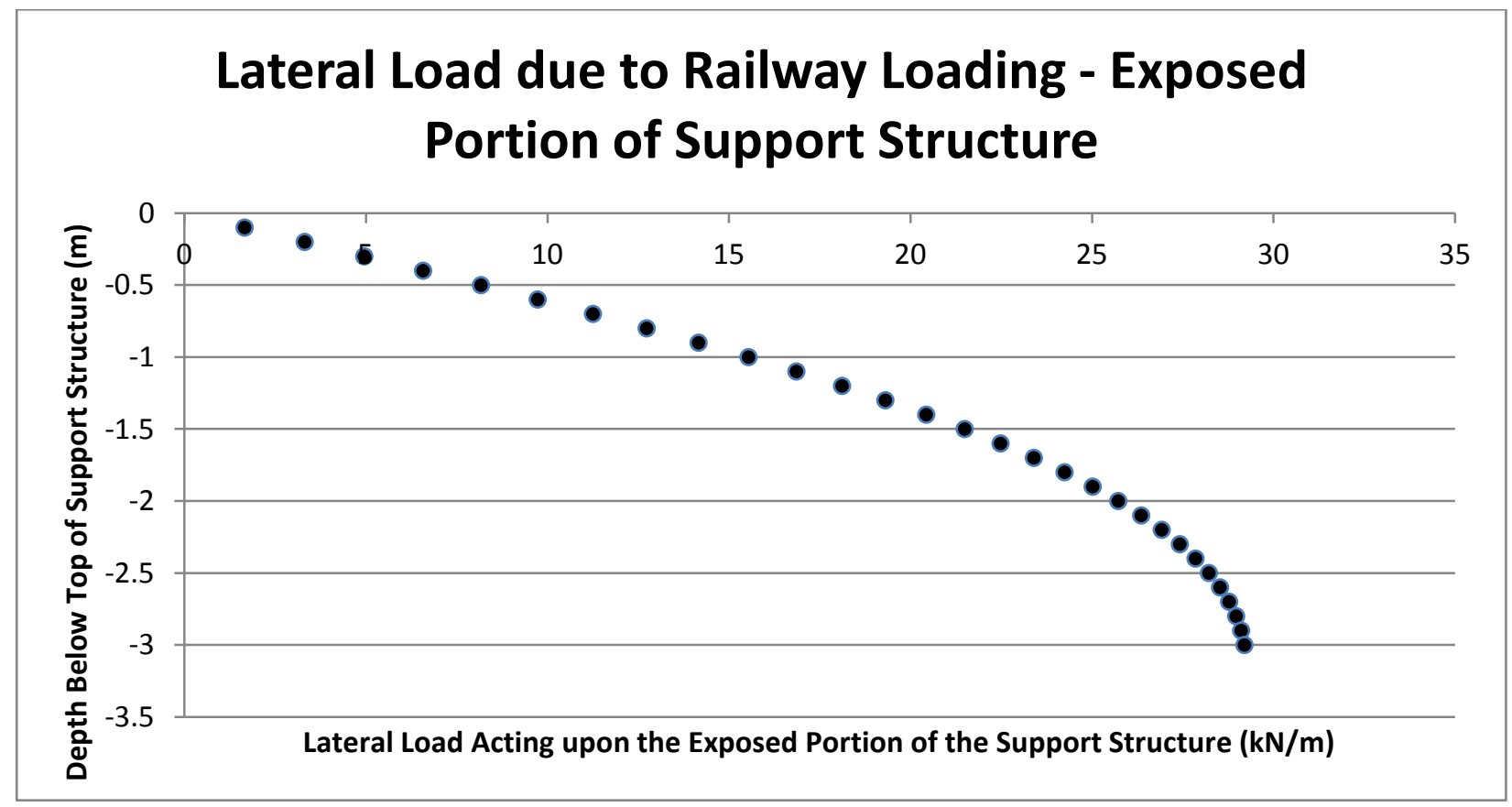

Figure 91: Lateral Loads acting upon the Exposed Portion of the Support Structure due to Railway Loading 
Based on the figures above, the maximum pressure ordinate due to railway loading was 24.29 $\mathrm{kN} / \mathrm{m}^{2}$.

\subsubsection{Steel Soldier Pile Design:}

In order to design the steel soldier pile, the maximum moments acting upon the steel pile were calculated. Using the tributary area method for a single row of tie-backs, the maximum moment will be at the anchor level, or between the anchor level and the bottom of the excavation. The bending moment at ground anchor level may be calculated by summing moments about the ground anchor. In order to sum moments, the reaction force at the bottom of the excavation level was required. It is assumed that the reaction force is equal to lateral earth pressure and railway surcharge loads acting upon the wall between the top of excavation and half way to the ground anchor (between 2.75 and 3.0 metres below the top of the retaining structure).

$R_{s}=$ Lateral Earth Pressure + Lateral Railway Surcharge Load

$R_{S}=4.82+15.87$

$R_{s}=20.69 \mathrm{kN} / \mathrm{m}$

Based on the soil reaction force acting at the bottom of the excavation and the resultant forces estimated from Figure 88 and Figure 91, moments were summed about the ground anchor (at a distance of 2.5 metres below the top of the shoring wall). At the level of the ground anchors, an internal pile moment of $58.34 \mathrm{kN} . \mathrm{m} / \mathrm{m}$ was calculated. Assuming a pile spacing of 3 metres, the internal moment in each pile was $174.71 \mathrm{kN} . \mathrm{m}$.

Using the tributary method proposed by the Federal Highway Administration, the maximum moment between the row of ground anchors and the bottom of excavation was be estimated using the equation:

$$
\begin{aligned}
& M=\frac{1}{10} H_{2}^{2}\left(p_{a}+p_{s}\right) \\
& M=\frac{1}{10}(0.5)^{2}(14.62+29.24) \\
& M=1.10 \mathrm{kN} \cdot \mathrm{m} / \mathrm{m}
\end{aligned}
$$


For a pile spacing of 3 metres, the internal pile moment was calculated to be $3.30 \mathrm{kN} / \mathrm{m}$. As a result, 174.71 kN.m governs.

The bending stress within a steel soldier pile should not exceed $55 \%$ of the yield stress of the steel. Assuming the Grade 300 steel, the required section modulus was calculated:

$S_{\text {req }}=\frac{M_{\text {max }}}{0.55 F_{y}}$

$S_{\text {req }}=\frac{175}{0.55(300)}$

$S_{\text {req }}=1,061,000 \mathrm{~mm}^{3}$

Therefore a solder pile with a minimum section modulus of $1,061,000 \mathrm{~mm}^{3}$ was required to resist the maximum moment. A W360x72 steel section $\left(S_{x}=1,150,000 \mathrm{~mm}^{3}\right)$ was chosen. This pile will accommodate precast lagging with a thickness of up to approximately $275 \mathrm{~mm}$. Assuming $75 \mathrm{~mm}$ cover on the steel soldier pile, the minimum concrete footing diameter:

$D_{\min }=(2) 0.075+\sqrt{(0.5 b)^{2}+d^{2}}$

$D_{\min }=0.15+\sqrt{(0.5(0.204))^{2}+(0.350)^{2}}$

$D_{\min }=0.515 \mathrm{~m}$

Therefore, a minimum footing diameter of approximately 0.55 metres is required given a W360x72 steel pile section.

\subsubsection{Footing Design:}

The pile footing must provide sufficient lateral resistance to counteract the active forces applied upon the exposed and embedded portions of the pile:

Exposed Pile Soil and Railway Surcharge Loads:

$20.69 \mathrm{kN} / \mathrm{m}$ not resisted by the ground anchor 
Soil Forces on Embedded Portion:

$R_{e}=0.5 D K_{a} \gamma(2 H+D) b$

$\left.R_{e}=0.5 D(0.3)(16)(2(3)+D)\right) b$

$R_{e}=14.4 D b+2.4 D^{2} b$

Railway Loads on Embedded Portion:

Sum of Lateral Railway Loads in Figure 90, below the bottom of excavation (equal to $155 \mathrm{kN}$, assuming the pile does not extend more than 10 metres below the bottom of the excavation).

Maximum Lateral Resistance at Bottom of Pile Using Broms' Method:

$R_{p}=3 K_{p} \gamma D b$

$R_{p}=3(5)(16) D b$

Total Passive Resistance per Pile:

$P=0.5 R_{p} D$

Once again, a Factor of Safety of 3 was applied to account for the presence of the slope and the tendency of Broms' Methods to underestimate lateral deflection:

$P_{F O S=3}=\frac{0.5 R_{p} D}{3}$ 
Through an iterative process, considering a maximum soldier pile spacing of 3 metres, an embedment of 5.5 metres would be sufficient given a footing diameter of 0.7 metres:

$R_{\text {Load }}=20.69+14.4(5.5)(0.7)+2.4(5.5)^{2}(0.7)+155 \quad R_{p}=240(5.5)(0.7)$

$R_{\text {Load }}=281.95 \mathrm{kN} / \mathrm{m} \quad R_{p}=924 \mathrm{kN}$

Considering a pile spacing of $3 \mathrm{~m}$ : $\quad P=0.5(924)(5.5)$

$R_{\text {Load }}=281.95(3) \quad P=2541 \mathrm{kN}$

$R_{\text {Load }}=845.85 \mathrm{kN} \quad P_{\text {FOS }=3}=\frac{2541}{3}$

$P_{F O S=3}=847 \mathrm{kN}$

$P_{\text {FOS }=3}>R_{\text {Load }}$

\subsubsection{Ground Anchor Design}

It was assumed that the one row of ground anchors would resist all lateral forces applied to support structure between the top of the structure, and the midpoint between the anchors and bottom of the excavation. Based on the tributary area method, total soil and railway surcharge loads were calculated by summing all soil and railway surcharge loads acting over this area. Using Figure 88 and Figure 91, it was calculated that the each ground anchor had to resist $27.64 \mathrm{kN} / \mathrm{m}$ of lateral earth pressure and $52.98 \mathrm{kN} / \mathrm{m}$ of railway surcharge loads. Assuming the ground anchors installed at a 15 degree angle and spaced every three metres, the total anchor design load was calculated:

$A_{D L}=\frac{(27.64+52.98)(3)}{\cos 15}$

$A_{D L}=250.39 \mathrm{kN}$

The Federal Highway Administration recommends the ground anchor test load does not exceed $80 \%$ of the specified minimum tensile strength. From Table 16, assuming a test load of $133 \%$ (330 kN), 9-15 mm diameter Grade 270 steel strands were chosen for each ground anchor.

Next, the unbonded length was estimated. For prestressing strands, the unbonded length must be at least 4.5 metres and extend at least 1.5 metres beyond the critical failure surface. For an 
internal angle of friction of 30 degrees, the critical failure surface was assumed to form an angle of 60 degrees with the horizontal, and extend from the bottom of the 5.5 metre embedded pile.

Given ground anchors installed 2.5 metres below the top of the wall, at an angle of 15 degrees, the unbonded length was calculated:

Horizontal Distance $(x)$ from the Wall to Critical Failure Surface (2.5 metres below the top of wall):

$\tan (90-60)=\frac{x}{6}$

$x=3.46 m$

Distance $(y)$ from the Wall to the Critical Failure Surface (measured along the ground anchor):

$\cos 15=\frac{3.46}{y}$

$y=3.58 m$

Minimum Unbonded Length $(z)$ :

$z=3.58+1.5$

$z=5.08 m$

Therefore, the minimum unbonded ground anchor length is 5.08 metres.

The last step in designing the ground anchors was to calculate the required bond length. From Table 14, the ultimate transfer load for loose sand was estimated at $100 \mathrm{kN} / \mathrm{m}$. For a $250 \mathrm{kN}$ ground anchor force and a factor of safety of two:

Bond Length $=\frac{250(2)}{100}$

Bond Length $=5 \mathrm{~m}$ 
Therefore, a bond length of 5 metres was required. Given a ground anchor angle of 15 degrees, a total ground anchor length of 7.58 (from the wall to the midpoint of the bonded section) is approximately equal to the minimum ground cover of 4.5 metres:

Ground Cover $=2.5+\sin 15\left(5.08+\frac{5}{2}\right)$

Ground Cover $=4.46 \mathrm{~m}$

\subsubsection{Axial Pile Capacity}

Finally, the soldier pile was also checked to ensure the vertical loads do not exceed the axial capacity of the pile. First, the vertical loads acting upon the pile foundation were calculated:

W360x72 Steel Pile:

$D L_{\text {Steel }}=$ Length $\times$ Unit Mass

$D L_{\text {Steel }}=8.5(0.70)$

$D L_{\text {Steel }}=5.95 \mathrm{kN}$

Precast Concrete Lagging:

$D L_{\text {Lagging }}=$ Length $\times$ Height $\times$ Thickness $\times$ Density

$D L_{\text {Lagging }}=3(3)(0.275)(23)$

$D L_{\text {Lagging }}=56.92 \mathrm{kN}$

Concrete Footing:

$D L_{\text {Footing }}=$ Footing Area $\times$ Depth $\times$ Density

$D L_{\text {Footing }}=\frac{\pi(0.70)^{2}}{4}(5.5)(23)$

$D L_{\text {Footing }}=48.68 \mathrm{kN}$ 
Vertical Component of Ground Anchor:

$A_{V L}=80.62(\sin 15)$

$A_{V L}=20.87 k N$

Total Dead Load $=132.42 \mathrm{kN}$

The next step was to calculate the skin friction acting upon the embedded concrete footing, based on the beta coefficient and average vertical stress acting upon the footing:

$\beta=\frac{N}{15}\left(1.5-0.42 z^{0.34}\right)$

$\beta=\frac{6}{15}\left(1.5-0.42(5.5)^{0.34}\right)$

$\beta=0.30$

$p_{o}=0.5 H \gamma+0.5 D \gamma$

$p_{o}=0.5(3)(19)+0.5(5.5)(16)$

$p_{o}=72.5 \mathrm{kN} / \mathrm{m}^{2}$

$f_{s}=\beta p_{o}$

$f_{s}=0.30(72.5)$

$f_{s}=21.75 \mathrm{kN} / \mathrm{m}^{2}$

The end bearing resistance of the embedded concrete footing was calculated, with the toe bearing coefficient estimated from Figure 75 : 
$q_{t}=N_{t} p_{t}$

$q_{t}=6(25)$

$q_{t}=150 \mathrm{kN} / \mathrm{m}^{2}$

Considering a factor of safety of 2 for the skin friction and a factor of safety of 2.5 for end bearing resistance, the axial capacity of the pile was calculated as:

$Q_{u l t}=\frac{f_{s} A_{s}}{2}+\frac{q_{t} A_{t}}{2.5}$

$Q_{u l t}=\frac{21.75(5.5) \pi(0.7)}{2}+\frac{150 \pi(0.7)^{2}}{2.5(4)}$

$Q_{u l t}=154.63$

$Q_{u l t}=154.63 \mathrm{kN}>D L=132.42 \mathrm{kN}$

Therefore, a 5.5 metre deep footing with a diameter of 0.7 metres is sufficient to provide the required axial resistance.

\subsubsection{Maximum Moment in Concrete Lagging:}

No soil arching would be expected as the granular fill would be packed tightly against the concrete lagging. As a result, the precast concrete lagging shall be designed to resist a moment:

$M_{f}=\frac{1}{12} R_{S}$ Length ${ }^{2}$

$M_{f}=\frac{1}{12}(80.62)\left(3^{2}\right)$

$M_{f}=60.47 \mathrm{kN} / \mathrm{m}$

The timber lagging must be designed to resist a moment of $60.46 \mathrm{kN}$ per metre height of retained soil. 


\subsubsection{Summary of Retaining Structure for New Track:}

The final retaining structure design is summarized in Table 25:

\begin{tabular}{|l|l|}
\hline Height of Exposed Wall: & 3 metres \\
\hline Embedment Depth: & 5.5 metres \\
\hline Concrete Footing Diameter: & 0.70 metres \\
\hline Soldier Pile: & W360x72 Grade 300 Steel Section \\
\hline Ground Anchor Strands: & $9-15 \mathrm{~mm}$ Diameter Grade 270 Steel Strands \\
\hline Angle of Ground Anchors & 15 Degrees \\
\hline Ground Anchor Unbonded Length: & 5.08 metres \\
\hline Ground Anchor Bonded Length: & 5 metres \\
\hline Concrete Lagging Thickness: & Maximum 0.275 metres \\
\hline Concrete Lagging Moment Resistance: & Moment Resistance of 60.5 kN.m per metre Height \\
\hline
\end{tabular}

Table 25: Final Retaining Structure Design for the Proposed Access Road 


\subsection{Conclusion}

Many retaining structures, including soldier pile and lagging walls, rely on piles for lateral support. In order to understand the behaviour of laterally loaded piles, existing theories related to lateral earth pressures and lateral pile resistance were investigated. A parametric study of ultimate lateral pile capacity was also performed using Broms' methods for a variety of pile properties and soil conditions. Broms' methods were then compared to RocScience finite element software to estimate appropriate factors of safety that may be used in the design of piles, including piles installed near slopes.

For the piles and soil conditions analysed within this project, it was found that Broms' methods provided a reasonable estimate of pile deflections for laterally loaded, free head short piles under working loads. Based on finite element analysis for both cohesive and cohesionless soils, Broms' methods estimated ultimate lateral loads associated with less than $20 \mathrm{~mm}$ of deflection. However, for the pile and soil conditions considered, Broms' methods typically underestimated deflections for laterally loaded, free head long piles under working loads. Based on finite element analysis, it was found that ultimate loads calculated using Broms' methods resulted in up to $50 \mathrm{~mm}$ of lateral deflection. However, by applying a factor of safety of 1.5 to the ultimate lateral load calculated using Broms' methods, deflections were limited to approximately $30 \mathrm{~mm}$.

From the finite element analysis of free head long and short steel piles installed at the crest of a $2 \mathrm{H}: 1 \mathrm{~V}$ slope, it was found that, for a given lateral load, the presence of the slope resulted in additional deflections of approximately $23 \%$ and $27 \%$ for long and short piles, respectively. For a given lateral load, the presence of the slope also resulted in increased maximum moments within the pile. For long piles, the presence of the slope increased the maximum internal moment by $7 \%$ when compared to the same pile installed in horizontal ground. For short piles, the maximum internal moment was $30 \%$ larger than if the pile were installed in level ground. It was found that Broms' methods may be used to estimate ultimate lateral loads for piles installed near slopes if an appropriate factor of safety was applied. For the pile properties and soil conditions analysed, it was found that a factor of safety of 2 (for short piles) and a factor of safety of 4 (for long piles) would limit lateral deflections to less than the $12.7 \mathrm{~mm}$ recommended by the Union Pacific Temporary Shoring Guideline. 


\section{Appendix A: RocScience Modeling Results \\ Piles Installed near 2H:1V Slope}

\section{Pile Properties:}

\begin{tabular}{|c|c|}
\hline Pile Property & Assumed Value \\
\hline Pile Length (Short Pile) & $5 \mathrm{~m}$ \\
\hline Pile Length (Long Pile) & $15 \mathrm{~m}$ \\
\hline Pile Diameter & $1 \mathrm{~m}$ \\
\hline & \\
\hline Pile Thickness & $0.1 \mathrm{~m}$ \\
\hline Steel Yield Strength & $250 \mathrm{MPa}$ \\
\hline Elastic Modulus & $200 \mathrm{GPa}$ \\
\hline Poisson's Ratio & 0.3 \\
\hline & Calculated Value \\
\hline Cross-Sectional Area & $0.15 \mathrm{~m}^{2}$ \\
\hline Second Moment of Area & $0.01688 \mathrm{~m}^{4}$ \\
\hline Section Modulus & $0.03376 \mathrm{~m}^{3}$ \\
\hline Yield Resistance of Pile Section & $10968 \mathrm{kN}-\mathrm{m}$ \\
\hline
\end{tabular}

\section{Cohesive Soil Properties:}

\begin{tabular}{|c|l|c|}
\hline Soil Type & \multicolumn{1}{|c|}{ Soil Property } & Value \\
\hline \multirow{3}{*}{ Stiff Clay } & Undrained Shear Strength & $150 \mathrm{kPa}$ \\
\cline { 2 - 3 } & Modulus of Elasticity & $30 \mathrm{GPa}$ \\
\cline { 2 - 3 } & Poisson's Ratio & 0.2 \\
\cline { 2 - 3 } & Coefficient of Horizontal Subgrade Reaction & $50 \mathrm{MN} / \mathrm{m}^{3}$ \\
\hline
\end{tabular}

\section{Cohesionless Soil Properties:}

\begin{tabular}{|c|l|c|}
\hline \multirow{4}{*}{ Medium Sand } & Internal Angle of Friction & 30 Degrees \\
\cline { 2 - 3 } & Unit Weight & $19 \mathrm{kN} / \mathrm{m}^{3}$ \\
\cline { 2 - 3 } & Cohesion & $0 \mathrm{kPa}$ \\
\cline { 2 - 3 } & Modulus of Elasticity & $50 \mathrm{GPa}$ \\
\cline { 2 - 3 } & Poisson's Ratio & 0.3 \\
\cline { 2 - 3 } & Rankine's Passive Earth Pressure Coefficient & 3 \\
\cline { 2 - 3 } & Coefficient of Soil Modulus Variation & $25 \mathrm{MN} / \mathrm{m}^{3}$ \\
\hline
\end{tabular}




\section{Investigation \#1: Long Piles - Stiff Clay:}

$15 \mathrm{~m}$ from Slope Crest

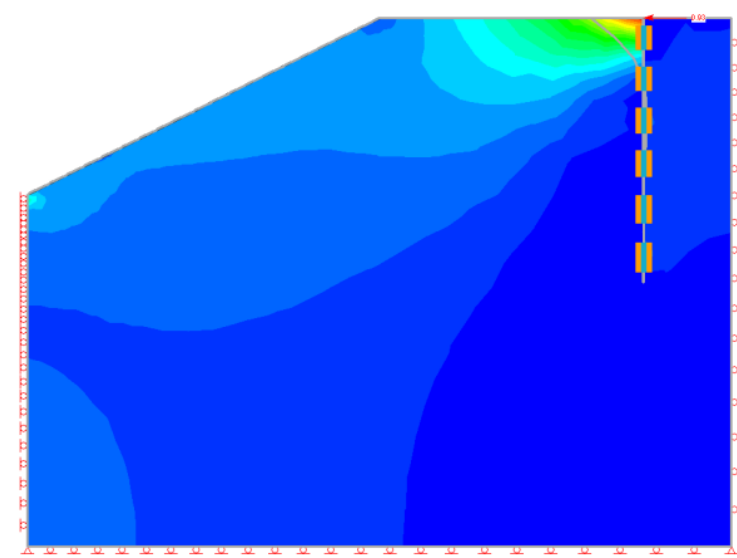

Lateral Load Applied to Top of Pile: $925 \mathrm{kN}$ :

- Deflection: $12.7 \mathrm{~mm}$

- Maximum Pile Moment: 647 kN.m

\section{$5 \mathrm{~m}$ from Slope Crest}

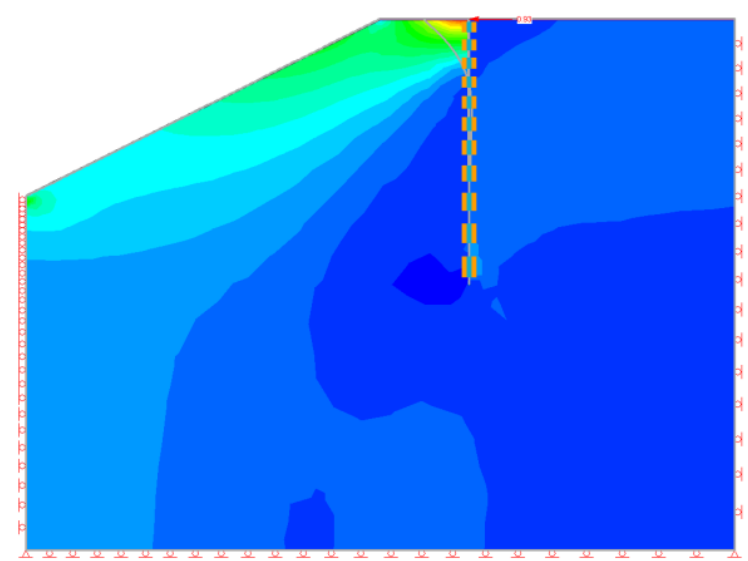

Lateral Load Applied to Top of Pile: $925 \mathrm{kN}$ :

- Deflection: $14.6 \mathrm{~mm}$

- Maximum Pile Moment: 685 kN.m
$10 \mathrm{~m}$ from Slope Crest

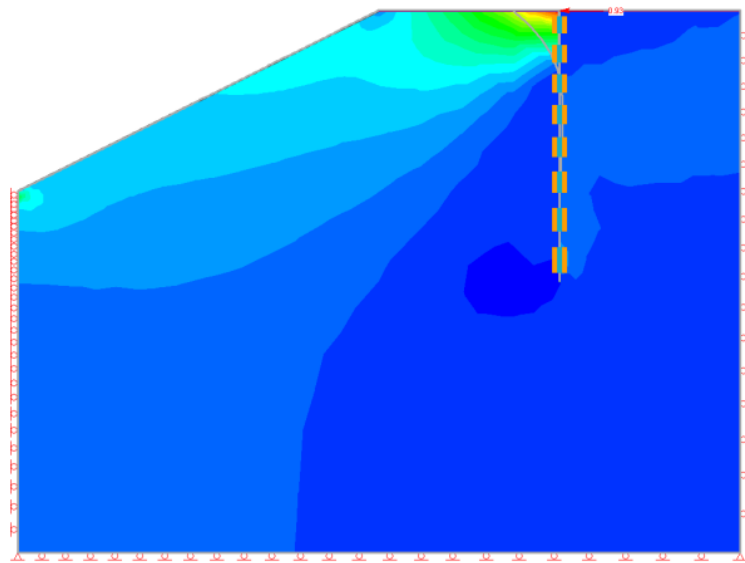

Lateral Load Applied to Top of Pile: $925 \mathrm{kN}$ :

- Deflection: $13.6 \mathrm{~mm}$

- Maximum Pile Moment: 666 kN.m

\section{$2 \mathrm{~m}$ from Slope Crest}

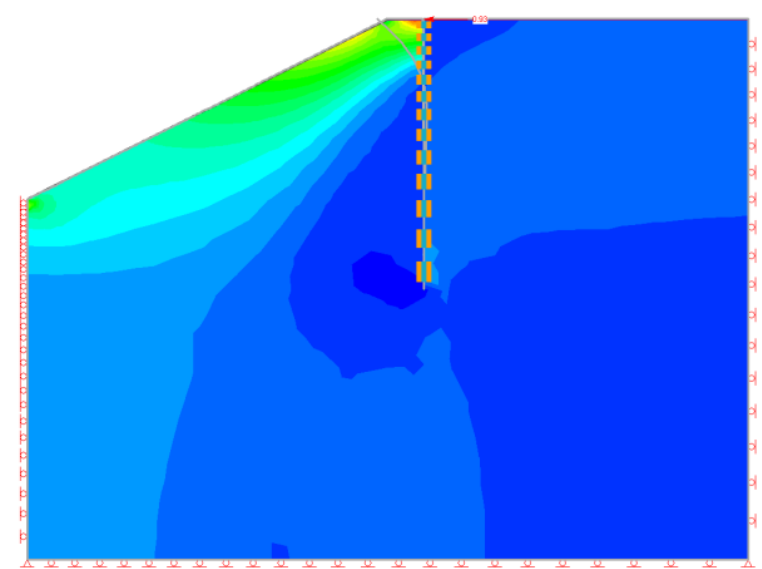

Lateral Load Applied to Top of Pile: $925 \mathrm{kN}$ :

- Deflection: $15.1 \mathrm{~mm}$

- Maximum Pile Moment: 687 kN.m 
$1 \mathrm{~m}$ From Slope Crest:

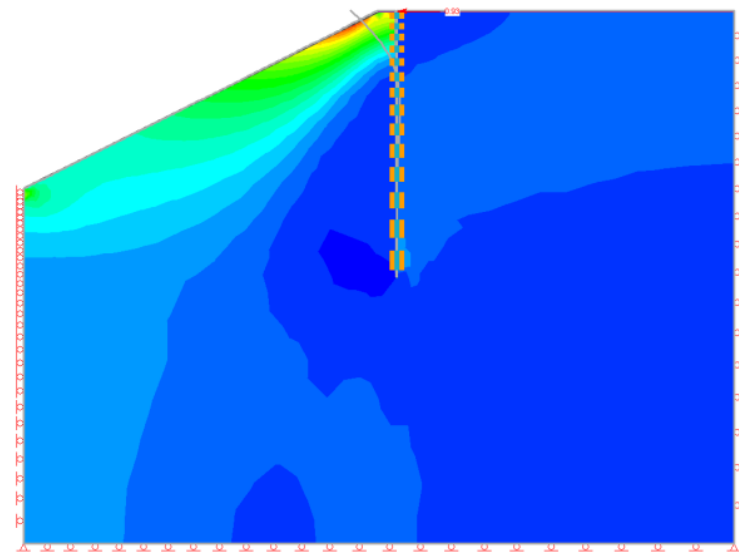

Lateral Load Applied to Top of Pile: $925 \mathrm{kN}$ :

- Deflection: $15.4 \mathrm{~mm}$

- Maximum Pile Moment: 692 kN.m

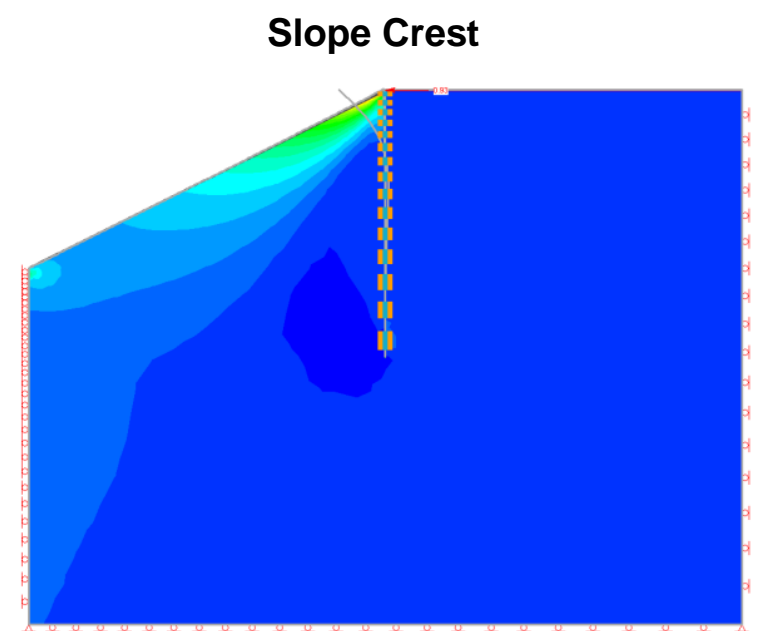

Lateral Load Applied to Top of Pile: $925 \mathrm{kN}$ :

- Deflection: $15.7 \mathrm{~mm}$

- Maximum Pile Moment: 692 kN.m

For $12.7 \mathrm{~mm}$ Deflection:

- Maximum Lateral Load: $750 \mathrm{kN}$

- Maximum Pile Moment: 561 kN

\section{Investigation \#2: Short Piles - Stiff Clay:}

$15 \mathrm{~m}$ from Slope Crest

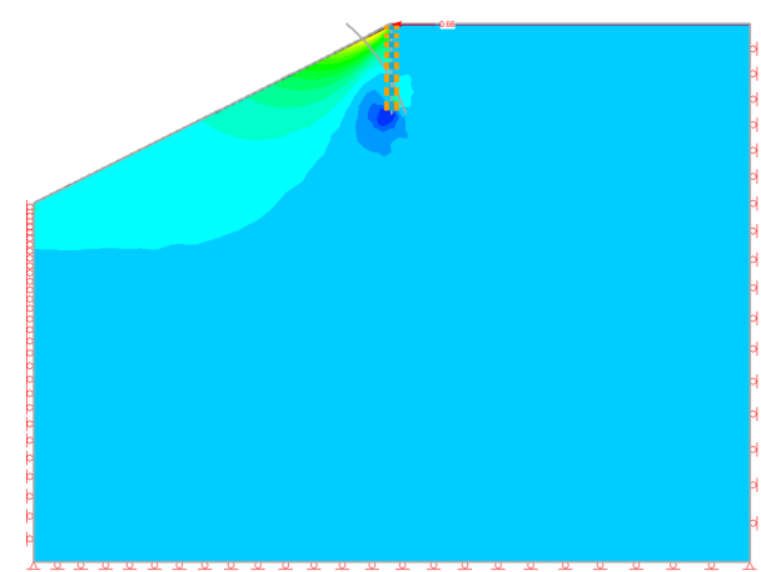

Lateral Load Applied to Top of Pile: $850 \mathrm{kN}$ :

- Deflection: $12.7 \mathrm{~mm}$

- Maximum Pile Moment: 431 kN
$10 \mathrm{~m}$ from Slope Crest

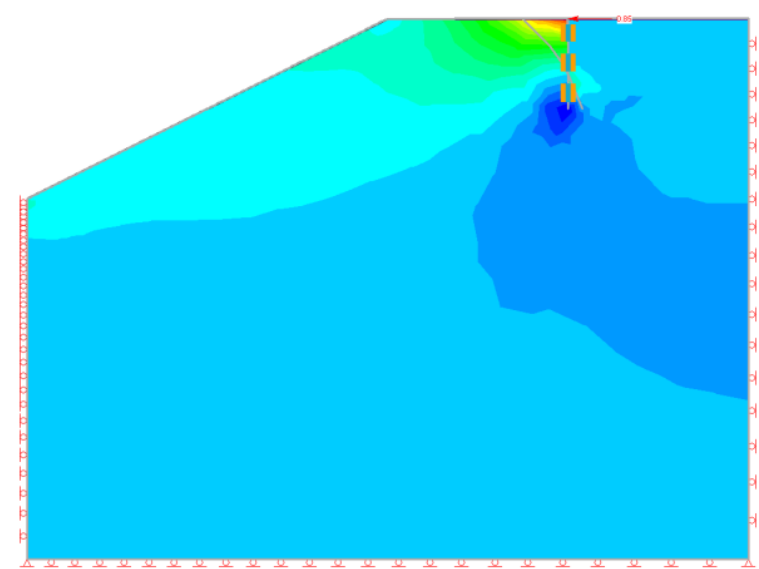

Lateral Load Applied to Top of Pile: $850 \mathrm{kN}$ :

- Deflection: $13.6 \mathrm{~mm}$

- Maximum Pile Moment: 537 kN 


\section{$5 \mathrm{~m}$ from Slope Crest}

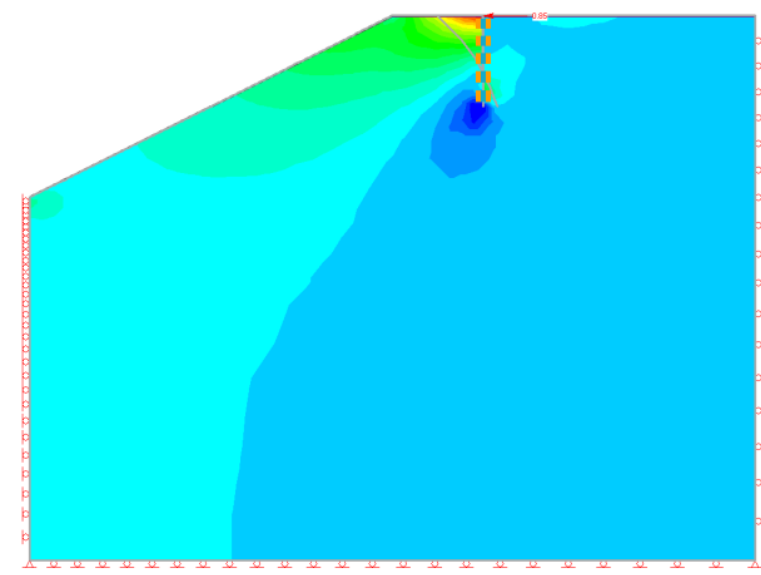

Lateral Load Applied to Top of Pile: $850 \mathrm{kN}$ :

- Deflection: $14.7 \mathrm{~mm}$

- Maximum Pile Moment: 542 kN

$1 \mathrm{~m}$ from Slope Crest

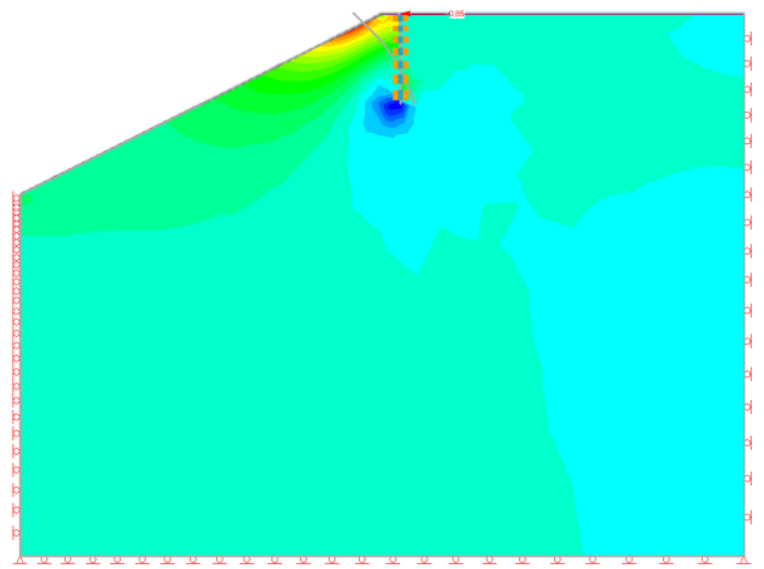

Lateral Load Applied to Top of Pile: $850 \mathrm{kN}$ :

- Deflection: $15.4 \mathrm{~mm}$

- Maximum Pile Moment: 552 kN
$2 \mathrm{~m}$ from Slope Crest

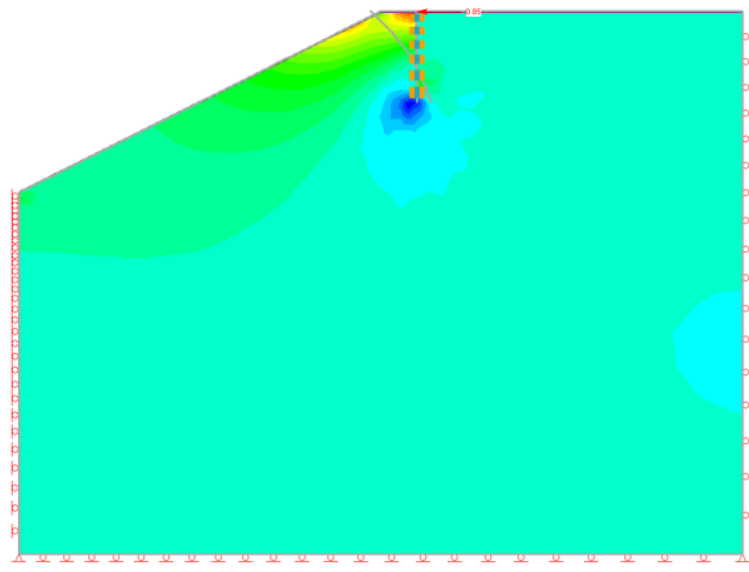

Lateral Load Applied to Top of Pile: 850 kN:

- Deflection: $15.1 \mathrm{~mm}$

- Maximum Pile Moment: 553 kN

\section{Slope Crest}

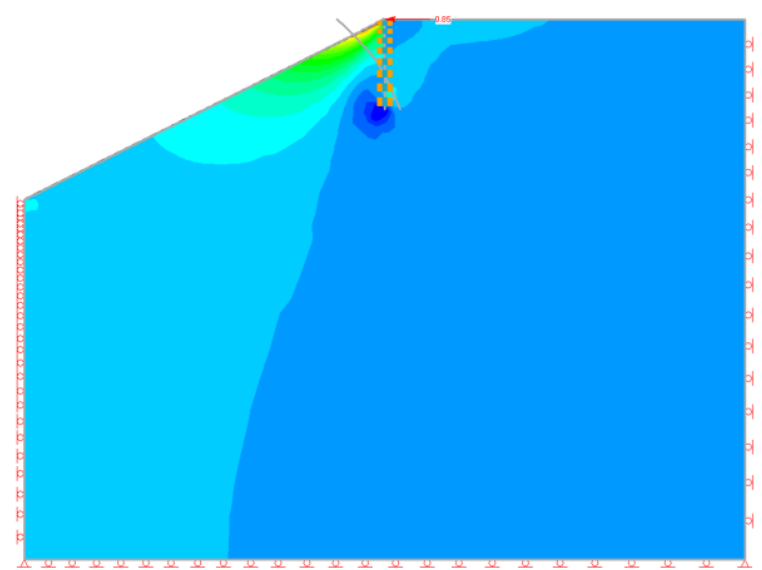

Lateral Load Applied to Top of Pile: $850 \mathrm{kN}$ :

- Deflection: $15.7 \mathrm{~mm}$

- Maximum Pile Moment: 557 kN

For $12.7 \mathrm{~mm}$ Deflection:

- Maximum Lateral Load: 675 kN

- Maximum Pile Moment: 442 kN.m 


\section{Investigation \#3: Long Piles - Medium Sand:}

$15 \mathrm{~m}$ from Slope Crest

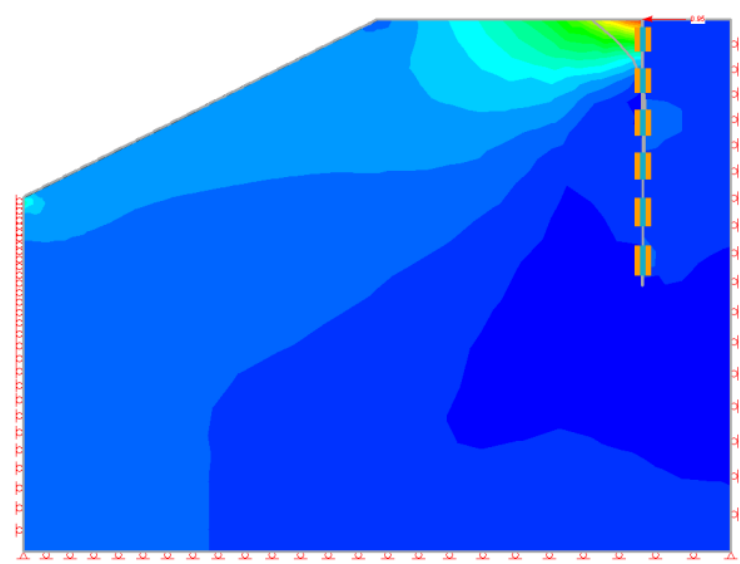

Lateral Load Applied to Top of Pile: $950 \mathrm{kN}$ :

- Deflection: $12.7 \mathrm{~mm}$

- Maximum Pile Moment: 664 kN.m

$5 \mathrm{~m}$ from Slope Crest:

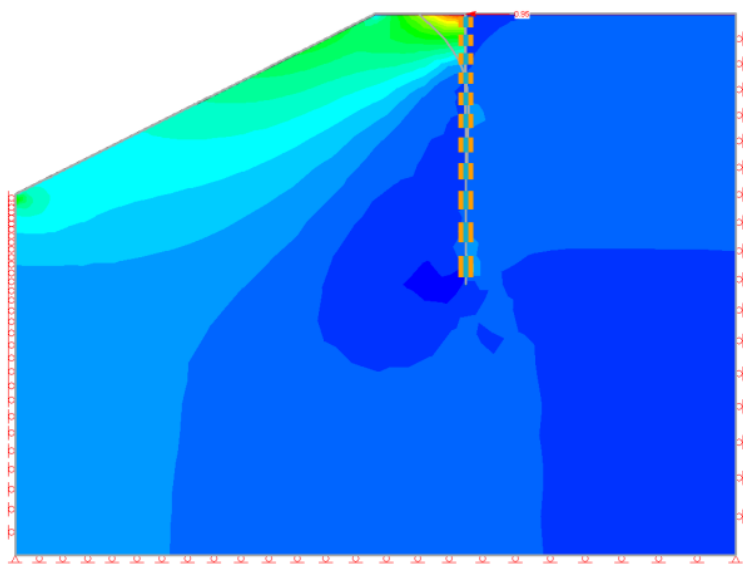

Lateral Load Applied to Top of Pile: $950 \mathrm{kN}$ :

- Deflection: $14.9 \mathrm{~mm}$

- Maximum Pile Moment: 704 kN.m
$10 \mathrm{~m}$ from Slope Crest

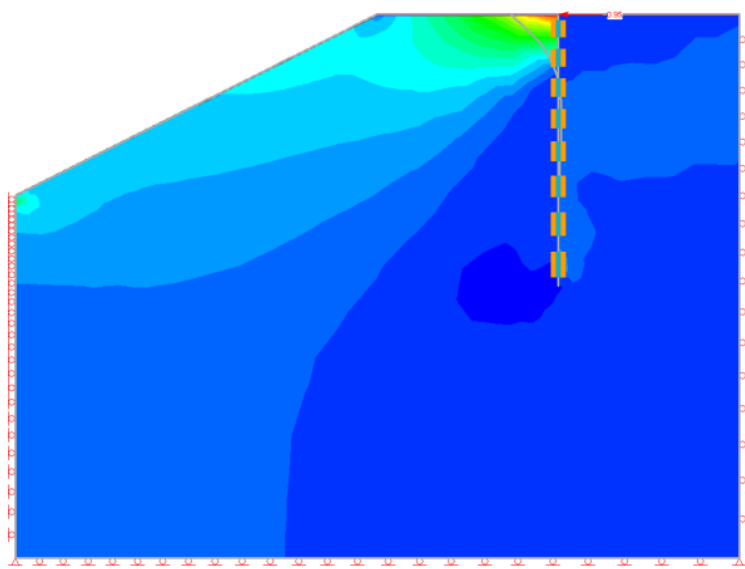

Lateral Load Applied to Top of Pile: $950 \mathrm{kN}$ :

- Deflection: $13.9 \mathrm{~mm}$

- Maximum Pile Moment: 684 kN.m

$2 \mathrm{~m}$ from Slope Crest:

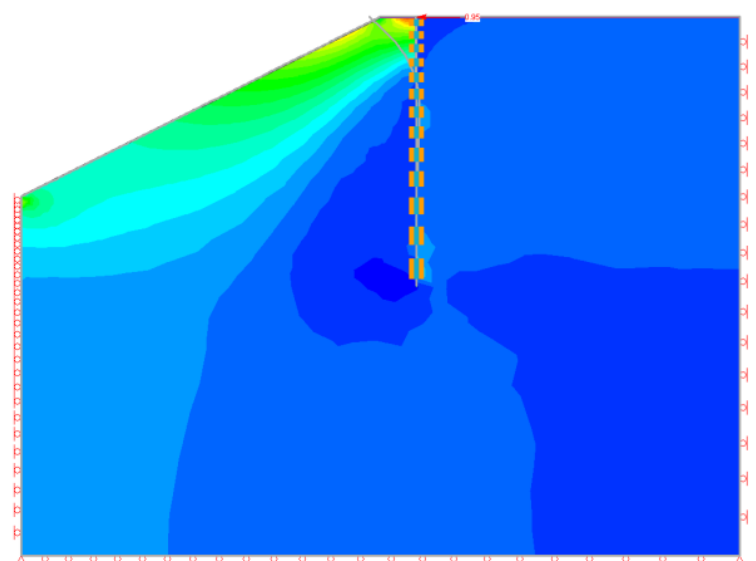

Lateral Load Applied to Top of Pile: $950 \mathrm{kN}$ :

- Deflection: $15.4 \mathrm{~mm}$

- Maximum Pile Moment: 706 kN.m 


\section{$1 \mathrm{~m}$ from Slope Crest}

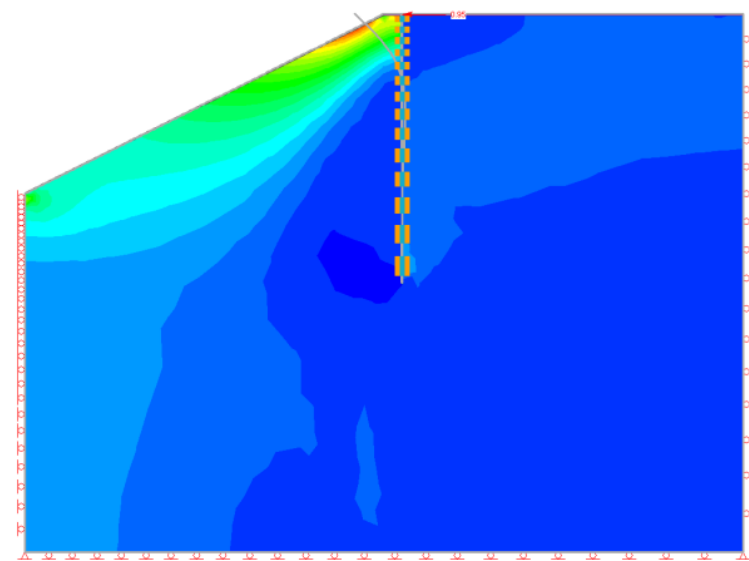

Lateral Load Applied to Top of Pile: $950 \mathrm{kN}$ :

- Deflection: $15.6 \mathrm{~mm}$

- Maximum Pile Moment: 711 kN.m

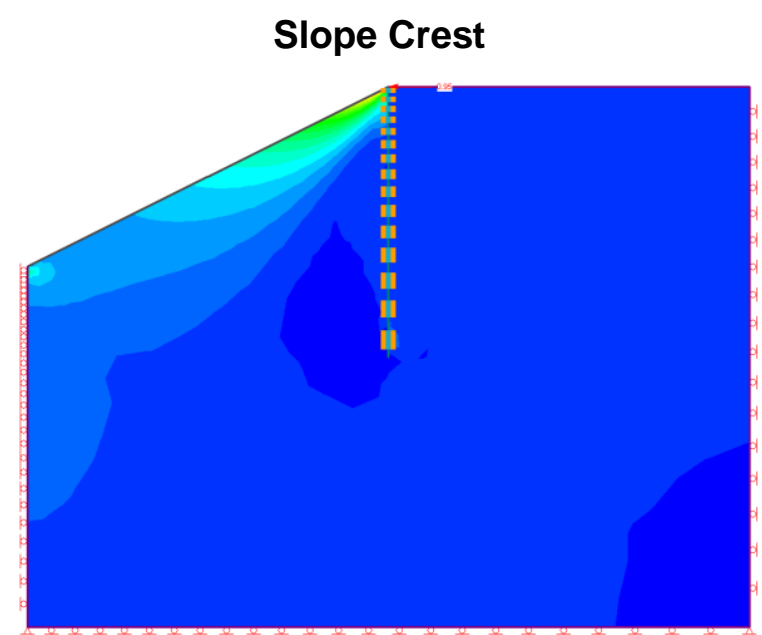

Lateral Load Applied to Top of Pile: $950 \mathrm{kN}$ :

- Deflection: $15.8 \mathrm{~mm}$

- Maximum Pile Moment: 710 kN.m

For $12.7 \mathrm{~mm}$ Deflection:

- Maximum Lateral Load: 750 kN

- Maximum Pile Moment: 561 kN

Investigation \#4: Short Piles - Medium Sand:

$15 \mathrm{~m}$ from Slope Crest

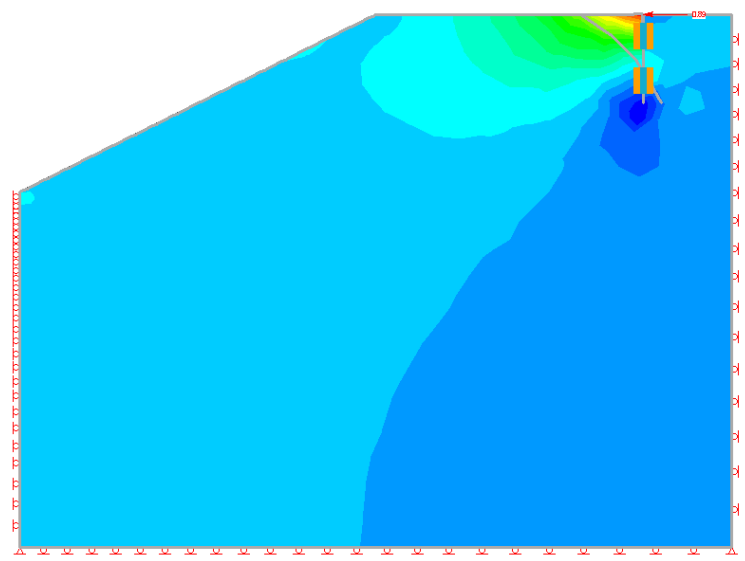

Lateral Load Applied to Top of Pile: $885 \mathrm{kN}$ :

- Deflection: $12.7 \mathrm{~mm}$

- Maximum Pile Moment: 447 kN.m
$10 \mathrm{~m}$ from Slope Crest

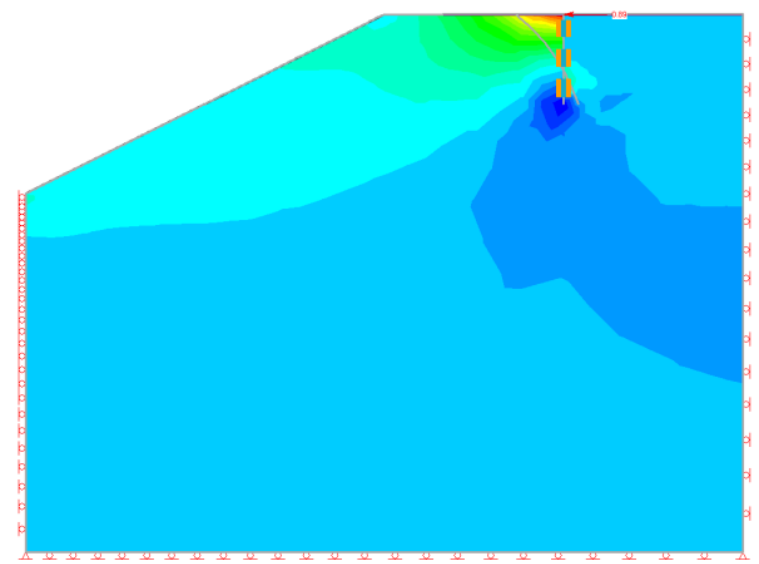

Lateral Load Applied to Top of Pile: $885 \mathrm{kN}$ :

- Deflection: $14.1 \mathrm{~mm}$

- Maximum Pile Moment: 560 kN.m 


\section{$5 \mathrm{~m}$ from Slope Crest}

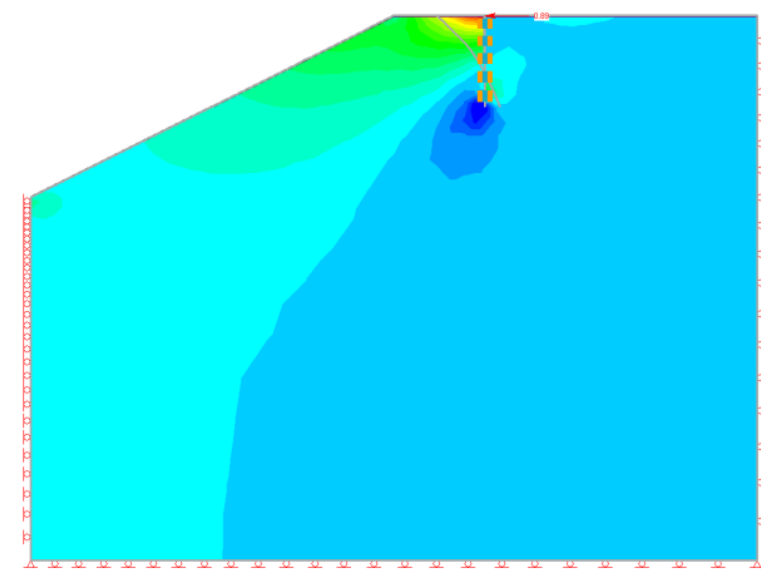

Lateral Load Applied to Top of Pile: $885 \mathrm{kN}$ :

- Deflection: $15.1 \mathrm{~mm}$

- Maximum Pile Moment: 564 kN.m

$1 \mathrm{~m}$ from Slope Crest

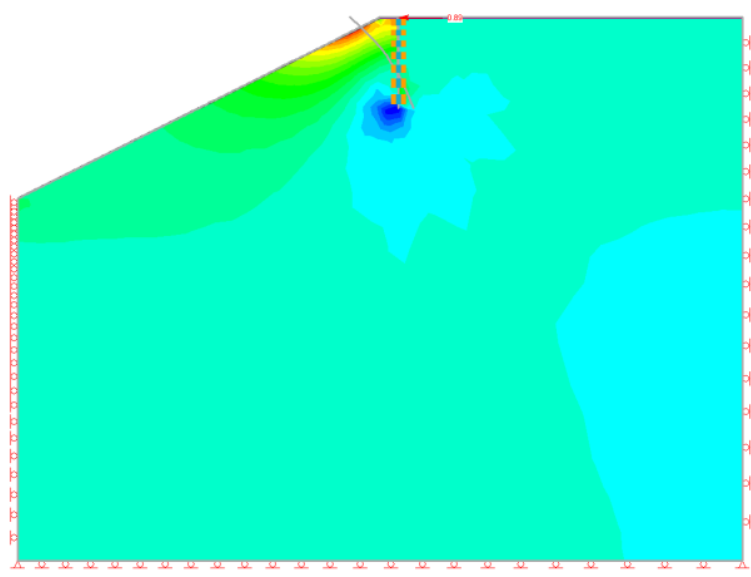

Lateral Load Applied to Top of Pile: $885 \mathrm{kN}$ :

- Deflection: $15.9 \mathrm{~mm}$

- Maximum Pile Moment: 575 kN.m
$2 \mathrm{~m}$ from Slope Crest

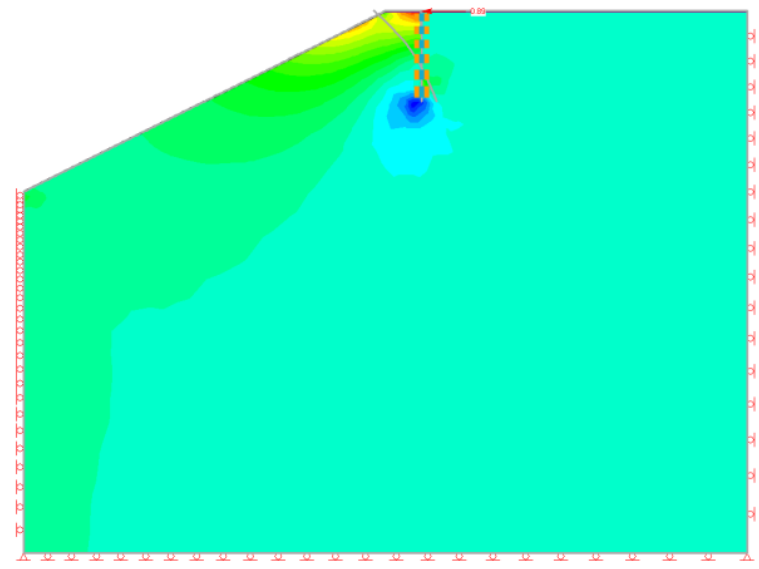

Lateral Load Applied to Top of Pile: $885 \mathrm{kN}$ :

- Deflection: $15.6 \mathrm{~mm}$

- Maximum Pile Moment: 576 kN.m Slope Crest

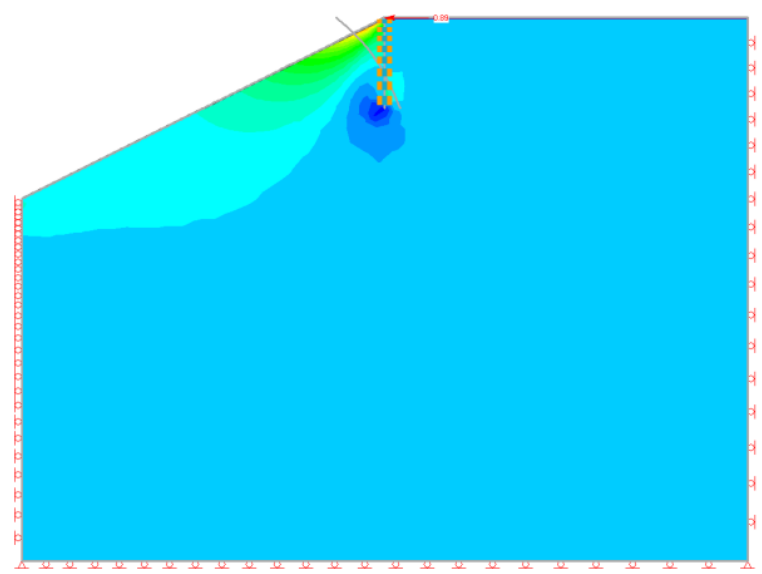

Lateral Load Applied to Top of Pile: $885 \mathrm{kN}$ :

- Deflection: $16.1 \mathrm{~mm}$

- Maximum Pile Moment: 579 kN.m

For $12.7 \mathrm{~mm}$ Deflection:

- Maximum Lateral Load: $700 \mathrm{kN}$

- Maximum Pile Moment: 458 kN 


\section{References}

ABG Geosynthetics. (n.d.). Structural Drainage: Retaining Wall Drainage, Deckdrain, Delhi-Arga Road, India. Retrieved from http://www.abg-geosynthetics.com/case-studies.html

AREMA. (2016). Manual for Railway Engineering. Lanham, MD: AREMA.

Australian Hardwood Network. (n.d.). Landscape Structures. Retrieved from

http://www.hardwood.timber.net.au/applications/landscapestructures(5).htm

Broms, B. (1964a). Lateral Resistance of Piles in Cohesive Soils. Journal of the Soil Mechanics and Foundations Division. Proceedings of the American Society of Civil Engineers, 90(SM2). 27-63.

Broms, B. (1964b). Lateral Resistance of Piles in Cohesionless Soils. Journal of the Soil Mechanics and Foundations Division. Proceedings of the American Society of Civil Engineers, 90 (SM3). 123-157.

Budhu, M. (2011). Soil Mechanics and Foundations. Hoboken, NJ: John Wiley \& Sons, Inc. Canadian Highway Bridge Design Code. (2006). Mississauga, ON: Canadian Standards Association.

Das, B. M. (2005). Fundamentals of Geotechnical Engineering ( $2^{\text {nd }}$ ed.). Toronto, ON: Nelson. Fidler, H. (1891). Notes on Building Construction. London, Great Britain: Longmans, Green \& co.

Georgiadis, G. \& Georgiadis, G. (2010). Undrained Lateral Pile Response in Sloping Ground. Journal of Geotechnical and Geoenvironmental Engineering, 136(11). 1489-1500.

Georgiadis, G. \& Georgiadis, G. (2012). Development of p-y curves for undrained response of piles near slopes. Computers and Geotechnics, 4. 53-61. doi: 10.1016/jcompgeo.2011.09.005

Georgiadis, G., Georgiadis, G. \& Anagnostopoulos, C. (2012). Lateral bearing capacity of rigid piles near clay slopes. Soils and Foundations, 53(1). 144-154. doi:10.1016/j.sandf.2012.12.010 
Hazzar, L., Karray, M., Bouassida, M., \& Nussien, M.N. (2013). Ultimate lateral resistance of Piles in Cohesive Soil. DFI Journal - The Journal of the Deep Foundations Institute, 7(1), 59-68. doi:10.1179/dfi.2013.005

Jahan, S. \& Abedin, M.Z. (2012). Use of Broms' Charts for Evaluating Lateral Load Capacity of Vertical Piles in a Two Layer Soil System. Paper presented at the $1^{\text {st }}$ International Conference on Advances in Civil Engineering 2012 (ICACE 2012), Chittagong, Bangladesh, December 1214, 2012.

Kitch, W. (2014, Sept 30). Stress \& Strain in Solids: Mohr Circle. [Video File]. Retrieved from https://www.youtube.com/watch?v=yz22gB9RKhs

Kitch W. (2015a, Jan 9). Earth Pressure Theory: Rankine Earth Pressure. [Video File].

Retrieved from https://www.youtube.com/watch?v=HsuuQDFIXKU

Kitch, W. (2015b, Jan 13). Earth Pressure Theory: Coulomb Earth Pressure. [Video File]. Retrieved from https://www.youtube.com/watch?v=FCVnQycAMXc

MapQuest. (2017). Official MapQuest - Maps, Driving Directions, Live Traffic. Retrieved from https://www.mapquest.ca/

Mezazigh, S. \& Levacher, D. (1998). Laterally loaded piles in sand: slope effect on P-Y reaction curves. Canadian Geotechnical Journal. 35. 431-452.

Meyer, B. J., \& Reese, L. C. (1979). Analysis of Single Piles under Lateral Loading. (Texas State Department of Highways and Public Transportation Research Report 244-1). Austin, Texas: The University of Texas Centre for Transportation Research.

Murthy, V.S.N. (2002). Geotechnical Engineering: Principles and Practices of Soil Mechanics and Foundation Engineering. New York, NY: Marcel Decker Inc.

National Programme on Technology Enhanced Learning. (n.d.). Dynamic Soil Properties. [Lecture Slides] Kanpur, India: Department of Civil Engineering, Indian Institute of Technology. Retrieved from http://nptel.ac.in/courses/105104136/Module\%203/Lecture\%2010.pdf 
Nguyen, Q. V., Fatahi, B. \& Khabbaz, H., (2013). Three dimensional numerical simulation to predict pile performance of laterally loaded piles on clay-sand layered slope. Paper presented at Geo Montreal 2013, Montreal, Quebec.

Rankine, W. J. M. (1857). On the Stability of Loose Earth. Philisophical Transactions of the Royal Society of London. 147, 9-27. doi: 10.1098/rstl.1857.0003

Sadrekarimi, J. \& Ghamari, M.A. (2007). The Coefficient of Subgrade Reaction and Its Accuracy on Design of Foundations. Paper presented at the Sixth International Conference on Case Histories in Geotechnical Engineering, Arlington, VA, August 11-16, 2008.

Transport Canada. (1992). Standards Respecting Railway Clearances. Retrieved from https://www.tc.gc.ca/media/documents/railsafety/TC_E_05e.pdf

Terzaghi, K. (1955). Evaluation of Coefficients of Subgrade Reaction. Geotechnique, 5(4). 297326.

Sabatini, P. J., Pass, D. G. \& Bachus, R.C. (1999). Geotechnical Engineering Circular No. 4: Ground Anchors and Anchored Systems. Washington, DC: U.S. Department of Transportation. Skempton, A.W. (1996). Embankments and Cuttings on the early Railways. Construction History, 11. 33-49.

Union Pacific. (2004). Guidelines for Temporary Shoring. Omaha, NE: Union Pacific. Retrieved from https://www.up.com/cs/groups/public/@uprr/@customers/@industrialdevelopment/ @operationsspecs/@specifications/documents/up_pdf_nativedocs/pdf_up_str_temp-shoring.pdf 